\title{
Ambiente de testes utilizando verificação de componentes java com tratamento de exceções
}

\author{
Kleber da Silva Xavier \\ DisSERTAÇÃo APRESENTADA \\ $\mathrm{AO}$ \\ Instituto de Matemática e Estatística \\ $\mathrm{DA}$ \\ Universidade de SÃo Paulo \\ PARA \\ OBTENÇÃO DO TÍTULO \\ $\mathrm{DE}$ \\ Mestre em CiÊnCias \\ Área de Concentração: Ciência da Computação \\ Orientadora: Profa. Dra. Ana Cristina Vieira de Melo
}

São Paulo, março de 2008 


\title{
Ambiente de testes utilizando verificação de componentes java com tratamento de exceções
}

\author{
Este exemplar corresponde à redação \\ final da dissertação devidamente corrigida \\ e defendida por (Kleber da Silva Xavier) \\ e aprovada pela Comissão Julgadora.
}

Banca Examinadora:

- Profa. Dra. Ana Cristina Vieira de Melo (orientadora) - IME-USP.

- Prof. Dr. Francisco Carlos da Rocha Reverbel - IME-USP.

- Profa. Dra. Patricia Duarte de Lima Machado - UFCG. 


\section{Agradecimentos}

Aos meus pais Antônio e Helena que sempre me incentivaram e me mostraram o valor do estudo.

À minha esposa Joelma, que teve paciência e compreensão com todos os feriados perdidos e nos períodos em que me enclausurei para me dedicar ao mestrado.

À minha orientadora, professora Ana Cristina Vieira de Melo, que soube me mostrar a luz quando eu estava perdido.

Aos amigos e sócios André e Junio, que forneceram valiosas opiniões e comentários nas primeiras versões deste trabalho.

Aos amigos Yara e Vinicius que me incentivaram a embarcar nesta jornada, e que contribuiram para que ela se tornasse possível.

Aos colegas do IME Simone e Rodrigo, que me ajudaram bastante neste último ano.

Aos meus avós, irmãos, tios e primos, que me incentivaram através de seus exemplos ou simplesmente me apoiando.

Aos professores do IME pelos ensinamentos recebidos durante este período. 


\section{Resumo}

Um sistema de software que apresente problemas em sua execução pode gerar conseqüências desde um simples incômodo ao usuário, até desastres como a perda de uma sonda da NASA em Marte. As atividades de teste visam identificar erros nos sistemas de software, prevenindo estas conseqüências indesejáveis. Porém, os testes podem envolver entre $30 \%$ e $40 \%$ do esforço de desenvolvimento do sistema, e em sistemas críticos, seu custo pode ser de 3 a 5 vezes maior do que o custo combinado das demais atividades.

Para tentar reduzir estes custos podemos automatizar parte das atividades. No presente caso, pretende-se minimizar os casos de teste gerados manualmente, utilizando uma técnica denominada verificação de modelos. Esta técnica consiste em verificar propriedades definidas formalmente através de expressões matemáticas, utilizando uma ferramenta de verificação que simula a execução do código.

Além disso, um sistema que utilize um tratamento de condições excepcionais eficiente, tem sua manutenibilidade, robustez e confiabilidade melhoradas. Por isso, definimos propriedades relacionadas ao tratamento de exceções, como ponto de entrada para a verificação de modelos. Apresentamos um ambiente de testes criado para permitir a verificação destas propriedades com o verificador Java PathFinder e a exibição das estatísticas de cobertura de testes de acordo com o critério selecionado. Este ambiente facilita a execução dos testes, pois apresenta uma interface gráfica com o usuário que permite a configuração e execução dos testes sem que seja necessária a escrita de código pelo testador.

Apresentamos também o resultado do uso deste ambiente para o teste de vários programas exemplo, utilizando desde código concorrente até diferentes estratégias de tratamento de exceção e discutimos as características, cuidados no uso e limitações das ferramentas utilizadas. 


\section{Abstract}

A software system that shows some failure at runtime execution may bring consequences that range from a simple user annoyance to great disasters such as the lost NASA probe on Mars. The test activities aim to find errors in software systems, preventing these undesirable consequences. However, tests may take between $30 \%$ and $40 \%$ of total development time, and on critical systems, its cost can be from 3 to 5 times greater than the combined cost of the other activities.

In an effort to reduce these costs, we may automate some of the activities. In this work we intend to minimize test case manual generation, using a technique called model checking. This technique involves the checking of properties defined through the use of mathematical formulas, using a tool, that simulates code execution.

In addition, a system with an efficient exception handling mechanism, has its maintainability, robustness and reliability enhanced. So, in this work we define exception handling related properties, as an input for model checking. We present a test tool created to allow checking of these properties using the Java PathFinder model checker, and to list the test coverage statistics, according to the selected test criteria. This tool makes easy the test execution, since it presents a graphical user interface that allows configuration and running of tests with no need to write any lines of code.

We also show the results of running several tests with the GUI, using some programs implemented with concurrent code and several exception handling techniques and discuss the main features, pitfalls and limitations of the underlying tools. 


\section{Sumário}

Lista de Figuras $\quad$ xiii

Lista de Tabelas $\quad$ xv

1 Introdução 1

1.1 Motivação . . . . . . . . . . . . . . . . . . . . . . . . . . 1

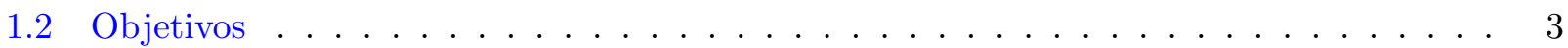

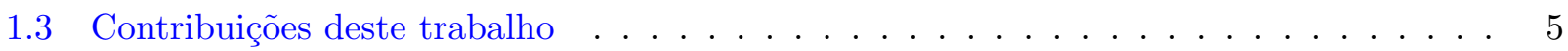

1.4 Organização . . . . . . . . . . . . . . . . . . . . . 5

$\begin{array}{lll}2 & \text { Critérios de teste } & 7\end{array}$

2.1 Teste de Software . . . . . . . . . . . . . . . . . . . . . 7

2.1 Definições Preliminares . . . . . . . . . . . . . . . . 12

2.2 Critérios de teste para programas procedurais . . . . . . . . . . . . . . . . . 14

2.2.1 Testes baseados em fluxo de controle . . . . . . . . . . . . . . . . . . 17

2.2 .2 Testes baseados em fluxo de dados . . . . . . . . . . . . . . . . . . . 20

2.3 Critérios de teste para programas orientados a objetos . . . . . . . . . . . . 23

2.3.1 Problemas no teste de sistemas orientados a objetos . . . . . . . . . . . . 24

2.3.2 Critérios de fluxo de dados estendidos . . . . . . . . . . . . . . 25 
2.3 .3 Critérios de fluxo de objetos . . . . . . . . . . . . . . . . 27

2.3.4 Critérios baseados em estados . . . . . . . . . . . . . . . . 28

2.4 Critérios de Teste Englobando Tratamento de Exceções . . . . . . . . . . . . . . . . 31

2.4 .1 Estrutura de exceções em Java . . . . . . . . . . . . . . . . . . . . . . . . 31

2.4 .2 Exemplo. . . . . . . . . . . . . . . . . . . . 32

2.4 .3 Termos utilizados . . . . . . . . . . . . . . . . . 33

2.4.4 Definição e uso de exceções . . . . . . . . . . . . . . . . . . . . . 34

2.4.5 Ativação e desativação de exceções . . . . . . . . . . . . . . . . . 35

2.4 .6 Critérios de Teste . . . . . . . . . . . . . . . 35

2.4.7 Grafo de Fluxo de Controle . . . . . . . . . . . . . . . . . 36

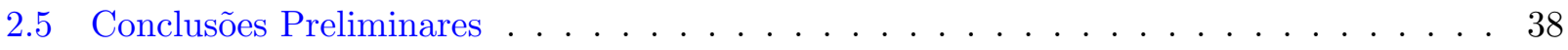

3 Verificação de Propriedades $\quad 41$

3.1 Ferramentas para verificação . . . . . . . . . . . . . . . . . . . 42

3.1 .1 Bandera . . . . . . . . . . . . . . . . . . . . 42

3.1 .2 Java PathFinder . . . . . . . . . . . . . . . . . . . . . 44

3.2 Propriedades Relativas a Tratamento de Exceções . . . . . . . . . . . . . . . . . . . 46

3.2.1 Propriedades no Java PathFinder . . . . . . . . . . . . . . . . . . . 46

3.2 .2 Tratamento de Exceções . . . . . . . . . . . . . . . . . . . . 47

3.2.3 Apresentação de Práticas Relativas ao Tratamento de Exceções . . . . . . . . . 48

3.2.4 Práticas relativas ao uso da instrução throws . . . . . . . . . . . . . . . . 49

3.2.5 Práticas relativas à falta de tratamento de exceção . . . . . . . . . . . . . . 56

3.2.6 Práticas relativas ao código de tratamento da exceção . . . . . . . . . . . . 57

3.2.7 Práticas relativas ao uso da instrução catch . . . . . . . . . . . . . . . 67

3.2 .8 Práticas relativas ao uso da instrução finally . . . . . . . . . . . . . . . 68 
3.3 Conclusões Preliminares . . . . . . . . . . . . . . . . . . . . . . . . 69

4 Ambiente de Testes $\quad 71$

4.1 Atividades necessárias para os testes . . . . . . . . . . . . . . . . 71

4.2 Arquivo de compartilhamento de dados . . . . . . . . . . . . . . . . . . 72

4.3 Elementos de extensão ao JPF . . . . . . . . . . . . . . . . . . . . . . . . . . 74

4.3.1 Listener de rastreamento de instruções executadas . . . . . . . . . . . . . . 75

4.3 .2 gerador de escolhas para exceções . . . . . . . . . . . . . . . . . . 75

4.4 Aplicativo para execução e análise dos testes . . . . . . . . . . . . . . 76

4.5 Exemplo de uso do ambiente . . . . . . . . . . . . . . . . . . . . 81

5 Análise dos Programas Exemplo $\quad 87$

5.1 Resultados obtidos . . . . . . . . . . . . . . . . . . . 87

5.1 .1 Programa CatchExceptionExample.java . . . . . . . . . . . . . 87

5.1.2 Programa DestructiveWrappingExample.java . . . . . . . . . . . . . . . 90

5.1 .3 Programa EmptyCatchExample.java . . . . . . . . . . . . . . . . . 92

5.1.4 Programa EmptyInterruptedExceptionExample.java . . . . . . . . . . . . . 94

5.1.5 Programa ExceptionNeverThrownExample.java . . . . . . . . . . . . . 96

5.1 .6 Programa FinallyExample.java . . . . . . . . . . . . . . . . . . . 99

5.1.7 Programa LogRethrowExceptionExample.java . . . . . . . . . . . . . . . . . . 101

5.1 .8 Programa LogReturnNullExample.java . . . . . . . . . . . . . . . . . . 103

5.1 .9 Programa LostCauseExample.java . . . . . . . . . . . . . . . . . 104

5.1 .10 Programa MultipleLogExample.java . . . . . . . . . . . . . . . 107

5.1 .11 Programa ThrowExceptionExample.java . . . . . . . . . . . . . . 108

5.1 .12 Programa ThrowsManyExample.java . . . . . . . . . . . . . . . . . . 109 
5.1 .13 Programa UncaughtExceptionExample.java . . . . . . . . . . . . . . . 111

5.2 Conclusões Preliminares . . . . . . . . . . . . . . . . . . . . . . . 112

6 Análise de programas concorrentes $\quad 115$

6.1 Resultados Obtidos . . . . . . . . . . . . . . . . . . . . 115

6.1 .1 Programa Start.java . . . . . . . . . . . . . . . 116

6.1 .2 Programa Dead.java . . . . . . . . . . . . . . . . . 119

6.1 .3 Programa NestedMonitor.java . . . . . . . . . . . . . . . . . 120

6.1 .4 Programa PCSimple.java . . . . . . . . . . . . . . . 121

6.1 .5 Programa PipeInteger.java . . . . . . . . . . . . . . . 122

6.1.6 Conclusões Preliminares . . . . . . . . . . . . . . . . . 125

$\begin{array}{llr}7 \text { Conclusão } & 129\end{array}$

7.1 Resultados Obtidos . . . . . . . . . . . . . . . . . . . 130

7.1.1 Características observadas . . . . . . . . . . . . . . . 130

7.1 .2 Cuidados a serem tomados . . . . . . . . . . . . . . 132

7.2 Trabalhos Futuros . . . . . . . . . . . . . . . . . . . 132

$\begin{array}{ll}\text { A Glossário de termos } & 135\end{array}$

B Código Fonte das Propriedades Criadas 141

B.1 Método declara lançar java.lang.Exception . . . . . . . . . . . . . . . . . . . . 141

B.1.1 ThrowsExceptionProperty.java . . . . . . . . . . . . . . . . 141

B.2 Método declara lançar muitas exceções . . . . . . . . . . . . . . . . . . . . . . . . 143

B.2.1 ThrowsManyProperty.java . . . . . . . . . . . . . . . . . 143

B.3 Exceção declarada mas nunca lançada . . . . . . . . . . . . . . . . . . . . . . . 145 
B.3.1 ExceptionNeverThrownProperty.java . . . . . . . . . . . . . . . . 145

B.4 Bloco de captura vazio . . . . . . . . . . . . . . . . . . . . . . . . . 148

B.4.1 EmptyCatchProperty.java . . . . . . . . . . . . . . . . . 148

B.5 Captura de java.lang.Exception . . . . . . . . . . . . . . . . . . . . . . 149

B.5.1 CatchExceptionProperty.java . . . . . . . . . . . . . . . . 149

C XML Schema dos arquivos de compartilhamento de dados

D.1 Código Fonte dos Programas Com Deadlock . . . . . . . . . . . . . . . . . . . . 153

D.1.1 Start.java . . . . . . . . . . . . . . . . . 153

D.1.2 Dead.java . . . . . . . . . . . . . . . . . . 154

D.1.3 NestedMonitor.java . . . . . . . . . . . . . . . . . . 155

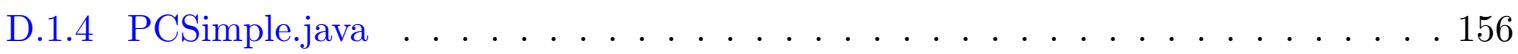

D.1.5 PipeInteger.java . . . . . . . . . . . . . . . . . 158

D.2 Código Fonte dos Programas Sem Deadlock ～. . . . . . . . . . . . . . . 161

D.2.1 Start_s.java . . . . . . . . . . . . . . . . . . 161

D.2.2 Dead_s.java . . . . . . . . . . . . . . . . . . . 162

D.2.3 NestedMonitor_s.java . . . . . . . . . . . . . . . . 163

D.2.4 PCSimple_s.java . . . . . . . . . . . . . . . . . . 164

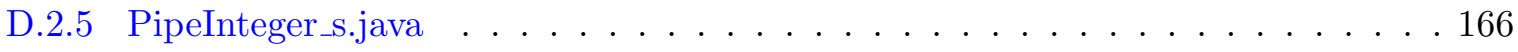

$\begin{array}{ll}\text { Referências Bibliográficas } & 171\end{array}$ 


\section{Lista de Figuras}

1.1 resumo do funcionamento do sistema . . . . . . . . . . . . . . . . . 4

2.1 atividades de teste de software . . . . . . . . . . . . . . . 10

2.2 Exemplo de programa Java . . . . . . . . . . . . . . . . . 16

2.3 classe Frame modificada . . . . . . . . . . . . . . . . . . . . . . . 18

2.4 fluxo para o primeiro caso de teste . . . . . . . . . . . . . . . . 19

2.5 fluxo para o segundo caso de teste . . . . . . . . . . . . . . . . . 19

2.6 linha adicionada à classe Teste . . . . . . . . . . . . . . . . . . . 20

2.7 fluxo adaptando a classe de teste para o critério all-statements . . . . . . . . . . 20

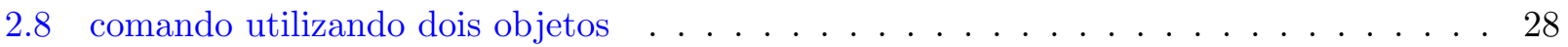

2.9 Exemplo de programa Java . . . . . . . . . . . . . . . . . . 30

2.10 código Java com tratamento de erros . . . . . . . . . . . . . . . . 33

2.11 diagrama de fluxo . . . . . . . . . . . . . . . . . . 37

4.1 Atividades Executadas no Ambiente de Testes . . . . . . . . . . . . . . . . . . 73

4.2 exemplo de arquivo compartilhamento de dados . . . . . . . . . . . . . . . . . 74

4.3 Exemplo de código com método que lança múltiplas exceções . . . . . . . . . . . . 77

4.4 Tela de configuração do JPF . . . . . . . . . . . . . . . . . . . 78

4.5 Tela de seleção de propriedades . . . . . . . . . . . . . . . . . . . . 79 
4.6 Tela de configuração dos listeners . . . . . . . . . . . . . . . . . . . . 80

4.7 Tela de exibição dos resultados . . . . . . . . . . . . . . . . . . . . . . . . 81

4.8 Tela de rastreamento de estados . . . . . . . . . . . . . . . . . . . . . . 82

4.9 arquivo entrada_CatchExceptionExample.xml . . . . . . . . . . . . . 83

4.10 Tela de configuração do JPF para o programa CatchExceptionExample.java . . . . . . 84

4.11 Tela de configuração dos listeners para o programa CatchExceptionExample.java . . . 84

4.12 Tela de seleção das propriedades para o programa CatchExceptionExample.java . . . . 85

4.13 Tela de resultados para o programa CatchExceptionExample.java . . . . . . . . . . 85

4.14 Tela de rastreamento de estados para o programa CatchExceptionExample.java . . . . 86 


\section{Lista de Tabelas}

2.1 ferramentas de teste . . . . . . . . . . . . . . . . . . . 13

2.2 definições e usos . . . . . . . . . . . . . . . . . . . . . . . . . 21

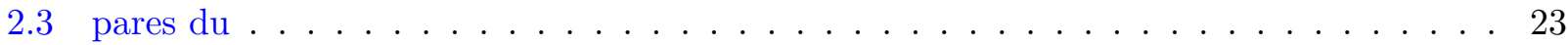

2.4 pares du estendidos . . . . . . . . . . . . . . . . . . . 26

2.5 definições e usos do objeto do exemplo . . . . . . . . . . . . . . . . . . . 27

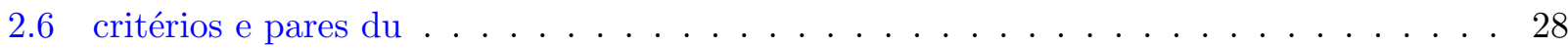

2.7 estados e usos . . . . . . . . . . . . . . . . . . . . . 30

2.8 critérios baseados em definição-uso . . . . . . . . . . . . . . . . . . 38

2.9 critérios baseados em ativação-desativação . . . . . . . . . . . . . . . . . . 38

3.1 Tabela de exceções para os exemplos . . . . . . . . . . . . . . . . . . . . . . . 59

3.2 Tabela de variáveis locais para o exemplo sem catch vazio . . . . . . . . . . . . . . 59

3.3 Tabela de variáveis locais para o exemplo com catch vazio . . . . . . . . . . . . . 59

5.1 triplas a serem percorridas para o programa CatchExceptionExample . . . . . . . . 88

5.2 triplas percorridas para o programa CatchExceptionExample . . . . . . . . . . . 89

5.3 Rastreamento de Estados para o programa CatchExceptionExample - Sem Gerador de Escolhas . . . . . . . . . . . . . . . . . . . . . 89 
5.4 Rastreamento de Estados para o programa CatchExceptionExample - Com Gerador de Escolhas . . . . . . . . . . . . . . . . . . . . . . . . . 90

5.5 triplas a serem percorridas para o programa DestructiveWrappingExample . . . . . . . 91

5.6 triplas percorridas para o programa DestructiveWrappingExample . . . . . . . . . 92

5.7 Rastreamento de Estados para o programa DestructiveWrappingExample - Sem Gerador de Escolhas . . . . . . . . . . . . . . . . . . . . . . . . . . . 92

5.8 Rastreamento de Estados para o programa DestructiveWrappingExample - Com Gerador de Escolhas . . . . . . . . . . . . . . . . . . . . . . 92

5.9 triplas a serem percorridas para o programa EmptyCatchExample . . . . . . . . 93

5.10 triplas percorridas para o programa EmptyCatchExample . . . . . . . . . . . . 93

5.11 Rastreamento de Estados para o programa EmptyCatchExample - Sem Gerador de Escolhas . . . . . . . . . . . . . . . . . . . . . . 93

5.12 Rastreamento de Estados para o programa EmptyCatchExample - Com Gerador de

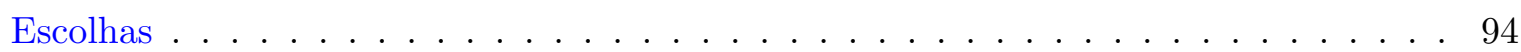

5.13 linhas a serem percorridas para o programa EmptyInterruptedExceptionExample . . . 94

5.14 triplas percorridas para o programa EmptyInterruptedExceptionExample . . . . . . 95

5.15 Rastreamento de Estados para o programa EmptyInterruptedExceptionExample - Sem Gerador de Escolhas . . . . . . . . . . . . . . . . . . . . . 95

5.16 Rastreamento de Estados para o programa EmptyInterruptedExceptionExample Com Gerador de Escolhas . . . . . . . . . . . . . . . . . . . . . . . 95

5.17 triplas a serem percorridas para o programa ExceptionNeverThrownExample - versão com violação de propriedade . . . . . . . . . . . . . . . . . . . 96

5.18 triplas percorridas para o programa ExceptionNeverThrownExample - versão com violação de propriedade . . . . . . . . . . . . . . . . . . 96

5.19 Rastreamento de Estados para o programa ExceptionNeverThrownExample - Sem Gerador de Escolhas - versão com violação de propriedade . . . . . . . . . . . . . 97 
5.20 Rastreamento de Estados para o programa ExceptionNeverThrownExample - Com Gerador de Escolhas - versão com violação de propriedade . . . . . . . . . . . . . . . . 97

5.21 triplas a serem percorridas para o programa ExceptionNeverThrownExample - versão sem violação de propriedade . . . . . . . . . . . . . . . . . . . . . 98

5.22 triplas percorridas para o programa ExceptionNeverThrownExample - versão sem violação de propriedade . . . . . . . . . . . . . . . . . . . . . . . . . 98

5.23 Rastreamento de Estados para o programa ExceptionNeverThrownExample - Sem Gerador de Escolhas - versão sem violação de propriedade . . . . . . . . . . . . . . . . 99

5.24 Rastreamento de Estados para o programa ExceptionNeverThrownExample - Com Gerador de Escolhas - versão sem violação de propriedade . . . . . . . . . . . . . . . . 99

5.25 triplas a serem percorridas para o programa FinallyExample . . . . . . . . . . . . 100

5.26 triplas percorridas para o programa FinallyExample . . . . . . . . . . . . . 100

5.27 Rastreamento de Estados para o programa FinallyExample - Sem Gerador de Escolhas 100

5.28 Rastreamento de Estados para o programa FinallyExample - Com Gerador de Escolhas101

5.29 triplas a serem percorridas para o programa LogRethrowExceptionExample . . . . . . 102

5.30 triplas percorridas para o programa LogRethrowExceptionExample . . . . . . . . . 102

5.31 Rastreamento de Estados para o programa LogRethrowExceptionExample - Sem Gerador de Escolhas . . . . . . . . . . . . . . . . . . . . . . . . . 103

5.32 Rastreamento de Estados para o programa LogRethrowExceptionExample - Com Gerador de Escolhas . . . . . . . . . . . . . . . . . . . . . . . . 103

5.33 triplas a serem percorridas para o programa LogReturnNullExample . . . . . . . . . . 104

5.34 triplas percorridas para o programa LogReturnNullExample . . . . . . . . . . . . . . . 104

5.35 Rastreamento de Estados para o programa LogReturnNullExample - Sem Gerador de Escolhas . . . . . . . . . . . . . . . . . . . . . . . . . . . 104

5.36 Rastreamento de Estados para o programa LogReturnNullExample - Com Gerador de Escolhas . . . . . . . . . . . . . . . . . . . . . . 105 
5.37 triplas a serem percorridas para o programa LostCauseExample . . . . . . . . . . 105

5.38 triplas percorridas para o programa LostCauseExample . . . . . . . . . . . . 106

5.39 Rastreamento de Estados para o programa LostCauseExample - Sem Gerador de Es-

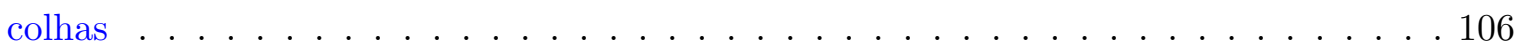

5.40 Rastreamento de Estados para o programa LostCauseExample - Com Gerador de Escolhas . . . . . . . . . . . . . . . . . . . . . 106

5.41 triplas a serem percorridas para o programa MultipleLogExample . . . . . . . . . . 107

5.42 triplas percorridas para o programa MultipleLogExample . . . . . . . . . . . . . 108

5.43 Rastreamento de Estados para o programa MultipleLogExample - Sem Gerador de Escolhas . . . . . . . . . . . . . . . . . . . . . . . 108

5.44 Rastreamento de Estados para o programa MultipleLogExample - Com Gerador de Escolhas . . . . . . . . . . . . . . . . . . . . . . . . 108

5.45 triplas a serem percorridas para o programa ThrowExceptionExample . . . . . . . . 109

5.46 triplas percorridas para o programa ThrowExceptionExample . . . . . . . . . . . 109

5.47 Rastreamento de Estados para o programa ThrowExceptionExample - Sem Gerador de Escolhas . . . . . . . . . . . . . . . . . . . . . . . . 109

5.48 Rastreamento de Estados para o programa ThrowExceptionExample - Com Gerador de Escolhas . . . . . . . . . . . . . . . . . . . . . . . . . 110

5.49 triplas a serem percorridas para o programa ThrowsManyExample . . . . . . . . . . 110

5.50 triplas percorridas para o programa ThrowsManyExample . . . . . . . . . . . . . 110

5.51 Rastreamento de Estados para o programa ThrowsManyExample - Sem Gerador de Escolhas . . . . . . . . . . . . . . . . . . . . . . . 111

5.52 Rastreamento de Estados para o programa ThrowsManyExample - Com Gerador de Escolhas . . . . . . . . . . . . . . . . . . . . . . . . . 111

5.53 triplas a serem percorridas para o programa UncaughtExceptionExample . . . . . . 112 5.54 triplas percorridas para o programa UncaughtExceptionExample . . . . . . . . . 112 
5.55 Rastreamento de Estados para o programa UncaughtExceptionExample - Sem Gerador de Escolhas . . . . . . . . . . . . . . . . . . . . . . . . . . . 112

5.56 Rastreamento de Estados para o programa UncaughtExceptionExample - Com Gerador de Escolhas . . . . . . . . . . . . . . . . . . . . . . . . . 113

6.1 Resultados para os programas com Deadlock . . . . . . . . . . . . . 116

6.2 Resultados para os programas sem Deadlock . . . . . . . . . . . . . . . . . 116

6.3 Resultados para o programa Start . . . . . . . . . . . . . . . . . 116

6.4 Rastreamento de Estados para o programa Start . . . . . . . . . . . . . . . . . . 117

6.5 Rastreamento de Estados para o programa Start_s . . . . . . . . . . . . . . . . . 118

6.6 Resultados para o programa Dead . . . . . . . . . . . . . . . . . . 119

6.7 Rastreamento de Estados para o programa Dead . . . . . . . . . . . . . . . . 119

6.8 Rastreamento de Estados para o programa Dead $\_$. . . . . . . . . . . . . . . . . 120

6.9 Resultados para o programa NestedMonitor . . . . . . . . . . . . . . . . . . 120

6.10 Rastreamento de Estados para o programa NestedMonitor . . . . . . . . . . . . . . . 121

6.11 Rastreamento de Estados para o programa NestedMonitor_s . . . . . . . . . . . . . . . 121

6.12 Resultados para o programa PCSimple . . . . . . . . . . . . . . . . . . . 121

6.13 Rastreamento de Estados para o programa PCSimple . . . . . . . . . . . . . 122

6.14 Rastreamento de Estados para o programa PCSimple_s . . . . . . . . . . . . . . . . 122

6.15 Resultados para o programa PipeInteger . . . . . . . . . . . . . . . . . . 123

6.16 Rastreamento de Estados para o programa PipeInteger . . . . . . . . . . . . . 125

6.17 Rastreamento de Estados para o programa PipeInteger_s . . . . . . . . . . . . . . . . 125 


\section{Capítulo 1}

\section{Introdução}

Neste capítulo, apresentamos a motivação para este trabalho, a nossa contribuição para as atividades de teste e verificação de uma maneira geral e a estrutura na qual estão organizados os demais capítulos deste documento.

\subsection{Motivação}

Segundo Pressman, o esforço aplicado às atividades de teste normalmente varia entre $30 \%$ e $40 \%$ do esforço total do desenvolvimento do sistema de software. E em casos extremos para sistemas críticos (controle de vôo em aeronaves, monitoração de reatores nucleares), o custo pode ser de 3 a 5 vezes maior do que o custo combinado de todas as demais atividades [27].

Logo, qualquer pesquisa em metodologias que diminuam este custo é interessante, pois tem um impacto significativo no custo total do desenvolvimento do sistema. Este trabalho propõe a automatização de parte das atividades de teste de maneira a reduzir este custo.

Para executar os testes de um sistema é necessário elaborar casos de teste (conjuntos de entradas e saídas esperadas) que serão exercitados. A criação destes casos de teste pode exigir um esforço considerável se executada manualmente, conforme será detalhado mais adiante neste trabalho. Nossa abordagem para a redução do custo é focada na redução da criação manual dos casos de teste.

Existem diversas abordagens para geração automática de casos de teste. Csallner [8] utiliza verificação estática de pré-condições implícitas de programas Java para geração de casos de teste. Outras abordagens que estão sendo bem investigadas envolvem a busca de entradas que executem um determinado caminho, instrução ou par definição-uso no programa sendo testado através de 
algoritmos genéticos ${ }^{1}$ [26], [23], [22].

Heimdahl e Devaraj [15] apresentam uma técnica para geração e posterior redução de um conjunto de testes, porém a partir de uma especificação formal de um modelo de software.

Nossa abordagem para redução da criação manual dos casos de teste envolve utilizar a técnica de verificação de modelos associada aos testes. Esta técnica consiste em verificar se determinada propriedade é satisfeita em um modelo. O modelo descreve o comportamento do sistema em uma linguagem formal enquanto a propriedade corresponde a algum requisito de funcionamento do sistema representado como uma fórmula lógica [11]. O uso da verificação de propriedades, independente dos testes, garante que certo requisito de funcionamento do sistema é atendido. Assim, combinando as duas técnicas, além da redução da criação manual dos casos de teste ainda podemos garantir certas propriedades sobre o código.

Alguns outros trabalhos que misturam verificação de modelos e testes são apresentados por Beyer [1], que mostra uma metodologia para geração automática de casos de teste, a partir de contraexemplos gerados por um verificador de modelos ao fazer verificação de propriedades.

Outro exemplo vem de Ball [36], que apresenta uma metodologia que consiste na execução de casos de teste de um software e na posterior verificação dos estados visitados. Caso os estados sejam adequados é feita então uma verificação de propriedades, ou em caso contrário é feita a geração de testes adicionais.

Além disso, pesquisas feitas em aplicativos Java [32], mostram que o uso de estruturas de controle para tratamento de exceção está presente em até $19 \%$ do código do programa, e que grande parte dos critérios de teste utilizados ignoram este tipo de estruturas.

Jiang, Zhang e Yan [20] propõem uma abordagem para o teste das estruturas de tratamento de exceções através da injeção de falhas no programa original utilizando uma ferramenta para código $\mathrm{C}++$ desenvolvida por eles, denominada AutoETool. Além de trabalharmos com código Java, nossa abordagem tem duas diferenças principais. Conforme descrito em mais detalhes no capítulo 4, utilizamos um gerador de escolhas na ferramenta de verificação que simula os lançamentos de exceções sem que seja necessária a injeção de falhas. Utilizamos este recurso para forçar a execução das estruturas de tratamento de exceção.

\footnotetext{
${ }^{1}$ algoritmos genéticos envolvem o uso de heurísticas que imitam a evolução natural das espécies para descoberta de soluções ótimas para um problema
} 
Outra diferença é que definimos propriedades baseadas em más práticas no tratamento de exceções. Desta forma, além do objetivo de redução do espaço de testes, também conseguimos garantir a qualidade do código em relação às propriedades definidas.

É importante ressaltar que não é possivel perceber esta más práticas através somente das atividades de teste. Se não forem utilizadas propriedades definidas para o verificador de modelos, estas práticas só podem ser percebidas através de técnicas como inspeção de código ou ferramentas de análise estática como por exemplo FindBugs ${ }^{2}$ ou $\mathrm{PMD}^{3}$.

A inspeção de código é manual e depende da habilidade do inspetor, além de levar mais tempo e provavelmente implicar em um custo maior em relação ao uso de alguma ferramenta. Já o uso de ferramentas de análise estática apresenta uma desvantagem em relação à análise dinâmica realizada em uma verificação de propriedades, pois pode apontar más práticas em trechos de código que nunca serão executados, enquanto o verificador aponta as violações em código que ele executou. A única desvantagem do uso das ferramentas estaria na necessidade do testador escrever as propriedades relativas às práticas que pretende verificar, porém no nosso caso já escrevemos diversas propriedades e integramos à ferramenta. Com o tempo, é possivel montar uma biblioteca de propriedades com as principais más práticas.

Nossa proposta, então, é utilizar uma ferramenta de verificação de modelos para verificar propriedades baseadas em tratamento de exceções. A partir do rastreamento do código executado pela ferramenta na verificação, levantamos a cobertura obtida de acordo o critério de teste adotado. Com isso reduzimos os casos de teste que devem ser gerados manualmente para aqueles que irão gerar a cobertura do código que não foi exercitado pela ferramenta.

Num exemplo simplificado, suponha que nosso critério estabelece a execução de $100 \%$ das linhas de código. Selecionamos uma propriedade e executamos a ferramenta de verificação. Após a verificação identificamos o código executado e percebemos que $70 \%$ já foi exercitado. Resta apenas criar casos de teste para exercitar os $30 \%$ de código faltantes. Além disso, também sabemos que as más práticas associadas as propriedades verificadas não estão presentes no código executado.

\subsection{Objetivos}

Neste trabalho, pretende-se:

\footnotetext{
${ }^{2}$ http://findbugs.sourceforge.net/

${ }^{3}$ http://pmd.sourceforge.net/
} 


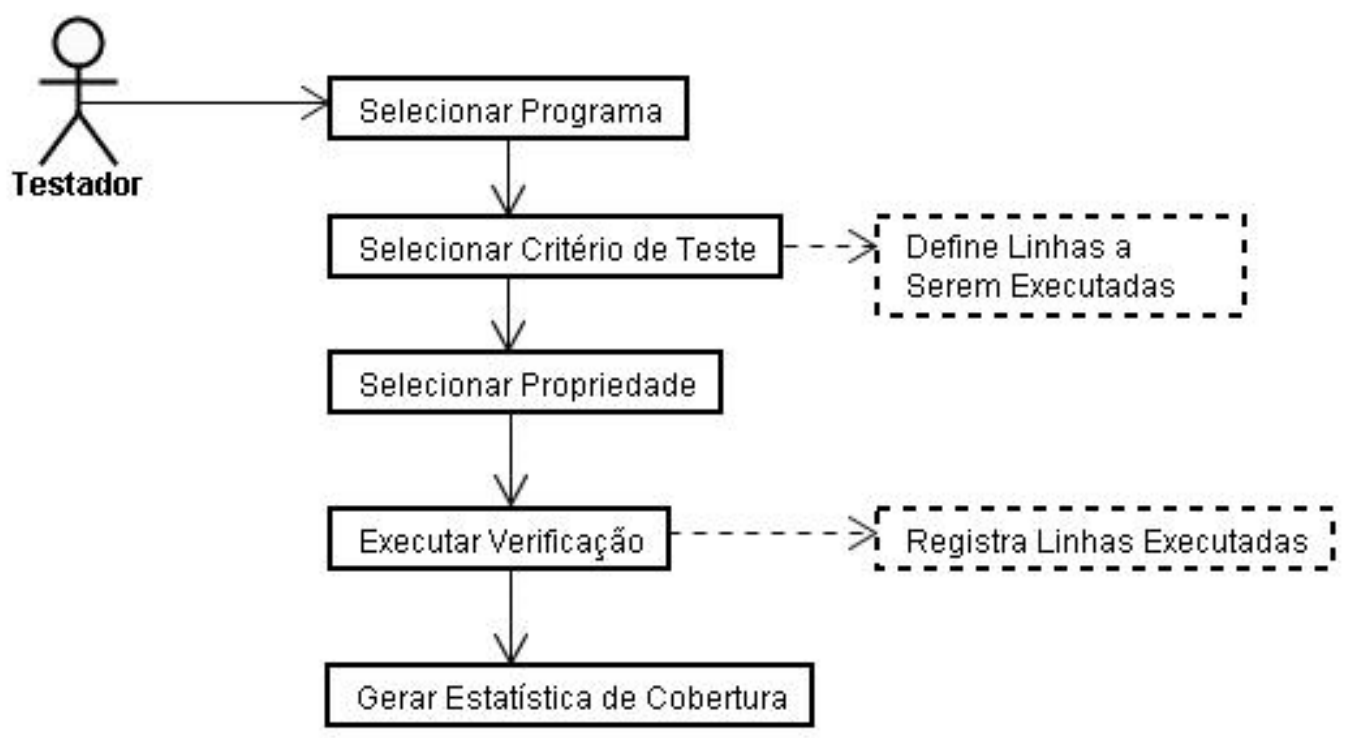

Figura 1.1: resumo do funcionamento do sistema

- apresentar e propor a verificação de propriedades como forma de auxílio nas atividades de teste;

- definir propriedades relacionadas a más práticas comuns no tratamento de exceções;

- apresentar um ambiente de testes composto por um conjunto de ferramentas para facilitar e viabilizar o uso da técnica de verificação de propriedades como atividade auxiliar nas atividades de teste.

A Figura 1.1 ilustra o comportamento desejado para o sistema e as atividades executadas pelo testador. As atividades nas caixas com linha tracejada são desempenhadas automaticamente pelas ferramentas. As demais são solicitadas pelo testador na interface gráfica desenvolvida para o ambiente de teste..

As ferramentas utilizadas foram o Java PathFinder [34], para a verificação de propriedades, e a Ocongra [25], desenvolvida no próprio IME-USP, para geração das linhas de código a serem percorridas. 


\subsection{Contribuições deste trabalho}

Neste trabalho foram criadas diversas extensões para a ferramenta Java PathFinder:

- propriedades baseadas em más práticas de tratamento de exceção;

- gerador de escolhas que permite a simulação do lançamento de exceções na execução da verificação de programas;

- listener que rastreia e registra todas as instruções executadas pelo verificador, e não somente aquelas utilizadas para um contra-exemplo;

- interface gráfica para configuração e uso do Java PathFinder em conjunto com as extensões citadas nos itens anteriores.

Com isso nos concentramos em duas áreas ainda pouco exploradas nas pesquisas de teste e verificação:

- tratamento de exceções nas atividades de teste e verificação;

- uso de propriedades para verificação de más práticas de programação: existem várias ferramentas de análise estática de código fonte para isso, mas durante nosso trabalho não encontramos nenhuma abordagem dinâmica. Além disso, o mais comum é trabalhar com propriedades baseadas em especificação e não código fonte, como estamos fazendo.

\subsection{Organização}

O presente trabalho está organizado da seguinte forma:

Capítulo 2 São apresentados os principais conceitos relativos a testes, bem como diversos critérios de teste englobando critérios para programas procedurais, orientados a objetos e que incluem tratamento de exceções

Capítulo 3 São analisadas as características de algumas ferramentas de auxílio ao teste. A característica principal destas ferramentas é que funcionam como verificadores de modelo. Também são definidas algumas propriedades relativas aos erros comuns no tratamento de exceções apresentados no capítulo anterior. Estas propriedades serão utilizadas com o verificador de modelos. 
Capítulo 4 É apresentado o ambiente de testes que foi utilizado. São apresentadas as customizações feitas nas ferramentas existentes e o aplicativo que foi desenvolvido para configuração e realização dos testes e análise dos restultados.

Capítulo 5 São apresentados os resultados obtidos na execução das verificações de propriedades baseadas em exceções para 13 programas com caracteristicas específicas de tratamento de exceções.

Capítulo 6 São apresentados os resultados obtidos na execução das verificações de propriedades baseadas em exceções e deadlock para 5 programas de código concorrente.

Capítulo 7 Apresentamos as conclusões e resultados obtidos e descrevemos como o trabalho pode ser estendido. 


\section{Capítulo 2}

\section{Critérios de teste}

Como testar todas as possíveis entradas para um programa em geral é infactível, costumamos trabalhar com subconjuntos reduzidos, mas que tenham alta probabilidade de encontrar defeitos, caso eles existam. As regras que determinam estes subconjuntos são os critérios de teste [10]

Neste capítulo, apresentamos os conceitos básicos relativos a testes e alguns critérios de teste para programas procedurais, bem como suas limitações na aplicação a programas orientados a objetos. Em seguida apresentamos as principais características da programação orientada a objetos que causam dificuldades nas atividades de teste. Finalizamos apresentando critérios de teste para programas orientados a objetos e critérios que englobam tratamento de exceções.

\subsection{Teste de Software}

Hoje em dia, os sistemas de software são parte integrante do dia a dia das pessoas. As atividades do cotidiano, como fazer compras em um supermercado, alugar um filme em uma locadora ou comprar ingressos para uma peça no teatro, cada vez mais utilizam sistemas de software para agilizar e facilitar sua operação. Com a expansão da Internet, foram criados serviços que podem ser acessados por um usuário sem que ele saia de casa, como serviços de comércio eletrônico e de pagamento de contas on-line. Isso sem contar os sistemas de software internos de empresas, como controle de estoque e gerenciamento de folha de pagamento.

Nada mais incômodo para um usuário do que utilizar um desses sistemas que não funcione corretamente, ou seja, que apresente algum problema em sua execução. Alguns exemplos catastróficos de defeitos de software são a queda do foguete francês Ariane 5, em 1996, devido a um erro de conversão de um valor de ponto flutuante de 64 bits para um inteiro de 16 bits [4], e a perda de uma sonda 
da NASA em Marte devido à incompatibilidades entre dois componentes de software, onde um deles utilizava o sistema inglês e o outro o sistema métrico de medidas [24].

Problemas no funcionamento de sistemas de software podem gerar a execução de operações indevidas ou a não execução de operações necessárias. As conseqüências de problemas no funcionamento de sistemas de software podem variar desde simples incômodos até coisas mais graves como danos materiais, prejuízo financeiro ou perda de vidas humanas. Para evitar conseqüências indesejadas, executamos atividades que visam identificar falhas ou bugs nos softwares. Estas atividades são os testes.

Algumas perguntas que devemos responder para entender melhor as atividades de teste são:

1. Por que erros de software ocorrem?

O desenvolvimento de software é uma atividade realizada por seres humanos, que consiste na codificação de instruções a serem executadas por um computador. O computador é um objeto formal e literal e não possui a capacidade humana de abstração. Dito de outra maneira, ele não consegue "adivinhar" a intenção humana a partir do código escrito, limitando-se, assim, a seguir exatamente as instruções que são fornecidas.

Já o ser humano está acostumado a uma linguagem mais informal que permite que ele compreenda uma mensagem mesmo a partir de informações não tão precisas. Desta maneira, é comum que o código escrito contenha erros decorrentes de imprecisão ou mesmo incompleteza. Alguns erros podem ser evitados simplesmente pelo nível de experiência do desenvolvedor, mas a própria natureza humana garante que erros sempre existirão. Soma-se a isso fatores como prazo apertado, complexidade do código, mudanças de tecnologia e interações entre múltiplos sub-sistemas, que aumentam ainda mais a chance de erros serem cometidos [18].

Estes erros viram bugs do código e devem ser corrigidos o mais cedo possível. Se um erro for descoberto apenas quando o sistema já está em produção, sua correção é mais difícil. Isto ocorre devido a fatores como a necessidade de tentar reproduzir o erro encontrado em produção no ambiente de desenvolvimento e a impossibilidade de parar o sistema em uso a qualquer momento para efetuar as correções necessárias, entre outros. Logo, o custo para correção de um sistema em produção é bem maior do que o custo da correção na etapa de desenvolvimento.

2. Como os testes ajudam? 
A atividade de teste é a responsável por identificar estes bugs. É importante que esta atividade seja a mais eficiente possível, de forma a não permitir, ou ao menos minimizar, a presença de erros nos programas utilizados em produção.

Os testes podem aumentar a confiança na qualidade de um sistema. Quando bugs são encontrados e corrigidos, aumenta a confiança de que o sistema esteja funcionando corretamente.

Além disso, podemos aproveitar a experiência dos testes de projetos anteriores para aumentar a qualidade de novos projetos. Após identificados, não devemos cometer os mesmos erros novamente.

3. Quando encerrar os testes?

Para decidir quando devemos encerrar os testes devemos levar em consideração fatores como os riscos do projeto, assim como restrições de tempo e orçamento. Numa análise baseada em riscos, estes são utilizados para identificar quais as áreas que devem ser testadas. Podemos identificar riscos como:

- O potencial do software causar danos a um indivíduo/empresa;

- Baixa qualidade do software na usabilidade, confiabilidade, desempenho, etc.

- Software que não oferece as funcionalidades desejadas.

Por outro lado, as atividades de teste têm um custo elevado. As atividades de teste envolvem o desenvolvimento de um sistema de software em paralelo ao sistema principal, sendo necessária toda uma análise e projeto, além da execução dos testes propriamente ditos.

Os testes devem fornecer aos patrocinadores do sistema informações suficientes para que sejam tomadas decisões adequadas relativas à entrega do software em questão.

É importante, então, que seja adotado algum critério de testes e que sejam gerados casos de teste aderentes ao critério. Este critério funciona como um conjunto de requisitos que determinam o que deve ser testado e quando é suficiente parar os testes, ou seja, quando o sistema está adequadamente testado. Estes critérios podem variar de cenário a cenário com base em diversos fatores, como por exemplo, o custo dos testes e a funcionalidade dos programas. Alguns critérios $[6,16,17,31]$ podem exigir mais casos de teste aumentando o custo, sem necessariamente aumentar o grau de segurança em seus resultados. Por isto, é importante conhecer diversos critérios para aplicá-los corretamente ao cenário exigido. 


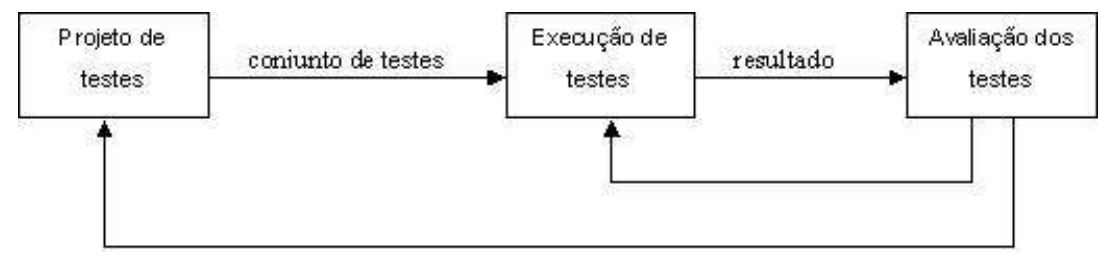

Figura 2.1: atividades de teste de software

Além disso, muitos critérios são antigos, tendo sido desenvolvidos para testes de sistemas procedurais, não levando em conta estruturas utilizadas em sistemas orientados a objetos. Em particular, critérios que levem em conta a existência de estruturas de tratamento de exceções são raros, o que pode ser problemático, levando-se em conta que atualmente, uma parte relevante do código escrito está relacionada a este tipo de estruturas [32].

4. Quais são as atividades de teste?

Teste de software pode ser visto como um problema de engenharia de sistemas. É o projeto e implementação de um sistema de software que exercita outro sistema com o intuito de encontrar bugs.

Para isso, é importante utilizar abstrações e modelos, que permitem representar de forma simplificada o sistema sob estudo. Binder [2] cita lógica combinatória e máquinas de estado como exemplos para a geração de modelos genéricos e apresenta uma discussão sobre os modelos específicos do aplicativo. Estes modelos podem ser utilizados para a geração de um conjunto de testes (test suite).

O diagrama 2.1 mostra as principais atividades envolvidas no processo de teste de software. Estas atividades encontram-se descritas mais detalhadamente a seguir.

O projeto de testes (test design) envolve alguns passos [2]:

- Identificação, modelagem e análise das responsabilidades do sistema sob teste

- Projeto de casos de teste baseados nesta perspectiva externa

- Adição de casos de teste baseados na análise de código, suspeitas e heurísticas

- Desenvolvimento dos resultados esperados para cada caso de teste ou escolha de uma maneira de avaliar o status passou/não passou de cada caso de teste. 
Depois que o projeto está completo, os testes são aplicados ao sistema. Isto pode ser feito manualmente ou com o uso de ferramentas de automação de testes.

A execução dos testes tipicamente segue alguns passos [2], que não são todos obrigatórios:

- Estabelecer que a implementação está minimamente operacional, exercitando as interfaces entre as partes.

- Executar o conjunto de testes. O resultado de cada teste é avaliado como passou/não passou.

- Utilizar uma ferramenta de cobertura para instrumentar o sistema sob teste. Executar os testes novamente e avaliar o relatório de cobertura.

- Se necessário, desenvolver novos testes para exercitar código não coberto.

- Parar os testes quando a meta de cobertura for atingida e todos os testes passarem.

A execução e projeto de testes são mais efetivos quando ocorrem em paralelo com o desenvolvimento do aplicativo.

É importante ressaltar algumas atividades, que embora importantes para prevenção e remoção de bugs de software não são testes [2]:

- melhorias na interface com o usuário ou descoberta de requisitos através de protótipos.

- verificação de um modelo de análise ou projeto por simulação ou verificadores de sintaxe.

- revisão de documentação ou código por humanos em inspeções.

- análise estática de código utilizando ferramentas.

- uso de analisadores dinâmicos para identificação de "memory leaks"ou similares.

- depuração, apesar de um teste bem sucedido levar a depuração.

Dependendo do tipo de teste sendo executado, podemos ter o foco em diferentes objetivos. Durante o desenvolvimento do software, o objetivo é descobrir o máximo de bugs possíveis, de maneira a poder corrigi-los. Em testes de aceitação, o objetivo principal pode ser confirmar que o sistema funciona da maneira esperada. Em alguns casos, o objetivo principal pode ser aumentar a confiança na qualidade do software, para que os financiadores do projeto possam tomar uma decisão sobre a entrega ou não do sistema ou produto. Na manutenção do software, o objetivo pode ser garantir que não foram inseridos novos bugs 
5. Quais são as limitações dos testes?

Segundo Dijkstra [9], "teste de programas pode ser utilizado para mostrar a presença de defeitos, mas não sua ausência". Testes apresentam resultados de acordo com as entradas fornecidas em um caso de teste. Desta forma, a menos que seja feito um teste exaustivo (que é inviável, conforme definido anteriormente) o teste não garante que o sistema esteja livre de bugs.

Outros princípios básicos de testes que valem a pena ser mencionados são [18]:

- As atividades de teste devem começar o mais cedo possível no ciclo de desenvolvimento de software

- Testes são realizados de maneiras diferentes em contextos diferentes. Um software para controle de tráfego aéreo é testado de maneira diferente de um software de comércio eletrônico.

- Encontrar e remover bugs não adianta nada se o sistema não atende às necessidades do cliente.

6. Existem ferramentas para testes?

Existem diversas ferramentas comerciais e open-source de auxílio à atividade de testes ${ }^{1}$. Algumas destas ferramentas automatizam a execução do conjunto de testes (test suite), outras focam em alguns tipos mais específicos de teste, como testes unitários ou testes de carga.

A Tabela 2.1 lista algumas ferramentas e uma breve descrição de suas funcionalidades.

Outro fator importante é que muito da pesquisa em testes de sistemas orientados a objeto é baseada em teste da especificação. Contudo, na prática, poucos sistemas são especificados formalmente e existem muitos sistemas que não possuem nem mesmo uma especificação informal [16]. Desta forma, é importante levar-se em conta métodos de teste baseados no código.

\subsubsection{Definições Preliminares}

A seguir apresentamos as definições dos principais termos relativos a atividades de teste, importantes para a compreensão deste trabalho. No Apêndice A encontra-se uma lista mais completa. As definições foram extraídas de [2], [10] e [19].

\footnotetext{
${ }^{1}$ Em http://www.testingfaqs.org/ podemos encontrar uma lista compreensiva de ferramentas.
} 


\begin{tabular}{|l|l|}
\hline ferramenta & descrição \\
\hline \hline Compuware QACenter & $\begin{array}{l}\text { Oferece um conjunto de ferramentas que abran- } \\
\text { gem automação de testes funcionais e de re- } \\
\text { gressão, testes de performance e atividades de } \\
\text { gerenciamento. }\end{array}$ \\
\hline Apache JMeter & Ferramenta para teste de carga e de stress \\
\hline Mercury LoadRunner & $\begin{array}{l}\text { Ferramenta para testes de sistemas cli- } \\
\text { ente/servidor com foco em teste de performance } \\
\text { e de carga }\end{array}$ \\
\hline Rational Functional Tester & $\begin{array}{l}\text { Ferramenta com suporte a criação de scripts e } \\
\text { execução de teste funcional e de regressão }\end{array}$ \\
\hline Borland SilkTest & $\begin{array}{l}\text { Ferramenta para automação de teste funcionais } \\
\text { e de regressão }\end{array}$ \\
\hline Junit & $\begin{array}{l}\text { Framework para execução de testes unitários } \\
\text { Framework para execução de testes unitários } \\
\text { inspirado no JUnit }\end{array}$ \\
\hline TesteNG & $\begin{array}{l}\text { Framework para execução de testes unitários } \\
\text { em aplicativos Java do lado servidor (Servlets, } \\
\text { EJBs, etc.) }\end{array}$ \\
\hline Cactus
\end{tabular}

Tabela 2.1: ferramentas de teste

Citamos anteriormente que o objetivo das atividades de teste é encontrar bugs ou problemas em um sistema de software. A literatura tradicional estabelece termos para diversos destes problemas. Vamos identificá-los:

Uma falha(failure) é a falta de capacidade de um sistema ou componente de fornecer a funcionalidade esperada. É percebido através de saídas incorretas, finalizações anormais ou o não cumprimento de metas estabelecidas para restrições de tempo e espaço. Um defeito (fault) é a ausência de código ou presença de código incorreto. Um erro (error) é uma ação humana que produz um defeito. Estes três elementos não ocorrem em uma relação um-para-um. Ou seja, várias falhas podem resultar de um único defeito, por exemplo.

É importante observar que essas definições não são seguidas sempre e nem são unanimidade entre os pesquisadores da área [10]. Particularmente, o termo "erro"é comumente utilizado podendo ter qualquer um dos significados apresentados para "erro", "falha"e "defeito".

Também mencionamos várias vezes o termo "casos de teste" durante a apresentação das atividades 
de teste. Um caso de teste define o estado anterior ao teste do elemento a ser testado, bem como de seu ambiente, as entradas ou condições de teste e os resultados esperados. Os resultados esperados definem o que o sistema deve produzir a partir das entradas de teste. Isto inclui mensagens geradas pelo sistema, exceções, valores retornados e o estado resultante do sistema e de seu ambiente.

Já um conjunto de testes (test suite) é um conjunto de casos de teste relacionados e uma execução de testes é a execução de um conjunto de testes.

Após a execução dos testes, eles devem ser avaliados. Um teste cujos resultados reais são iguais aos resultados esperados é classificado como "passou", caso contrário é classificado como "não passou". Um teste com resultado "não passou" revela um bug e é considerado um teste com sucesso, mesmo que, na verdade os resultados indiquem um defeito no aplicativo.

Também para a execução dos testes é comum a implementação de elementos de programa auxiliares. Um test driver é uma classe ou programa utilitário que aplica casos de teste a um sistema. Um stub é uma implementação parcial, temporária de um componente. Pode servir como um substituto para um componente incompleto ou implementar código de suporte ao teste.

Uma abordagem pode ser dita formal, quando suas capacidades em revelar falhas foram estabelecidas por uma análise matemática, ou heurística quando é baseada no julgamento ou experiência de especialistas para seleção dos casos de teste.

Um conjunto de teste exaustivo requer que sejam testados todos os valores e possiveis sequências de entradas, e aplicados a todos os possíveis estados do sistema, o que é inviável mesmo para sistemas pequenos $[2]$.

Quão completo um conjunto de testes é, relativo a um método específico de projeto de caso de testes, é medido pela cobertura. Cobertura é o percentual de elementos exercitados por um dado conjunto de testes.

\subsection{Critérios de teste para programas procedurais}

Um critério de teste busca definir o que deve ser testado em um determinado programa. A partir deste critério, estabelece-se um conjunto de casos de teste que buscam atendê-lo. Existem duas principais abordagens de teste que são utilizadas correntemente:

- Teste funcional (teste caixa preta) : é a abordagem de teste mais comum. Consiste em fornecer diversas entradas para o sistema e verificar se as saídas correspondentes são aceitáveis [27]. Não 
exige nenhum conhecimento sobre a estrutura do código do programa. Este tipo de teste está focado nos requisitos funcionais do programa.

- Teste estrutural (teste caixa branca) : exige um conhecimento da estrutura do código. Com base neste conhecimento são geradas entradas que forçam determinados trechos de código a serem executados no programa. Os critérios para este tipo de teste $[6,16,17,31]$ medem a cobertura do código em relação ao critério. Idealmente, você obtém $100 \%$ de cobertura, ou seja, todos os trechos relevantes são executados, mas nem sempre isto é possível.

Para exemplificar a diferença entre as duas abordagens de teste apresentamos na Figura 2.2 um exemplo de código Java, adaptado a partir de [28]. Este mesmo exemplo será utilizado sempre que possível no decorrer deste trabalho. De maneira a já destacar algumas limitações dos critérios para programas procedurais, quando aplicados a programas orientados a objetos, estamos utilizando um programa OO como exemplo.

Este código apresenta algumas classes Java que devem ser testadas (Frame, Circle, Shape e Square) e uma classe de testes. O conceito básico consiste em criar casos de teste e verificar se as saídas geradas correspondem aos valores esperados. Estes casos de teste consistem no conjunto formado pelos pares entre os dados de teste (parâmetros de entrada) e saídas esperadas [10].

Vamos testar os métodos setShapeObj e drawFrame. Utilizando um teste caixa preta não nos preocupamos com a implementação dos métodos, somente com o que eles devem fazer. O método setShapeObj deve criar um objeto Circle ou Square. O método drawFrame deveria desenhar o objeto criado. Por simplicidade, a nossa implementação somente imprime o nome do objeto que seria desenhado. Nosso código de teste aceita como entradas valores para o tipo de objeto a ser desenhado (variável shape com os valores 1 para Square e 2 para Circle), perímetro (variável perimeter) e coordenadas $\mathrm{x}$ e y do ponto base para o desenho do objeto (variáveis $x$ e $y$, respectivamente).

Vamos criar casos de teste para a criação e desenho de um objeto Square e outro Circle. Assim, podemos utilizar os seguintes casos de teste para o programa da Figura 2.2.

- $($ shape $=1$, perimeter $=5, \mathrm{x}=5, \mathrm{y}=5)$ : deve gerar a saída "Desenhando Square com perimetro 5".

- $($ shape $=2$, perimeter $=5, \mathrm{x}=5, \mathrm{y}=5)$ : deve gerar a saída "Desenhando Circle com perimetro 5".

Estes casos de teste foram criados manualmente, selecionando valores adequados para as variáveis de entrada. Em um sistema real, poderiamos gerar diversos outros casos de teste para simular outras 


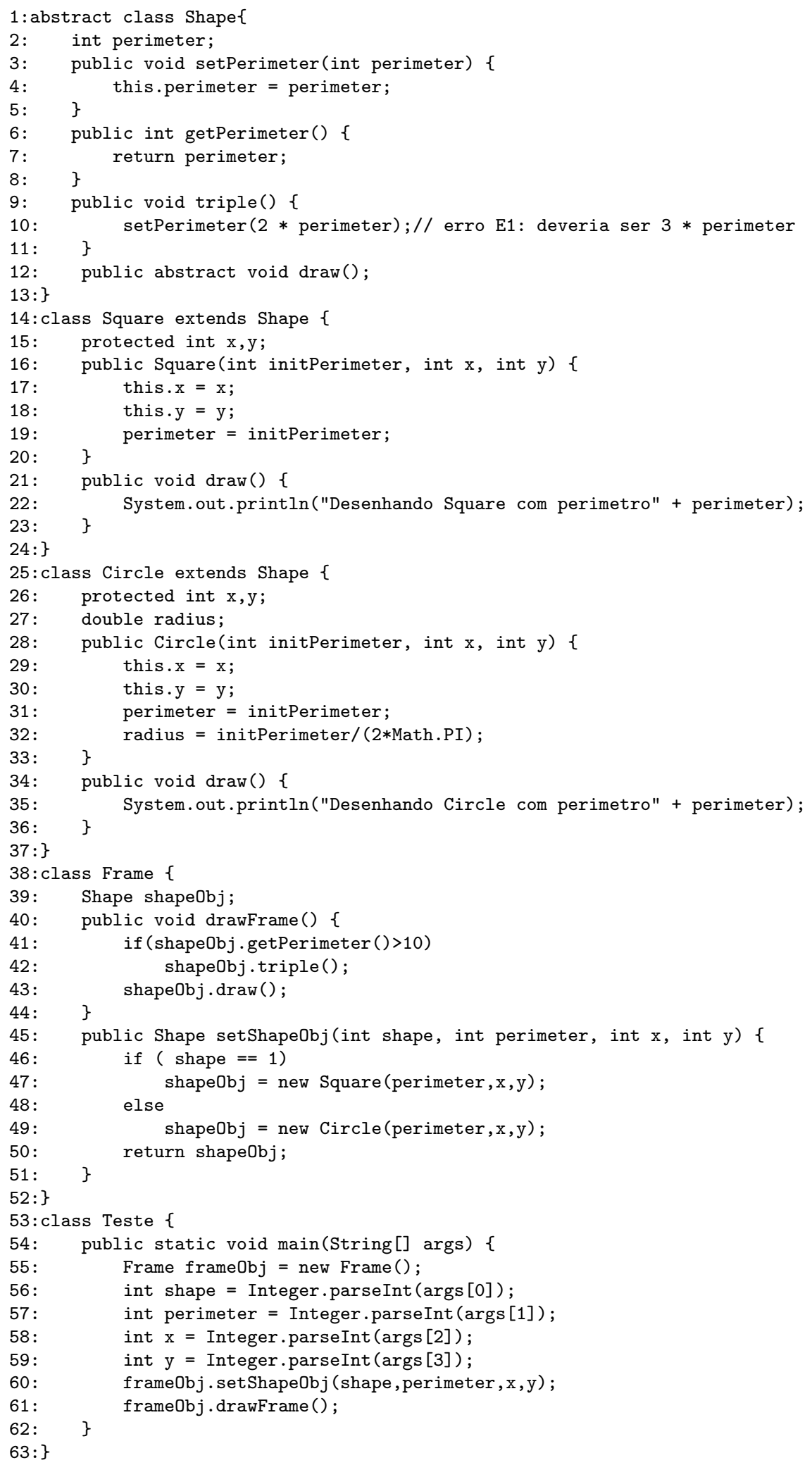

Figura 2.2: Exemplo de programa Java 


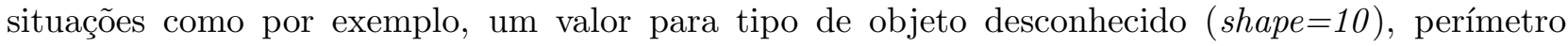
negativo ou outros valores inválidos.

Para um teste caixa branca, devemos conhecer a estrutura do código e usar este conhecimento para guiar a geração dos casos de teste. Podemos, por exemplo, utilizar um critério que exija que sejam executadas todas as possíveis ramificações de condicionais no programa [16]. Desta maneira, podemos utilizar os seguintes casos de teste:

- $($ shape $=1$,perimeter $=5, \mathrm{x}=5, \mathrm{y}=5)$ : deve gerar a saída "Desenhando Square com perimetro 5".

- $($ shape $=2$,perimeter $=5, \mathrm{x}=5, \mathrm{y}=5)$ : deve gerar a saída "Desenhando Circle com perimetro 5".

- $($ shape $=1$,perimeter $=12, \mathrm{x}=5, \mathrm{y}=5)$ : deve gerar a saída "Desenhando Square com perimetro $36 "$.

Acrescentamos um caso de teste para exercitar todas as ramificações a partir da linha 41. Neste caso, como há um erro na linha 10, a resposta será diferente da esperada. A saída será "Desenhando Square com perimetro $24 "$.

No nosso exemplo, o erro foi identificado a partir de um teste caixa branca (estrutural) e não no caixa preta (funcional). Dependendo do caso de teste utilizado, o mesmo erro poderia ter sido identificado no teste funcional.

Neste trabalho, vamos nos concentrar nos testes estruturais. Inicialmente, vamos apresentar alguns conceitos básicos de critérios de testes estruturais tradicionais, verificar suas limitações quando aplicados a sistemas orientados a objetos e apresentar extensões a estes modelos.

\subsubsection{Testes baseados em fluxo de controle}

Conforme visto anteriormente, testes estruturais visam "varrer' algumas instruções ou linhas de código de um programa. Para seleção dos trechos a serem executados utilizamos algum critério de teste. Vamos analisar critérios baseados no fluxo de controle e no fluxo de dados de um programa.

Critérios baseados em fluxo de controle [31] utilizam os caminhos percorridos na execução do código como parâmetros para os requisitos do teste. Seus dois principais critérios [16] são:

- Todas as ramificações (all-branches) : critério que exige que sejam percorridos todos os trechos 


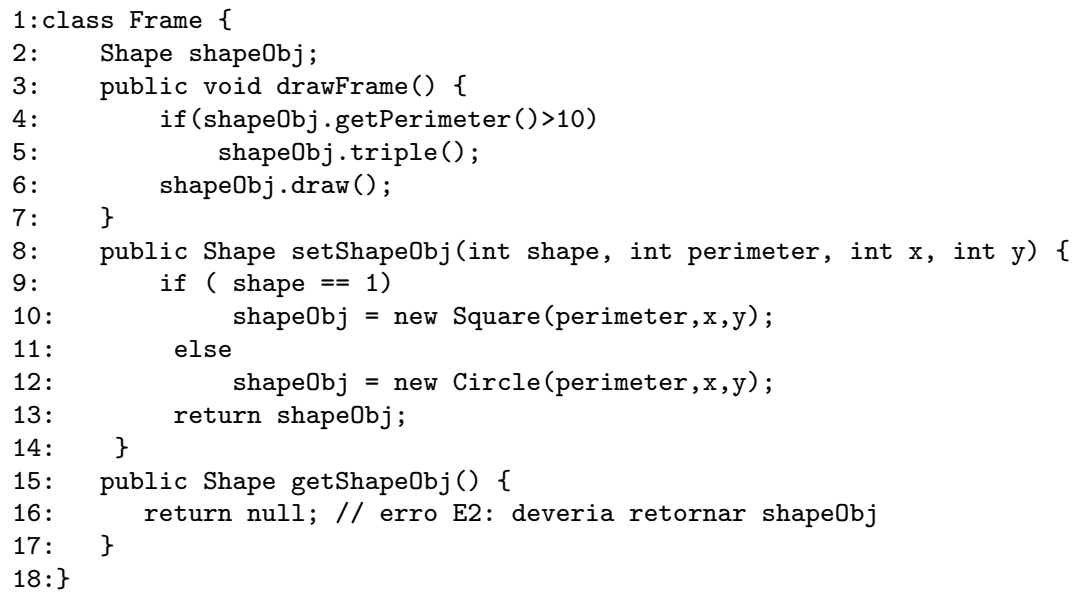

Figura 2.3: classe Frame modificada

de código que contém ramificações, sendo que para cada ramificação devem ser percorridos todos os seus resultados.

- Todos os comandos (all-statements) : critério que exige que sejam percorridas todas as linhas de comando de um programa.

Apresentamos, na Figura 2.3, uma pequena modificação na classe Frame exibida anteriormente na Figura 2.2. Foi inserido um método getShapeObj() contendo um erro. Com base neste exemplo, exibimos os casos de teste que seriam necessários para atender aos critérios acima.

Para o critério all-branches precisamos exercitar as linhas $(4,5),(9,10),(9,12)$ e podemos utilizar os mesmos casos de teste apresentados anteriormente para o exemplo de teste funcional:

- $($ shape $=2$,perimeter $=5, \mathrm{x}=5, \mathrm{y}=5)$ : deve gerar a saída "Desenhando Circle com perimetro 5". Exercita as linhas $(9,12)$.

- $($ shape $=1$, perimeter $=12, \mathrm{x}=5, \mathrm{y}=5)$ : deve gerar a saída "Desenhando Square com perimetro $36 "$. Exercita as linhas $(4,5)$ e $(9,10)$

Percebemos que por este critério não é exercitada a linha 16 que contém um erro.

A Figura 2.4 mostra os fluxos executados pelo primeiro caso de teste, e a Figura 2.5 mostra 

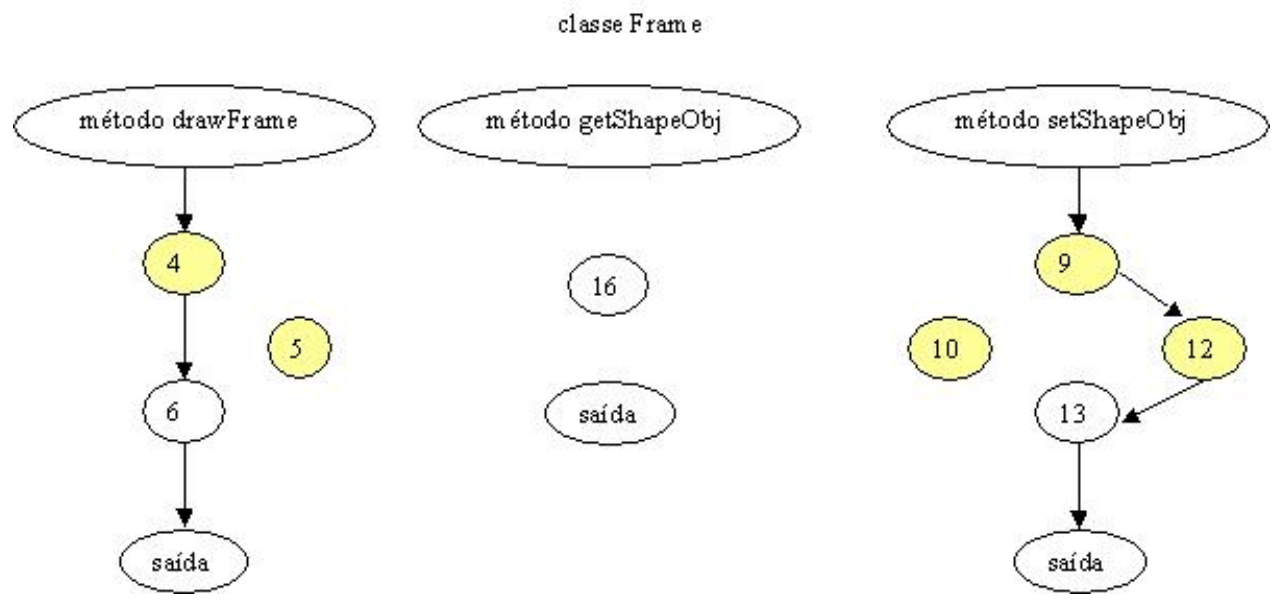

Figura 2.4: fluxo para o primeiro caso de teste
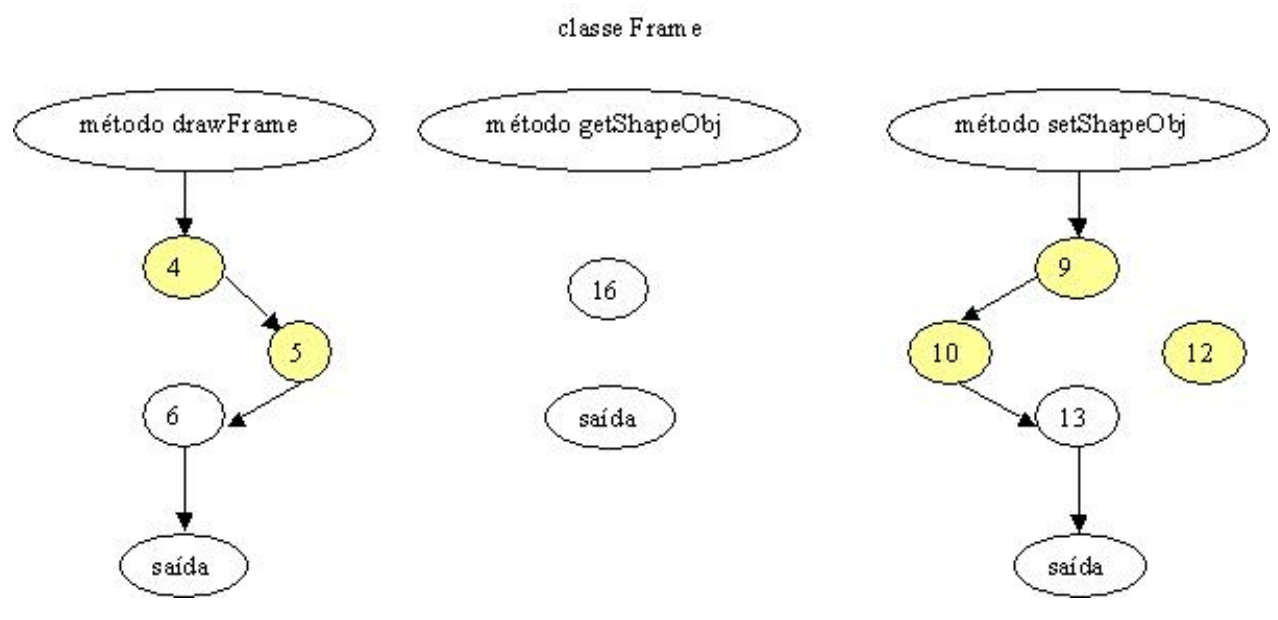

Figura 2.5: fluxo para o segundo caso de teste

os fluxos para o segundo caso de teste. As elipses mais escuras destacam as linhas que devem ser executadas segundo o critério.

Para o critério all-statements todas as linhas devem ser executadas. Podemos utilizar as mesmas entradas do exemplo anterior, porém devemos modificar nossa classe de teste para que exercite a linha 16. Isto pode ser feito acrescentando-se a linha da Figura 2.6 à classe Teste.

Percebemos que por este critério é possível perceber o erro E2 na linha 16. A Figura 2.7 ilustra 
System.out.println("Objeto construido $="+$ frameObj.getShapeObj());

Figura 2.6: linha adicionada à classe Teste

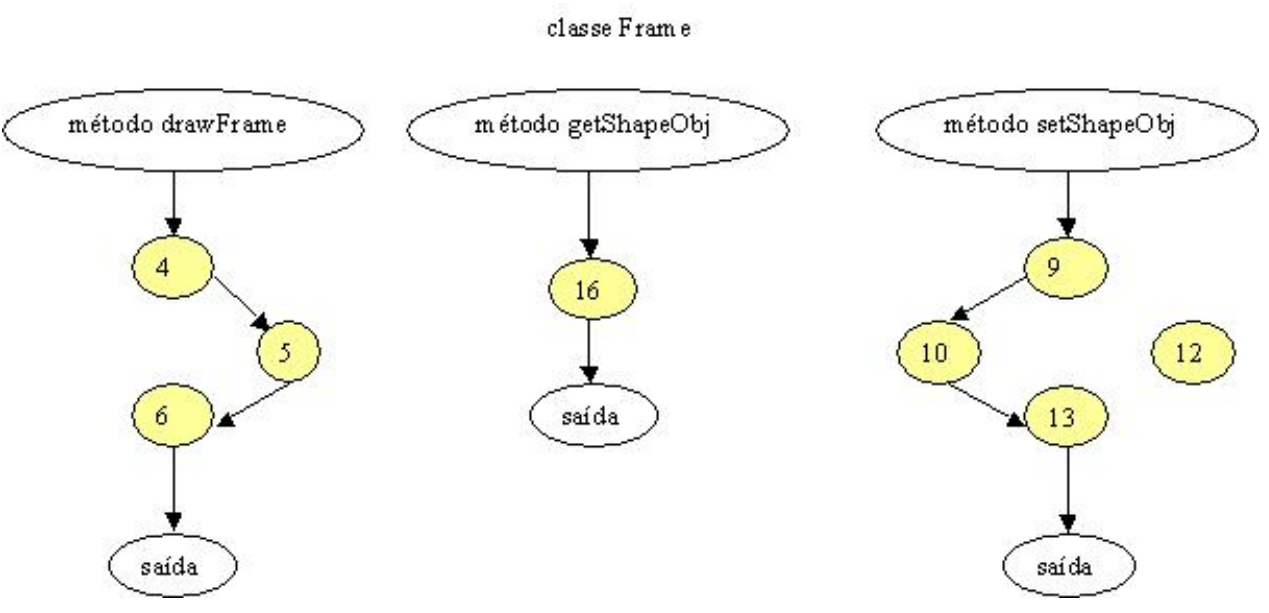

Figura 2.7: fluxo adaptando a classe de teste para o critério all-statements

o fluxo percorrido para o segundo caso de teste adaptando o código para o novo critério.

O problema na detecção do erro E2 pelo critério all-branches é compreensível, visto que ele foi projetado para testes de programas prodedurais e não orientados a objetos. Nestes programas é comum ter-se um ponto de entrada e a partir daí percorrer todo o código, enquanto em programas OO temos métodos que podem ou não ser chamados. Ou seja, mesmo sem utilizar nenhum recurso específico da orientação a objetos, a simples estrutura da classe, separada em métodos e atributos dificulta o uso dos critérios tradicionais como visto acima.

\subsubsection{Testes baseados em fluxo de dados}

Critérios baseados em fluxo de dados não têm um foco tão grande em executar linhas de código, mas sim em utilizar as variáveis (dados) de um programa [5]. Também são baseadas em caminhos de código, porém focam caminhos que percorrem as definições e os usos das variáveis.

Alguns conceitos importantes para entender estes critérios são:

- definição: por definição de uma variável entende-se uma linha de código aonde esta variável tem um valor atribuído. 


\begin{tabular}{|c|c|c|c|}
\hline variável & def & c-use & p-use \\
\hline \hline Shape.perimeter & 4 & 7,10 & \\
Square.perimeter & 4,19 & $7,10,22$ & \\
Square.x & 17 & & \\
Square.y & 18 & & \\
Circle.perimeter & 4,31 & $7,10,35$ & \\
Circle.x & 29 & & \\
Circle.y & 30 & & \\
Circle.radius & 32 & & \\
Frame.shapeObj & 47,49 & 42,43 & 41 \\
\hline
\end{tabular}

Tabela 2.2: definições e usos

- uso: por uso entende-se as linhas de código aonde a variável tem seu valor utilizado em uma computação (c-use) ou predicado (p-use) [17]. Os usos em computação incluem instruções de saída (ex: System.out.println()).

- caminho livre de definição: Um caminho livre de definição entre duas linhas de comando é um caminho entre uma definição de uma variável e um uso, sem que haja uma redefinição da variável antes do uso.

- par du: Chamamos par du uma associação entre uma linha de definição e uma linha de uso de uma variável.

A Tabela 2.2 identifica para o exemplo da Figura 2.2 todas as linhas de definição e uso para cada variável. Não são levadas em consideração variáveis locais nem parâmetros de métodos. Ou seja, consideramos apenas os atributos das classes.

Alguns atributos não são utilizados no programa, devido às simplificações que fizemos. Os atributos $x, y$ e radius seriam utilizados dentro do método draw em uma implementação completa.

A simples aplicação dos conceitos básicos definidos anteriormente já apresenta alguns complicantes quando utilizada em sistemas orientados a objetos. Se tivermos uma classe simples com atributos de tipos primitivos, conseguimos aplicar as definições sem maiores problemas, pois este caso se assemelha à estrutura procedural para a qual os critérios foram criados.

No nosso exemplo, temos alguns problemas: o atributo shapeObj da classe Frame, por exemplo, é um objeto e não uma primitiva. Desta maneira, fizemos algumas adaptações na nossa análise, 
considerando qualquer chamada de método no objeto como um uso do atributo. Uma definição mais elaborada será apresentada na Seção 2.3.3.

Além disso, fizemos algumas simplificações para levar a herança em consideração. Neste caso, foram incluídas as definições e usos do atributo perimeter nas subclasses de Shape como se fossem na própria classe.

Os critérios baseados em fluxo de dados definem quais os pares du que devem ser exercitados pelos casos de teste. Os principais critérios são [17]:

- Todas as definições (all-defs): requer que seja executado pelo menos um caminho livre de definição, entre cada definição e pelo menos um uso. Por exemplo, para o atributo Shape.perimeter podemos exercitar o par $(4,7)$.

- Todos os usos em computação (all-c-uses): requer que sejam percorridos todos os usos em computação da variável a partir de cada definição. Por exemplo, para o atributo Shape.perimeter podemos exercitar os pares $(4,7)$ e $(4,10)$.

- Todos os usos em computação e alguns em predicado (all-c-uses/some-p-uses): A idéia deste critério é complementar o anterior englobando os casos aonde uma definição não possui usos em computação (c-use). Pelo critério anterior estas definições não precisariam ser exercitadas.Por este critério, para definições sem c-use deve ser exercitado ao menos um par du com um caminho para um uso em predicado (p-use). No nosso exemplo, todas as definições têm uso computacional, então os casos de teste gerados são idênticos aos do critério anterior.

- Todos os usos em predicado (all-p-uses): requer que sejam percorridos todos os usos em predicado a partir de cada definição e todos os sucessores de cada predicado alcançado. Por exemplo, para o atributo Frame.shapeObj podemos exercitar os pares $(47,(41,42)),(47,(41,43))$, $(49,(41,42))$ e $(49,(41,43))$.

- Todos os usos em predicado e alguns em computação (all-p-uses/some-c-uses) : A idéia deste critério é complementar o anterior englobando os casos aonde uma definição não possui usos em predicado ( $p$-use). Pelo critério anterior estas definições não precisariam ser exercitadas. Por este critério, para definições sem $p$-use deve ser exercitado ao menos um par du com um caminho para um uso em computação (c-use). Por exemplo, para o atributo Shape.perimeter podemos exercitar o par $(4,7)$ 


\begin{tabular}{|l|l|}
\hline critério & pares du \\
\hline \hline all-def & $(4,7),(19,7),(31,7),(47,43),(49,43)$ \\
\hline all-c-uses & $(4,7),(4,10), \quad(4,22), \quad(4,35),(19,7)$, \\
& $(19,10),(19,22),(31,7),(31,10),(31,35)$, \\
& $(47,42),(47,43),(49,42),(49,43)$ \\
\hline all-c-uses/some-p-uses & $(4,7),(4,10),(4,22), \quad(4,35), \quad(19,7)$, \\
& $(19,10),(19,22),(31,7),(31,10),(31,35)$, \\
& $(47,42),(47,43),(49,42),(49,43)$ \\
\hline all-p-uses & $(47,(41,42)),(47,(41,43)), \quad(49,(41,42))$, \\
& $(49,(41,43))$ \\
\hline all-p-uses/some-c-uses & $(47,(41,42)),(47,(41,43)), \quad(49,(41,42))$, \\
& $(49,(41,43)),(4,7)$ \\
\hline all-uses & $(4,7),(4,10),(4,22), \quad(4,35), \quad(19,7)$, \\
& $(19,10),(19,22),(31,7),(31,10),(31,35)$, \\
& $(47,(41,42)), \quad(47,(41,43)), \quad(49,(41,42))$, \\
& $(49,(41,43))$ \\
\hline
\end{tabular}

Tabela 2.3: pares du

- Todos os usos(all-uses): requer que seja percorrido pelo menos um caminho livre de definição entre cada definição e todos os seus usos. Por exemplo, para o atributo Shape.perimeter podemos exercitar os pares $(4,7)$ e $(4,10)$.

A Tabela 2.3 identifica para o exemplo da Figura 2.2 os pares du que devem ser exercitados para cada critério.

Podemos verificar que os critérios all-def e all-p-uses têm um custo mais baixo de execução pois geram menos pares que devem ser exercitados, porém o critério all-def não garante a detecção do erro E1. Já os critérios all-c-uses, all-c-uses/some-p-uses, all-p-uses/some-c-uses e all-uses possuem um custo maior, pois geram um número maior de pares du a serem exercitados, porém conseguem detectar o erro. Neste caso específico, o critério com a melhor relação custo/benefício é o all-p-uses.

\subsection{Critérios de teste para programas orientados a objetos}

A programação orientada a objetos traz diversas características importantes como encapsulamento, herança, polimorfismo e vinculação dinâmica (dynamic binding). Estas características favorecem o reuso de software e o desenvolvimento baseado em componentes. Porém, elas trazem novos 
tipos de falhas que são difíceis de detectar com os métodos tradicionais de teste. Como conseqüência, técnicas de teste que levem estas características em consideração são importantes.

\subsubsection{Problemas no teste de sistemas orientados a objetos}

Devido a suas características distintas, os sistemas orientados a objetos são suscetíveis a tipos diferentes de bugs. Com isso, é necessário alterar os modelos de falha e estratégias de teste de maneira a detectá-los. Binder [2] apresenta um guia compreensivo de padrões de teste de sistemas orientados a objetos.

A seguir, comentamos algumas características da orientação a objetos que podem gerar estes tipos diferentes de bugs.

- Encapsulamento

Apesar de não contribuir diretamente para o surgimento de bugs, representa um obstáculo aos testes. Como no encapsulamento o acesso a alguns elementos da classe é restrito, isto pode dificultar que o sistema de teste tenha acesso ao estado do objeto.

\section{- Herança}

A herança permite que subclasses herdem estado e comportamento de suas superclasses ou ancestrais, permitindo a criação de tipos e subtipos e favorecendo o reuso de componentes.

Porém, segundo Weide [35], "Uma implementação concreta deve entender os detalhes de implementação e convenções de representação sutis de todos os seus ancestrais de maneira a implementar o componente corretamente. A não ser que seja tomado cuidado, é possível introduzir componentes que parecem trabalhar corretamente, porém, através da manipulação das representações internas de dados de seus ancestrais, violam condições sutis e implícitas que são necessárias para o correto funcionamento do ancestral."

Quando ocorre a sobrescrita de métodos, isto é, a subclasse cria um novo método com a mesma assinatura, mas que substitui um método herdado, dificilmente pode ser reaproveitado o conjunto de testes pré-existente para os mesmos métodos na superclasse [2].

- Polimorfismo e vinculação dinâmica (dynamic binding)

O polimorfismo permite o vínculo dinâmico entre classes clientes (classes que chamam métodos)

e classes servidoras (classes que têm seus métodos chamados), aumentando a reutilização e 
flexibilidade do código. Porém apresenta alguns riscos que podem gerar bugs:

- uma classe servidora pode ter sua implementação alterada, sem alterar a assinatura do método, de forma incompatível com o comportamento esperado pela classe cliente.

- a classe cliente pode ser vinculada à classe servidora errada.

- Seqüências de mensagens e bugs relativos ao estado

Algumas funcionalidades podem requerer que sejam chamados métodos em uma ordem específica, ou que certas chamadas de métodos sejam inválidas de acordo com o estado de um objeto.

- Novas associações definição-uso

Quando testamos bibliotecas orientadas a objeto existem novos tipos de associações definiçãouso que devem ser consideradas devido aos seguintes fatores [5]:

- "aliasing" de entrada em métodos públicos: Se um método recebe os parâmetros a1 e a2 de entrada, e estes parâmetros apontam para o mesmo objeto, existe um relacionamento entre os dois que não ocorre se as referências forem para objetos distintos.

- Chamada dinâmica a métodos: o relacionamento entre definição e uso depende do tipo em tempo de execução do objeto associado a referência

- Tratamento de erros: as estruturas de tratamento de erros provocam desvios no fluxo de execução de um aplicativo, fazendo por exemplo, que uma chamada a um método não retorne para a linha de código posterior a sua execução.

Alguns critérios de teste foram propostos, com o intuito de abordar alguns dos problemas descritos acima. Na seqüência vamos descrever alguns desses critérios.

\subsubsection{Critérios de fluxo de dados estendidos}

Hsia, Li e Kung [17] apresentam uma modificação dos critérios de fluxo de dados tradicionais, de forma a incluir o fato da execução não seqüencial, comum a sistemas orientados a objetos.

Nestes critérios é incluído um novo requisito denominado MIR (Method Inclusion Requirement) que estabelece que, se uma variável é utilizada em um método $\mathrm{m}$, o conjunto de testes deve incluir a execução deste método. 


\begin{tabular}{|l|l|}
\hline critério & pares du \\
\hline \hline use/method & $(4,7),(4,10),(19,7), \quad(19,10) \quad(31,7)$, \\
& $(31,10),(47,43),(49,43)$ \\
\hline all-p-uses/c-use/method & $(47,(41,42)),(47,(41,43)), \quad(49,(41,42))$, \\
& $(49,(41,43)),(4,7),(4,10)$ \\
\hline all-c-uses/p-use/method & $(4,7),(4,10),(4,22), \quad(4,35), \quad(19,7)$, \\
& $(19,10),(19,22),(31,7),(31,10),(31,35)$, \\
& $(47,42),(47,43),(49,42),(49,43)$ \\
\hline
\end{tabular}

Tabela 2.4: pares du estendidos

Com exceção do critério all-uses, nenhum dos demais critérios atende este requisito. Portanto, foram criados os seguintes critérios adicionais:

- use/method : estende o critério all-defs exigindo que pelo menos um caminho livre de definição para cada método que usa a variável seja percorrido. No nosso exemplo, para o atributo Shape.perimeter devemos exercitar o par $(4,7)$, que apresenta um uso no método getPerimeter, e o par $(4,10)$, que apresenta um uso no método triple.

- all-p-uses/c-use/method : acrescenta a all-p-uses/some-c-uses a necessidade de percorrer todos os métodos aonde ocorra um uso computacional. No nosso exemplo, para o atributo Shape.perimeter devemos exercitar o par $(4,7)$, que apresenta um uso no método getPerimeter, e o par $(4,10)$, que apresenta um uso no método triple.

- all-c-uses/p-use/method : acrescenta a all-c-uses/some-p-uses a necessidade de percorrer todos os métodos aonde ocorra um uso em predicado. Por exemplo, para o atributo Shape.perimeter podemos exercitar os pares $(4,7)$ e $(4,10)$. Neste caso, os pares exercitados são os mesmos que os utilizados para os critérios all-c-uses/some-p-uses. Isto ocorre pois o atributo possui somente c-uses.

A Tabela 2.4 apresenta os pares du necessários para atender aos novos critérios, para o código de exemplo da Figura 2.2.

Pode-se observar que todos os critérios permitem a detecção do erro E1. Uma vantagem destes critérios em relação ao critério all-uses de fluxo de dados tradicional está associado ao custo menor, em virtude da necessidade de um número menor de pares du. 


\begin{tabular}{|c|c|c|}
\hline objeto & definição & uso \\
\hline \hline shapeObj & $42,47,49$ & $41,42,43$ \\
\hline
\end{tabular}

Tabela 2.5: definições e usos do objeto do exemplo

\subsubsection{Critérios de fluxo de objetos}

Chen e Kao [6] propõem dois novos critérios baseados em fluxo de dados. Algumas definições são utilizadas para apresentação dos critérios de teste.

Um objeto é definido quando seu estado é inicializado ou alterado, ou seja, quando uma das seguintes condições ocorre:

1. O construtor do objeto é chamado;

2. O valor de um atributo de estado é definido, ou seja, é feita uma atribuição explícita a ele;

3. Uma função que altera o valor de um atributo de estado é chamada;

Um objeto é utilizado quando uma das seguintes condições ocorre:

1. Um de seus atributos de estado é utilizado em uma computação ou predicado;

2. Uma de suas funções que utilizam os atributos de estado é utilizada;

3. O objeto é passado como parâmetro para alguma função.

Uma concretização ocorre quando uma variável é associada a um objeto de uma determinada classe. No exemplo da Figura 2.2, temos concretizações nas linhas 47 e 49, quando shapeObj é associado a uma instância de Square e Circle, respectivamente.

A Tabela 2.5 apresenta as linhas aonde ocorrem as definições e usos dos objetos utilizados no código de exemplo da Figura 2.2.

Com base nestas definições mudamos o foco de fluxo de dados puro que é baseado em variáveis para um foco baseado em objetos, o qual chamamos de fluxo de objetos. Os seguintes critérios são definidos : 


\begin{tabular}{|l|c|}
\hline critério & pares du \\
\hline \hline all-bindings & $(42,41),(42,43),(47,41),(47,42),(47,43),(49,41),(49,42),(49,43)$ \\
\hline all-du-pairs & $(42,41),(42,43),(47,41),(47,42),(47,43),(49,41),(49,42),(49,43)$ \\
\hline
\end{tabular}

Tabela 2.6: critérios e pares du

System.out.println("Soma de perímetros = " + shape1.getPerimeter () + shape2.getPerimeter ();

Figura 2.8: comando utilizando dois objetos

- Todas as concretizações (all-bindings): visa cobrir as características de herança e polimorfismo dos objetos. Define que toda possível concretização de cada objeto deve ser exercitada pelo menos uma vez.

- Todos os pares du (all-du-pairs): visa cobrir o comportamento dinâmico dos objetos. Define que pelo menos um caminho de cada definição de objeto para todos os seus possíveis usos deve ser exercitado pelos casos de teste.

Para utilizarmos os testes baseados nestes critérios é necessário primeiro realizar a análise do fluxo de objetos de maneira a identificar todas as concretizações e pares du.

A Tabela 2.6 apresenta os pares du que devemos exercitar de forma a atender aos novos critérios definidos.

Neste caso, os pares du coincidiram, mas em alguns casos o critério all-bindings pode exigir mais pares. Por exemplo, se algum comando utilizar mais de um objeto, será necessário exercitar todas as possíveis combinações no critério all-bindings. Isto não é necessário com o critério all-du-pairs. Para o exemplo da Figura 2.8, será necessário testar o comando utilizando dois objetos Circle, dois objetos Square e a combinação entre um Square e um Circle.

\subsubsection{Critérios baseados em estados}

Critérios baseados em estados partem de uma representação dos estados e transições de um sistema e tentam executar a cobertura com base em critérios que exigem o teste de todos os estados (all-states) ou todas as transições entre estados (all-transition).

Hsia, Li e Kung em [16], estabelecem critérios semelhantes aos critérios tradicionais baseados em estado, nos quais não é necessário existir uma especificação formal dos estados e suas transições. O 
intuito é estabelecer critérios que possam ser utilizados para análise baseada no código.

Primeiro, estabelecemos que uma classe atende à propriedade EDM (Enumerate Data Member) quando seus atributos de estado são enumerações. Os requisitos e critérios definidos para classes com propriedade EDM podem posteriormente ser expandidos para incluir outras classes. Definimos também atribuição de objeto como o conjunto de atribuições de valores aos atributos que compõem o estado de um objeto. Os requisitos básicos são:

- Cobertura básica: o critério garante que cada conjunto de atribuições de objeto possível é coberto por pelo menos um caso de teste

- Cobertura efetiva: o critério deve garantir que cada conjunto de atribuições não é sobrescrito antes de ser utilizado. Caso este estado seja perdido, a sua cobertura em um caso de testes não traz nenhum resultado conclusivo.

- Cobertura semântica: o critério garante que ele deve testar mais do que uma seqüência (caso existam) que possam chegar a um estado do objeto.

Para estabelecer critérios que cubram os requisitos básicos são utilizadas as seguintes definições:

- Conjunto State-statement : conjunto das linhas de comando onde podem ser feitas atribuições para as variáveis de estado de um determinado objeto. Cada conjunto contém as linhas de atribuição de cada variável que resultam em um determinado estado: Ex: $\{1,3\}$ - define que nas linhas 1 e 3 são feitas atribuições que resultam em um determinado estado. Poderíamos ter $1: \mathrm{a}=10$ e $3: \mathrm{b}=0$, onde $\mathrm{a}$ e b são as variáveis de estado do objeto.

- Ordenação de state-statement: define a ordem dos elementos em um conjunto de state-statements.

- Par state def-use: um par entre um state-statement e a linha de código onde um dos elementos de estado é utilizado

Com base nestas definições estabelecemos os seguintes critérios:

- Critério 1 : para cada conjunto factível state-statement pelo menos um par state def-use deve ser coberto pelos testes. 


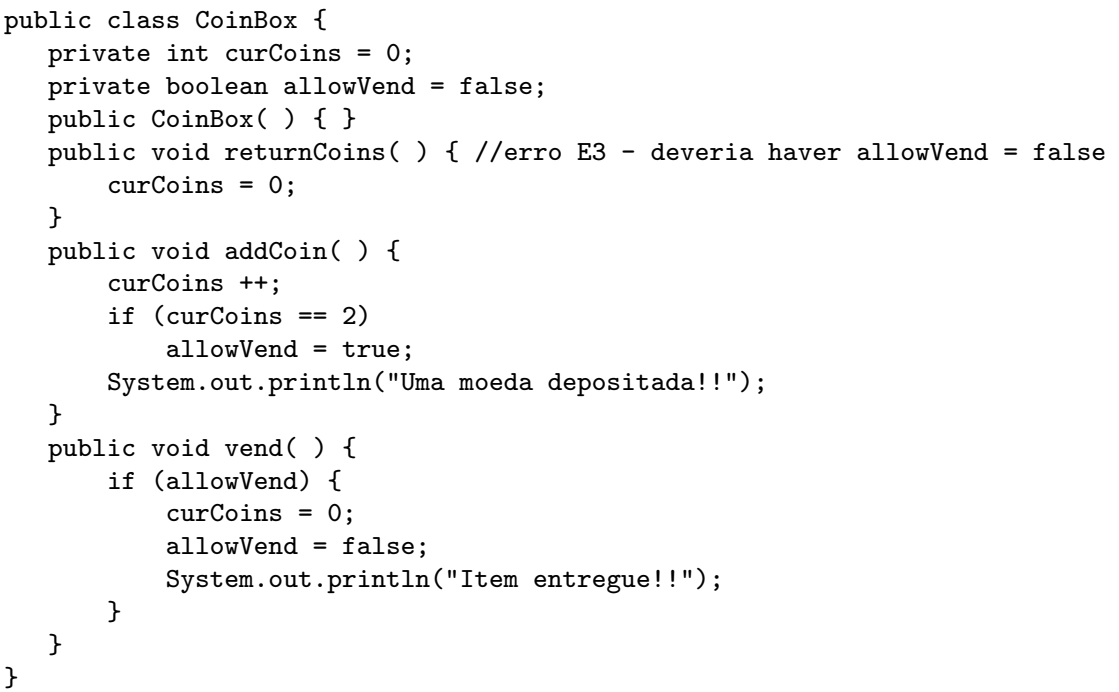

Figura 2.9: Exemplo de programa Java

\begin{tabular}{|l|l|}
\hline state-statements & $\{2,3\},\{2,11\},\{2,17\},\{3,6\},\{3,9\}$, \\
& $\{3,16\},\{6,11\},\{6,17\},\{9,11\},\{9,17\}$, \\
& $\{11,16\},\{16,17\}$ \\
\hline usos de objetos & $9,10,15$ \\
\hline
\end{tabular}

Tabela 2.7: estados e usos

- Critério 2 : para cada conjunto factível state-statement todos os pares state def-use devem ser cobertos.

- Critério 3 : para cada conjunto, todos os pares state def-use devem ser cobertos e todas as ordenações de state-statement também devem ser cobertas.

Os Critérios 1 e 2 satisfazem os requisitos de cobertura básica e efetiva. O Critério 3 também satisfaz o requisito de cobertura semântica.

No código apresentado na Figura 2.9 existe um erro que permite que seja feita uma venda gratuita. A sequência $\operatorname{CoinBox}() \rightarrow \operatorname{addCoin}() \rightarrow \operatorname{addCoin}() \rightarrow \operatorname{return} \operatorname{Coins}() \rightarrow$ vend () demonstra o erro.

A Tabela 2.7 define os conjuntos state-statements e os usos dos objetos no código apresentado na Figura 2.9. 
O exercício do par state def-use $(6,11,15)$ garante a exposição do erro. O Critério 1 não garante o exercício deste par, porém os Critérios 2 e 3 sim.

Os critérios baseados em estado podem se apresentar problemáticos, pois em alguns sistemas o número de estados pode ser muito grande [7].

\subsection{Critérios de Teste Englobando Tratamento de Exceções}

Existem diversas técnicas utilizadas para análise de programas. Para análise de programas que possuem um mecanismo para tratamento de exceções, como Java e C++ é importante que os mesmos sejam levados em consideração. As técnicas de análise e teste estrutural de programas baseadas em fluxo, levam em conta a cobertura do programa, ou seja, quanto do fluxo de controle ou dados do programa é coberto no conjunto de testes. Estudos mostram que as estruturas de tratamento de exceções são utilizadas em grande parte dos programas existentes [32]. Se elas não forem levadas em consideração, os percentuais de cobertura levantados pelas análises tradicionais estarão incorretos.

Harrold e Sinha [31] apresentam critérios de teste baseados em fluxo de dados, definindo conceitos de definição e uso para exceções. Além disso, apresentam uma técnica para análise de fluxo de exceções [30], que facilita a identificação das definições e uso para aplicação dos critérios.

A seguir vamos apresentar estes critérios de teste. Para isso, é preciso conhecer um pouco melhor a estrutura de exceções da linguagem Java, que será utilizada nos exemplos, bem como algumas técnicas de análise de fluxos de exceções.

\subsubsection{Estrutura de exceções em Java}

Em Java, quando ocorre uma condição excepcional, é criada uma instância de um objeto que representa o problema (a exceção), e o fluxo de execução do aplicativo é transferido do escopo local onde surgiu a exceção, até um ponto que pode ser definido pelo programador. Dizemos que uma exceção é lançada, no ponto onde ela ocorreu, e capturada no ponto para onde o controle foi transferido [14].

Em Java, podemos classificar as exceções em diversos tipos:

- Síncronas: ocorrem em pontos bem determinados do programa e são geradas através da avaliação de expressões, chamadas a métodos ou através de um comando throw. 
- Verificadas (checked): são verificadas pelo compilador. Isto significa que o compilador garante que para cada exceção lançada existe uma estrutura que faz a sua captura.

- Não Verificadas (unchecked): não são verificadas pelo compilador. Isto significa que estas exceções podem ser lançadas no código, sem que seja obrigatória a criação de uma estrutura para sua captura.

- Implícitas: lançadas por uma chamada a uma sub-rotina ou pelo ambiente de execução.

- Explícitas: lançadas pelo usuário através de um comando throw.

- Assíncronas: ocorrem em pontos não determinísticos do programa, geradas pela JVM ou por outras threads em processos concorrentes através de um comando stop().

Para uso nos critérios, iremos considerar apenas as exceções síncronas lançadas explicitamente.

Além disso, Java apresenta quatro elementos para tratamento de exceções que iremos considerar para modelagem do fluxo de dados (try, catch, finally e throw).

O comando try define um bloco de código sujeito a lançamento de exceções. Para cada bloco try, pode-se ter um conjunto de blocos catch, cada um associado a um tipo específico de exceção. Estes blocos representam pontos de desvio incondicional no caso da ocorrência de alguma exceção, ou seja, caso ocorra uma exceção tipo E dentro do bloco try, o fluxo de controle é desviado para o respectivo bloco catch.

Além disso, tem-se blocos finally para conjuntos de instruções que devem ser executadas incondicionalmente, ou seja, tanto na situação normal, quanto na ocorrência de exceções.

Por fim, o comando throw é utilizado para o lançamento explícito de uma exceção.

Java também define uma instrução throws que deve ser utilizada na declaração de um método quando este pode lançar exceções para o código chamador (exceções implícitas). Esta instrução não é considerada na definição dos critérios, mas será importante mais adiante quando definirmos propriedades baseadas em exceções.

\subsubsection{Exemplo}

Na Figura 2.10 encontra-se um exemplo simples com um trecho de código que será utilizado no restante da análise. O exemplo, apesar de simples, ilustra o uso de todas as instruções de tratamento de exceções em Java. 


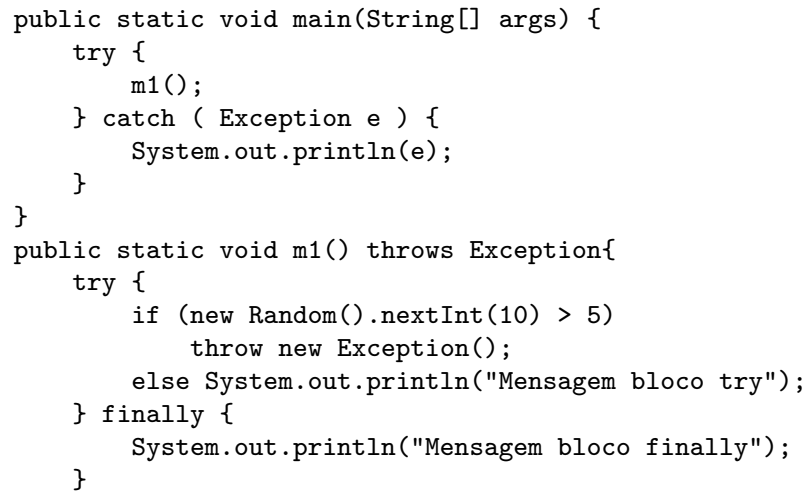

Figura 2.10: código Java com tratamento de erros

Neste exemplo temos uma chamada(linha 3) a um método denominado $m 1$ feita dentro de um bloco protegido de código (bloco delimitado por uma instrução try). Este método declara que pode lançar uma exceção (linha 8) através da instrução throws. Para captura desta exceção temos o bloco catch que vai da linha 4 à linha 6.

Dentro do método $m 1$ temos a geração de um número aleatório entre 0 e 10, que pode gerar o lançamento de uma exceção (linha 11), caso seja maior do que 5. Além disso, temos um bloco de execução incondicional delimitado pela instrução finally (linhas 13 a 15).

\subsubsection{Termos utilizados}

Apresentamos algumas definições de termos a serem utilizados no critério de teste:

- Tipo de Exceção: Classe da exceção. Por exemplo, RuntimeException, IOException, etc. No nosso exemplo Exception.

- Objeto de Exceção: Instância de uma classe de exceção. Representamos por $e o b j_{i}$, onde i representa a linha onde o objeto foi instanciado. No nosso exemplo, temos um objeto de exceção instanciado na linha 11 (eobj11).

- Variável de Exceção : variável cujo tipo é um tipo de Exceção. No nosso exemplo, temos a variável $e$. 
- Variável temporária de exceção: variável de exceção associada a alguma cláusula throw. Representamos a variável por evar ${ }_{i}$, onde i representa a linha do respectivo throw. No nosso caso temos uma variável temporária de exceção definida pelo comando throw na linha 11 (evar $\left.{ }_{11}\right)$.

- Objeto de exceção ativo: objeto de exceção lançado através de uma cláusula throw. Em qualquer instante só pode existir um único objeto de exceção ativo. Representado por evar active. Em cada instante do programa esta variável pode ter o valor null, quando não existir nenhuma exceção não tratada, ou algum objeto $e o b j_{i}$. No nosso exemplo, o objeto de exceção é inicializado na linha 11.

\subsubsection{Definição e uso de exceções}

Harrold e Sinha [31] estabeleceram os seguintes conceitos para definição e uso de exceções.

Exceções são definidas nas seguintes condições:

1. Um valor é associado a uma variável de exceção.

Ex: Exception e = new Exception();

2. Em um nó catch um valor é associado a uma variável de exceção e evar ${ }_{\text {active }}$ é associado a null. Ex: $\operatorname{catch}($ Exception e)

3. Em um nó throw que utiliza uma variável temporária de exceção evar.

Ex: throw new Exception();

4. Em um nó throw é feita uma associação a evar ${ }_{\text {active }}$.

Ex: throw new Exception();

ou throw e;

Exceções são utilizadas nas seguintes condições:

1. O valor de uma variável de exceção é acessado.

Ex: System.out.println(e);

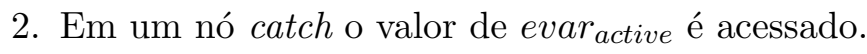

Ex: $\operatorname{catch}($ Exception e) 
3. Em um nó throw com uma variável temporária de exceção.

Ex: throw new Exception();

Um conjunto definição-uso para uma exceção (e-du) é uma tripla ( v, i, j ), onde tem-se i a linha de definição da variável v e j seu uso.

Para o exemplo da Figura 2.10 temos as seguintes triplas e-du:

- $(\mathrm{e}, 4,5)$

- $\left(\operatorname{evar}_{11}, 11,11\right)$

- $\left(\right.$ evar $\left._{\text {active }}, 11,4\right)$

- $\left(\operatorname{evar}_{11} \rightarrow \mathrm{e}, 11,5\right)$

\subsubsection{Ativação e desativação de exceções}

Além das definições e uso, exceções apresentam um outro conceito associado a ativação e desativação [31], ou seja quando um objeto de exceção é associado ou desassociado a evar ${ }_{\text {active }}$.

Uma cláusula throw ativa uma exceção e uma cláusula catch desativa uma exceção. Além disso, uma exceção pode ser desativada dentro de uma cláusula finally com o uso de return, break, continue ou outra cláusula throw.

Um conjunto ativação-desativação para uma exceção ( e-ad ) é uma tripla ( v, i, j ) onde tem-se i a linha de ativação do objeto v e j sua desativação.

Para o exemplo do item anterior temos a seguintes tripla e-ad:

- $\left(\operatorname{eobj}_{11}, 11,4\right)$

\subsubsection{Critérios de Teste}

Os critérios de teste exigem que sejam realizadas operações com dados sobre o programa de forma a exercitar os conjuntos definição-uso e ativação-desativação. Ou seja, devem ser gerados casos de teste com dados que percorram as triplas definidas anteriormente.

Dentre estes critérios podemos definir por exemplo: 
- all-throw: devemos varrer todos os nós throw.

- all-catch: devemos varrer todos os nós catch.

- all-e-defs: devemos varrer os caminhos de programa de forma a cobrir todas as definições de exceções e pelo menos um uso de cada uma. É análogo ao critério all-defs de testes baseados em fluxo de dados. No nosso exemplo, para a variável de exceção $e$ devemos varrer a tripla (e, $4,5)$.

- all-e-use: devemos varrer todas as triplas definição-uso das exceções.

- all-e-act: devemos varrer os caminhos de programa de forma a cobrir todas as ativações de exceções e pelo menos uma desativação de cada uma. É análogo ao critério all-e-defs, trocando as definições e usos por ativações e desativações.

- all-e-deact: devemos varrer todas as triplas ativação-desativação das exceções.

\subsubsection{Grafo de Fluxo de Controle}

Para identificação das triplas que devem ser varridas é interessante a criação de um gráfico de fluxo de controle. Principalmente para programas maiores, se torna muito difícil a identificação através da análise direta do código fonte. Harrold e Sinha definem uma técnia para a criação de um gráfico de fluxo de controle para exceções [30]. Para tal seguimos os seguintes passos:

1. Numeramos todas as linhas do programa

2. Cada linha do programa é representada por um nó com seu respectivo número

3. Os nós são interligados por arestas contínuas

4. Para cada ponto onde é feita uma chamada a um método dividimos o nó em um ponto de saída para o método e retorno do método. As arestas de fluxo entre métodos são representadas pontilhadas

5. Cada método tem um nó de entrada e um nó de saída.

6. Cada lançamento de exceção (throw) gera uma aresta de saída com a identificação da exceção que está sendo gerada. 


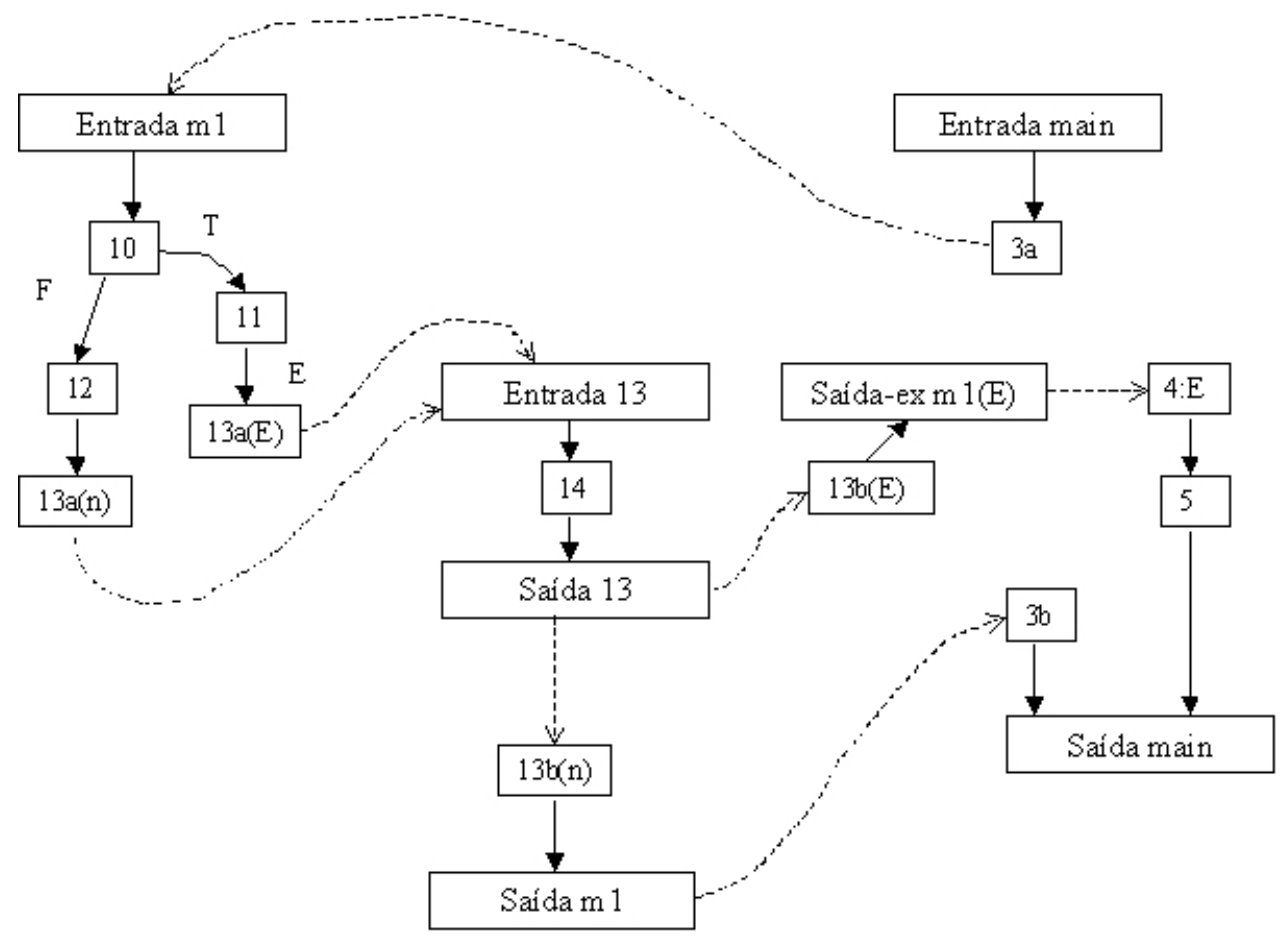

Figura 2.11: diagrama de fluxo

7. Caso a exceção seja capturada por uma cláusula catch no mesmo método, esta aresta será conectada ao nó correspondente, caso contrário será criado um nó de saída excepcional para retorno ao método chamador. Este nó de saída identifica o tipo de exceção que o gerou.

8. Cada nó de bloco catch apresenta a representação do tipo de exceção que trata além do número da linha.

9. Blocos finally são tratados como se fossem métodos, possuindo nós de entrada e saída.

Na Figura 2.11 encontra-se o diagrama de fluxo para o exemplo apresentado na Figura 2.10. Só estão representados os nós relevantes para a análise do tratamento de erros.

As Tabelas 2.8 e 2.9 definem as triplas a serem percorridas para cada um dos critérios de teste, com base no exemplo de código da Figura 2.10. 


\begin{tabular}{|l|c|}
\hline critério & tripla e-du \\
\hline \hline all-throw & $\left(\right.$ evar $\left._{11}, 11,11\right)$ \\
\hline all-catch & $(\mathrm{e}, 4,5)$ \\
\hline all-e-defs & $(\mathrm{e}, 4,5),\left(\right.$ evar $\left._{11}, 11,11\right),\left(\right.$ evar $\left._{\text {active }}, 11,4\right)$ \\
\hline all-e-use & $(\mathrm{e}, 4,5),\left(\right.$ evar $\left._{11}, 11,11\right),\left(\right.$ evar $\left._{\text {active }}, 11,4\right),\left(\right.$ evar $\left._{11} \rightarrow \mathrm{e}, 11,5\right)$ \\
\hline
\end{tabular}

Tabela 2.8: critérios baseados em definição-uso

\begin{tabular}{|l|c|}
\hline critério & tripla e-ad \\
\hline \hline all-e-act & $\left(e o b j_{11}, 11,4\right)$ \\
\hline all-e-deact & $\left(e o b j_{11}, 11,4\right)$ \\
\hline
\end{tabular}

Tabela 2.9: critérios baseados em ativação-desativação

\subsection{Conclusões Preliminares}

Neste capítulo, mostramos que os critérios de teste servem de guia para a criação dos casos de teste, bem como indicam quando podem ser encerrados os testes. Apresentamos critérios de teste para programas procedurais e orientados a objetos, bem como critérios de teste englobando tratamento de exceções. Nosso objetivo é utilizar estes critérios como base para a geração dos casos de teste.

Para os exemplos apresentados, que constituem código bem simples, foi feita a criação de casos de teste manualmente. Para sistemas reais, a criação de casos de teste pode consumir um tempo considerável, se feita manualmente. Por isso, uma estratégia para diminuir este tempo, e consequentemente o custo das atividades de teste, é interessante. Para isso, podemos tentar automatizar a geração de casos de teste ou diminuir os casos que são gerados manualmente.

No capítulo 1, citamos algumas ferramentas que auxiliam as atividades de teste. Estas ferramentas permitem a automação dos testes principalmente através da escrita de scripts ou código para exercitar o sistema sob teste, mas não fornecem recursos para redução dos casos de teste. Os dados a serem utilizados nos casos de teste devem ser gerados manualmente. Outra característica destas ferramentas é que apresentam suporte limitado ao teste do comportamento para o tratamento de exceções.

Por estes motivos, vamos utilizar ferramentas que apresentam uma abordagem diferente das apresentadas anteriormente: verificadores formais de modelos.

Na sequência, vamos apresentar algumas ferramentas de auxílio aos testes, que utilizam verificação formal de propriedades, e que podem ser utilizadas para reduzir o espaço de testes manual e verificar 
o uso de más práticas relativas ao comportamento excepcional dos programas. 


\section{Capítulo 3}

\section{Verificação de Propriedades}

Apresentamos diversos critérios de teste no capítulo anterior. Para aplicá-los em sistemas reais, que tendem a ser grandes e complexos é necessário o auxílio de ferramentas, de forma a simplificar os testes. A criação de casos de teste manualmente demanda muito tempo e está sujeita a erros humanos. Por isso, observamos algumas ferramentas que podem nos auxiliar nos procedimentos de testes.

As ferramentas analisadas se baseiam em uma técnica denominada verificação de modelos. Esta técnica consiste em verificar exaustivamente um modelo de estados finitos de um sistema em busca da violação de uma determinada propriedade especificada formalmente [7]. Esta propriedade pode ser, por exemplo, a propriedade de deadlock em sistemas concorrentes. Caso a propriedade seja violada é gerado um contra-exemplo que permite verificar quais trechos do programa foram percorridos. Nossa proposta é estender este comportamento na ferramenta, de maneira a verificar quais trechos do programa foram percorridos, mesmo quando não ocorre violação da propriedade.

Desta maneira, estas ferramentas podem ser utilizadas através da verificação de diversas propriedades até que o critério de teste selecionado para o sistema tenha sido atendido. Caso não seja possivel atender o critério de testes somente através da verificação das propriedades, os casos de teste para exercitar o código restante podem ser gerados manualmente. De qualquer forma, será necessário gerar menos casos de teste do que sem o auxílio das ferramentas.

Duas características importantes levaram ao uso deste tipo de ferramenta:

- a capacidade de executar diversos caminhos dentro do código, na busca da violação de uma propriedade. Esta é uma característica que ajuda na cobertura de código, sendo útil para os 
testes em geral.

- a possibilidade de verificar propriedades customizadas. Esta característica é a principal para este trabalho, pois permite a criação e verificação de propriedades baseadas em más práticas no tratamento de exceção. A verificação destas más práticas não é possivel com ferramentas de teste tradicionais.

Neste capítulo apresentamos as ferramentas analisadas e suas principais características, e definimos as propriedades baseadas em tratamento de exceções.

\subsection{Ferramentas para verificação}

Nenhuma das ferramentas analisadas contempla o processo de testes completamente. Ou seja, não existe ainda nenhuma ferramenta na qual se possa selecionar o critério de teste, inserir o código fonte e gerar um relatório dos resultados de forma automatizada. Em particular, as ferramentas analisadas se concentram na geração de um modelo a partir do código do programa, verificação deste modelo e retorno de contra-exemplo. O mapeamento do contra-exemplo para o critério de testes ainda é feito manualmente. Por exemplo, para um critério baseado em definição e uso, o mapeamento do contra-exemplo (linhas de código executadas) para pares du deve ser feito manualmente. Por isso, uma das atividades que foi realizada neste trabalho, foi a criação de extensões para automatizar este mapeamento.

Um dos critérios importantes para a escolha da ferramenta a ser utilizada neste trabalho foi o suporte a código Java. Por isso, concentramos nossa análise em duas ferramentas: Bandera e Java PathFinder. A seguir apresentamos uma análise mais detalhada de cada uma delas.

\subsubsection{Bandera}

A Bandera ${ }^{1}$ é uma ferramenta baseada em componentes para verificação de programas Java. Foi desenvolvida pelo grupo SAnToS (Specification, Analysys and Transformation of Software) da Universidade do Kansas. Suas principais características são [7] :

- reuso de tecnologias de verificação existentes: são gerados modelos de acordo com as linguagens utilizadas por verificadores de modelo já existentes.

\footnotetext{
${ }^{1}$ http://bandera.projects.cis.ksu.edu/
} 
- suporte a técnicas utilizadas por projetistas de modelo experientes: a ferramenta não faz simplesmente uma tradução da linguagem de programação para a linguagem do verificador. São utilizadas diversas técnicas de otimização como fatiamento, abstração de dados e restrição de componentes.

- modelos especializados para propriedades específicas: ao invés de gerar um único tipo de modelo para o teste de qualquer propriedade, são gerados modelos especializados de acordo com a propriedade a ser testada.

- projeto aberto e extensível: a arquitetura do sistema permite a adição de novas propriedades.

- sinergia para integração com outras ferramentas: é possivel utilizar a Bandera acoplada a IDEs Java como Eclipse, e outras ferramentas como Java PathFinder

Atualmente, temos duas versões da ferramenta, a 0.3 e a 1.0. Além das características gerais vistas anteriormente, temos os seguintes pontos positivos e negativos em cada uma das versões:

- Bandera 0.3

- pontos positivos

* possui interface gráfica.

* gera os contra-exemplos em Java.

* suporte a vários verificadores já embutido ( Spin, SMV, dSpin e JPF).

- pontos negativos

* projeto descontinuado.

* não suporta os elementos introduzidos com o Java 5.

* não suporta tratamento de exceção. As linhas de código presentes em blocos de tratamento de erro são ignoradas.

- Bandera 1.0

- pontos positivos

* suporta os elementos introduzidos com o Java 5.

* suporta tratamento de exceção. 
* projeto totalmente modular e customizável.

- pontos negativos

* não possui interface gráfica.

* suporte nativo ao verificador Bogor do grupo SAnTos. Para uso de outros verificadores é necessário criar ferramentas.

* gera os contra-exemplos na linguagem nativa do Bandera, denominada BIR.

* projeto atualmente em "hibernação".

\subsubsection{Java PathFinder}

A ferramenta Java PathFinder ${ }^{2}$ foi desenvolvida pelo centro de pesquisas da NASA. É um verificador de modelo que funciona como uma JVM executando um programa alvo de todas as maneiras possíveis, procurando por violações de propriedades como deadlocks ou exceções não tratadas. Caso um erro seja encontrado, todos os passos seguidos até a ocorrência do erro são exibidos.

Uma diferença no uso de verificação de modelos em comparação aos testes está na simulação do não determinismo. O JPF oferece duas características importantes que auxiliam nesta verificação:

- Backtracking: O JPF pode retornar aos passos anteriores da execução do programa, para verificar se existem estados não executados. Isto é mais eficiente do que executar novamente o programa do início.

- State Matching: O estado do sistema é armazenado como um par de uma amostra do heap e do stack da thread executando. Quando um estado já visitado é encontrado, o JPF executa o backtracking até encontrar um estado novo inexplorado.

Programas grandes podem ocasionar uma explosão de estados, que consiste na geração de um número muito grande de estados a serem verificados em busca da violação de propriedades. De forma a minimizar este problema o JPF conta com os seguintes recursos:

1. estratégias de busca configuráveis: consiste na aplicação de filtros que determinam que estados são interessantes ou não verificar.

\footnotetext{
${ }^{2}$ http://javapathfinder.sourceforge.net/
} 
2. redução do número de estados: a ferramenta utiliza alguns mecanismos, listados a seguir:

- geradores de escolha heurísticos: consiste em restringir as escolhas de valores para teste de estado. Por exemplo, para um número inteiro bastaria comparar se ele é menor, igual ou maior do que um determinado valor, ao invés de testar todos os valores possiveis de inteiro.

- redução de ordem parcial: é o mecanismo mais importante em programas concorrentes. Consiste em levar em consideração apenas operações que podem ter efeitos em outras threads, como instruções que alteram objetos acessíveis externamente. Desta maneira, operações puramente locais são desconsideradas.

- execução de VM aninhada: O JPF executa sobre a JVM nativa. Isto permite que determinadas operações sejam delegadas para a JVM nativa ao invés de executadas pelo JPF. Desta forma, estas execuções não têm seu estado rastreado.

O JPF oferece alguns mecanismos que permitem sua extensão:

- Search/VMListeners: é permitida a criação de classes Java que utilizam o padrão de projeto Observer para serem notificados quando ocorrem eventos como execução de determinadas instruções de bytecode ou avanço/retrocesso nos passos de execução. Podemos utilizar estes elementos para verificação de propriedades complexas, executar buscas, estender o modelo de estado interno do JPF ou colher estatísticas de execução do programa, como por exemplo, a sequência de instruções executada.

- Model Java Interface(MJI): permite a separação da execução com rastreamento de estado do JPF e a execução nativa da JVM. Pode ser utilizada para construção de abstrações de APIs que reduzem a geração de estados necessária.

Alguns pontos positivos e negativos da ferramenta são:

- pontos positivos

- suporta os elementos introduzidos com o Java 5.

- suporta tratamento de exceções.

- gera os contra-exemplos na linguagem Java. 
- extensibilidade nas propriedades testadas: suporta originalmente testes nas propriedades de deadlock, asserções e exceções não tratadas, mas permite a criação de novas propriedades.

- integração com ferramentas existentes: permite a utilização de ferramentas gráficas como front-end, como por exemplo, Sun NetBeans, Eclipse e a própria interface gráfica da ferramenta Bandera.

- pontos negativos

- não possui interface gráfica.

- não permite o uso de outros verificadores de modelo.

\subsection{Propriedades Relativas a Tratamento de Exceções}

Das ferramentas analisadas, foi selecionada a Java PathFinder para uso neste trabalho. Os principais fatores que levaram a esta escolha foram a facilidade de criação de novas propriedades e de extensão de funcionalidades, suporte a tratamento de exceções e à última versão do Java e a facilidade de integração com outros aplicativos.

Para continuar nosso estudo devemos criar algumas propriedades a serem verificadas com a ferramenta Java PathFinder. Nossa abordagem foi selecionar algumas práticas utilizadas comumente no tratamento de exceções em Java e transformá-las em propriedades da ferramenta. É importante ressaltar que mesmo que não se deseje utilizar a ferramenta para diminuir o espaço de testes ou geração de casos de uso manuais, podemos utilizá-la para melhorar a qualidade do código, garantindo que certas práticas não ocorrem.

\subsubsection{Propriedades no Java PathFinder}

Um dos motivos da escolha da ferramenta JPF para utilização neste trabalho, foi a facilidade na sua customização e criação de propriedades. Todas as propriedades no JPF sao classes Java que implementam uma interface comum: gov.nasa.jpf.Property.

Outra característica importante utilizada foi a capacidade de criar classes (listeners) que são notificadas pela ferramenta na ocorrência de eventos relativos a execução do código, como execução de instruções e lançamento de exceções. Para isso existem algumas interfaces que devem ser implemen- 
tadas pelas classes interessadas na notificação de eventos. A criação destas classes segue o padrão de projeto Observer [13].

Assim, para criação de propriedades customizadas basta criar uma implementação de Property e registrá-la para verificação com a ferramenta. Este registro poder ser feito via customização do arquivo de inicialização padrão da ferramenta (jpf.properties) ou em tempo de execução via código. Normalmente, dependendo apenas da propriedade, devem também ser criadas classes listener para monitorar a execução da ferramenta.

No nosso caso, como foi necessário criar um listener para cada propriedade, optou-se por utilizar uma superclasse disponível na ferramenta especificamente para estes casos denominada PropertyListenerAdapter. Todas as propriedades criadas são subclasses de gov.nasa.jpf.PropertyListenerAdapter.

\subsubsection{Tratamento de Exceções}

As atividades de teste têm o objetivo de detectar os bugs no código, mas estes não são os únicos tipos de erros que podem acontecer. Durante a execução do código, podemos nos deparar com problemas que impedem sua continuação. Chamamos estes problemas de condições excepcionais [12]. Exemplos de condições excepcionais envolvem a perda de uma conexão de rede, a queda de um servidor de bancos de dados, a leitura de um arquivo de entrada mal-formatado, etc.

Denominamos "Tratamento de Exceções" o código criado para o tratamento das condições excepcionais.

$\mathrm{C}$ e outras linguagens mais antigas estabeleciam uma metodologia para o tratamento de exceções por convenção e não embutidas na própria linguagem. Era comum que o código que percebesse uma condição excepcional sinalizasse este fato através de um valor retornado por um método ou configurando algum "flag". O código "cliente" era responsável por verificar se ocorreu ou não uma exceção e consequentemente tomar as medidas julgadas necessárias.

Essa abordagem acaba se transformando em uma limitação para a criação de sistemas grandes, robustos e de boa manutenibilidade devido a fatores como [12]:

- a leitura e verificação de flags de erro acabam tornando o código muito burocrático, prejudicando a clareza e legibilidade.

- código dependente da disciplina do desenvolvedor em escrever as verificações necessárias. Mui- 
tos desenvolvedores subestimavam a probabilidade dos erros ocorrerem e não faziam a leitura dos flags e valores de retorno das sub-rotinas

Linguagens mais modernas como o Java e o C\# incluem estruturas para tratamento de exceções na própria sintaxe. Quando bem utilizadas, estas estruturas podem melhorar a legibilidade, confiabilidade e manutenibilidade de um programa [3].

Neste trabalho, nos preocupamos não somente com a localização de bugs, mas também com a identificação da presença de más práticas relativas ao tratamento de condições excepcionais.

\subsubsection{Apresentação de Práticas Relativas ao Tratamento de Exceções}

Existem algumas práticas no tratamento de exceções que podem dificultar a tarefa de manutenção do sistema $[21,29]$. As seguintes práticas foram analisadas neste trabalho e algumas delas foram transformadas em propriedades para o Java PathFinder:

1. lançar java.lang.Exception na assinatura do método

2. lançar um grande número de exceções na assinatura do método

3. declarar uma exceção na assinatura do método que nunca é lançada

4. ignorar a exceção

5. capturar e ignorar a exceção

6. capturar e ignorar InterruptedException

7. logar e relançar a exceção

8. logar e retornar null

9. múltiplas mensagens de log para a mesma exceção

10. encapsulamento destrutivo

11. utilizar o método getCause sem recuperar a exceção original

12. capturar java.lang.Exception 
13. lançar exceções dentro do bloco finally

A seguir analisamos cada uma delas e apresentamos o resultado da tentativa de transformá-las em propriedades para o JPF. A estrutura utilizada para apresentação das propriedades utiliza os seguintes tópicos:

- problema: Descrição do problema ou problemas decorrentes da má prática descrita.

- propriedade: Descrição da prática como uma propriedade a ser implementada no JPF. Grande parte das propriedades descritas podem ser verificadas estaticamente através da análise do código fonte ou dinamicamente durante a execução do código. Nosso foco está na análise dinâmica via JPF, por isto, a descrição da propriedade leva este aspecto em consideração.

- exemplo: Exemplo de código Java aonde a prática está presente

- análise: Explicação do exemplo e análise do que é necessário para a implementação de uma classe no JPF que represente a propriedade. Inclui a discussão da possibilidade e/ou viabilidade da implementação desejada e suas possíveis limitações.

- classe: Inclui o nome da classe criada para representar a propriedade, quando esta for possivel e viável. Não foram escritas classes para todas as propriedades, apenas o suficiente para permitir os testes propostos por este trabalho. O código fonte das classes criadas encontra-se no apêndice B.

\subsubsection{Práticas relativas ao uso da instrução throws}

\section{Lançar java.lang.Exception na assinatura do método}

Problema: java.lang.Exception é muito genérica, não fornecendo informações úteis sobre os erros que podem ocorrer no processamento do método.

Propriedade: É executada uma instrução correspondente à chamada de um método e java.lang.Exception pertence ao conjunto de exceções lançadas na assinatura do método.

\section{Exemplo:}

1: public class ThrowExceptionExample \{ 


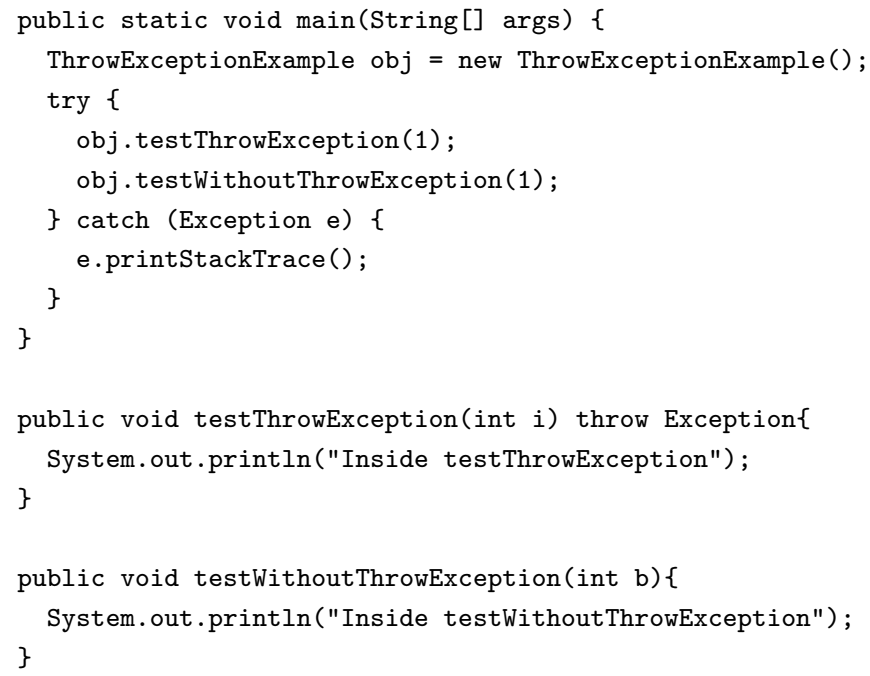

Análise: A informação das exceções lançadas pelos métodos da classe faz parte do bytecode gerado. Desta forma, é possivel identificar a cada instrução de invocação de método se java.lang.Exception faz parte das exceções que podem ser lançadas.

Na execução da instrução obj.testThrowException(1) na linha 6 do código de teste é gerada uma violação de propriedade pois o método declara java.lang.Exception na sua lista de exceções lançadas.

Classe: br.usp.jpf.property.ThrowsExceptionProperty

Para configurar esta propriedade para verificação pela ferramenta Java PathFinder, devemos acrescentar o nome da classe no arquivo de configuração jpf.properties, conforme ilustrado a seguir. Neste exemplo apresentamos também a configuração das demais propriedades, porém as mesmas estão comentadas.

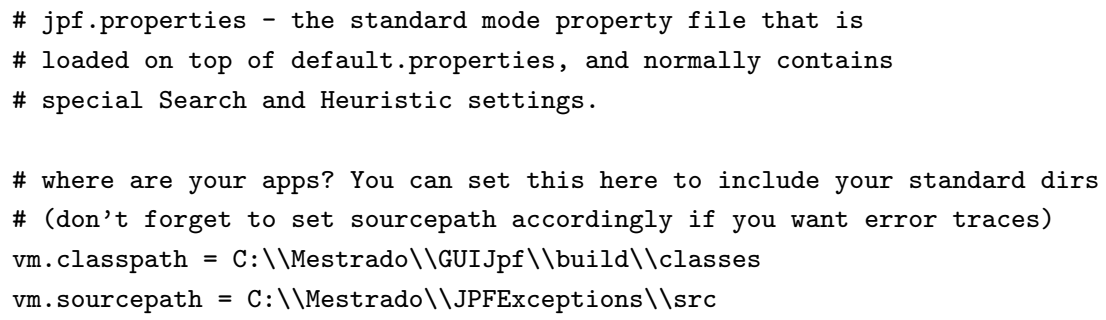




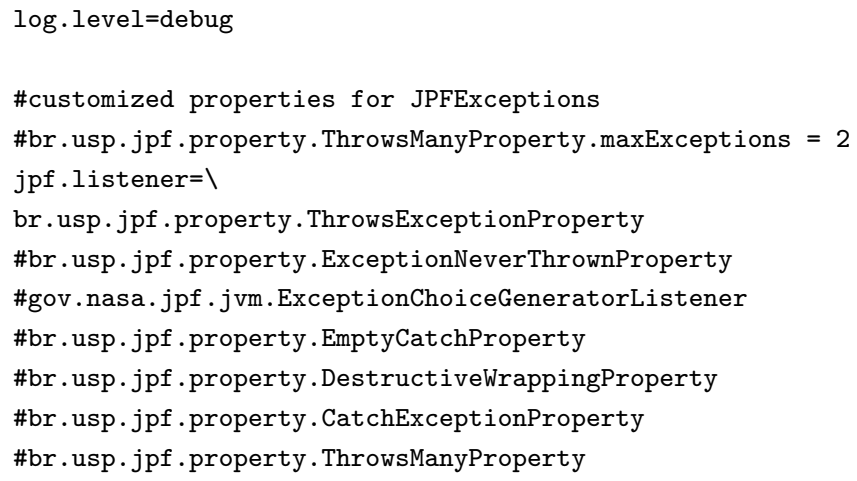

O resultado da verificação é apresentado a seguir. No capítulo 4 apresentamos um aplicativo que facilita a configuração das propriedades e exibição do resultado da verificação.

JavaPathfinder v4.1 - (C) 1999-2007 RIACS/NASA Ames Research Center

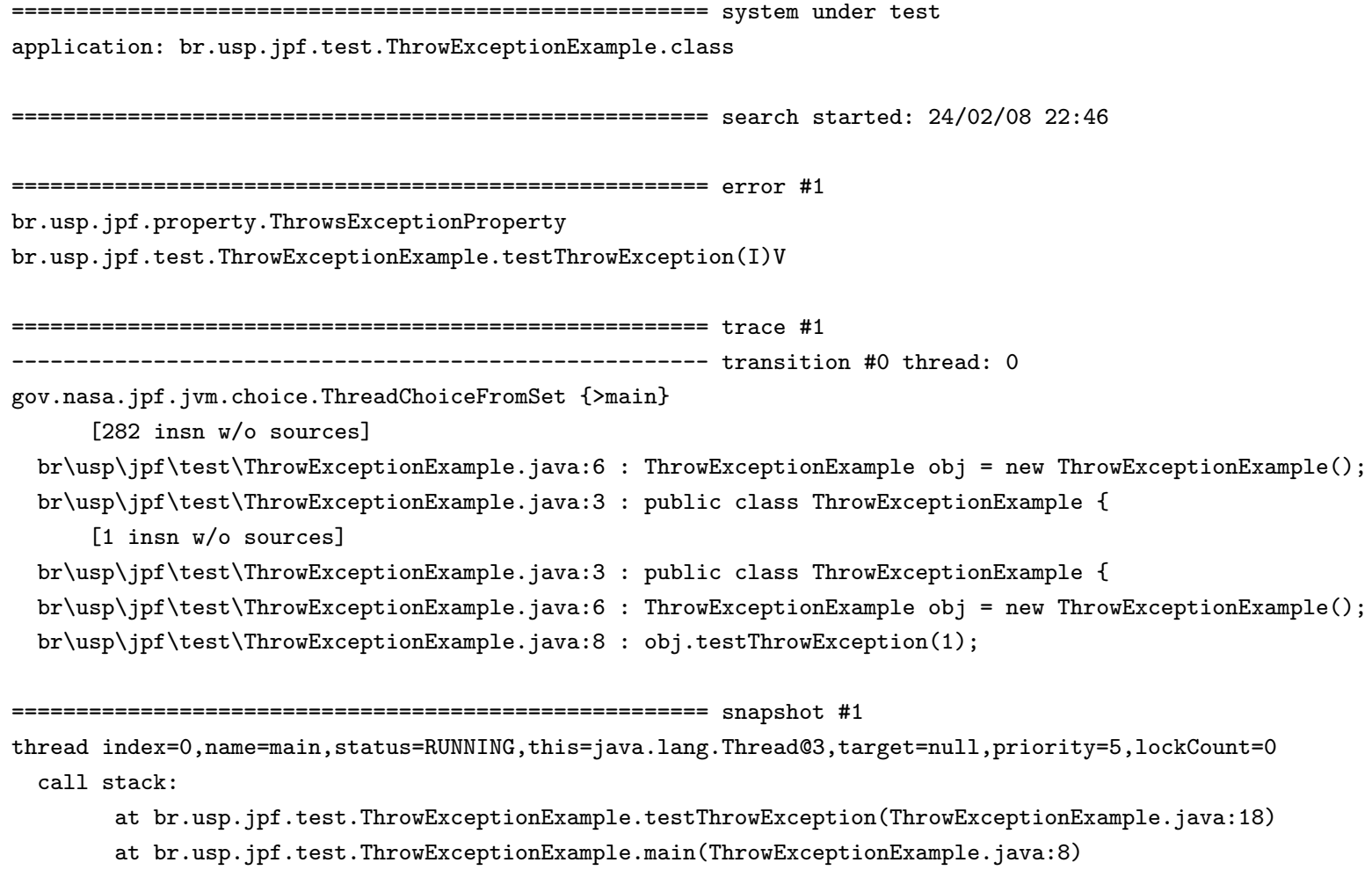




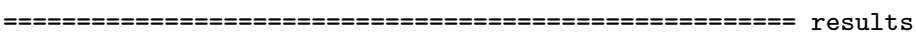

error \#1: br.usp.jpf.property.ThrowsExceptionProperty "br.usp.jpf.test.ThrowExceptionExample.testThrowExcept..."

search finished: 24/02/08 22:46

\section{Lançar um grande número de exceções na assinatura do método}

Problema: Só é válido se cada exceção necessitar de um tratamento diferenciado. Em caso contrário apenas polui o código.

Propriedade: É executada uma instrução correspondente à chamada de um método e o número de elementos no conjunto de exceções lançadas pelo método é maior do que n e este conjunto não está contido no conjunto de tratadores de exceção presentes no código chamador.

\section{Exemplo:}

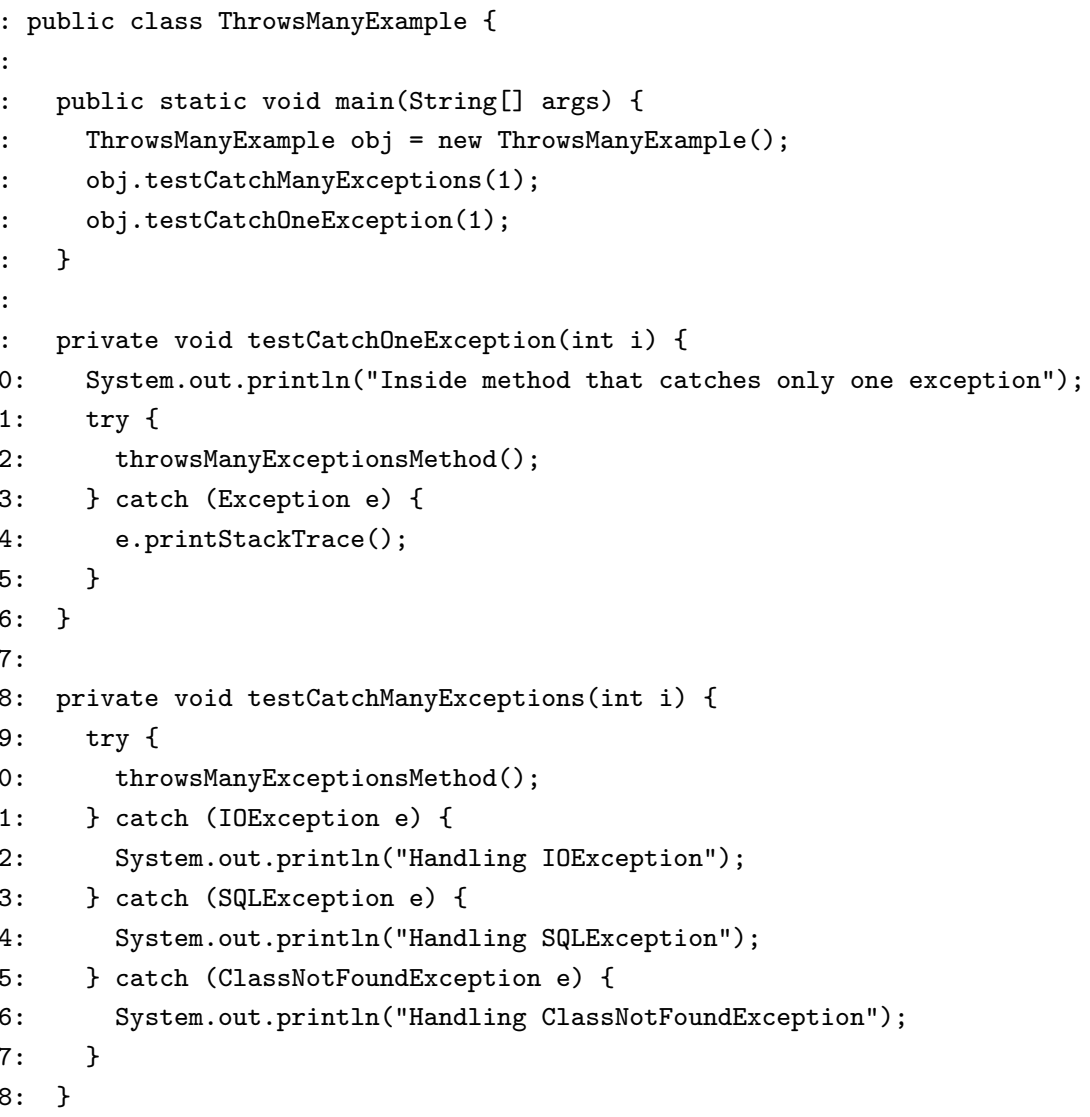


29:

30:

31:

32:

33: $\}$

$34:\}$

Análise: A informação das exceções lançadas pelos métodos da classe faz parte do bytecode gerado. Desta forma é possivel identificar a cada instrução de invocação de método quantas exceções estão declaradas na sua assinatura.

Além disso, os tratadores de evento (blocos catch) são alocados em uma área especial no bytecode da classe gerada. É possivel identificar dinamicamente dentro de cada método quais são os tratadores declarados e compará-los com as exceções lançadas nas chamadas locais de métodos.

No código de exemplo, para um número máximo de exceções configurado para 2, ocorre uma violação da propriedade na linha 12. O método testCatchOneException chama o método throwsManyExceptionsMethod, que lança 3 exceções, violando o número máximo. Além disso, o método chamador utiliza apenas um tratador para java.lang.Exception e não um para cada exceção lançada, violando a segunda condição da propriedade que determina que o conjunto de tratadores de exceção deve conter o conjunto de exceções lançadas.

Se comentarmos a chamada ao método testCatchOneException, na linha 6 não ocorre violação da propriedade, visto que o método testCatchManyExceptions, apesar de chamar um método que lança mais exceções do que o número máximo permitido, possui um conjunto de tratadores de exceção que contém o conjunto de exceções lançadas.

Classe: br.usp.jpf.property.ThrowsManyProperty

\section{Declarar uma exceção na assinatura do método que nunca é lançada}

Problema: Só é válido na definição de métodos abstratos. Obriga o desenvolvedor a capturar exceções que nunca serão lançadas.

Propriedade: É executada uma instrução correspondente à chamada de um método e existem exceções pertencentes ao conjunto de exceções lançadas pelo método, que não possuem um correspondente comando throw contido no corpo do método, direta ou indiretamente. Não é necessário verificar se o método é abstrato, pois é necessária uma implementação concreta para ser executada. 


\section{Exemplo:}

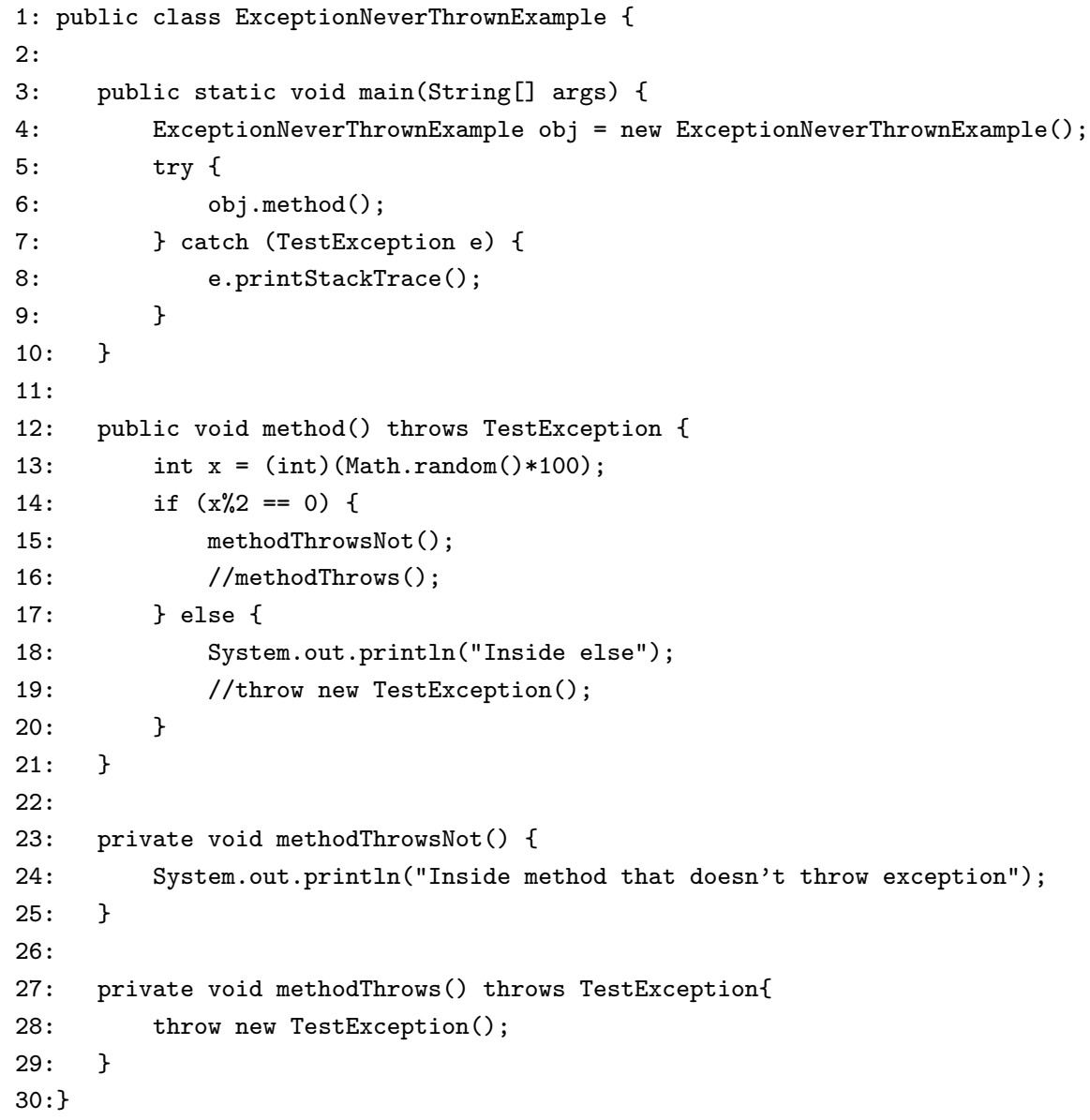

Análise: No exemplo de código, mantendo as linhas comentadas ocorre uma violação da propriedade, pois TestException nunca é lançada, mas somos obrigados a criar um código de tratamento de erro, por exigência do compilador Java.

Se removermos o comentário da linha 19, pode ocorrer um lançamento direto da exceção e a propriedade não é violada. Se removermos o comentário da linha 16, pode ocorrer um lançamento indireto da exceção e a propriedade também não é violada.

Para um determinado método, o bytecode tem todas as informações de instruções que podem ser executadas no método. Podemos tentar então localizar se existe uma instrução ATHROW 
(lançamento direto) ou instrução de chamada de método. Caso exista uma instrução de chamada de método podemos verificar se a exceção lançada pelo método principal está sendo declarada no método chamado (lançamento indireto). Porém esta abordagem é uma análise estática baseada em bytecode ao invés de código fonte Java e possui uma limitaçao. A instrução ATHROW no bytecode nao possui informação do tipo específico de exceção que está sendo lançada. Ela simplesmente recupera a referência a um objeto da pilha de execução e faz o lançamento. Por isso a simples verificação de sua existência não é suficiente.

No exemplo modificado a seguir alteramos a linha 19 do exemplo original para um caso no qual a propriedade seria violada e não seria percebido. Neste caso é lançada uma exceção diferente (IllegalArgumentException).

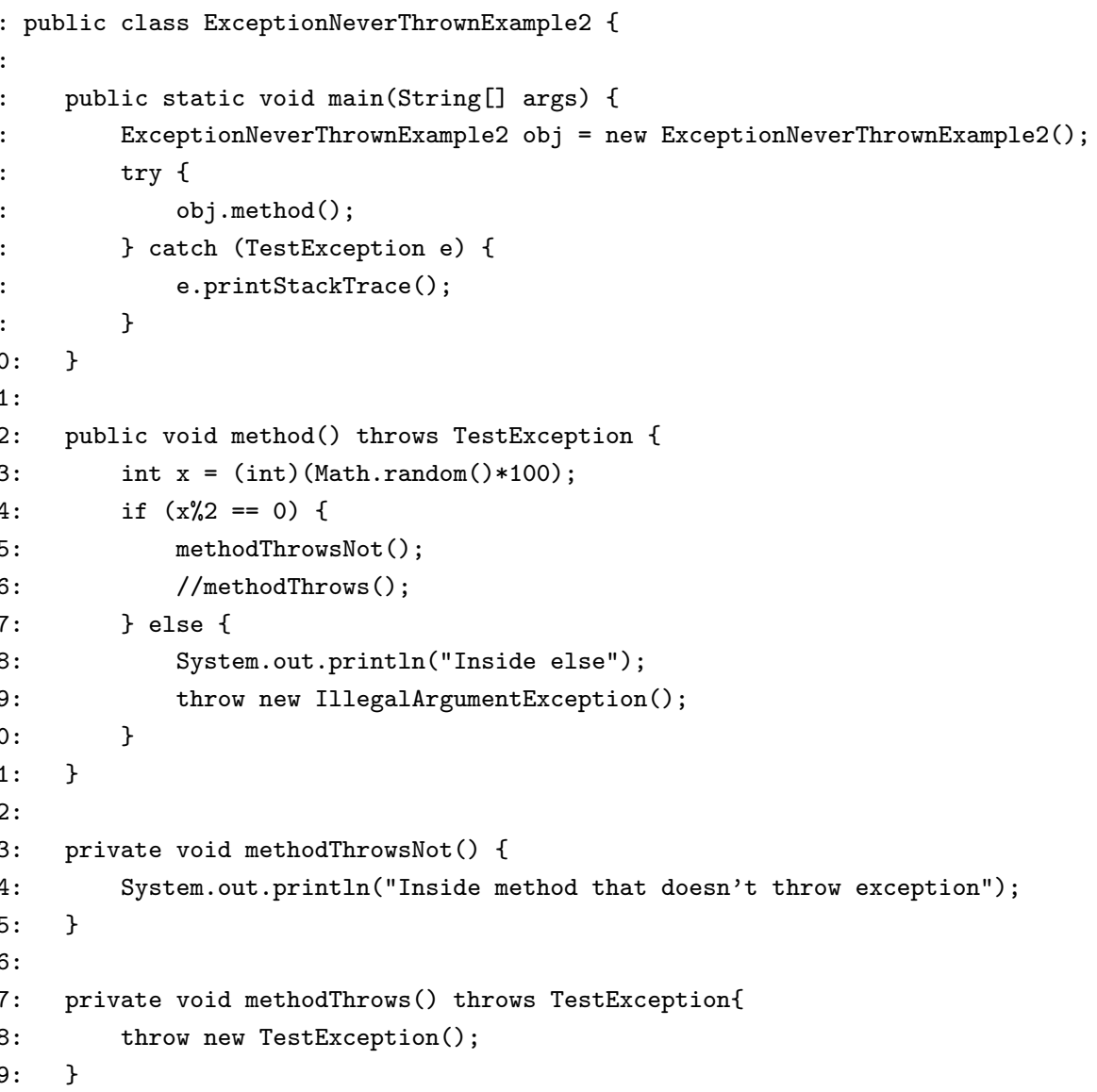


Esta é uma propriedade mais complexa de ser analisada dinamicamente do que as anteriores, pois depende de um comportamento futuro do código(linhas que ainda vão ser executadas) ao invés do comportamento presente ou passado(código que já foi ou está sendo executado). Nos exemplos anteriores, no instante da chamada ao método temos toda a informação necessária para a verificação das propriedades. Neste caso, não sabemos ainda qual código vai ser executado.

Classe: br.usp.jpf.property.ExceptionNeverThrownProperty. Esta classe não garante que a propriedade é percebida em todas as situações, conforme descrito no item anterior, porém ela não gera falsas violações.

\subsubsection{Práticas relativas à falta de tratamento de exceção}

\section{Ignorar a exceção}

Problema: Torna o código menos robusto pois exceções não tratadas podem provocar o término anormal da execução sem a possibilidade de recuperação oferecida pelo tratamento de erros.

Propriedade: Uma exceção é lançada através de um comando throw para a qual não existe um bloco correspondente de tratamento.

\section{Exemplo de classe que viola a propriedade:}

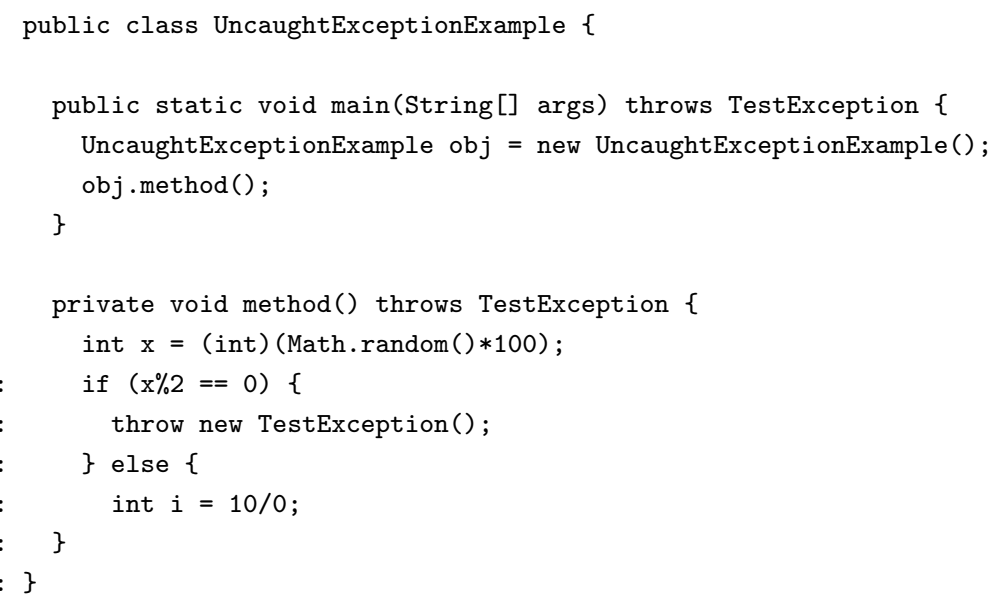

Análise: Para verificar esta propriedade devemos confirmar a existência de um bloco de tratamento correspondente que capture cada exceção lançada no código. O bytecode permite identificar uma instrução de lançamento de exceção e quais blocos de tratamento (exception handlers) existem 
em cada método. Portanto é possivel verificar esta propriedade dinamicamente.

O compilador Java obriga checked exceptions a serem tratadas ou relançadas. Isto não garante o tratamento da exceção pois o desenvolvedor pode relançá-las indefinidamente até atingir a classe principal que executou o aplicativo. O código de exemplo mostra este caso para TestException através das linhas 8 e 3 .

Existem duas possibilidades de lançamento de exceções que violam a propriedade no código de exemplo:

- TestException: lançada explicitamente na linha 11 através de um comando throw. Esta exceção não é capturada sendo relançada até o código chamador original.

- ArithmeticException: lançada implicitamente através da divisão por zero que ocorre na linha 13. Como a exceção é do tipo RuntimeException, não existe nenhuma verificação por parte do compilador, permitindo que ela seja completamente ignorada no código (não possui tratamento nem relançamento).

Classe: A ferramenta Java PathFinder já possui uma classe para representar a propriedade gov.nasa.jpf.jvm.NoUncaughtExceptionsProperty

\subsubsection{Práticas relativas ao código de tratamento da exceção}

\section{Capturar e ignorar a exceção}

Problema: Esconde que ocorreram erros na execução.

Propriedade: Uma exceção é lançada e seu tratamento consiste em um bloco de código vazio.

\section{Exemplo:}

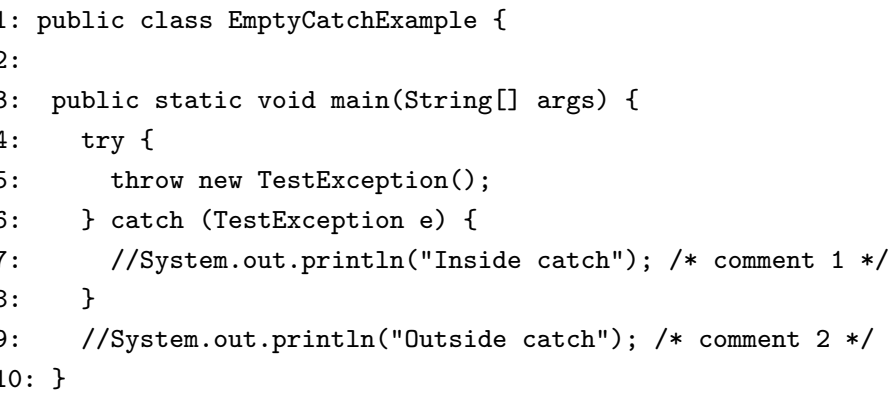


$11:\}$

Análise: Em tempo de execução, não é possivel distinguir se uma instrução ocorre dentro de um bloco catch ou após o bloco catch. Isto ocorre porque não existe nenhuma instrução especial para saída do bloco catch no conjunto de instruções definidos pelo bytecode Java. No arquivo .class existe uma tabela com a indicação de onde se inicia um bloco de tratamento de exceção, mas não temos como definir onde este bloco termina.

A seguir mostramos o bytecode gerado para duas execuções do código.

1. catch com instrução: removendo o comentário 1 e mantendo o comentário 2.

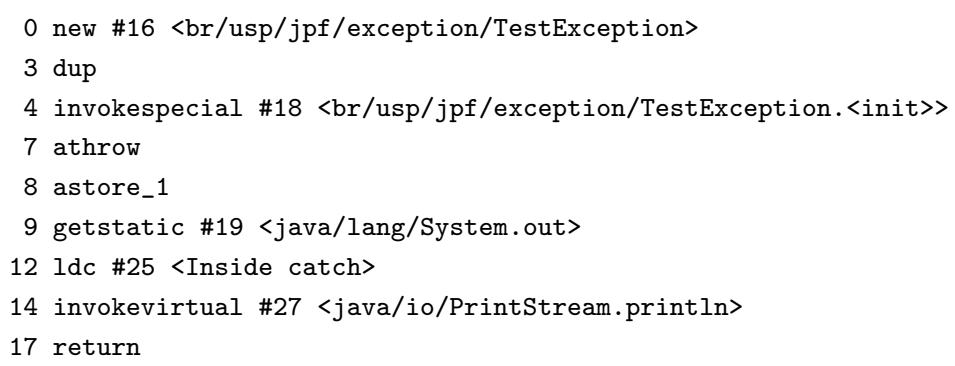

2. catch sem instrução: removendo o comentário 2 e mantendo o comentário 1 .

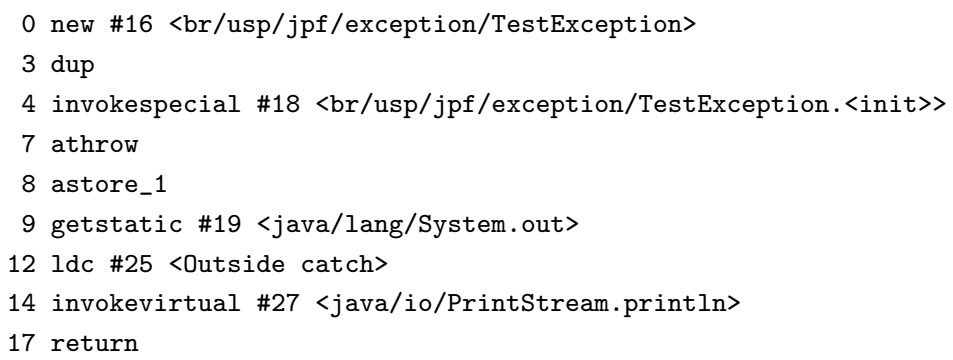

Percebe-se que não há nenhuma diferença entre o bytecode gerado para as duas classes. Só podemos diferenciá-los pelas mensagens "Inside Catch"e "Outside Catch" que foram colocadas especificamente com este propósito.

Para os dois casos, a tabela de exceções do método main é apresentada na Tabela 3.1. Ela estabelece que existe um código de tratamento de exceção que se inicia na linha de bytecode 8 , referente ao lançamento da exceção br.usp.jpf.exception.TestException entre as linhas 0 e 8. Mas somente esta informação não é suficiente para a verificação da propriedade. 


\begin{tabular}{|c|c|c|c|}
\hline linha inicio & linha fim & linha tratador & tipo de exceção \\
\hline \hline 0 & 8 & 8 & $\mathrm{br} /$ usp/jpf/exception/TestException \\
\hline
\end{tabular}

Tabela 3.1: Tabela de exceções para os exemplos

\begin{tabular}{|c|c|c|c|c|}
\hline linha inicio & comprimento & índice & nome & tipo \\
\hline \hline 9 & 8 & 1 & e & br.usp.jpf.exception.TestException \\
\hline 0 & 18 & 0 & args & java.lang.String[] \\
\hline
\end{tabular}

Tabela 3.2: Tabela de variáveis locais para o exemplo sem catch vazio

Porém, existe uma abordagem alternativa que permite a identificação da propriedade em alguns casos. Quando o código é compilado com informações extras de debug, é gerada uma tabela adicional no arquivo .class, que contém dados sobre a declaração e escopo de variáveis locais do método. Dentre estes dados estão a linha onde é inicializada a variável e durante quantas linhas de código ela está dentro de um escopo válido. Uma destas variáveis é aquela que é utilizada dentro de um bloco catch para a captura da exceção.

Assim, podemos comparar a informação de onde se inicia um bloco de tratamento de exceção com a definição e escopo da variável de captura para verificar a propriedade. Se existir uma variável com escopo diferente de zero o bloco de tratamento de exceções não é vazio. Caso a variável não exista ou possua um escopo igual a zero (depende do compilador utilizado), a propriedade é violada.

Compilando o código de exemplo utilizando a opção de gerar informações extras de debug obtivemos as tabelas de variáveis locais apresentadas na Tabela 3.2 e na Tabela 3.3

Com estas informações podemos perceber que na Tabela 3.3 a variável "e" que captura a exceção tem escopo de comprimento zero, o que significa que o bloco catch é vazio. As colunas das tabelas são auto-explicativas, com exceção da coluna índice que representa a posição aonde a variável local se encontra na pilha de execução (stack). Esta informação é necessária no código de implementação da propriedade para correta localização da variável.

\begin{tabular}{|c|c|c|c|c|}
\hline linha inicio & comprimento & índice & nome & tipo \\
\hline \hline 9 & 0 & 1 & $\mathrm{e}$ & br.usp.jpf.exception.TestException \\
\hline 0 & 18 & 0 & args & java.lang.String[] \\
\hline
\end{tabular}

Tabela 3.3: Tabela de variáveis locais para o exemplo com catch vazio 
Classe: br.usp.jpf.property.EmptyCatchProperty. Para sua utilização é necessário que o código seja compilado gerando a tabela de variáveis locais para os métodos. Esta tabela é um item opcional do arquivo .class gerado quando solicitamos compilação para debug (diretiva -g no compilador javac da Sun).

\section{Capturar e Ignorar InterruptedException}

Problema: Em código concorrente muitas vezes InterruptedException é utilizada para notificar a thread de que ela deve cessar o seu processamento atual. Ignorar a exceção pode fazer com que a thread fique em execução quando deveria parar. É um caso particular do item anterior sobre capturar e ignorar a exceção.

Propriedade: Uma exceção do tipo java.lang.InterruptedException é lançada e seu tratamento consiste em um bloco de código vazio.

\section{Exemplo:}

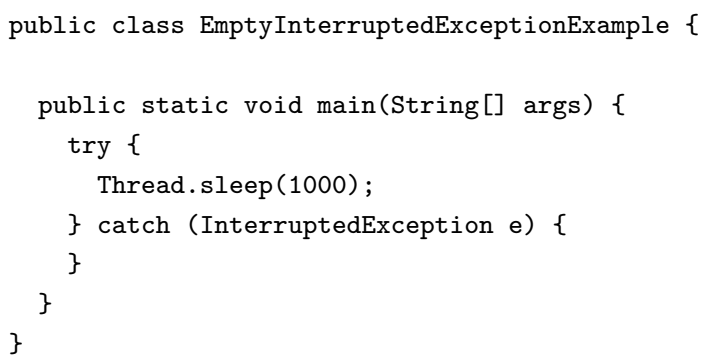

Análise: No exemplo, é feita uma chamada ao método sleep() da classe Thread, que pode lançar uma java.lang.InterruptedException. Sua captura é realizada na linha 6, mas o bloco de tratamento é vazio.

Valem as mesmas observações feitas no item 3.2.6.

Classe: Não foi criada uma classe para representar a propriedade.

\section{Logar e relançar a exceção}

Problema: Pode gerar múltiplas mensagens de erro para a mesma exceção, dificultando o trabalho de manutenção.

Propriedade: Uma exceção é lançada e dentro de seu bloco de tratamento (bloco catch) existe 
uma chamada a um método de log e um comando de lançamento de exceção (comando throw).

\section{Exemplo:}

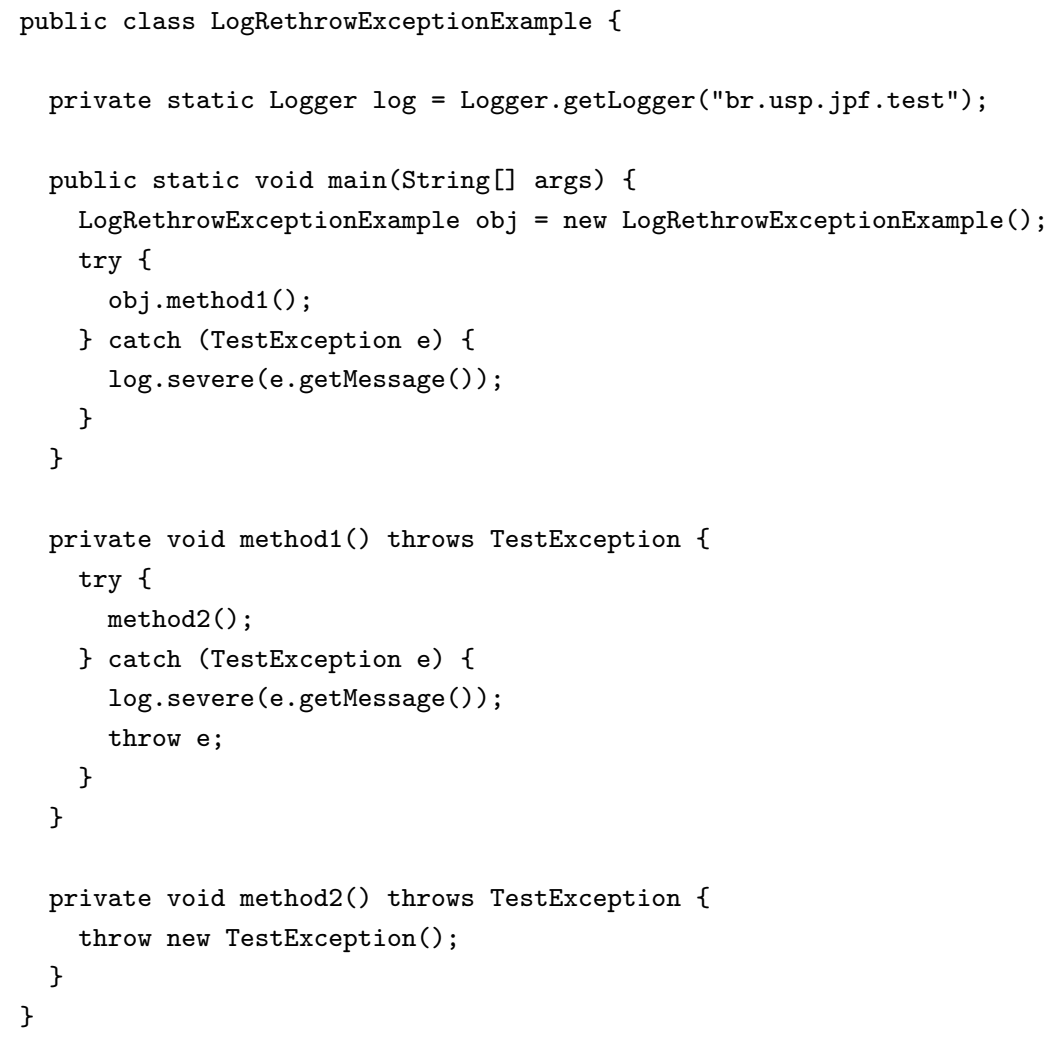

Análise: No exemplo a propriedade é violada com o lançamento da exceção TestException na linha 24. Sua captura é feita na linha 17, e seu tratamento consiste na execução de um método de log (linha 18) e um relançamento da exceção (linha 19). O exemplo também ilustra o problema decorrente da violação da propriedade pois geramos múltiplas mensagens para a mesma exceção (linhas 18 e 10). Estas mensagens podem aparecer em pontos distintos de um arquivo de log. Isto pode dar a impressão de que duas exceções foram lançadas, quando na verdade somente uma foi.

Para verificação desta propriedade seria necessária a existência de uma lista com métodos de log, a captura de um comando de lançamento de exceção e perceber que um determinado código está sendo executado dentro de um bloco catch.

A captura de um lançamento de exceção é trivial e perceber que um determinado código está 
sendo executado em um bloco catch está sujeito a algumas restrições, conforme discutido no item 3.2.6. O ponto mais crítico para esta propriedade seria a criação de uma lista com métodos de log. Em termos de implementação envolveria comparar cada invocação de método chamada dentro de um bloco catch à lista. Esta não é uma solução muito robusta, pois a lista teria que ser atualizada constantemente para ser utilizável.

Além disso, na execução do código de exemplo, onde foi utilizada a implementação de logging padrão do Java, constatou-se que o suporte da ferramenta às classes necessárias ainda não se encontra implementado. Isto provocou o lançamento de algumas exceções não relacionadas ao exemplo. A ferramenta JPF não tem suporte completo a todas as APIs do Java, apresentando ainda algumas limitações especialmente naquelas que dependem de código nativo [33]. É o que ocorre com a API de logging padrão (pacote java.util.logging) para a versão da ferramenta utilizada (4.1).

Por este motivos optou-se por não implementar a classe relativa a esta propriedade.

Classe: Não foi criada uma classe para representar a propriedade.

\section{Logar e retornar null}

Problema: Não permite diferenciar quando o valor retornado pelo método é legítimo ou resultado de uma exceção.

Propriedade: Uma exceção é lançada e dentro de seu bloco de tratamento (bloco catch) existe uma chamada a um método de log e um comando return null.

\section{Exemplo:}

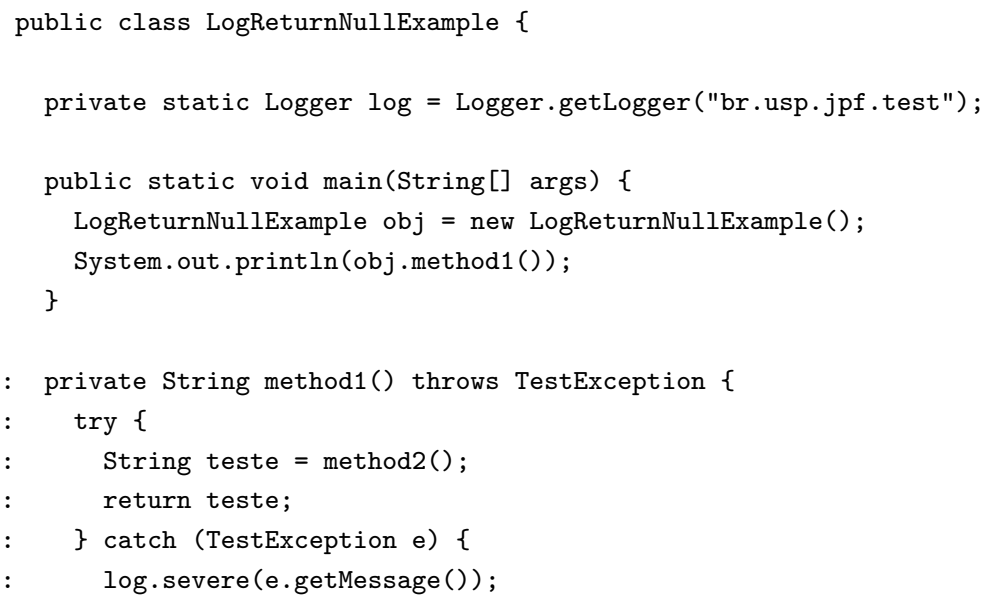




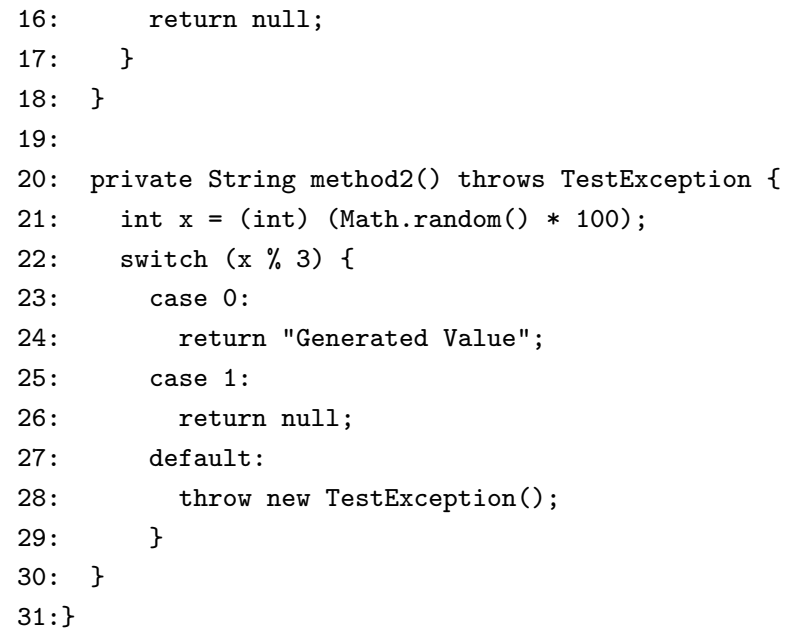

Análise: No exemplo a propriedade é violada com o lançamento da exceção TestException na linha 28. Sua captura é feita na linha 14, e seu tratamento consiste na execução de um método de log (linha 15) e uma instrução que retorna o valor null (linha 16). O exemplo também ilustra o problema decorrente da violação da propriedade pois no processamento do valor retornado pelo método (linha 7) não é possivel distinguir se foi resultado de um processamento legítimo (linha 26) ou do lançamento de uma exceção (linha 28).

Para a verificação desta propriedade seria necessária a existência de uma lista com métodos de log, a captura de um comando return e perceber que um determinado código está sendo executado dentro de um bloco catch.

Valem as mesmas observações feitas para o item 3.2.6

Classe: Não foi criada uma classe para representar a propriedade.

\section{Múltiplas mensagens de log para a mesma exceção}

Problema: Dependendo do mecanismo de log, as mensagens podem acabar espalhadas no arquivo ao invés de serem exibidas em conjunto.

Propriedade: Uma exceção é lançada e dentro de seu bloco de tratamento (bloco catch) existem múltiplas chamadas a métodos de log.

\section{Exemplo:}




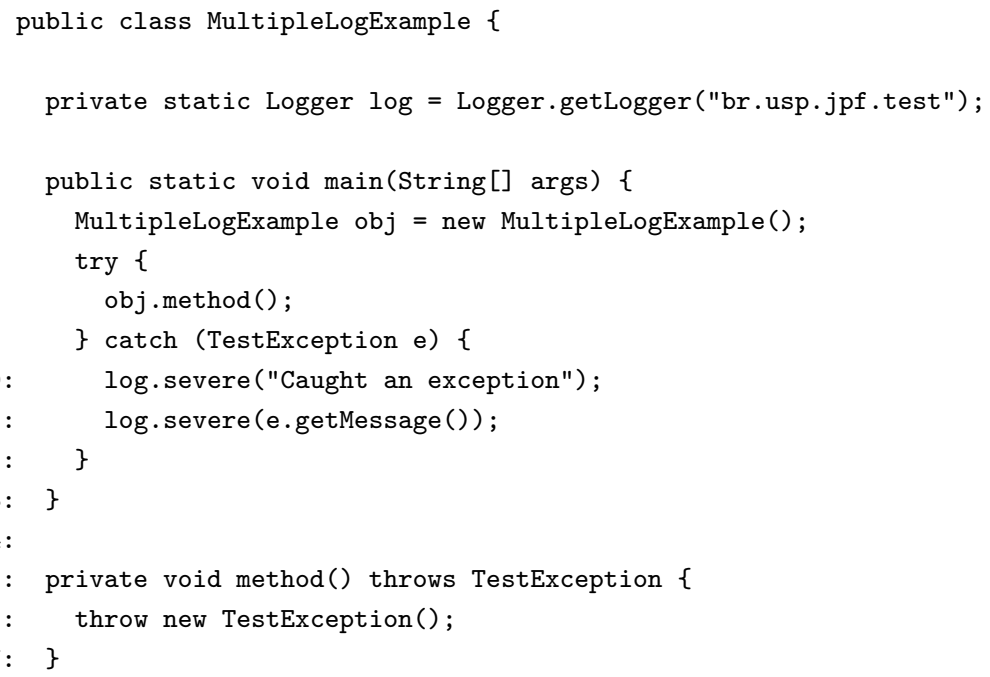

Análise: No exemplo a propriedade é violada com o lançamento da exceção TestException na linha 16. Sua captura é feita na linha 9 , e seu tratamento consiste na execução de múltiplos métodos de $\log$ (linhas 10 e 11). O efeito gerado é bem semelhante ao descrito no item 3.2.6, com a geração de múltiplas mensagens para uma mesma exceção.

Para a verificação desta propriedade seria necessária a existência de uma lista com métodos de log e perceber que um determinado código está sendo executado dentro de um bloco catch.

Valem as mesmas observações feitas para o item 3.2.6

Classe: Não foi criada uma classe para representar a propriedade.

\section{Encapsulamento destrutivo}

Problema: Ocorre quando a exceção é relançada mudando o tipo, sem armazenamento da exceção original. Os dados da exceção original são perdidos.

Propriedade: Existe um comando throw dentro de um bloco de captura catch lançando uma exceção diferente da capturada, sem passar a referência à exceção capturada em seu construtor.

\section{Exemplo:}

1: public class DestructiveWrappingExample \{

2: 


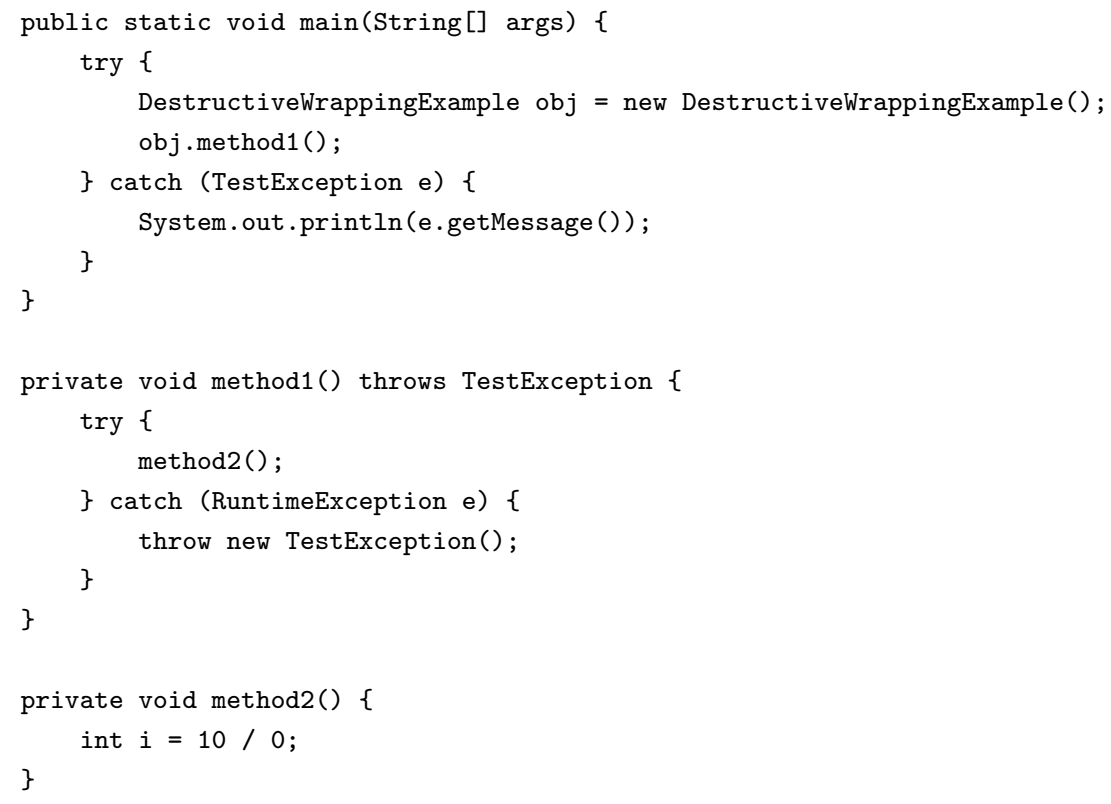

Análise: No exemplo a propriedade é violada na linha 16, ao ser lançada uma TextException, que esconde a ocorrência da ArithmeticException original, que foi lançada na linha 21. O exemplo também ilustra o problema decorrente da violação da propriedade, pois no tratamento da exceção TestException, feito no método principal (linha 8) perde-se a mensagem de erro original.

A verificação dinâmica desta propriedade exige uma investigação mais profunda da estrutura de bytecode. Neste trabalho, optou-se por não investir mais nesta investigação pois o número de propriedades descritas atende os objetivos propostos. Em trabalhos futuros pode-se retomar o estudo desta propriedade.

Classe: Não foi criada uma classe para representar a propriedade.

\section{Utilizar o método getCause() sem recuperar a Exceção original}

Problema: Este método é utilizado para recuperar a exceção original, quando ocorre um encapsulamento. Porém, este encapsulamento pode ser múltiplo. Para obter a exceção original é necessário encadear chamadas ao método até que null seja retornado.

Propriedade: Em um bloco de tratamento de exceção existe uma chamada ao método Throwable.getCause, que não seja a comparação de seu valor de retorno com null, dentro de uma condição 
de parada de laço.

\section{Exemplo:}

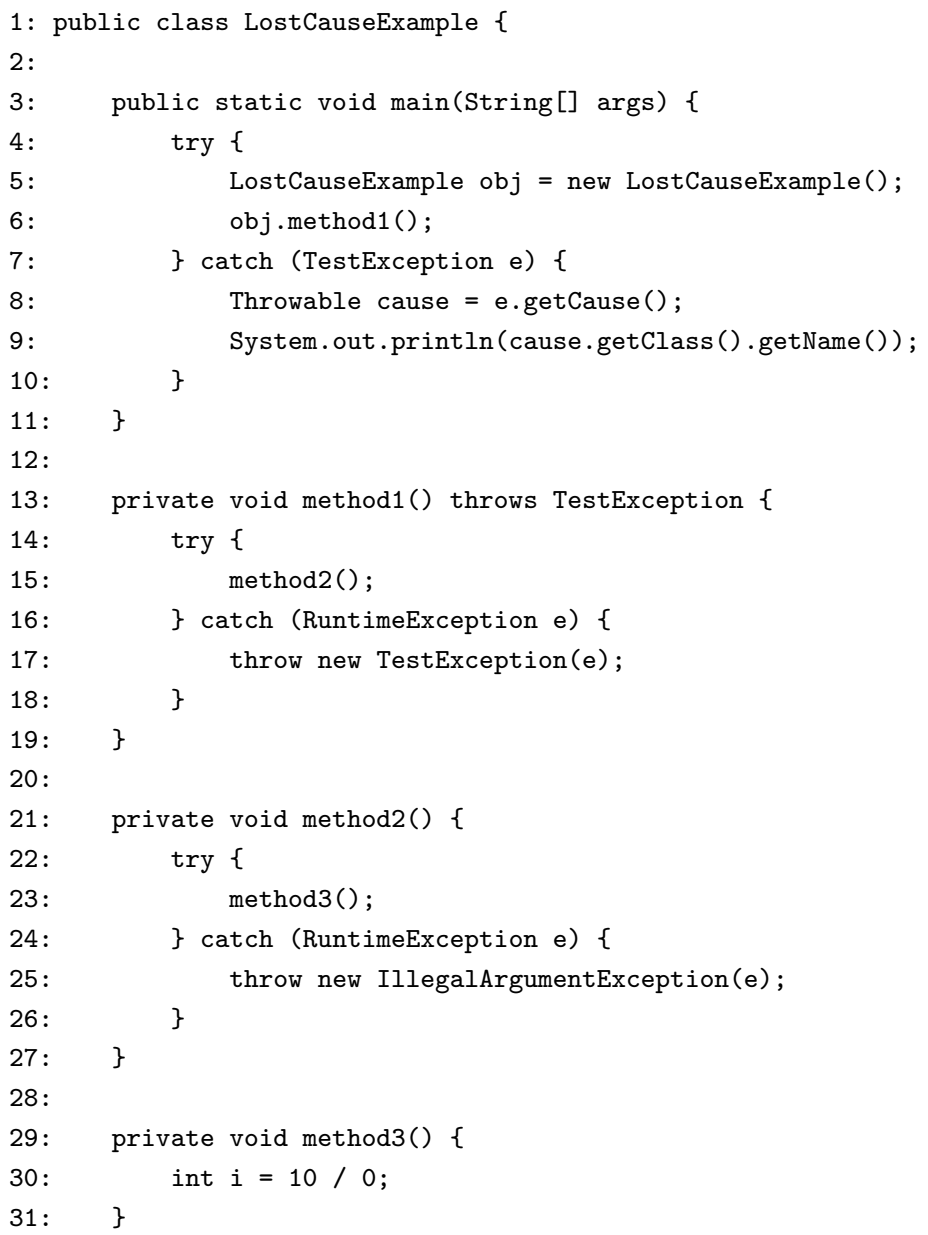

Análise: No exemplo a propriedade é violada na linha 8,com a chamada ao método getCause() sem que seja feita a verificação de seu valor de retorno. O exemplo também ilustra o problema decorrente da violação da propriedade, pois no tratamento da exceção TestException, feito no método principal (linha 9) a exceção IllegalArgumentException é tratada como sendo a exceção original, ao invés de ArithmeticException.

A verificação dinâmica desta propriedade exige uma investigação mais profunda da estrutura de bytecode. Neste trabalho, optou-se por não investir mais nesta investigação pois o número de 
propriedades descritas atende os objetivos propostos. Em trabalhos futuros pode-se retomar o estudo desta propriedade.

Classe: Não foi criada uma classe para representar a propriedade.

\subsubsection{Práticas relativas ao uso da instrução catch}

\section{Capturar java.lang.Exception}

Problema: Pode gerar problemas se o método que está sendo tratado for modificado para lançar novas exceções que devem ser manipuladas de modo diferenciado. O código tratador não ficará ciente de que existe esta nova exceção.

Propriedade: É executada uma instrução dentro de um método que possui um bloco de captura de java.lang.Exception em seu código.

\section{Exemplo:}

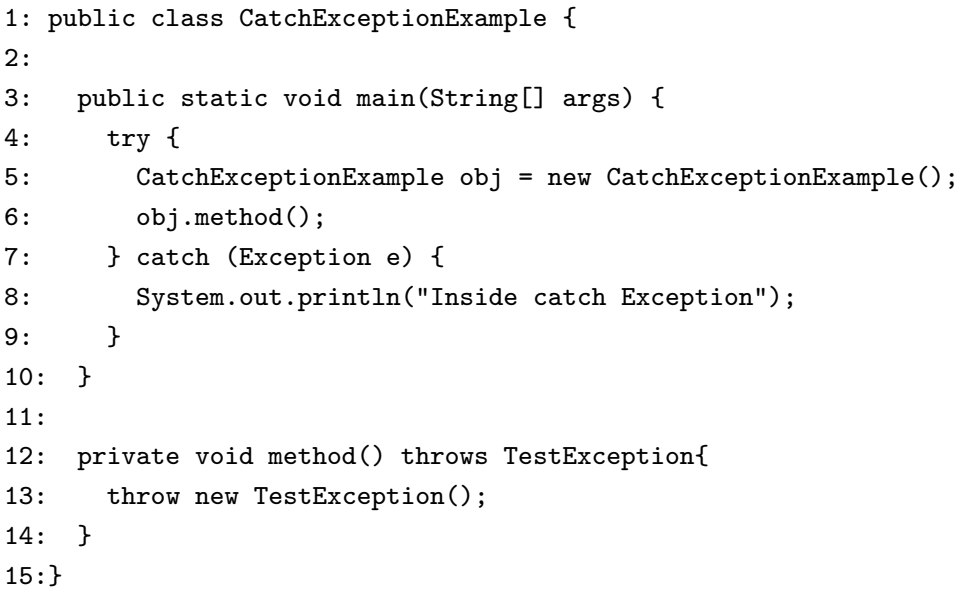

Análise: No exemplo, a propriedade é violada dentro do método main, pois ele possui um bloco de tratamento de exceção para java.lang.Exception (linha 7).

Para análise da propriedade é necessário determinar a cada método executado, se ele possui um bloco de tratamento de exceção para java.lang.Exception. Esta informaçao está disponível no bytecode gerado pelo compilador Java.

Classe: br.usp.jpf.property.CatchExceptionProperty 


\subsubsection{Práticas relativas ao uso da instrução finally}

\section{Lançar exceções dentro do bloco finally}

Problema: Esta exceção pode sobrescrever uma exceção gerada originalmente, perdendo os seus dados.

Propriedade: Dentro de um bloco finally existe uma instrução de lançamento de exceção(throw) ou uma chamada a método que lance exceção não capturada.

\section{Exemplo:}

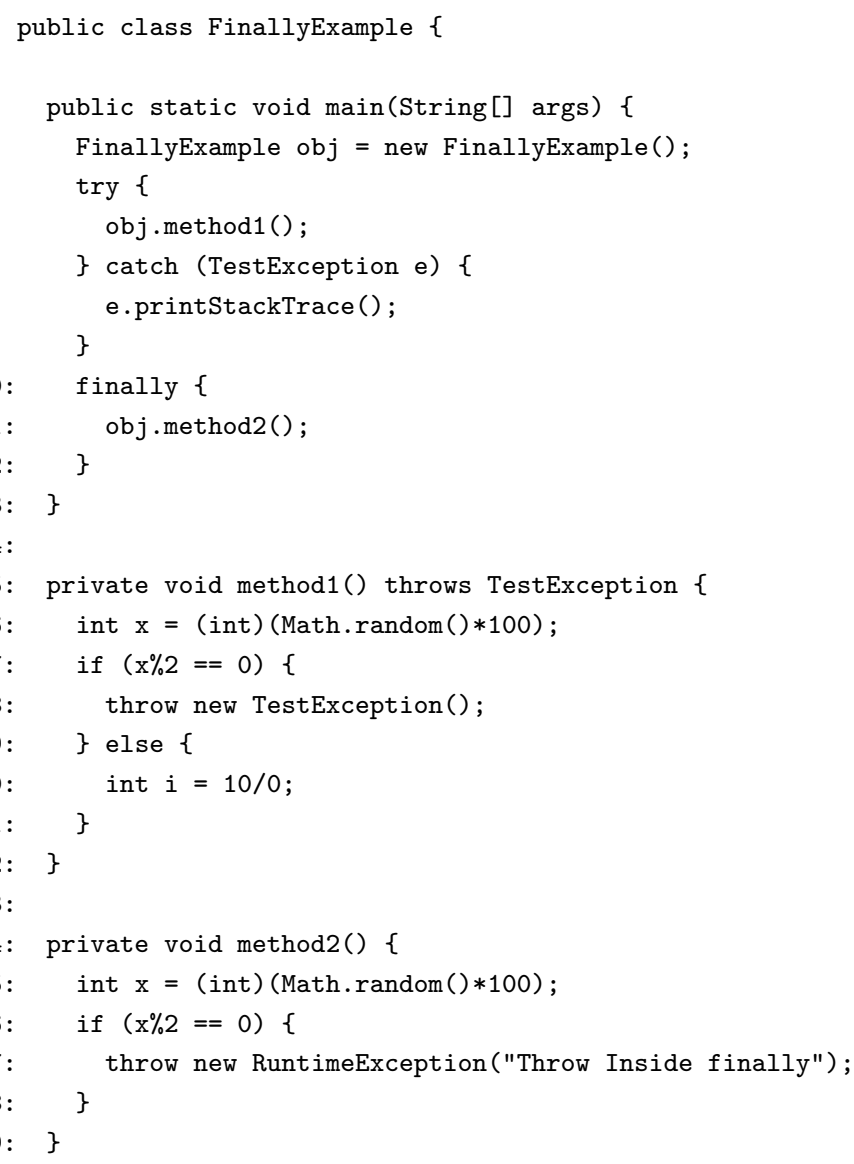

Análise: No exemplo, a propriedade é violada na linha 11, com a chamada ao método method2() que pode lançar uma RuntimeException. O exemplo também ilustra o problema decorrente da vi- 
olação da propriedade, pois o lançamento da exceção RuntimeException (linha 27) pode sobrescrever a exceção ArithmeticException (linha 20) lançada pelo método method1().

Para esta propriedade é necessário perceber que um determinado código está sendo executado dentro de um bloco finally. Não existe nenhuma instrução de bytecode que defina a entrada ou saída de um bloco finally.

A verificação dinâmica desta propriedade exige uma investigação mais profunda da estrutura de bytecode. Neste trabalho, optou-se por não investir mais nesta investigação pois o número de propriedades descritas atende os objetivos propostos. Em trabalhos futuros pode-se retomar o estudo desta propriedade.

Classe: Não foi criada uma classe para representar a propriedade.

\subsection{Conclusões Preliminares}

Neste capítulo apresentamos algumas ferramentas para verificação de modelos e selecionamos o Java PathFinder para uso em nosso trabalho. Também apresentamos algumas práticas relativas ao tratamento de exceções que podem gerar algum tipo de problema e criamos propriedades do JPF para algumas delas.

Comentamos anteriormente que a verificação de propriedades pode ser útil não somente para encontrar bugs (propriedade de deadlock), mas também para perceber más práticas de programação sendo utilizadas no código. Estas práticas dificilmente seriam percebidas somente com as atividades de teste tradicionais.

Com os resultados deste capítulo já apresentamos uma gama de propriedades que podem ser utilizados pelo testador ao fazer verificaçãos com a ferramenta JPF, de forma a garantir uma maior qualidade do código. A principal dificuldade na utilização de um verificador de modelo com este objetivo é a criação das propriedades. Aqui já apresentamos 5 propriedades referentes a práticas comuns de tratamento de exceção. 


\section{Capítulo 4}

\section{Ambiente de Testes}

Conforme descrito anteriormente, nosso objetivo é utilizar a verificação de propriedades baseadas em tratamento de exceções como um meio de reduzir a necessidade da geração de casos de teste manuais. Na seção 3.2 descrevemos as propriedades que foram implementadas para os testes. Neste capítulo, vamos descrever os demais elementos que foram implementados para auxílio aos testes.

\subsection{Atividades necessárias para os testes}

A sequência de testes envolve as seguintes atividades:

1. Seleção do programa a ser testado.

2. Análise do fluxo de dados do programa e geração de um arquivo XML com as instruções a serem varridas, de acordo com o critério selecionado.

3. Configuração das propriedades a serem verificadas.

4. Configuração dos listeners a serem utilizados.

5. Verificação das propriedades e rastreamento das instruções executadas

6. Exibição das estatísticas de cobertura.

Para auxiliar as atividades dispomos de 2 ferramentas. Uma delas é o verificador de modelos Java PathFinder que foi apresentado anteriormente no capítulo 3. Esta ferramenta é responsável por verificar as propriedades e gerar o rastreamento de instruções executadas (atividade 5). As 
propriedades foram definidas no seção 3.2 e o rastreamento de instruções é feito através de um listener customizado ${ }^{1}$, criado para este propósito.

A segunda ferramenta é um aplicativo Java que funciona como interface gráfica entre o testador e a ferramenta JPF. Foi desenvolvido para permitir a seleção do programa e das propriedades a serem testadas, bem como exibir as estatísticas de cobertura dos critérios (atividades 3, 4 e 6). Além disso, ela permite a configuração dinâmica da ferramenta JPF sem a necessidade de alteração de arquivos de propriedades.

Inicialmente planejou-se a utilização de uma terceira ferramenta (OcongraX), responsável por gerar um arquivo com as instruções que deveriam ser rastreadas, de acordo com o critério selecionado (atividade 2). Porém, a versão atual da ferramenta ainda não suporta a geração dos arquivos de acordo com as necessidades dos testes, por isso estes arquivos foram gerados manualmente. Esperase futuramente utilizar arquivos no mesmo formato, porém gerados pela ferramenta.

A Figura 4.1 mostra as atividades desempenhadas nos testes executados. Conforme observado anteriormente, a seleção do critério de testes e conseqüente geração do arquivo de instruções/linhas a serem executadas foi feito manualmente neste trabalho, mas o diagrama já reflete o comportamento desejado para a ferramenta Ocongra em trabalhos futuros.

A seguir descrevemos em mais detalhes cada um dos elementos que foi implementado para permitir as atividades de teste.

\subsection{Arquivo de compartilhamento de dados}

Conforme dito anteriormente, no IME-USP foi desenvolvida uma ferramenta denominada Ocongra [25], capaz de criar gráficos de fluxo de objetos. A partir destes fluxos é possivel estabelecer, para um determinado critério quais instruções devem ser executadas. A ferramenta JPF, através do listener que será descrito mais adiante, permite o rastreamento de instruções executadas. Juntando as duas ferramentas é possivel, para uma determinada verificação, estabelecer as estatísticas de cobertura.

Pensando em estabelecer uma integração entre as duas ferramentas estabeleceu-se um formato de arquivo XML a ser utilizado como saída do Ocongra e entrada para o JPF. Apesar de nos testes realizados não ter sido feita esta integração, de acordo com o discutido no item 4.1, arquivos neste formato foram criados manualmente. Isto facilita uma integração futura, já que a funcionalidade

\footnotetext{
${ }^{1}$ listeners foram apresentados juntamente com as propriedades, no capítulo anterior
} 


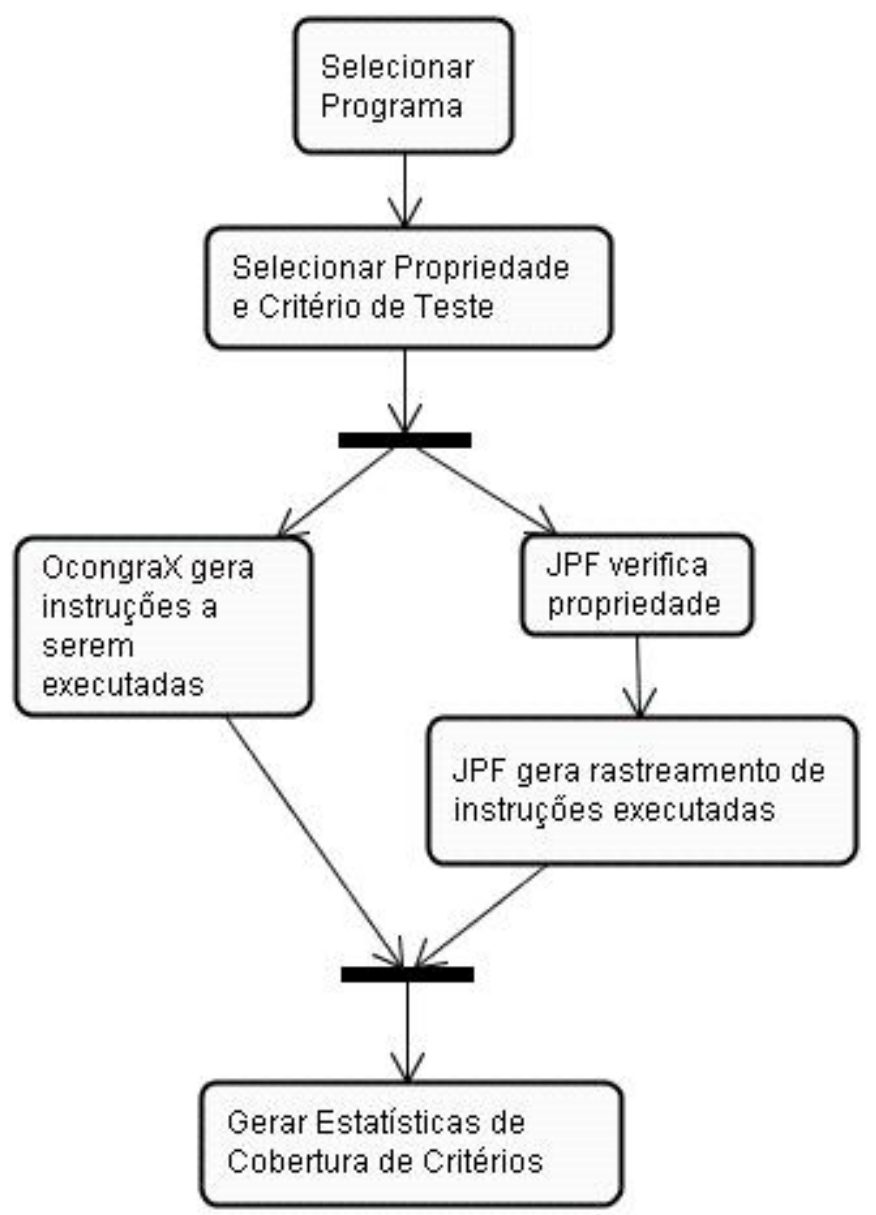

Figura 4.1: Atividades Executadas no Ambiente de Testes

de leitura dos arquivos pelo JPF já está pronta. Falta apenas a geração do arquivo de maneira automática, o que permite testes para programas maiores, nos quais a análise manual é difícil e mais propensa a erros.

O arquivo XML Schema de validação do arquivo de compartilhamento de dados se encontra no apêndice C. A Figura 4.2 apresenta um exemplo de arquivo.

Os seguintes elementos foram definidos:

- elements: tag raiz do documento 


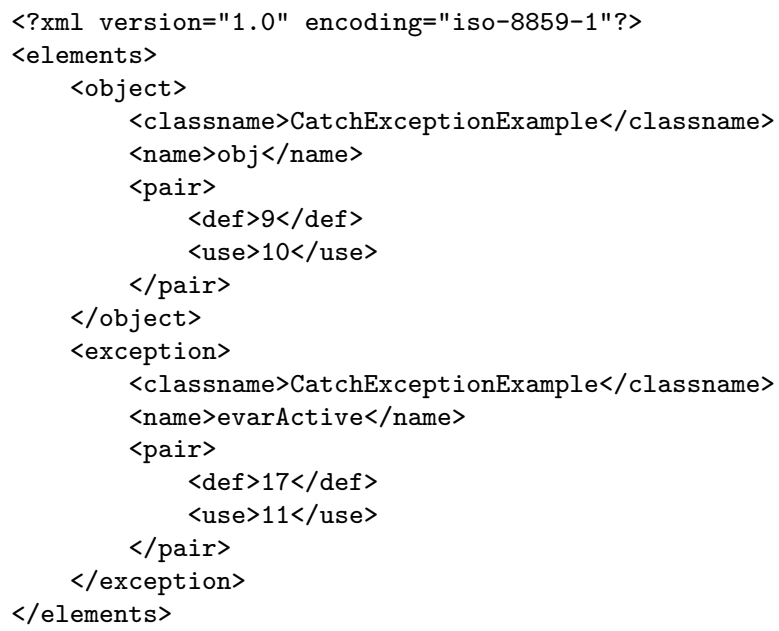

Figura 4.2: exemplo de arquivo compartilhamento de dados

- exception: tag raiz para a definição de elementos relativos a critérios baseados em tratamento de exceções

- object: tag raiz para definição de elementos relativos a outros critérios relativos a orientação a objetos

- classname: nome da classe aonde estão definidas as exceções ou objetos

- name: nome da variável a que se referem os pares do critério

- pair: tag raiz para definição de pares definição-uso

- def: linha aonde ocorre uma definição de objeto/exceção

- threaddef: nome da thread aonde ocorre uma definição

- use: linha aonde ocorre um uso de objeto/exceção

- threaduse: nome da thread onde ocorre um uso

\subsection{Elementos de extensão ao JPF}

Para estender as funcionalidades do JPF de acordo com as nossas necessidades foi necessária a criação dos seguintes elementos: 
1. um listener de rastreamento de instruções executadas

2. um gerador de escolhas para exceções

3. um listener de configuração para o gerador de escolhas para exceções

\subsubsection{Listener de rastreamento de instruções executadas}

Foi criado um listener que registra todas as instruções executadas, e ao término da verificação gera os seguintes arquivos:

- um arquivo com a lista de todas as linhas de código executadas na ordem de execução.

- um arquivo por thread de execução somente com as linhas de código executadas por aquela thread

Além disso, ao término da execução, o listener também faz a leitura do arquivo XML de compartilhamento de dados descrito no item anterior, e gera arquivos XML de saída no mesmo formato do arquivo de entrada, porém separando os pares que foram executados em um arquivo e aqueles que não foram executados em outro.

\subsection{2 gerador de escolhas para exceções}

Um gerador de escolhas (choice generator) é um elemento da ferramenta JPF que permite a execução de diversos caminhos. É este elemento que efetivamente faz com que a ferramenta simule diversas execuções. Sem ele a ferramenta executa as instruções do programa seqüencialmente do começo ao fim. Com geradores de escolha podemos forçar a criação de ramificações do código e forçar a ferramenta a executar todas as ramificações antes de encerrar sua execução.

A ferramenta oferece uma superclasse gov.nasa.jpf.jvm.ChoiceGenerator que deve ser herdada por cada gerador de escolhas.

A ferramenta já traz implementados alguns geradores de escolha, como por exemplo:

- ThreadChoiceGenerator: permite a simulação de execução não determinística de código concorrente. A cada instrução que pode ser afetada por outras threads é feita a geração de uma ou mais ramificações, dependendo do número de threads existentes naquele instante. São 
feitas, então, diversas execuções do programa a partir daquele ponto alternando a sequência de execuções de instruções entre as threads.

- CustomBooleanChoiceGenerator: utilizado em expressões condicionais para que seja feita a simulação da execução da expressão tanto com o valor true como false.

- IntChoiceFromSet: permite a simulação de valores de entrada inteiros selecionados a partir de um conjunto configurável.

Para nossos testes foi criado um gerador de escolhas de exceções. Seu funcionamento é simples. Para cada método executado que declara lançar exceções, o código é executado simulando o lançamento de cada uma das exceções declaradas, bem como a execução sem lançar exceções.

Para ilustrar melhor seu funcionamento vamos apresentar um exemplo. Na Figura 4.3 temos um exemplo de código Java com um método que lança múltiplas exceções. Em uma execução sem gerador de escolhas para exceções, os blocos de captura de exceção nunca são executados, visto que o código nunca chega a lançar exceções. Com isso a única mensagem impressa na console seria aquela correspondente ao código da linha 15.

O gerador de escolhas faz com que a ferramenta JPF simule 4 execuções para este exemplo de código. Uma execução sem lançamento de exceções mais uma execução simulando o lançamento para cada exceção que o método throwsManyExceptions declara. Com isso conseguimos uma cobertura melhor do código, forçando a execução das estruturas de tratamento de exceção.

Para utilizar o gerador de escolhas é necessário utilizar também um listener de eventos que é notificado a cada instrução executada. Este listener tem a função de criar uma instância do gerador de escolhas, configurada com as exceções necessárias, para cada execução de um método que lançar exceções.

\subsection{Aplicativo para execução e análise dos testes}

Para configuração do verificador e exibição dos resultados foi implementado um aplicativo Java utilizando a API gráfica Swing. A seguir apresentamos as telas criadas e suas respectivas funcionalidades.

O aplicativo consiste em uma janela principal que permite o acesso a diversos painéis através de abas conforme pode ser visto na Figura 4.4. As abas criadas foram: 


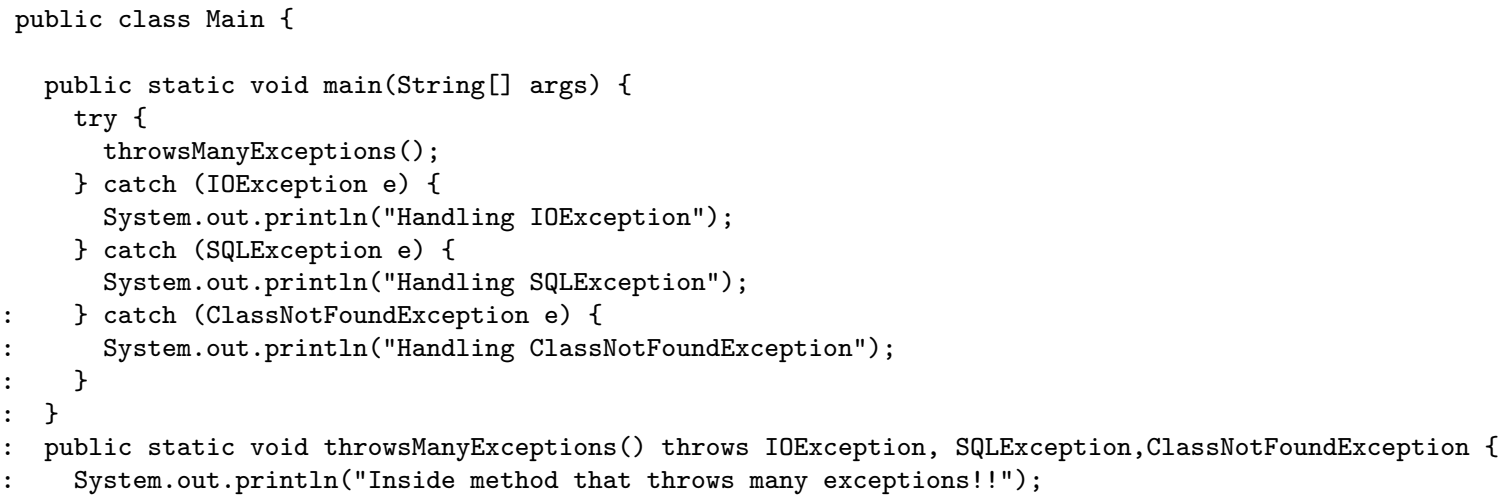

Figura 4.3: Exemplo de código com método que lança múltiplas exceções

- JPF Config: permite a configuração de elementos gerais da ferramenta JPF.

- Properties: permite a seleção das propriedades a serem verificadas.

- Listeners: permite a seleção e configuração dos listeners a serem utilizados.

- Results: permite a visualização das estatísticas de cobertura.

- State: permite a visualização do rastreamento de estados percorridos pela ferramenta. Esta capacidade de rastreamento já vem embutida no próprio JPF.

Na tela de configuração do JPF, mostrada na Figura 4.4 podemos selecionar os seguintes elementos de configuração da ferramenta:

- Base Dir: diretório raiz da ferramenta. Utilizado como base para leitura e escrita de arquivos, busca de códigos-fonte, etc.

- Classpath: diretório raiz para a busca de arquivos .class do Java.

- Main Class: utilizado para selecionar o programa a ser verificado.

- Max Depth: utilizado para configurar uma restrição de profundidade máxima de busca da ferramenta, durante a verificação. Serve para limitar a verificação para programas muito grandes ou que possam entrar em laços infinitos ou recursões infinitas. 


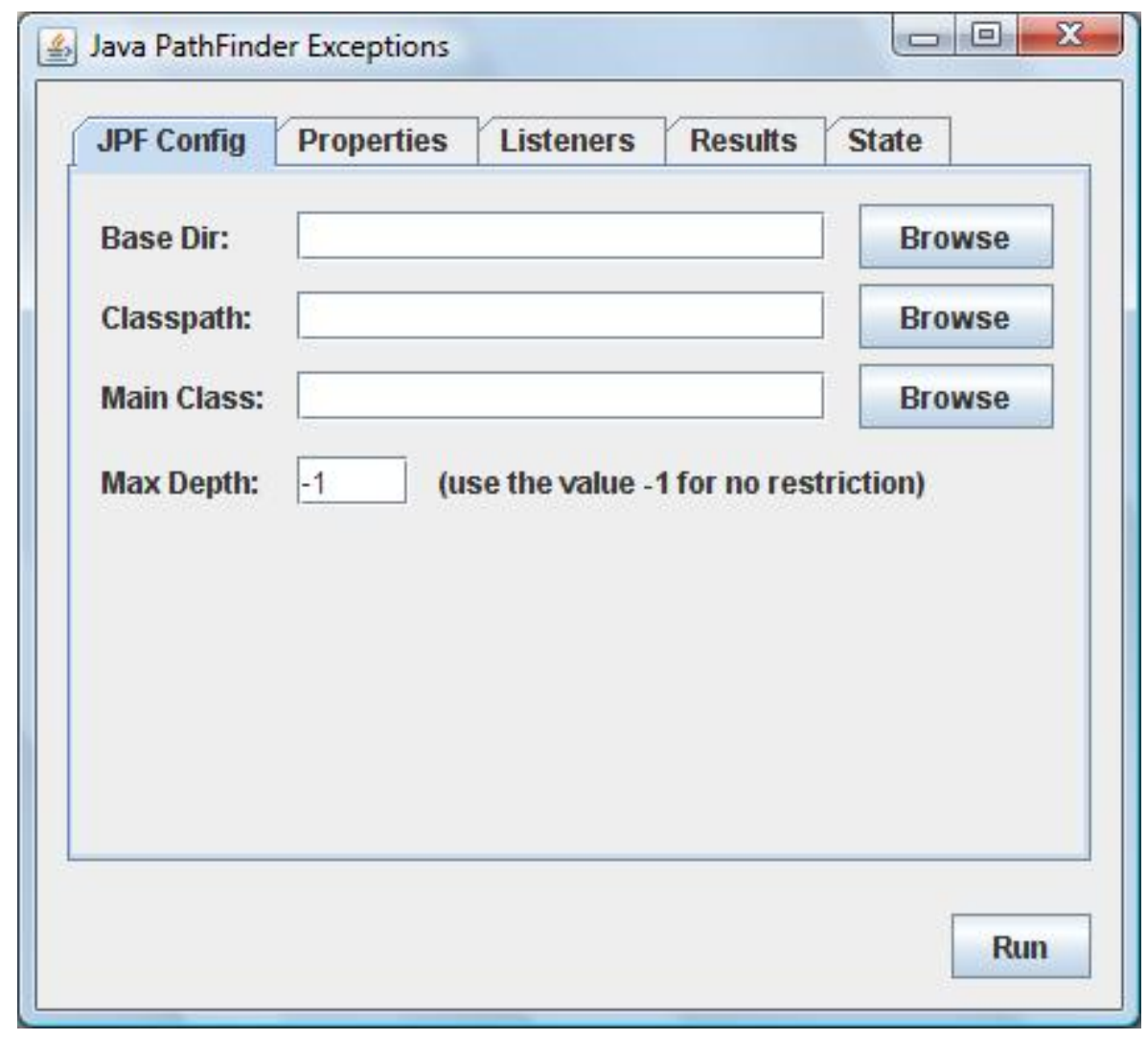

Figura 4.4: Tela de configuração do JPF

$\mathrm{Na}$ tela de seleção de propriedades, mostrada na Figura 4.5, podemos selecionar e configurar as propriedades a serem verificadas. Podemos selecionar o número de propriedades que for de interesse, desde todas até nenhuma propriedade. Nesta tela encontram-se as propriedades implementadas e aquelas nativas do JPF.

No caso da propriedade de múltiplas exceções lançadas, podemos configurar o número máximo de exceções que deve ser levado em conta como parâmetro para a violação da propriedade.

Na tela de seleção e configuração dos listeners, mostrada na Figura 4.6, podemos selecionar os listeners implementados, descritos anteriormente no item 4.3.

Para o listener de configuração do gerador de escolhas de exceção, podemos ainda habilitar ou não a verificação para classes de sistema. Por padrão, somente serão gerados lançamentos de exceção 


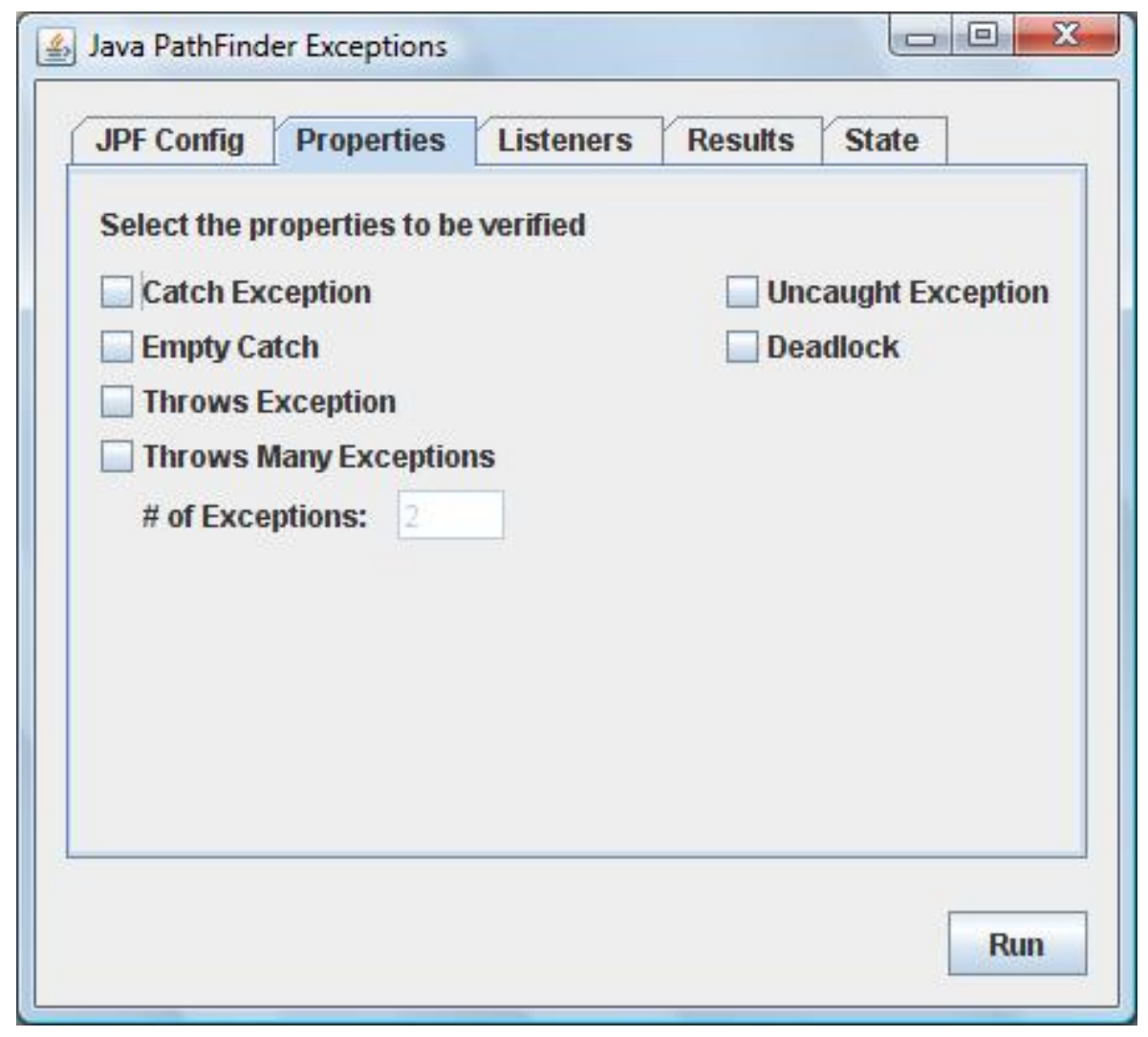

Figura 4.5: Tela de seleção de propriedades

para métodos desenvolvidos pelo programador. Se quisermos podemos habilitar também para classes do próprio Java.

Para o listener de linhas executadas temos os seguinte elementos de configuração:

- criação ou não de um arquivo texto com todas as linhas executadas

- Ocongra XML: arquivo XML de entrada de dados a ser utilizado para gerar a cobertura. Define as linhas que devem ser percorridas de acordo com o critério estabelecido.

- Ok XML: arquivo de saída com as linhas do critério que foram percorridas.

- Not Ok XML: arquivo de saída com as linhas do critério que não foram percorridas. 


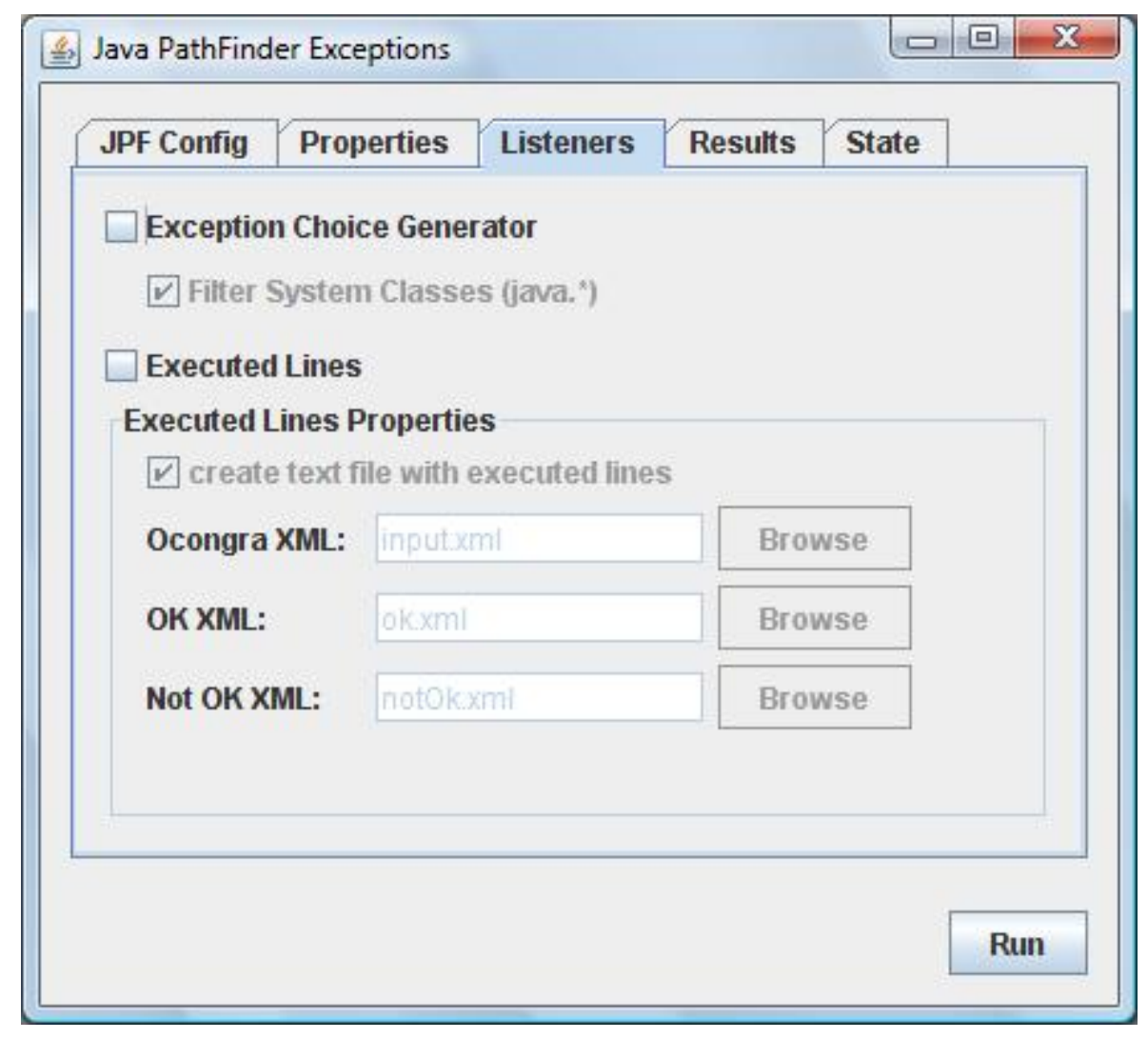

Figura 4.6: Tela de configuração dos listeners

A tela de resultados, mostrada na Figura 4.7 mostra a cobertura de código obtida após uma verificação. Para o processsamento da estatística pressionamos o botão "Process", e o botão "Reset"é utilizado para limpar a área de texto utilizada para exibição dos resultados.

A tela de rastreamento de estados, mostrada na Figura 4.8 exibe as estatísticas relativas a estado geradas pela ferramenta ( numéro de estados visitados, número de retornos executados, etc.). Para que as estatísticas sejam geradas e exibidas pela ferramenta é necessário selecionar habilitá-las selecionando o checkbox.

Por fim, temos um botão "Run" presente na parte inferior de todas as telas, utilizado para iniciar a verificação de propriedades. O resultado é exibido na barra de status inferior. Basicamente esta barra pode exibir as seguintes mensagens: 


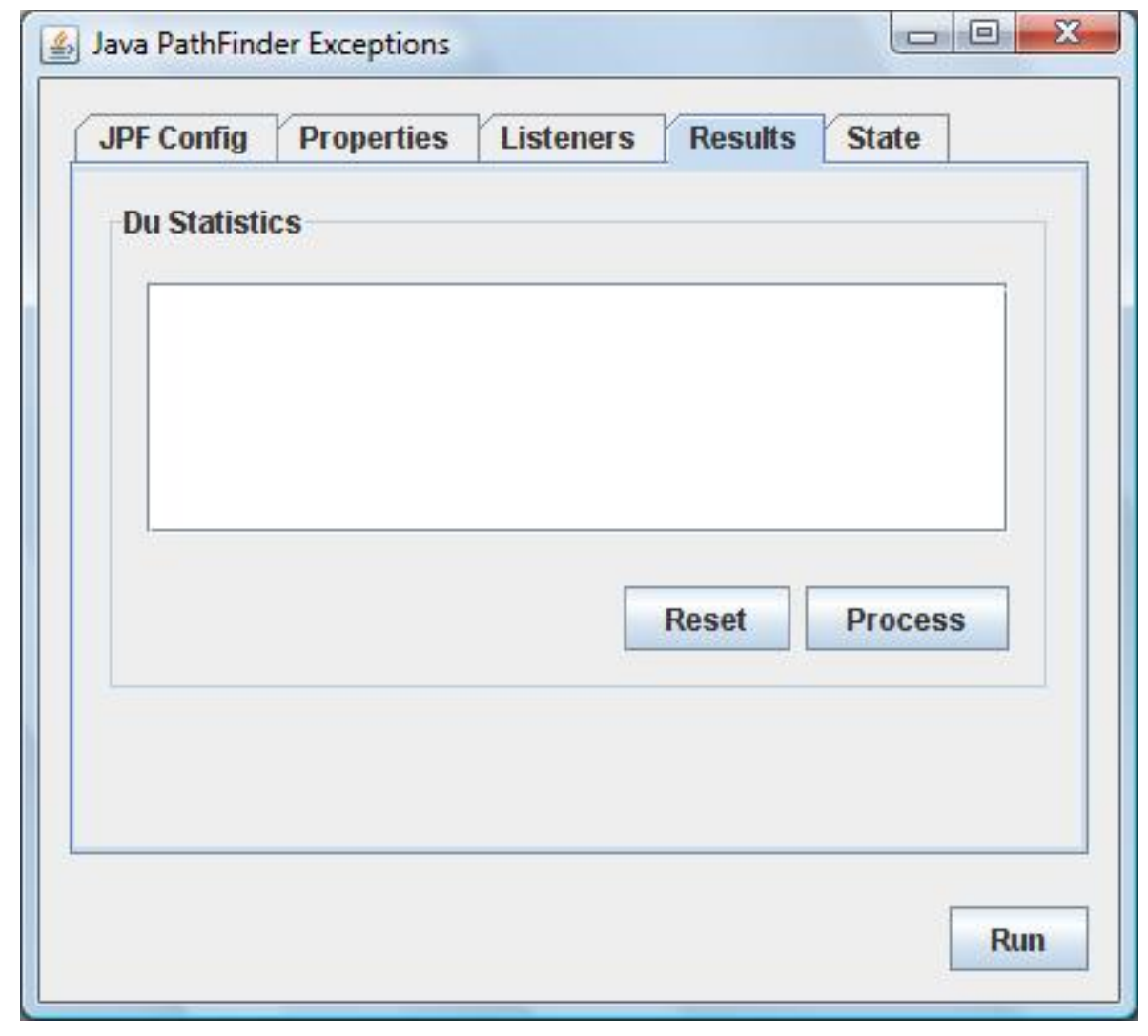

Figura 4.7: Tela de exibição dos resultados

- no property violated: quando nenhuma propriedade é violada na verificação.

- property $X$ violated: exibindo o nome da propriedade violada.

- constraint hit: quando a verificação é interrompida devido a uma restrição de busca, como por exemplo a restrição de profundidade configurada na tela da Figura 4.4.

\subsection{Exemplo de uso do ambiente}

Apresentamos a seguir um exemplo de uso do ambiente, para verificação da propriedade. Foi selecionado o programa CatchExceptionExample.java, mostrado anteriormente na seção 3.2.7.

Foi gerado manualmente um arquivo XML de entrada de dados para a ferramenta, conforme a Figura 4.9. Pode-se observar que as triplas relevantes para a análise encontram-se nos blocos entre 


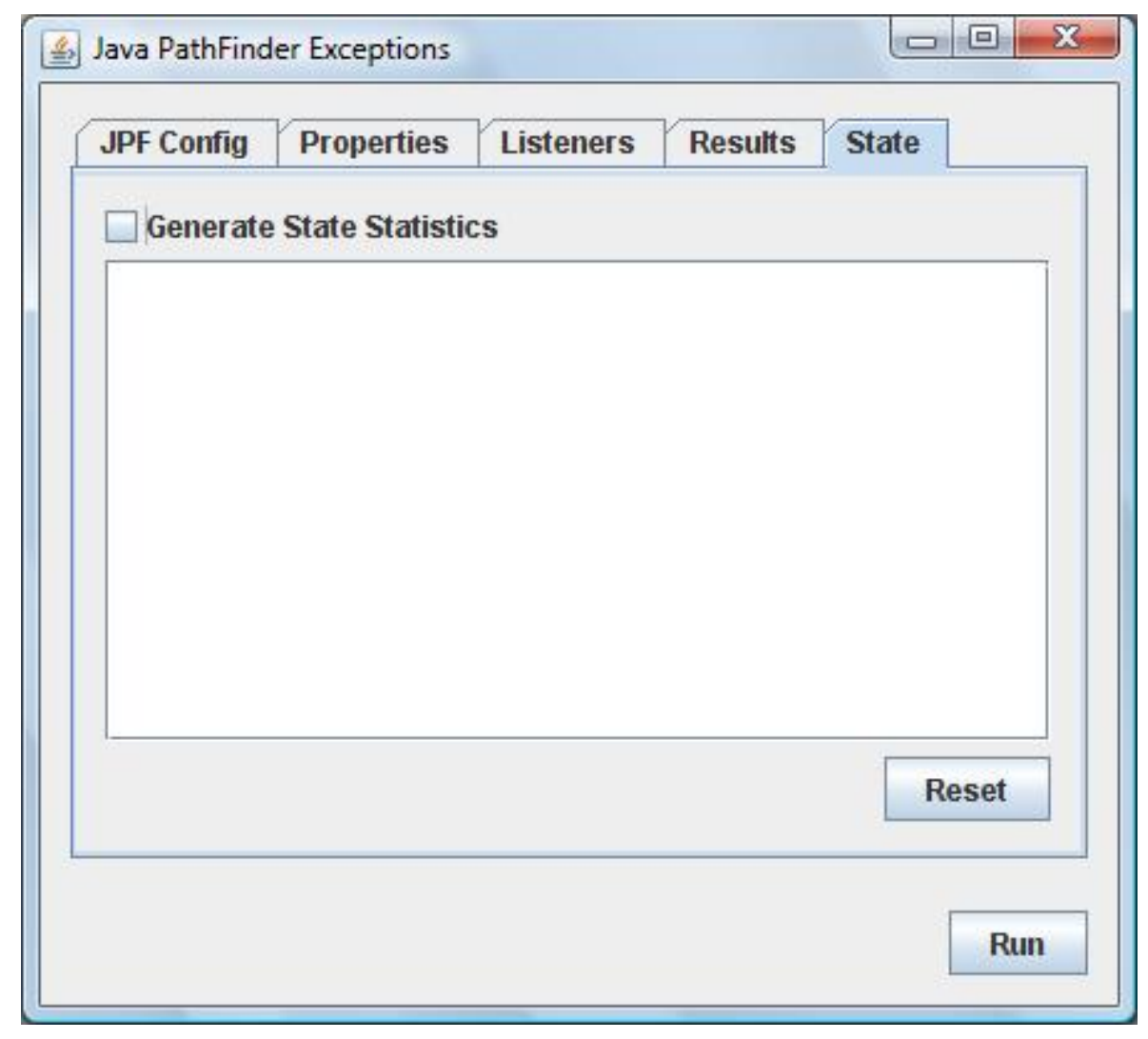

Figura 4.8: Tela de rastreamento de estados

as linhas 7 a 11 e 27 a 31 .

Para execução da verificação do programa com o aplicativo desenvolvido foi feita a configuração inicial do JPF conforme a tela apresentada na Figura 4.10

Foi configurado o uso dos listeners de linhas executadas e do gerador de escolhas de exceção conforme pode ser observado na Figura 4.11.

Foi executada uma verificação para cada propriedade. Na Figura 4.12 pode ser vista a configuração para verificação da propriedade de captura de exceção (Catch Exception).

A tela apresentada na Figura 4.13 representa o resultado da verificação da propriedade. Para esta propriedade em particular ocorreu a violação, o que pode ser observado pela mensagem na barra inferior da tela. Além disso, obtivemos $0 \%$ de cobertura neste caso. 


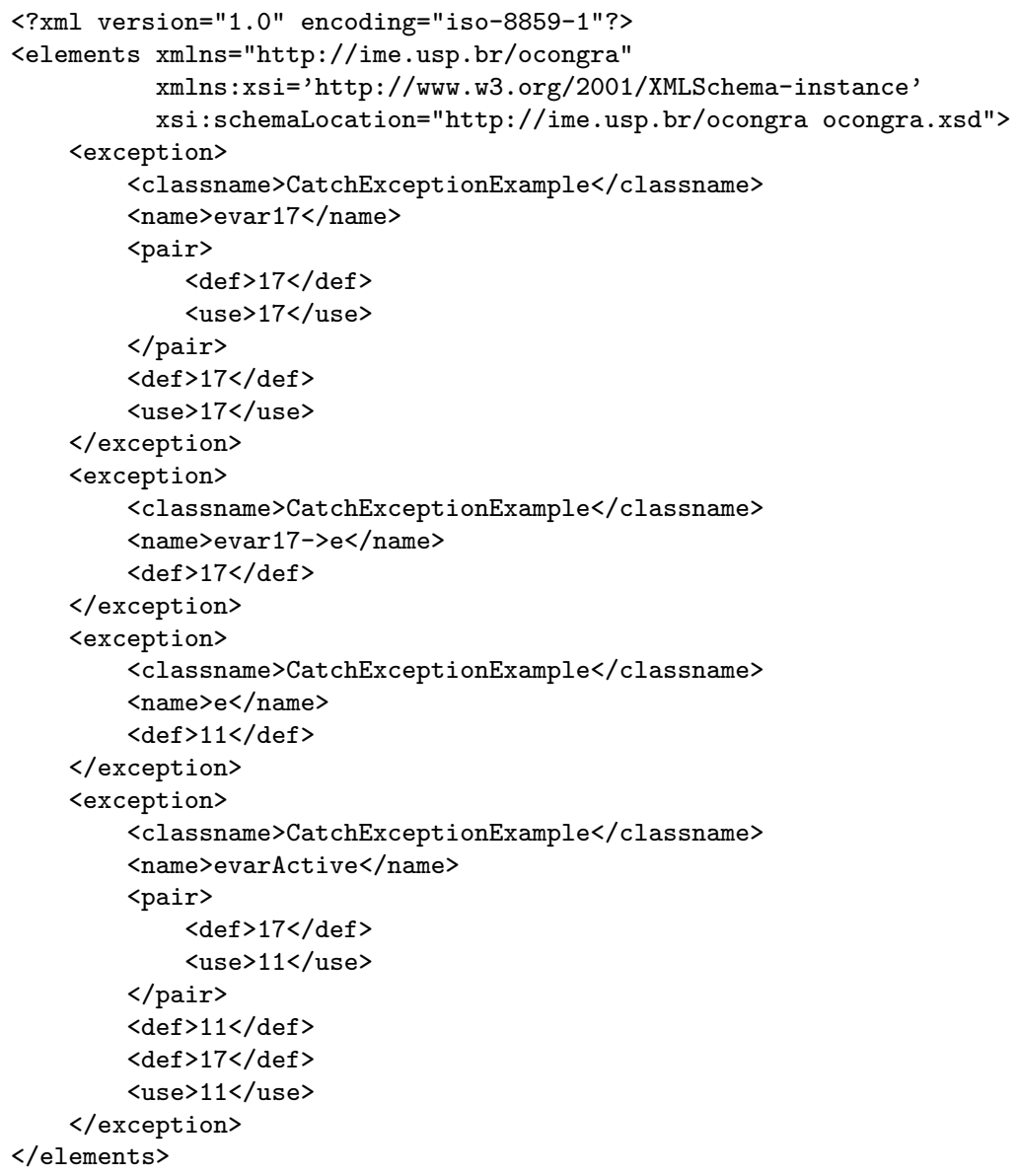

Figura 4.9: arquivo entrada_CatchExceptionExample.xml

A Figura 4.14 mostra as estatísticas de estado apresentadas na tela do programa para a verificação com o gerador de escolhas de exceções e a propriedade CatchException selecionada. No próximo capítulo detalhamos o significado de cada um dos elementos apresentados nesta tela. 


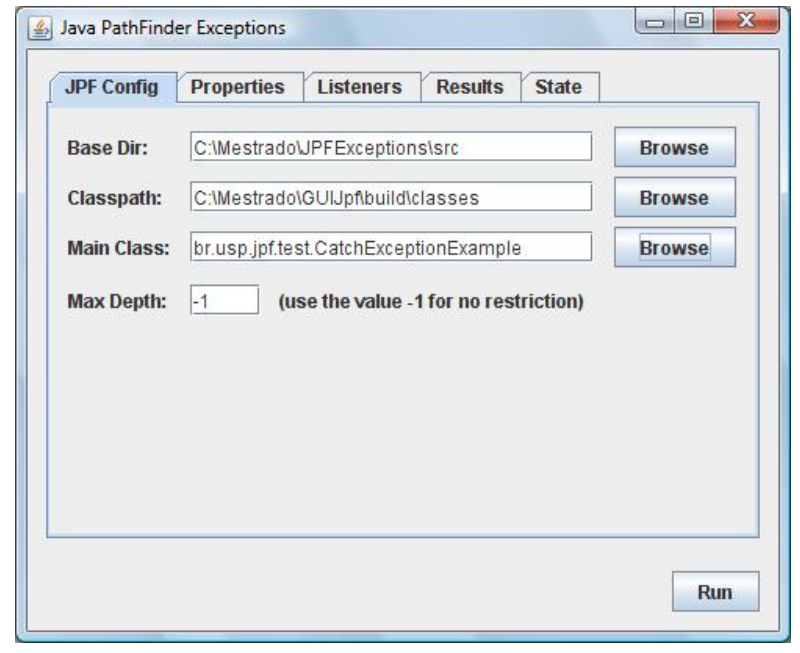

Figura 4.10: Tela de configuração do JPF para o programa CatchExceptionExample.java

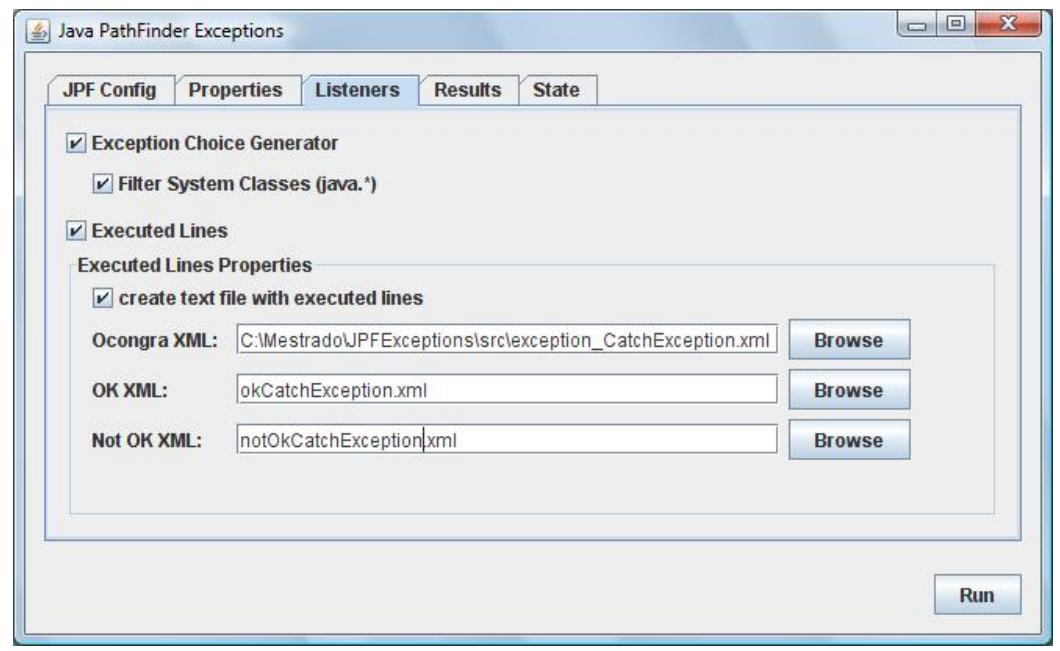

Figura 4.11: Tela de configuração dos listeners para o programa CatchExceptionExample.java 


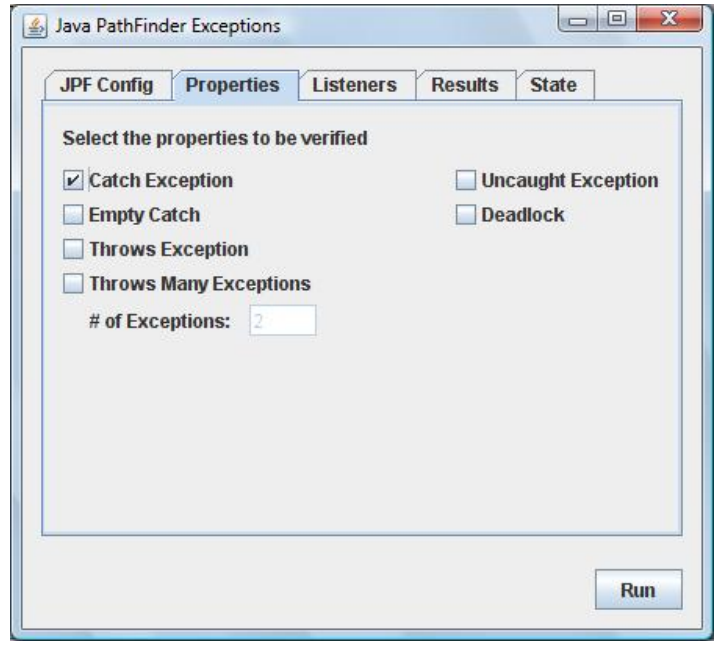

Figura 4.12: Tela de seleção das propriedades para o programa CatchExceptionExample.java

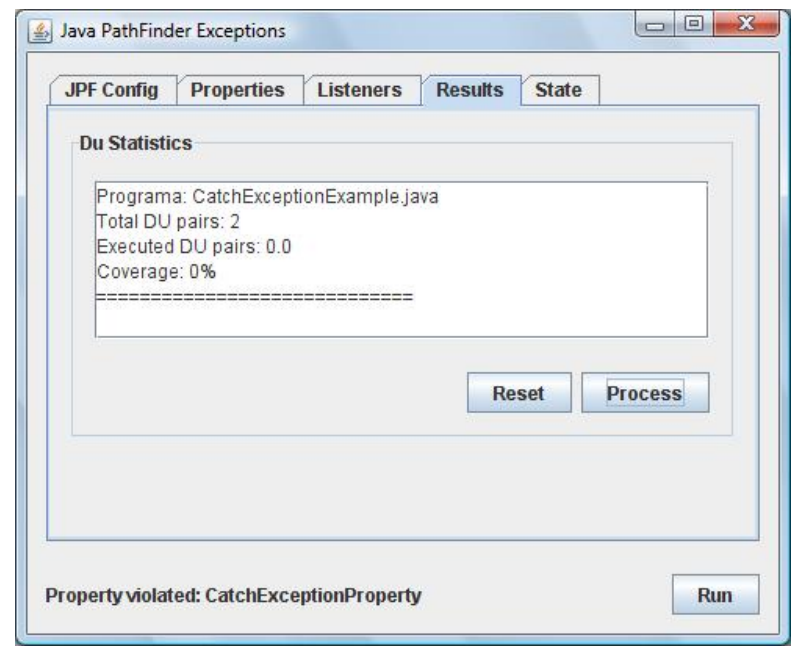

Figura 4.13: Tela de resultados para o programa CatchExceptionExample.java 


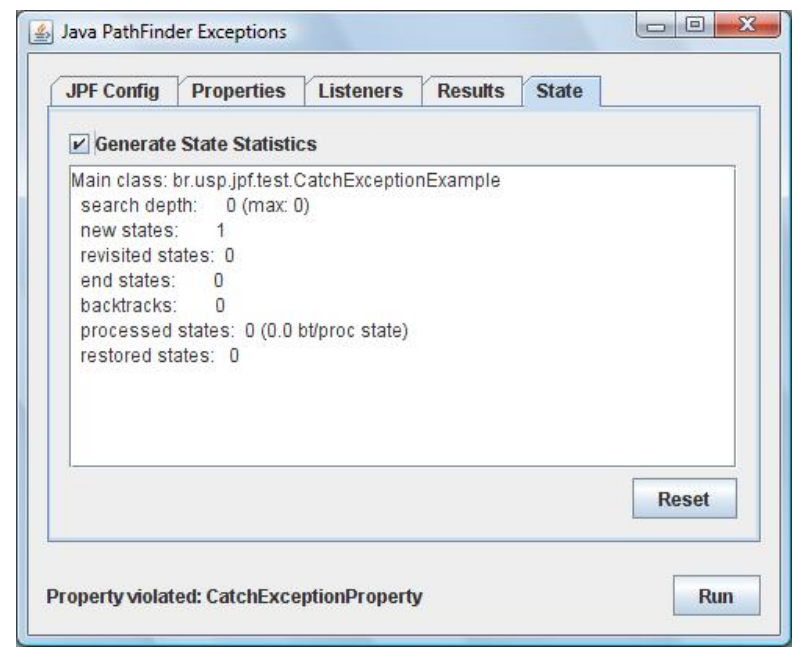

Figura 4.14: Tela de rastreamento de estados para o programa CatchExceptionExample.java 


\section{Capítulo 5}

\section{Análise dos Programas Exemplo}

Este capítulo tem como objetivo apresentar os resultados obtidos na verificação dos 13 programas apresentados na seção 3.2 para ilustrar as propriedades baseadas em exceções. Cada programa representa uma das propriedades. Foi feita a verificação dos programas utilizando a ferramenta Java PathFinder e a análise da cobertura utilizando a extensão implementada para a mesma ferramenta. Os critérios utilizados [31] são os mesmos apresentados na seção 2.4 .

Os levantamentos das triplas a serem varridas foi feito manualmente a partir da análise do código fonte. Como os exemplos são bem simples, este tipo de análise é viável, mas para programas maiores é interessante o uso de uma ferramenta como o Ocongra [25]. A presente versão da ferramenta ainda não suporta a geração automática das triplas a serem varridas.

\subsection{Resultados obtidos}

A seguir apresentamos os resultados obtidos para cada um dos programas. Para o primeiro programa mostramos de maneira mais detalhada como foram utilizadas as ferramentas apresentadas no capítulo 4 .

\subsubsection{Programa CatchExceptionExample.java}

Para o programa CatchExceptionExample.java as seguintes triplas e-du foram identificadas:

- $\left(\operatorname{evar}_{17}, 17,17\right)$

- $\left(\right.$ evar $\left._{\text {active }}, 17,11\right)$ 
A seguinte tripla e-ad foi identificada:

- $\left(e o b j_{17}, 17,11\right)$

As triplas que devem ser percorridas para cada um dos critérios de teste encontram-se na Tabela 5.1

\begin{tabular}{|c|c|}
\hline critério & tripla e-du ou e-ad \\
\hline all-throw & $\left(\right.$ evar $\left._{17}, 17,17\right)$ \\
\hline all-catch & $\left(\right.$ evar $\left._{\text {active }}, 17,11\right)$ \\
\hline all-e-defs & $\left(\right.$ evar $\left._{17}, 17,17\right),\left(\right.$ evar $\left._{\text {active }}, 17,11\right)$ \\
\hline all-e-use & $\left(\right.$ evar $\left._{17}, 17,17\right),\left(\right.$ evar $\left._{\text {active }}, 17,11\right)$ \\
\hline all-e-act & $\left(e o b j_{17}, 17,11\right)$ \\
\hline all-e-deact & $\left(e^{o b j} j_{17}, 17,11\right)$ \\
\hline
\end{tabular}

Tabela 5.1: triplas a serem percorridas para o programa CatchExceptionExample

Os resultados obtidos com a verificação de cada uma das propriedades encontram-se na Tabela 5.2

As seguintes abreviações foram utilizadas para cada uma das propriedades:

CE: Captura de java.lang.Exception (Catch Exception)

EC: bloco de captura vazio (Empty Catch)

TE: lançamento de java.lang.Exception (Throws Exception)

TME: lançamento de muitas exceções (Throws Many Exceptions)

UE: exceção não tratada (Uncaught Exception)

D: deadlock

NP: nenhuma propriedade (No Property)

As estatísticas de estado encontram-se na Tabela 5.3 e na Tabela 5.4. A primeira foi obtida sem o uso do gerador de escolhas de exceções e a segunda com o seu uso.

Antes de analisá-la é importante descrever o significado de cada uma de suas colunas. 


\begin{tabular}{|l|c|c|c|c|c|c|c|c|}
\hline & total & \multicolumn{7}{|c|}{ triplas exercitadas } \\
\cline { 3 - 9 } critério & triplas & CE & EC & TE & TME & UE & D & NP \\
\hline \hline all-throw & 1 & 0 & 1 & 1 & 1 & 1 & 1 & 1 \\
\hline all-catch & 1 & 0 & 1 & 1 & 1 & 1 & 1 & 1 \\
\hline all-e-defs & 2 & 0 & 2 & 2 & 2 & 2 & 2 & 2 \\
\hline all-e-use & 2 & 0 & 2 & 2 & 2 & 2 & 2 & 2 \\
\hline all-e-act & 1 & 0 & 1 & 1 & 1 & 1 & 1 & 1 \\
\hline all-e-deact & 1 & 0 & 1 & 1 & 1 & 1 & 1 & 1 \\
\hline
\end{tabular}

Tabela 5.2: triplas percorridas para o programa CatchExceptionExample

- máxima profundidade: Representa a profundidade máxima que a ferramenta JPF avançou no código até encontrar um estado final ou retornar. Representa o número máximo de estados consecutivos encontrados em um determinado caminho de código.

- novos estados: Número de estados distintos encontrados na execução do código.

- estados revisitados: Número de estados varridos pelo código que já haviam sido varridos anteriormente. A soma dos estados revisitados e novos estados representa o total de estados varridos pela ferramenta.

- retornos: A ferramenta JPF simula a execução de diversos caminhos diferentes de código. Esta coluna indica quantas vezes a ferramenta voltou a um estado anterior para executar um caminho diferente. É importante ressaltar que ela não representa o número de caminhos diferentes executados. Algumas vezes são realizados vários retornos sem que se encontre um novo caminho a ser executado.

- estados finais: Número de estados finais varridos na execução do código. Um estado final representa um estado no qual o programa encerraria sua execução. Para a ferramenta JPF significa que todas as threads de execução do programa se encerraram.

\begin{tabular}{|c|c|c|c|c|c|}
\hline propriedade & $\begin{array}{c}\text { máxima } \\
\text { profundidade }\end{array}$ & $\begin{array}{c}\text { novos } \\
\text { estados }\end{array}$ & $\begin{array}{c}\text { estados } \\
\text { revisitados }\end{array}$ & $\begin{array}{c}\text { estados } \\
\text { finais }\end{array}$ & retornos \\
\hline \hline Catch Exception & 0 & 1 & 0 & 0 & 0 \\
\hline demais & 0 & 1 & 0 & 1 & 0 \\
\hline
\end{tabular}

Tabela 5.3: Rastreamento de Estados para o programa CatchExceptionExample - Sem Gerador de Escolhas 


\begin{tabular}{|c|c|c|c|c|c|}
\hline propriedade & $\begin{array}{c}\text { máxima } \\
\text { profundidade }\end{array}$ & $\begin{array}{c}\text { novos } \\
\text { estados }\end{array}$ & $\begin{array}{c}\text { estados } \\
\text { revisitados }\end{array}$ & $\begin{array}{c}\text { estados } \\
\text { finais }\end{array}$ & retornos \\
\hline \hline Catch Exception & 0 & 1 & 0 & 0 & 0 \\
\hline demais & 1 & 3 & 0 & 2 & 2 \\
\hline
\end{tabular}

Tabela 5.4: Rastreamento de Estados para o programa CatchExceptionExample - Com Gerador de Escolhas

Pode-se observar que todas as triplas foram varridas quando nenhuma propriedade é violada. Quanto foi violada a propriedade de existência de bloco de captura para java.lang.Exception nenhuma tripla foi varrida. Pode-se observar também que somente um estado é gerado. Isto pode ser explicado pela maneira como foi implementada a propriedade. Toda vez que se inicia a execução de um método é verificado se existe o bloco de captura (bloco catch) naquele método, antes do início da execução de suas instruções. Como neste exemplo o próprio método main possui o bloco que viola a propriedade, nenhuma das triplas é varrida.

Outro fato observado é que quando nenhuma propriedade é violada o resultado é sempre o mesmo. Além disso, é o mesmo comportamento observado quando não se seleciona nenhuma propriedade para verificação. Isto pode ser explicado pois na ferramenta JPF, a propriedade pode apenas fazer com que a execução seja abortada quando é violada, mas não influencia na sequência de caminhos percorrida.

O elemento que influencia na escolha de caminhos é o gerador de escolhas (choice generator). Neste exemplo o seu uso não afetou as triplas percorridas, mas gerou novos estados e retornos, conforme pode ser observado comparando as tabelas de estados.

\subsubsection{Programa DestructiveWrappingExample.java}

Para o programa DestructiveWrappingExample.java as seguintes triplas e-du foram identificadas:

- (te, 12, 13)

- $\left(\operatorname{evar}_{21}, 21,21\right)$

- $\left(\right.$ evar $\left._{\text {active }}, 21,12\right)$

- $\left(\right.$ evar $_{21} \rightarrow$ te, 21,13$)$

A seguinte tripla e-ad foi identificada: 
- $\left(\operatorname{eobj}_{21}, 21,12\right)$

As triplas que devem ser percorridas para cada um dos critérios de teste encontram-se na Tabela 5.5

\begin{tabular}{|l|c|}
\hline critério & tripla e-du ou e-ad \\
\hline \hline all-throw & $\left(\right.$ evar $\left._{21}, 21,21\right)$ \\
\hline all-catch & {$\left[\left(\right.\right.$ te $\left._{1} 12,13\right)$ ou $\left(\right.$ evar $\left.\left._{\text {active }}, 21,12\right)\right]$ e linha 20} \\
\hline all-e-defs & $($ te $, 12,13),\left(\right.$ evar $\left._{21}, 21,21\right),\left(\right.$ evar $\left._{\text {active }}, 21,12\right),\left(\right.$ evar $_{21} \rightarrow$ te $\left., 21,13\right)$ \\
\hline all-e-use & $($ te $, 12,13),\left(\right.$ evar $\left._{21}, 21,21\right),\left(\right.$ evar $\left._{\text {active }}, 21,12\right),\left(\right.$ evar $_{21} \rightarrow$ te $\left., 21,13\right)$ \\
\hline all-e-act & $\left(\right.$ eobj $\left._{21}, 21,12\right)$ \\
\hline all-e-deact & $\left(\right.$ eobj $\left._{21}, 21,12\right)$ \\
\hline
\end{tabular}

Tabela 5.5: triplas a serem percorridas para o programa DestructiveWrappingExample

Vale observar que para atender os critérios all-throw e all-catch, nem sempre a execução precisa corresponder a uma tripla var-def-use. Na verdade, estes critérios correspondem a varrer determinadas linhas, aonde ocorrem comandos throw e catch, respectivamente. Neste estudo estamos tomando a liberdade de considerar as triplas que passam por estas linhas, sempre que possivel, para facilitar a comparação com os outros critérios. No presente exemplo, não foi possivel seguir esta abordagem a risca pois nenhuma tripla passa pela linha 20, onde há uma das ocorrências de comando catch do exemplo.

Neste caso, nenhuma tripla passa pela linha mencionada devido a uma restrição do critério, no que diz respeito à definição das triplas. O critério não leva em conta exceções lançadas implicitamente (algumas exceções de runtime e lançamento declarado na assinatura de métodos). No exemplo, é lançada uma ArithmeticException devido à divisão por zero na linha 26 do programa.

Os resultados obtidos com a verificação de cada uma das propriedades encontram-se na Tabela 5.6

As estatísticas de estado encontram-se na Tabela 5.7 e na Tabela 5.8. A primeira foi obtida sem o uso do gerador de escolhas de exceções e a segunda com o seu uso.

Na verificação deste programa não ocorreu a violação de nenhuma propriedade o que fez com que todos os caminhos percorridos fossem iguais. As únicas diferenças de caminhos ocorreram com o uso ou não do gerador de escolhas, conforme pode ser visto nas tabelas de rastreamento de estados. 


\begin{tabular}{|l|c|c|c|c|c|c|c|c|}
\hline & total & \multicolumn{7}{|c|}{ triplas exercitadas } \\
\cline { 3 - 9 } critério & triplas & CE & EC & TE & TME & UE & D & NP \\
\hline \hline all-throw & 1 & 1 & 1 & 1 & 1 & 1 & 1 & 1 \\
\hline all-catch & 2 & 2 & 2 & 2 & 2 & 2 & 2 & 2 \\
\hline all-e-defs & 4 & 4 & 4 & 4 & 4 & 4 & 4 & 4 \\
\hline all-e-use & 4 & 4 & 4 & 4 & 4 & 4 & 4 & 4 \\
\hline all-e-act & 1 & 1 & 1 & 1 & 1 & 1 & 1 & 1 \\
\hline all-e-deact & 1 & 1 & 1 & 1 & 1 & 1 & 1 & 1 \\
\hline
\end{tabular}

Tabela 5.6: triplas percorridas para o programa DestructiveWrappingExample

\begin{tabular}{|c|c|c|c|c|c|}
\hline propriedade & $\begin{array}{c}\text { máxima } \\
\text { profundidade }\end{array}$ & $\begin{array}{c}\text { novos } \\
\text { estados }\end{array}$ & $\begin{array}{c}\text { estados } \\
\text { revisitados }\end{array}$ & $\begin{array}{c}\text { estados } \\
\text { finais }\end{array}$ & retornos \\
\hline \hline todas & 0 & 1 & 0 & 1 & 0 \\
\hline
\end{tabular}

Tabela 5.7: Rastreamento de Estados para o programa DestructiveWrappingExample - Sem Gerador de Escolhas

A simplicidade do programa auxiliou para que todas as triplas fossem varridas. Neste exemplo, uma única execução do programa passa por todas as linhas de código.

\subsubsection{Programa EmptyCatchExample.java}

Para o programa EmptyCatchExample.java as seguintes triplas e-du foram identificadas:

- $\left(\operatorname{evar}_{16}, 16,16\right)$

- $\left(\right.$ evar $\left._{\text {active }}, 16,17\right)$

A seguinte tripla e-ad foi identificada:

- $\left(e o b j_{16}, 16,17\right)$

\begin{tabular}{|c|c|c|c|c|c|}
\hline propriedade & $\begin{array}{c}\text { máxima } \\
\text { profundidade }\end{array}$ & $\begin{array}{c}\text { novos } \\
\text { estados }\end{array}$ & $\begin{array}{c}\text { estados } \\
\text { revisitados }\end{array}$ & $\begin{array}{c}\text { estados } \\
\text { finais }\end{array}$ & retornos \\
\hline \hline todas & 1 & 3 & 0 & 2 & 2 \\
\hline
\end{tabular}

Tabela 5.8: Rastreamento de Estados para o programa DestructiveWrappingExample - Com Gerador de Escolhas 
As triplas que devem ser percorridas para cada um dos critérios de teste encontram-se na Tabela 5.9

\begin{tabular}{|l|c|}
\hline critério & tripla e-du ou e-ad \\
\hline \hline all-throw & $\left(\right.$ evar $\left._{16}, 16,16\right)$ \\
\hline all-catch & $\left(\right.$ evar $\left._{\text {active }}, 16,17\right)$ \\
\hline all-e-defs & $\left(\right.$ evar $\left._{16}, 16,16\right),\left(\right.$ evar $\left._{\text {active }}, 16,17\right)$ \\
\hline all-e-use & $\left(\right.$ evar $\left._{16}, 16,16\right),\left(\right.$ evar $\left._{\text {active }}, 16,17\right)$ \\
\hline all-e-act & $\left(\right.$ eobj $\left._{16}, 16,17\right)$ \\
\hline all-e-deact & $\left(\right.$ eobj $\left._{16}, 16,17\right)$ \\
\hline
\end{tabular}

Tabela 5.9: triplas a serem percorridas para o programa EmptyCatchExample

Os resultados obtidos com a verificação de cada uma das propriedades encontram-se na Tabela 5.10

\begin{tabular}{|l|c|c|c|c|c|c|c|c|}
\hline & total & \multicolumn{7}{|c|}{ triplas exercitadas } \\
\cline { 3 - 9 } critério & triplas & CE & EC & TE & TME & UE & D & NP \\
\hline \hline all-throw & 1 & 1 & 1 & 1 & 1 & 1 & 1 & 1 \\
\hline all-catch & 1 & 1 & 0 & 1 & 1 & 1 & 1 & 1 \\
\hline all-e-defs & 2 & 2 & 1 & 2 & 2 & 2 & 2 & 2 \\
\hline all-e-use & 2 & 2 & 1 & 2 & 2 & 2 & 2 & 2 \\
\hline all-e-act & 1 & 1 & 0 & 1 & 1 & 1 & 1 & 1 \\
\hline all-e-deact & 1 & 1 & 0 & 1 & 1 & 1 & 1 & 1 \\
\hline
\end{tabular}

Tabela 5.10: triplas percorridas para o programa EmptyCatchExample

As estatísticas de estado encontram-se na Tabela 5.11 e na Tabela 5.12.

\begin{tabular}{|c|c|c|c|c|c|}
\hline propriedade & $\begin{array}{c}\text { máxima } \\
\text { profundidade }\end{array}$ & $\begin{array}{c}\text { novos } \\
\text { estados }\end{array}$ & $\begin{array}{c}\text { estados } \\
\text { revisitados }\end{array}$ & $\begin{array}{c}\text { estados } \\
\text { finais }\end{array}$ & retornos \\
\hline \hline Empty Catch & 0 & 1 & 0 & 0 & 0 \\
\hline demais & 0 & 1 & 0 & 1 & 0 \\
\hline
\end{tabular}

Tabela 5.11: Rastreamento de Estados para o programa EmptyCatchExample - Sem Gerador de Escolhas

A única propriedade violada foi a de bloco de captura vazio (Empty Catch). Em sua execução somente uma das triplas é executada, o que varia de acordo com o critério de $0 \%$ a 100\%. Foi obtida cobertura total para o criterio all-throw neste caso, pois existe uma única instrução throw e a 


\begin{tabular}{|c|c|c|c|c|c|}
\hline propriedade & $\begin{array}{c}\text { máxima } \\
\text { profundidade }\end{array}$ & $\begin{array}{c}\text { novos } \\
\text { estados }\end{array}$ & $\begin{array}{c}\text { estados } \\
\text { revisitados }\end{array}$ & $\begin{array}{c}\text { estados } \\
\text { finais }\end{array}$ & retornos \\
\hline \hline Empty Catch & 0 & 1 & 0 & 0 & 0 \\
\hline demais & 0 & 1 & 0 & 1 & 0 \\
\hline
\end{tabular}

Tabela 5.12: Rastreamento de Estados para o programa EmptyCatchExample - Com Gerador de Escolhas

propriedade é verificada no momento de sua execução, já identificando se existe um bloco de captura vazio ou não. O bloco de captura nem chega a ser executado.

Em relação ao uso dos geradores de escolha, neste caso não fez nenhuma diferença, como pode ser observado nas tabelas de rastreamento de estados. Isto ocorre pois o gerador de escolhas atua com base na declaração de exceções lançadas por métodos executados. No exemplo somente foi executado o método main que não declara lançar nenhuma exceção. Portanto não foi gerada nenhuma escolha, como pode ser observado pelo número de retornos na Tabela 5.12 que foi zero.

\subsubsection{Programa EmptyInterruptedExceptionExample.java}

Para o programa EmptyInterruptedExceptionExample.java não foi identificada nenhuma tripla e-du nem e-ad pois não existe nenhuma exceção lançada explicitamente no código. A única exceção existente é implícita, lançada pela chamada do método Thread.sleep().

Desta forma o único trecho de código que deve ser varrido, de acordo com os critérios utilizados é a linha aonde ocorre a captura da exceção java.lang. InterruptedException conforme pode ser visto na Tabela 5.13

\begin{tabular}{|l|c|}
\hline critério & tripla e-du ou e-ad \\
\hline \hline all-throw & - \\
\hline all-catch & linha 8 \\
\hline all-e-defs & - \\
\hline all-e-use & - \\
\hline all-e-act & - \\
\hline all-e-deact & - \\
\hline
\end{tabular}

Tabela 5.13: linhas a serem percorridas para o programa EmptyInterruptedExceptionExample

Os resultados obtidos com a verificação de cada uma das propriedades encontram-se na Tabela 5.14 


\begin{tabular}{|c|c|c|c|c|c|c|c|c|}
\hline & total & \multicolumn{7}{|c|}{ triplas exercitadas } \\
\cline { 3 - 9 } critério & triplas & CE & EC & TE & TME & UE & D & NP \\
\hline \hline all-catch & 1 & 1 & 0 & 1 & 1 & 1 & 1 & 1 \\
\hline
\end{tabular}

Tabela 5.14: triplas percorridas para o programa EmptyInterruptedExceptionExample

As estatísticas de estado encontram-se na Tabela 5.15 e na Tabela 5.16.

\begin{tabular}{|c|c|c|c|c|c|}
\hline propriedade & $\begin{array}{c}\text { máxima } \\
\text { profundidade }\end{array}$ & $\begin{array}{c}\text { novos } \\
\text { estados }\end{array}$ & $\begin{array}{c}\text { estados } \\
\text { revisitados }\end{array}$ & $\begin{array}{c}\text { estados } \\
\text { finais }\end{array}$ & retornos \\
\hline \hline todas & 0 & 1 & 0 & 1 & 0 \\
\hline
\end{tabular}

Tabela 5.15: Rastreamento de Estados para o programa EmptyInterruptedExceptionExample - Sem Gerador de Escolhas

\begin{tabular}{|c|c|c|c|c|c|}
\hline propriedade & $\begin{array}{c}\text { máxima } \\
\text { profundidade }\end{array}$ & $\begin{array}{c}\text { novos } \\
\text { estados }\end{array}$ & $\begin{array}{c}\text { estados } \\
\text { revisitados }\end{array}$ & $\begin{array}{c}\text { estados } \\
\text { finais }\end{array}$ & retornos \\
\hline \hline Empty Catch & 1 & 2 & 0 & 0 & 0 \\
\hline demais & 1 & 3 & 0 & 2 & 2 \\
\hline
\end{tabular}

Tabela 5.16: Rastreamento de Estados para o programa EmptyInterruptedExceptionExample - Com Gerador de Escolhas

Neste exemplo, os resultados de cobertura só puderam ser obtidos com o uso do gerador de escolhas. Além disso, teve que ser desabilitado o filtro de classes de sistema. Por padrão, o gerador de escolhas somente simula as exceções lançadas por classes implementadas no projeto. Nesta caso, como a exceção é lançada por uma classe de sistema do próprio java (java.lang. Thread) é necessário desabilitar o filtro para que seja feita a simulação de caminhos com e sem o lançamento da exceção java.lang.InterruptedException. Caso este procedimento não seja seguido não há violação de propriedade e a cobertura é de $0 \%$ pois o bloco catch nunca é executado.

Com o uso do gerador percebe-se a violação da propriedade de bloco de captura vazio. Neste caso a cobertura continua $0 \%$ pois a propriedade é violada no momento em que a exceção é lançada, não passando pelo bloco de captura. Sem a configuração de verificação desta propriedade o programa prossegue em sua execução até o fim, exercitando a linha necessária para atingir a cobertura de $100 \%$ do critério. 


\subsubsection{Programa ExceptionNeverThrownExample.java}

Para o programa ExceptionNeverThrownExample.java foram feitos testes com duas versões do programa. Uma com violação da propriedade de "exceção declarada não lançada"e outra sem. Para a versão com violação da propriedade a seguinte tripla e-du foi identificada:

- $(\mathrm{e}, 12,13)$

Nesta versão não ocorre nenhuma tripla e-ad.

As triplas que devem ser percorridas para cada um dos critérios de teste da versão sem violação de propriedade encontram-se na Tabela 5.17

\begin{tabular}{|l|c|}
\hline critério & tripla e-du ou e-ad \\
\hline \hline all-throw & linha 34 \\
\hline all-catch & $(\mathrm{e}, 12,13)$ \\
\hline all-e-defs & $(\mathrm{e}, 12,13)$ \\
\hline all-e-use & $(\mathrm{e}, 12,13)$ \\
\hline all-e-act & - \\
\hline all-e-deact & - \\
\hline
\end{tabular}

Tabela 5.17: triplas a serem percorridas para o programa ExceptionNeverThrownExample - versão com violação de propriedade

Os resultados obtidos com a verificação de cada uma das propriedades encontram-se na Tabela 5.18

\begin{tabular}{|l|c|c|c|c|c|c|c|c|}
\hline & total & \multicolumn{7}{|c|}{ triplas exercitadas } \\
\cline { 3 - 9 } critério & triplas & CE & EC & TE & TME & UE & D & NP \\
\hline \hline all-throw & 1 & 0 & 0 & 0 & 0 & 0 & 0 & 0 \\
\hline all-catch & 1 & 1 & 1 & 1 & 1 & 1 & 1 & 1 \\
\hline all-e-defs & 1 & 1 & 1 & 1 & 1 & 1 & 1 & 1 \\
\hline all-e-use & 1 & 1 & 1 & 1 & 1 & 1 & 1 & 1 \\
\hline
\end{tabular}

Tabela 5.18: triplas percorridas para o programa ExceptionNeverThrownExample - versão com violação de propriedade

As estatísticas de estado encontram-se na Tabela 5.19 e na Tabela 5.20. 


\begin{tabular}{|c|c|c|c|c|c|}
\hline propriedade & $\begin{array}{c}\text { máxima } \\
\text { profundidade }\end{array}$ & $\begin{array}{c}\text { novos } \\
\text { estados }\end{array}$ & $\begin{array}{c}\text { estados } \\
\text { revisitados }\end{array}$ & $\begin{array}{c}\text { estados } \\
\text { finais }\end{array}$ & retornos \\
\hline \hline todas & 0 & 1 & 0 & 1 & 0 \\
\hline
\end{tabular}

Tabela 5.19: Rastreamento de Estados para o programa ExceptionNeverThrownExample - Sem Gerador de Escolhas - versão com violação de propriedade

\begin{tabular}{|c|c|c|c|c|c|}
\hline propriedade & $\begin{array}{c}\text { máxima } \\
\text { profundidade }\end{array}$ & $\begin{array}{c}\text { novos } \\
\text { estados }\end{array}$ & $\begin{array}{c}\text { estados } \\
\text { revisitados }\end{array}$ & $\begin{array}{c}\text { estados } \\
\text { finais }\end{array}$ & retornos \\
\hline \hline todas & 1 & 3 & 0 & 2 & 2 \\
\hline
\end{tabular}

Tabela 5.20: Rastreamento de Estados para o programa ExceptionNeverThrownExample - Com Gerador de Escolhas - versão com violação de propriedade

É importante observar que a cobertura só foi conseguida com o uso do gerador de escolhas. Um fato importante que pode ser obervado neste exemplo é que o uso do gerador de escolhas faz com que sejam percorridos caminhos que nunca seriam percorridos em uma execução real. Neste exemplo de código nunca é lançada nenhuma exceção, logo o bloco de captura nunca será executado. Como o gerador de escolhas simula o lançamento das exceções acaba percorrendo estes caminhos que nunca existiriam na execuçao do programa.

Para a versão sem violação da propriedade as seguintes triplas foram adicionadas.

- $\left(\operatorname{evar}_{24}, 24,24\right)$

- $\left(\right.$ evar $\left._{34}, 34,34\right)$

- evar $\left._{\text {active }}, 24,12\right),\left(\right.$ evar $\left._{\text {active }}, 34,12\right)$

- $\left(\right.$ evar $\left._{24} \rightarrow \mathrm{e}, 24,13\right)$

- $\left(\right.$ evar $\left._{34} \rightarrow \mathrm{e}, 34,13\right)$

Para a versão sem violação da propriedade as seguintes triplas e-ad foram identificadas:

- $\left(e o b j_{24}, 24,12\right)$

- $\left(e o b j_{34}, 34,12\right)$ 


\begin{tabular}{|c|c|}
\hline critério & tripla e-du ou e-ad \\
\hline -all-throw & $\left(\right.$ evar $\left._{24}, 24,24\right),\left(\right.$ evar $\left._{34}, 34,34\right)$ \\
\hline all-catch & $\begin{array}{l}\left(\text { evar }_{\text {active }}, 24,12\right) \text { ou }\left(\text { evar }_{\text {active }}, 34,12\right) \text { ou } \\
(\mathrm{e}, 12,13)\end{array}$ \\
\hline all-e-defs & $\begin{array}{l}\left(\operatorname{evar}_{24}, 24,24\right),\left(\text { evar }_{34}, 34,34\right),\left(\text { evar }_{\text {active }},\right. \\
24,12) \text { ou }\left(\text { evar }_{\text {active }}, 34,12\right),\left(\text { evar }_{24} \rightarrow \mathrm{e},\right. \\
24,13),\left(\text { evar }_{34} \rightarrow \mathrm{e}, 34,13\right),(\mathrm{e}, 12,13)\end{array}$ \\
\hline all-e-use & $\begin{array}{l}\left(\operatorname{evar}_{24}, 24,24\right),\left(\text { evar }_{34}, 34,34\right),\left(\text { evar }_{\text {active }},\right. \\
24,12),\left(\text { evar }_{\text {active }}, 34,12\right),\left(\text { evar }_{24} \rightarrow \mathrm{e}, 24,\right. \\
13),\left(\text { evar }_{34} \rightarrow \mathrm{e}, 34,13\right),(\mathrm{e}, 12,13)\end{array}$ \\
\hline all-e-act & $\left(\operatorname{eobj}_{24}, 24,12\right),\left(\right.$ eobj $\left._{34}, 34,12\right)$ \\
\hline all-e-deact & $\left(\right.$ eobj $\left._{34}, 34,12\right),\left(\right.$ eobj $\left._{34}, 34,12\right)$ \\
\hline
\end{tabular}

Tabela 5.21: triplas a serem percorridas para o programa ExceptionNeverThrownExample - versão sem violação de propriedade

As triplas que devem ser percorridas para cada um dos critérios de teste da versão com violação de propriedade encontram-se na Tabela 5.21

Os resultados obtidos com a verificação de cada uma das propriedades encontram-se na Tabela 5.22

\begin{tabular}{|l|c|c|c|c|c|c|c|c|}
\hline & total & \multicolumn{7}{|c|}{ triplas exercitadas } \\
\cline { 3 - 9 } critério & triplas & CE & EC & TE & TME & UE & D & NP \\
\hline \hline all-throw & 2 & 1 & 1 & 1 & 1 & 1 & 1 & 1 \\
\hline all-catch & 1 & 1 & 1 & 1 & 1 & 1 & 1 & 1 \\
\hline all-e-defs & 6 & 4 & 4 & 4 & 4 & 4 & 4 & 4 \\
\hline all-e-use & 7 & 4 & 4 & 4 & 4 & 4 & 4 & 4 \\
\hline all-e-act & 2 & 1 & 1 & 1 & 1 & 1 & 1 & 1 \\
\hline all-e-deact & 2 & 1 & 1 & 1 & 1 & 1 & 1 & 1 \\
\hline
\end{tabular}

Tabela 5.22: triplas percorridas para o programa ExceptionNeverThrownExample - versão sem violação de propriedade

As estatísticas de estado encontram-se na Tabela 5.23 e na Tabela 5.24.

Neste exemplo não foi possivel obter $100 \%$ de cobertura na maioria dos critérios, mesmo com o uso do gerador de escolhas. Isto ocorre pois existe uma expressão condicional que não é avaliada para todas as possíveis condições. Em um ramo são percorridas as triplas (evar $24,24,24)$, (evar active, 24, $12)$ e $\left(\right.$ evar $_{24} \rightarrow$ e, 24, 13), e em outro as triplas $\left(\right.$ evar $\left._{34}, 34,34\right)$, (evar active $\left., 34,12\right)$ e $\left(\right.$ evar $_{34} \rightarrow$ 


\begin{tabular}{|c|c|c|c|c|c|}
\hline propriedade & $\begin{array}{c}\text { máxima } \\
\text { profundidade }\end{array}$ & $\begin{array}{c}\text { novos } \\
\text { estados }\end{array}$ & $\begin{array}{c}\text { estados } \\
\text { revisitados }\end{array}$ & $\begin{array}{c}\text { estados } \\
\text { finais }\end{array}$ & retornos \\
\hline \hline todas & 0 & 1 & 0 & 1 & 0 \\
\hline
\end{tabular}

Tabela 5.23: Rastreamento de Estados para o programa ExceptionNeverThrownExample - Sem Gerador de Escolhas - versão sem violação de propriedade

\begin{tabular}{|c|c|c|c|c|c|}
\hline propriedade & $\begin{array}{c}\text { máxima } \\
\text { profundidade }\end{array}$ & $\begin{array}{c}\text { novos } \\
\text { estados }\end{array}$ & $\begin{array}{c}\text { estados } \\
\text { revisitados }\end{array}$ & $\begin{array}{c}\text { estados } \\
\text { finais }\end{array}$ & retornos \\
\hline \hline todas & 1 & 3 & 0 & 2 & 2 \\
\hline
\end{tabular}

Tabela 5.24: Rastreamento de Estados para o programa ExceptionNeverThrownExample - Com Gerador de Escolhas - versão sem violação de propriedade

e, 34, 13). A tripla (e, 12, 13) é percorrida em ambas as condições. Assim temos um máximo de 4 triplas percorridas.

Podemos observar também, que em termos de estados percorridos, não há diferença entre a versão com ou sem a violação da propriedade.

\subsubsection{Programa FinallyExample.java}

Para o programa FinallyExample.java as seguintes triplas e-du foram identificadas:

- $\left(\operatorname{evar}_{32}, 32,32\right)$

- $\left(\right.$ evar $\left._{23}, 23,23\right)$

- $\left(\right.$ evar $\left._{\text {active }}, 23,12\right)$

- $(\mathrm{e}, 12,13)$

- $\left(\right.$ evar $\left._{23} \rightarrow \mathrm{e}, 23,13\right)$

A seguinte tripla e-ad foi identificada:

- $\left(\operatorname{eobj}_{23}, 23,12\right)$

As triplas que devem ser percorridas para cada um dos critérios de teste encontram-se na Tabela 5.25 


\begin{tabular}{|l|c|}
\hline critério & tripla e-du ou e-ad \\
\hline \hline all-throw & $\left(\right.$ evar $\left._{32}, 32,32\right),\left(\right.$ evar $\left._{23}, 23,23\right)$ ou $\left(\right.$ evar $\left._{\text {active }}, 23,12\right)$ ou $\left(\right.$ evar $\left._{23} \rightarrow \mathrm{e}, 23,13\right)$ \\
\hline all-catch & $(\mathrm{e}, 12,13)$ ou $\left(\right.$ evar $\left._{\text {active }}, 23,12\right)$ \\
\hline all-e-defs & $\left(\right.$ evar $\left._{32}, 32,32\right),\left(\right.$ evar $\left._{23}, 23,23\right),\left(\right.$ evar $\left._{\text {active }}, 23,12\right),(\mathrm{e}, 12,13),\left(\right.$ evar $\left._{23} \rightarrow \mathrm{e}, 23,13\right)$ \\
\hline all-e-use & $\left(\right.$ evar $\left._{32}, 32,32\right),\left(\right.$ evar $\left._{23}, 23,23\right),\left(\right.$ evar $\left._{\text {active }}, 23,12\right),(\mathrm{e}, 12,13),\left(\right.$ evar $\left._{23} \rightarrow \mathrm{e}, 23,13\right)$ \\
\hline all-e-act & $\left(\right.$ eobj $\left._{23}, 23,12\right)$ \\
\hline all-e-deact & $\left(\right.$ eobj $\left._{23}, 23,12\right)$ \\
\hline
\end{tabular}

Tabela 5.25: triplas a serem percorridas para o programa FinallyExample

Os resultados obtidos com a verificação de cada uma das propriedades encontram-se na Tabela 5.26

\begin{tabular}{|l|c|c|c|c|c|c|c|c|}
\hline & total & \multicolumn{8}{|c|}{ triplas exercitadas } \\
\cline { 3 - 9 } critério & triplas & CE & EC & TE & TME & UE & D & NP \\
\hline \hline all-throw & 2 & 2 & 2 & 2 & 2 & 2 & 2 & 2 \\
\hline all-catch & 1 & 1 & 1 & 1 & 1 & 1 & 1 & 1 \\
\hline all-e-defs & 5 & 5 & 5 & 5 & 5 & 5 & 5 & 5 \\
\hline all-e-use & 5 & 5 & 5 & 5 & 5 & 5 & 5 & 5 \\
\hline all-e-act & 1 & 1 & 1 & 1 & 1 & 1 & 1 & 1 \\
\hline all-e-deact & 1 & 1 & 1 & 1 & 1 & 1 & 1 & 1 \\
\hline
\end{tabular}

Tabela 5.26: triplas percorridas para o programa FinallyExample

As estatísticas de estado encontram-se na Tabela 5.27 e na Tabela 5.28.

\begin{tabular}{|c|c|c|c|c|c|}
\hline propriedade & $\begin{array}{c}\text { máxima } \\
\text { profundidade }\end{array}$ & $\begin{array}{c}\text { novos } \\
\text { estados }\end{array}$ & $\begin{array}{c}\text { estados } \\
\text { revisitados }\end{array}$ & $\begin{array}{c}\text { estados } \\
\text { finais }\end{array}$ & retornos \\
\hline \hline Uncaught Exception & 0 & 0 & 1 & 0 & 0 \\
\hline demais & 0 & 0 & 1 & 0 & 0 \\
\hline
\end{tabular}

Tabela 5.27: Rastreamento de Estados para o programa FinallyExample - Sem Gerador de Escolhas

Neste exemplo houve uma grande variação de cobertura devido às expressões condicionais existentes no código. A cobertura apresentada na Tabela 5.26 se refere ao melhor resultado encontrado. O pior resultado encontrado com o uso de gerador de escolhas foi de 1 tripla varrida e o pior resultado sem o gerador foi de nenhuma tripla varrida. O melhor resultado, com $100 \%$ de cobertura pode ser encontrado em ambas as configurações. 


\begin{tabular}{|c|c|c|c|c|c|}
\hline $\begin{array}{c}\text { máxima } \\
\text { propriedade }\end{array}$ & $\begin{array}{c}\text { novos } \\
\text { profundidade }\end{array}$ & $\begin{array}{c}\text { estados } \\
\text { estados }\end{array}$ & $\begin{array}{c}\text { estados } \\
\text { revisitados }\end{array}$ & retornos \\
\hline \hline Uncaught Exception & 1 & 2 & 1 & 1 & 1 \\
\hline demais & 1 & 3 & 0 & 2 & 2 \\
\hline
\end{tabular}

Tabela 5.28: Rastreamento de Estados para o programa FinallyExample - Com Gerador de Escolhas

Outro resultado que vale a pena comentar refere-se a tabela de rastreamento de estados. Devido a um bug na implementação da ferramenta JPF é reportado 1 estado revisitado sem a existência de nenhum estado novo. Isto ocorre nas situações em que o programa lança uma exceção não capturada a partir do método main. Internamente no JPF não é gerado nenhum estado, porém, no código de implementação da contabilização, o contador de estados revisitados é incrementado em uma instrução else de uma condicional if-else quando o estado não é nem final, nem novo.

\subsubsection{Programa LogRethrowExceptionExample.java}

Para o programa LogRethrowExceptionExample.java as seguintes triplas e-du foram identificadas:

- $($ te1, 15, 16)

- (te2, 23, 24), (te2, 23, 25)

- $($ te $2 \rightarrow$ te $1,23,16)$

- $\left(\operatorname{evar}_{30}, 30,30\right)$

- $\left(\right.$ evar $\left._{30} \rightarrow \mathrm{te} 2,30,24\right),\left(\right.$ evar $\left._{30} \rightarrow \mathrm{te} 2,30,25\right)$

- $\left(\right.$ evar $\left._{\text {active }}, 30,23\right),\left(\right.$ evar $\left._{\text {active }}, 25,15\right)$

As seguintes triplas e-ad foram identificadas:

- $\left(e^{o b j} j_{30}, 30,23\right)$

- $\left(e o b j_{25}, 25,15\right)$

As triplas que devem ser percorridas para cada um dos critérios de teste encontram-se na Tabela 5.29 


\begin{tabular}{|c|c|}
\hline critério & tripla e-du ou e-ad \\
\hline / all-throw & $\begin{array}{l}(\mathrm{te} 2,23,25) \text { ou }\left(\text { evar }_{\text {active }}, 25,15\right), \\
\left(\text { evar }_{30}, 30,30\right) \text { ou }\left(\text { evar }_{30} \rightarrow \mathrm{te} 2,30,24\right) \text { ou } \\
\left(\text { evar }_{30} \rightarrow \mathrm{te} 2,30,25\right) \text { ou }\left(\text { evar }_{\text {active }}, 30,23\right)\end{array}$ \\
\hline all-catch & $\begin{array}{l}(\text { te } 1,15,16) \text { ou }\left(\text { evar }_{\text {active }}, 25,15\right),(\text { te } 2,23, \\
24) \text { ou }(\text { te } 2,23,25) \text { ou }(\text { te } 2 \rightarrow \text { te } 1,23,16) \text { ou } \\
\left(\text { evar }_{\text {active }}, 30,23\right)\end{array}$ \\
\hline all-e-defs & $\begin{array}{l}(\text { te } 1,15,16),(\text { te } 2,23,24) \text { ou }(\text { te } 2,23, \\
25),(\text { te } 2 \rightarrow \text { te } 1,23,16), \quad\left(\text { evar }_{30}, 30,30\right), \\
\left(\text { evar }_{30} \rightarrow \text { te } 2,30,24\right) \text { ou }\left(\text { evar }_{30} \rightarrow \text { te } 2,30,\right. \\
25),\left(\text { evar }_{\text {active }}, 30,23\right),\left(\text { evar }_{\text {active }}, 25,15\right)\end{array}$ \\
\hline all-e-use & 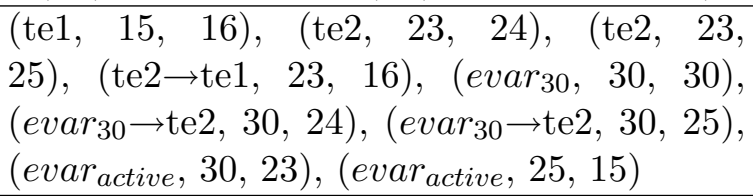 \\
\hline all-e-act & $\left(\operatorname{eobj}_{30}, 30,23\right),\left(\operatorname{eobj}_{25}, 25,15\right)$ \\
\hline all-e-deact & $\left(\operatorname{eobj}_{30}, 30,23\right),\left(\operatorname{eobj}_{25}, 25,15\right)$ \\
\hline
\end{tabular}

Tabela 5.29: triplas a serem percorridas para o programa LogRethrowExceptionExample

Os resultados obtidos com a verificação de cada uma das propriedades encontram-se na Tabela 5.30

\begin{tabular}{|l|c|c|c|c|c|c|c|c|}
\hline & total & \multicolumn{7}{|c|}{ triplas exercitadas } \\
\cline { 3 - 9 } critério & triplas & CE & EC & TE & TME & UE & D & NP \\
\hline \hline all-throw & 2 & 2 & 2 & 2 & 2 & 2 & 2 & 2 \\
\hline all-catch & 2 & 2 & 2 & 2 & 2 & 2 & 2 & 2 \\
\hline all-e-defs & 7 & 7 & 7 & 7 & 7 & 7 & 7 & 7 \\
\hline all-e-use & 9 & 9 & 9 & 9 & 9 & 9 & 9 & 9 \\
\hline all-e-act & 2 & 2 & 2 & 2 & 2 & 2 & 2 & 2 \\
\hline all-e-deact & 2 & 2 & 2 & 2 & 2 & 2 & 2 & 2 \\
\hline
\end{tabular}

Tabela 5.30: triplas percorridas para o programa LogRethrowExceptionExample

As estatísticas de estado encontram-se na Tabela 5.31 e na Tabela 5.32.

Neste exemplo foi atingida cobertura de 100\% mesmo sem a utilização do gerador de escolhas. Isto ocorre porque no programa, em uma única execução são lançadas todas as exceções, não sendo necessário simular o lançamento das exceções pelo gerador de escolhas. 


\begin{tabular}{|c|c|c|c|c|c|}
\hline propriedade & $\begin{array}{c}\text { máxima } \\
\text { profundidade }\end{array}$ & $\begin{array}{c}\text { novos } \\
\text { estados }\end{array}$ & $\begin{array}{c}\text { estados } \\
\text { revisitados }\end{array}$ & $\begin{array}{c}\text { estados } \\
\text { finais }\end{array}$ & retornos \\
\hline \hline todas & 0 & 1 & 0 & 1 & 0 \\
\hline
\end{tabular}

Tabela 5.31: Rastreamento de Estados para o programa LogRethrowExceptionExample - Sem Gerador de Escolhas

\begin{tabular}{|c|c|c|c|c|c|}
\hline propriedade & $\begin{array}{c}\text { máxima } \\
\text { profundidade }\end{array}$ & $\begin{array}{c}\text { novos } \\
\text { estados }\end{array}$ & $\begin{array}{c}\text { estados } \\
\text { revisitados }\end{array}$ & $\begin{array}{c}\text { estados } \\
\text { finais }\end{array}$ & retornos \\
\hline \hline todas & 1 & 4 & 1 & 2 & 4 \\
\hline
\end{tabular}

Tabela 5.32: Rastreamento de Estados para o programa LogRethrowExceptionExample - Com Gerador de Escolhas

\subsubsection{Programa LogReturnNullExample.java}

Para o programa LogReturnNullExample.java as seguintes triplas e-du foram identificadas:

- $(\mathrm{e}, 20,21)$

- $\left(\right.$ evar $\left._{34}, 34,34\right)$

- $\left(\operatorname{evar}_{34} \rightarrow \mathrm{e}, 34,21\right)$

- $\left(\right.$ evar $\left._{\text {active }}, 34,20\right)$

A seguinte tripla e-ad foi identificada:

- $\left(e o b j_{34}, 34,20\right)$

As triplas que devem ser percorridas para cada um dos critérios de teste encontram-se na Tabela 5.33

Os resultados obtidos com a verificação de cada uma das propriedades encontram-se na Tabela 5.34

As estatísticas de estado encontram-se na Tabela 5.35 e na Tabela 5.36.

Neste exemplo, existem condicionais no código do programa que fazem com que a cobertura varie de 0 a $100 \%$. Com o uso do gerador de escolhas temos no mínimo 1 tripla percorrida. 


\begin{tabular}{|l|c|}
\hline critério & tripla e-du ou e-ad \\
\hline \hline all-throw & $\left(\right.$ evar $\left._{34}, 34,34\right)$ ou $\left(\right.$ evar $\left._{34} \rightarrow \mathrm{e}, 34,21\right)$ ou $\left(\right.$ evar $\left._{\text {active }}, 34,20\right)$ \\
\hline all-catch & $(\mathrm{e}, 20,21)$ ou $\left(\right.$ evar $\left._{\text {active }}, 34,20\right)$ \\
\hline all-e-defs & $(\mathrm{e}, 20,21),\left(\right.$ evar $\left._{34}, 34,34\right),\left(\right.$ evar $\left._{34} \rightarrow \mathrm{e}, 34,21\right),\left(\right.$ evar $\left._{\text {active }}, 34,20\right)$ \\
\hline all-e-use & $(\mathrm{e}, 20,21),\left(\right.$ evar $\left._{34}, 34,34\right),\left(\right.$ evar $\left._{34} \rightarrow \mathrm{e}, 34,21\right),\left(\right.$ evar $\left._{a c t i v e}, 34,20\right)$ \\
\hline all-e-act & $\left(\right.$ eobj $\left._{34}, 34,20\right)$ \\
\hline all-e-deact & $\left(\right.$ eobj $\left._{34}, 34,20\right)$ \\
\hline
\end{tabular}

Tabela 5.33: triplas a serem percorridas para o programa LogReturnNullExample

\begin{tabular}{|l|c|c|c|c|c|c|c|c|}
\hline & total & \multicolumn{7}{|c|}{ triplas exercitadas } \\
\cline { 3 - 9 } critério & triplas & CE & EC & TE & TME & UE & D & NP \\
\hline \hline all-throw & 1 & 1 & 1 & 1 & 1 & 1 & 1 & 1 \\
\hline all-catch & 1 & 1 & 1 & 1 & 1 & 1 & 1 & 1 \\
\hline all-e-defs & 4 & 4 & 4 & 4 & 4 & 4 & 4 & 4 \\
\hline all-e-use & 4 & 4 & 4 & 4 & 4 & 4 & 4 & 4 \\
\hline all-e-act & 1 & 1 & 1 & 1 & 1 & 1 & 1 & 1 \\
\hline all-e-deact & 1 & 1 & 1 & 1 & 1 & 1 & 1 & 1 \\
\hline
\end{tabular}

Tabela 5.34: triplas percorridas para o programa LogReturnNullExample

\subsubsection{Programa LostCauseExample.java}

Para o programa LostCauseExample.java as seguintes triplas e-du foram identificadas:

- (te, 11,12$)$

- $(\mathrm{re} 1,20,21)$

- $($ re2, 28, 29)

- $\left(\operatorname{evar}_{21}, 21,21\right)$

- $\left(\right.$ evar $_{21} \rightarrow$ te, 21,12$)$

\begin{tabular}{|c|c|c|c|c|c|}
\hline propriedade & $\begin{array}{c}\text { máxima } \\
\text { profundidade }\end{array}$ & $\begin{array}{c}\text { novos } \\
\text { estados }\end{array}$ & $\begin{array}{c}\text { estados } \\
\text { revisitados }\end{array}$ & $\begin{array}{c}\text { estados } \\
\text { finais }\end{array}$ & retornos \\
\hline \hline todas & 0 & 1 & 0 & 1 & 0 \\
\hline
\end{tabular}

Tabela 5.35: Rastreamento de Estados para o programa LogReturnNullExample - Sem Gerador de Escolhas 


\begin{tabular}{|c|c|c|c|c|c|}
\hline propriedade & $\begin{array}{c}\text { máxima } \\
\text { profundidade }\end{array}$ & $\begin{array}{c}\text { novos } \\
\text { estados }\end{array}$ & $\begin{array}{c}\text { estados } \\
\text { revisitados }\end{array}$ & $\begin{array}{c}\text { estados } \\
\text { finais }\end{array}$ & retornos \\
\hline \hline todas & 1 & 3 & 0 & 2 & 2 \\
\hline
\end{tabular}

Tabela 5.36: Rastreamento de Estados para o programa LogReturnNullExample - Com Gerador de Escolhas

- $\left(\right.$ evar $\left._{29}, 29,29\right)$

- $\left(\operatorname{evar}_{29} \rightarrow \mathrm{re} 1,29,21\right)$

- $\left(\right.$ evar $\left._{\text {active }}, 29,20\right),\left(\right.$ evar $\left._{\text {active }}, 21,11\right)$

As seguintes triplas e-ad foram identificadas:

- $\left(\operatorname{eobj}_{21}, 21,11\right)$

- $\left(e o b j_{29}, 29,20\right)$

As triplas que devem ser percorridas para cada um dos critérios de teste encontram-se na Tabela 5.37

\begin{tabular}{|c|c|}
\hline critério & tripla e-du ou e-ad \\
\hline all-throw & 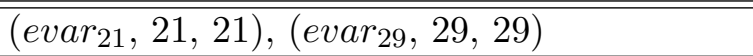 \\
\hline all-catch & $\begin{array}{l}\left.\text { (te,11,12), (re2, 28, 29), (evar }{ }_{\text {active }}, 29,20\right) \\
\text { ou }(\text { re1, 20, 21) }\end{array}$ \\
\hline all-e-defs & $\begin{array}{l}\left(\text { te }_{11,12}\right),(\mathrm{re} 1,20,21), \quad(\mathrm{re} 2,28,29), \\
\left(\text { evar }_{21}, 21,21\right), \quad\left(\text { evar }_{21} \rightarrow \mathrm{te}, 21,12\right), \\
\left(\text { evar }_{29}, 29,29\right), \quad\left(\text { evar }_{29} \rightarrow \mathrm{re} 1,29,21\right), \\
\left(\text { evar }_{\text {active }}, 29,20\right) \text { ou }\left(\text { evar }_{\text {active }}, 21,11\right)\end{array}$ \\
\hline all-e-use & 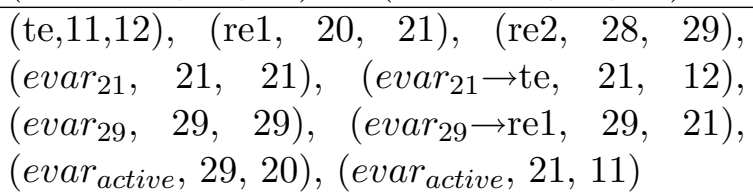 \\
\hline all-e-act & $\left(\operatorname{eobj}_{21}, 21,11\right),\left(e o b j_{29}, 29,20\right)$ \\
\hline all-e-deact & $\left(\operatorname{eobj}_{21}, 21,11\right),\left(\operatorname{eobj}_{29}, 29,20\right)$ \\
\hline
\end{tabular}

Tabela 5.37: triplas a serem percorridas para o programa LostCauseExample

Os resultados obtidos com a verificação de cada uma das propriedades encontram-se na Tabela 5.38 


\begin{tabular}{|l|c|c|c|c|c|c|c|c|}
\hline & total & \multicolumn{7}{|c|}{ triplas exercitadas } \\
\cline { 3 - 9 } critério & triplas & CE & EC & TE & TME & UE & D & NP \\
\hline \hline all-throw & 2 & 2 & 2 & 2 & 2 & 2 & 2 & 2 \\
\hline all-catch & 3 & 3 & 3 & 3 & 3 & 3 & 3 & 3 \\
\hline all-e-defs & 8 & 8 & 8 & 8 & 8 & 8 & 8 & 8 \\
\hline all-e-use & 9 & 9 & 9 & 9 & 9 & 9 & 9 & 9 \\
\hline all-e-act & 2 & 2 & 2 & 2 & 2 & 2 & 2 & 2 \\
\hline all-e-deact & 2 & 2 & 2 & 2 & 2 & 2 & 2 & 2 \\
\hline
\end{tabular}

Tabela 5.38: triplas percorridas para o programa LostCauseExample

As estatísticas de estado encontram-se na Tabela 5.39 e na Tabela 5.40.

\begin{tabular}{|c|c|c|c|c|c|}
\hline propriedade & $\begin{array}{c}\text { máxima } \\
\text { profundidade }\end{array}$ & $\begin{array}{c}\text { novos } \\
\text { estados }\end{array}$ & $\begin{array}{c}\text { estados } \\
\text { revisitados }\end{array}$ & $\begin{array}{c}\text { estados } \\
\text { finais }\end{array}$ & retornos \\
\hline \hline todas & 0 & 1 & 0 & 1 & 0 \\
\hline
\end{tabular}

Tabela 5.39: Rastreamento de Estados para o programa LostCauseExample - Sem Gerador de Escolhas

\begin{tabular}{|c|c|c|c|c|c|}
\hline propriedade & $\begin{array}{c}\text { máxima } \\
\text { profundidade }\end{array}$ & $\begin{array}{c}\text { novos } \\
\text { estados }\end{array}$ & $\begin{array}{c}\text { estados } \\
\text { revisitados }\end{array}$ & $\begin{array}{c}\text { estados } \\
\text { finais }\end{array}$ & retornos \\
\hline \hline Uncaught Exception & 1 & 2 & 0 & 1 & 0 \\
\hline demais & 1 & 3 & 0 & 2 & 2 \\
\hline
\end{tabular}

Tabela 5.40: Rastreamento de Estados para o programa LostCauseExample - Com Gerador de Escolhas

Neste exemplo pode-se observar um efeito colateral do uso do gerador de escolhas. Com o seu uso ocorreu uma violação de propriedade que não ocorre sem o seu uso. Esta violação não ocorre por causa da execução de um novo caminho, não exercitado anteriormente no código, onde a violação existe, mas sim é introduzida pelo próprio gerador de escolhas. Para este código em particular, o tratamento da exceção envolve extrair e processar o objeto retornado através do método getCause (linha 12). Como a exceção foi lançada artificialmente através do gerador, o valor retornado pelo método é null, o que acaba gerando uma exceção NullPointerException na linha seguinte que não é tratada. Isto viola a propriedade de não existência de exceção não tratada. Desabilitando a verificação desta propriedade o código é executado normalmente. 


\subsubsection{Programa MultipleLogExample.java}

Para o programa MultipleLogExample.java as seguintes triplas e-du foram identificadas:

- $(\mathrm{e}, 15,17)$

- $\left(\operatorname{evar}_{22}, 22,22\right)$

- $\left(\operatorname{evar}_{22} \rightarrow \mathrm{e}, 22,17\right)$

- $\left(\right.$ evar $\left._{\text {active }}, 22,15\right)$

A seguinte tripla e-ad foi identificada:

- $\left(e o b j_{22}, 22,15\right)$

As triplas que devem ser percorridas para cada um dos critérios de teste encontram-se na Tabela 5.41

\begin{tabular}{|l|l|}
\hline critério & tripla e-du ou e-ad \\
\hline \hline all-throw & $\left(\right.$ evar $\left._{22}, 22,22\right)$ \\
\hline all-catch & $(\mathrm{e}, 15,17)$ ou $\left(\right.$ evar $\left._{\text {active }}, 22,15\right)$ \\
\hline all-e-defs & $(\mathrm{e}, 15,17),\left(\right.$ evar $\left._{22}, 22,22\right),\left(\right.$ evar $_{22} \rightarrow \mathrm{e}, 22$, \\
& $17),\left(\right.$ evar $\left._{\text {active }}, 22,15\right)$ \\
\hline all-e-use & $(\mathrm{e}, 15,17),\left(\right.$ evar $\left._{22}, 22,22\right),\left(\right.$ evar $_{22} \rightarrow \mathrm{e}, 22$, \\
& $17),\left(\right.$ evar $\left._{\text {active }}, 22,15\right)$ \\
\hline all-e-act & $\left(\right.$ eobj $\left._{22}, 22,15\right)$ \\
\hline all-e-deact & $\left(\right.$ eobj $\left._{22}, 22,15\right)$ \\
\hline
\end{tabular}

Tabela 5.41: triplas a serem percorridas para o programa MultipleLogExample

Os resultados obtidos com a verificação de cada uma das propriedades encontram-se na Tabela 5.42

As estatísticas de estado encontram-se na Tabela 5.43 e na Tabela 5.44.

Para este exemplo foi obtida cobertura total mesmo sem o uso do gerador de escolhas. Isto ocorre pois na execução normal do programa já são lançadas todas as exceções, não sendo necessário simular seu lançamento com o gerador de escolhas. 


\begin{tabular}{|l|c|c|c|c|c|c|c|c|}
\hline & total & \multicolumn{7}{|c|}{ triplas exercitadas } \\
\cline { 3 - 9 } critério & triplas & CE & EC & TE & TME & UE & D & NP \\
\hline \hline all-throw & 1 & 1 & 1 & 1 & 1 & 1 & 1 & 1 \\
\hline all-catch & 1 & 1 & 1 & 1 & 1 & 1 & 1 & 1 \\
\hline all-e-defs & 4 & 4 & 4 & 4 & 4 & 4 & 4 & 4 \\
\hline all-e-use & 4 & 4 & 4 & 4 & 4 & 4 & 4 & 4 \\
\hline all-e-act & 1 & 1 & 1 & 1 & 1 & 1 & 1 & 1 \\
\hline all-e-deact & 1 & 1 & 1 & 1 & 1 & 1 & 1 & 1 \\
\hline
\end{tabular}

Tabela 5.42: triplas percorridas para o programa MultipleLogExample

\begin{tabular}{|c|c|c|c|c|c|}
\hline propriedade & $\begin{array}{c}\text { máxima } \\
\text { profundidade }\end{array}$ & $\begin{array}{c}\text { novos } \\
\text { estados }\end{array}$ & $\begin{array}{c}\text { estados } \\
\text { revisitados }\end{array}$ & $\begin{array}{c}\text { estados } \\
\text { finais }\end{array}$ & retornos \\
\hline \hline todas & 0 & 1 & 0 & 1 & 0 \\
\hline
\end{tabular}

Tabela 5.43: Rastreamento de Estados para o programa MultipleLogExample - Sem Gerador de Escolhas

\subsubsection{Programa ThrowExceptionExample.java}

Para o programa ThrowExceptionExample.java a seguinte tripla e-du foi identificada:

- $(\mathrm{e}, 11,12)$

Nenhuma tripla e-ad foi identificada.

As triplas que devem ser percorridas para cada um dos critérios de teste encontram-se na Tabela 5.45

Os resultados obtidos com a verificação de cada uma das propriedades encontram-se na Tabela 5.46

As estatísticas de estado encontram-se na Tabela 5.47 e na Tabela 5.48.

\begin{tabular}{|c|c|c|c|c|c|}
\hline propriedade & $\begin{array}{c}\text { máxima } \\
\text { profundidade }\end{array}$ & $\begin{array}{c}\text { novos } \\
\text { estados }\end{array}$ & $\begin{array}{c}\text { estados } \\
\text { revisitados }\end{array}$ & $\begin{array}{c}\text { estados } \\
\text { finais }\end{array}$ & retornos \\
\hline \hline todas & 1 & 2 & 1 & 1 & 2 \\
\hline
\end{tabular}

Tabela 5.44: Rastreamento de Estados para o programa MultipleLogExample - Com Gerador de Escolhas 


\begin{tabular}{|l|l|}
\hline critério & tripla e-du ou e-ad \\
\hline \hline all-throw & - \\
\hline all-catch & $(\mathrm{e}, 11,12)$ \\
\hline all-e-defs & $(\mathrm{e}, 11,12)$ \\
\hline all-e-use & $(\mathrm{e}, 11,12)$ \\
\hline all-e-act & - \\
\hline all-e-deact & - \\
\hline
\end{tabular}

Tabela 5.45: triplas a serem percorridas para o programa ThrowExceptionExample

\begin{tabular}{|l|c|c|c|c|c|c|c|c|}
\hline & total & \multicolumn{7}{|c|}{ triplas exercitadas } \\
\cline { 3 - 9 } critério & triplas & CE & EC & TE & TME & UE & D & NP \\
\hline \hline all-catch & 1 & 0 & 1 & 0 & 1 & 1 & 1 & 1 \\
\hline all-e-defs & 1 & 0 & 1 & 0 & 1 & 1 & 1 & 1 \\
\hline all-e-use & 1 & 0 & 1 & 0 & 1 & 1 & 1 & 1 \\
\hline
\end{tabular}

Tabela 5.46: triplas percorridas para o programa ThrowExceptionExample

Neste exemplo, a cobertura de $100 \%$ só foi obtida com o uso do gerador de escolhas e sem a verificação das propriedades violadas. Com a violação das propriedades, a execução do código é abortada antes de passar pela tripla desejada. Sem o gerador de escolhas a tripla também não é varrida pois a exceção nunca é lançada, portanto é necessário simular seu lançamento.

\subsubsection{Programa ThrowsManyExample.java}

Para o programa ThrowsManyExample.java a seguinte triplas e-du foi identificada:

- $(\mathrm{e}, 18,19)$

Nenhuma tripla e-ad foi identificada.

\begin{tabular}{|c|c|c|c|c|c|}
\hline propriedade & $\begin{array}{c}\text { máxima } \\
\text { profundidade }\end{array}$ & $\begin{array}{c}\text { novos } \\
\text { estados }\end{array}$ & $\begin{array}{c}\text { estados } \\
\text { revisitados }\end{array}$ & $\begin{array}{c}\text { estados } \\
\text { finais }\end{array}$ & retornos \\
\hline \hline Catch Exception & 0 & 1 & 0 & 0 & 0 \\
\hline Throw Exception & 0 & 1 & 0 & 0 & 0 \\
\hline demais & 0 & 1 & 0 & 1 & 0 \\
\hline
\end{tabular}

Tabela 5.47: Rastreamento de Estados para o programa ThrowExceptionExample - Sem Gerador de Escolhas 


\begin{tabular}{|c|c|c|c|c|c|}
\hline propriedade & $\begin{array}{c}\text { máxima } \\
\text { profundidade }\end{array}$ & $\begin{array}{c}\text { novos } \\
\text { estados }\end{array}$ & $\begin{array}{c}\text { estados } \\
\text { revisitados }\end{array}$ & $\begin{array}{c}\text { estados } \\
\text { finais }\end{array}$ & retornos \\
\hline \hline Catch Exception & 0 & 1 & 0 & 0 & 0 \\
\hline Throw Exception & 0 & 1 & 0 & 0 & 0 \\
\hline demais & 1 & 4 & 1 & 2 & 4 \\
\hline
\end{tabular}

Tabela 5.48: Rastreamento de Estados para o programa ThrowExceptionExample - Com Gerador de Escolhas

As triplas que devem ser percorridas para cada um dos critérios de teste encontram-se na Tabela 5.49

\begin{tabular}{|l|l|}
\hline critério & tripla e-du ou e-ad \\
\hline \hline all-throw & - \\
\hline all-catch & $(\mathrm{e}, 18,19)$, linha 26, linha 28, linha 30 \\
\hline all-e-defs & $(\mathrm{e}, 18,19)$ \\
\hline all-e-use & $(\mathrm{e}, 18,19)$ \\
\hline all-e-act & - \\
\hline all-e-deact & - \\
\hline
\end{tabular}

Tabela 5.49: triplas a serem percorridas para o programa ThrowsManyExample

Os resultados obtidos com a verificação de cada uma das propriedades encontram-se na Tabela 5.50

\begin{tabular}{|l|c|c|c|c|c|c|c|c|}
\hline & total & \multicolumn{8}{|c|}{ triplas exercitadas } \\
\cline { 3 - 9 } critério & triplas & CE & EC & TE & TME & UE & D & NP \\
\hline \hline all-catch & 4 & 0 & 4 & 4 & 0 & 4 & 4 & 4 \\
\hline all-e-defs & 1 & 0 & 1 & 1 & 0 & 1 & 1 & 1 \\
\hline all-e-use & 1 & 0 & 1 & 1 & 0 & 1 & 1 & 1 \\
\hline
\end{tabular}

Tabela 5.50: triplas percorridas para o programa ThrowsManyExample

As estatísticas de estado encontram-se na Tabela 5.51 e na Tabela 5.52.

Neste exemplo, de forma semelhante ao exemplo anterior, a cobertura de $100 \%$ só foi obtida com o uso do gerador de escolhas e sem a verificação das propriedades violadas. Com a violação das propriedades, a execução do código é abortada antes de passar pela tripla desejada. Sem o gerador de escolhas a tripla também não é varrida pois a exceção nunca é lançada, portanto é necessário simular seu lançamento. 


\begin{tabular}{|c|c|c|c|c|c|}
\hline propriedade & $\begin{array}{c}\text { máxima } \\
\text { profundidade }\end{array}$ & $\begin{array}{c}\text { novos } \\
\text { estados }\end{array}$ & $\begin{array}{c}\text { estados } \\
\text { revisitados }\end{array}$ & $\begin{array}{c}\text { estados } \\
\text { finais }\end{array}$ & retornos \\
\hline \hline Catch Exception & 0 & 1 & 0 & 0 & 0 \\
\hline Throws Many Exceptions & 0 & 1 & 0 & 0 & 0 \\
\hline demais & 0 & 1 & 0 & 1 & 0 \\
\hline
\end{tabular}

Tabela 5.51: Rastreamento de Estados para o programa ThrowsManyExample - Sem Gerador de Escolhas

\begin{tabular}{|c|c|c|c|c|c|}
\hline propriedade & $\begin{array}{c}\text { máxima } \\
\text { profundidade }\end{array}$ & $\begin{array}{c}\text { novos } \\
\text { estados }\end{array}$ & $\begin{array}{c}\text { estados } \\
\text { revisitados }\end{array}$ & $\begin{array}{c}\text { estados } \\
\text { finais }\end{array}$ & retornos \\
\hline \hline Catch Exception & 1 & 2 & 0 & 0 & 0 \\
\hline Throws Many Exceptions & 1 & 2 & 0 & 0 & 0 \\
\hline demais & 1 & 12 & 9 & 7 & 20 \\
\hline
\end{tabular}

Tabela 5.52: Rastreamento de Estados para o programa ThrowsManyExample - Com Gerador de Escolhas

Também foi possivel observar que o número de estados gerados neste exemplo foi bem maior do que nos anteriores. Isto ocorre pois os métodos deste programa declaram o lançamento de várias exceções, o que faz com que o gerador de escolhas simule todos os lançamentos.

Os testes foram feitos com uma configuração para o número máximo de exceções com o valor 2.

\subsubsection{Programa UncaughtExceptionExample.java}

Para o programa UncaughtExceptionExample.java a seguinte tripla e-du foi identificada:

- $\left(\operatorname{evar}_{18}, 18,18\right)$

Nenhuma tripla e-ad foi identificada.

As triplas que devem ser percorridas para cada um dos critérios de teste encontram-se na Tabela 5.53

Os resultados obtidos com a verificação de cada uma das propriedades encontram-se na Tabela 5.54

As estatísticas de estado encontram-se na Tabela 5.55 e na Tabela 5.56.

Neste exemplo, para o caso onde ocorre violação da propriedade, a execução com gerador de escolhas apresenta um resultado pior de cobertura. Sem o gerador de escolhas a cobertura varia 


\begin{tabular}{|l|l|}
\hline critério & tripla e-du ou e-ad \\
\hline \hline all-throw & $\left(\right.$ evar $\left._{18}, 18,18\right)$ \\
\hline all-catch & - \\
\hline all-e-defs & $\left(\right.$ evar $\left._{18}, 18,18\right)$ \\
\hline all-e-use & $\left(\right.$ evar $\left._{18}, 18,18\right)$ \\
\hline all-e-act & - \\
\hline all-e-deact & - \\
\hline
\end{tabular}

Tabela 5.53: triplas a serem percorridas para o programa UncaughtExceptionExample

\begin{tabular}{|l|c|c|c|c|c|c|c|c|}
\hline & total & \multicolumn{8}{|c|}{ triplas exercitadas } \\
\cline { 3 - 9 } critério & triplas & CE & EC & TE & TME & UE & D & NP \\
\hline \hline all-throw & 1 & 1 & 1 & 1 & 1 & 1 & 1 & 1 \\
\hline all-e-defs & 1 & 1 & 1 & 1 & 1 & 1 & 1 & 1 \\
\hline all-e-use & 1 & 1 & 1 & 1 & 1 & 1 & 1 & 1 \\
\hline
\end{tabular}

Tabela 5.54: triplas percorridas para o programa UncaughtExceptionExample

entre 0 e $100 \%$ devido à condicional presente no código. Com o gerador ela fica sempre em $0 \%$ pois a propriedade é violada na simulação do lançamento da exceção, sem que a linha de lançamento da exceção tenha sido executada.

Se desabilitarmos a verificação da propriedade os resultados de cobertura são iguais, tanto com o uso do gerador quanto sem. A cobertura varia entre 0 e $100 \%$ devido à condicional presente no código.

\subsection{Conclusões Preliminares}

Os programas utilizados possuem um código simples, com vários deles executando todas as instruções em uma única execução do código. Mesmo assim, eles tiveram uma variação de características que foi o suficiente para levantar-se vários fatos relevantes.

\begin{tabular}{|c|c|c|c|c|c|}
\hline $\begin{array}{c}\text { máxima } \\
\text { propriedade }\end{array}$ & $\begin{array}{c}\text { novos } \\
\text { profundidade }\end{array}$ & $\begin{array}{c}\text { estados } \\
\text { estados }\end{array}$ & $\begin{array}{c}\text { estados } \\
\text { revisitados }\end{array}$ & retornos \\
\hline \hline Uncaught Exception & 0 & 0 & 1 & 0 & 0 \\
\hline demais & 0 & 0 & 1 & 0 & 0 \\
\hline
\end{tabular}

Tabela 5.55: Rastreamento de Estados para o programa UncaughtExceptionExample - Sem Gerador de Escolhas 


\begin{tabular}{|c|c|c|c|c|c|}
\hline $\begin{array}{c}\text { máxima } \\
\text { propriedade }\end{array}$ & $\begin{array}{c}\text { novos } \\
\text { profundidade }\end{array}$ & $\begin{array}{c}\text { estados } \\
\text { estados }\end{array}$ & $\begin{array}{c}\text { estados } \\
\text { revisitados }\end{array}$ & retornos \\
\hline \hline Uncaught Exception & 1 & 2 & 0 & 1 & 0 \\
\hline demais & 1 & 3 & 0 & 2 & 2 \\
\hline
\end{tabular}

Tabela 5.56: Rastreamento de Estados para o programa UncaughtExceptionExample - Com Gerador de Escolhas

Como resultado da análise dos diversos programas apresentados podemos chegar a algumas conclusões que se aplicam de maneira geral e alguns cuidados que devem ser tomados. É importante ressaltar que as conclusões se aplicam à ferramenta utilizada.

1. os melhores resultados de cobertura são obtidos nas execuções aonde não ocorre nenhuma violação de propriedade. Isto ocorre pois a violação da propriedade aborta a execução do código, deixando alguns caminhos sem serem percorridos.

2. quando uma propriedade não é violada, sempre são executados os mesmos caminhos, independente de quantas e quais propriedades estejam configuradas para verificação. Ou seja, a cobertura é a mesma. Levando em consideração também o item anterior, para obter a cobertura máxima podemos executar os testes sem verificar nenhuma propriedade.

3. O elemento que efetivamente influencia a obtenção de uma cobertura maior ou menor é o gerador de escolhas.

4. De uma maneira geral, os melhores resultados de cobertura foram obtidos com o uso do gerador de escolhas para exceções. Os únicos casos onde isto não ocorreu, foram quando a geração da escolha provocou uma violação de propriedade.

5. A presença de condicionais no código afeta a cobertura obtida com os geradores de escolha utilizados.

6. Como os critérios utilizados não levam em consideração o lançamento implícito de exceções, as triplas identificadas não cobrem todo o comportamento excepcional do programa.

Alguns cuidados que devem ser tomados ao fazer-se a análise dos resultados obtidos com o uso do gerador de escolhas: 
1. podem ser gerados caminhos que nunca são percorridos. Isto ocorreu para o programa ExceptionNeverThrownExample.java

2. podem ser gerados erros ou violações de propriedade que não ocorrem no sistema real, introduzidos pelo gerador. Isto ocorreu para o programa LostCauseExample.java 


\section{Capítulo 6}

\section{Análise de programas concorrentes}

Este capítulo tem como objetivo apresentar os resultados obtidos na verificação de 5 programas de código concorrente Java em versões com e sem deadlock, utilizando a ferramenta Java PathFinder [34]. Os códigos fonte encontram-se no apêndice D. Foi feita a verificação de deadlock e das propriedades baseadas em exceção definidas no capítulo 3.2. O cálculo de cobertura foi feito utilizando-se o critério de Definição e Uso de objetos [6]. Os programas foram selecionados a partir de um estudo anterior [28], utilizando a ferramenta Bandera.

Esta análise foi feita de maneira a confirmar várias das características observadas no capítulo anterior, utilizando programas maiores e observar o comportamento dos elementos desenvolvidos para sistemas com tratamento de exceções em sistemas com outro tipo de características, neste caso com código concorrente.

\subsection{Resultados Obtidos}

A Tabela 6.1 apresenta os resultados obtidos na comparação da cobertura utilizando diversas propriedades para os programas com deadlock, enquanto a Tabela 6.2 apresenta os resultados obtidos para os programas sem deadlock. Os números marcados com * foram obtidos somente através da configuração de alguma restrição de busca na ferramenta, conforme descrito mais adiante.

A seguir apresentamos uma análise mais detalhada para cada programa. Os códigos fonte de cada programa se encontram no apêndice. Os pares DU para cada programa foram retirados diretamente de $[28]$. 


\begin{tabular}{|l|c|c|c|c|c|c|c|c|}
\cline { 3 - 10 } \multicolumn{2}{c|}{} & \multicolumn{7}{|c|}{ pares exercitados } \\
\hline programa & pares DU & CE & EC & TE & TME & UE & D & NP \\
\hline \hline Start.java & 20 & 14 & 14 & 14 & 14 & 14 & 12 & 14 \\
\hline Dead.java & 28 & 28 & 28 & 28 & 28 & 28 & 18 & 28 \\
\hline NestedMonitor.java & 13 & 11 & 11 & 11 & 11 & 11 & 8 & 11 \\
\hline PCSimple.java & 11 & 10 & 10 & 10 & 10 & 10 & 9 & 10 \\
\hline PipeInteger.java & 16 & $11^{*}$ & $11^{*}$ & $11^{*}$ & $11^{*}$ & $11^{*}$ & 8 & $11^{*}$ \\
\hline
\end{tabular}

Tabela 6.1: Resultados para os programas com Deadlock

\begin{tabular}{|l|c|c|c|c|c|c|c|c|}
\cline { 3 - 10 } \multicolumn{2}{c|}{} & \multicolumn{9}{|c|}{ pares exercitados } \\
\hline programa & pares DU & CE & EC & TE & TME & UE & D & NP \\
\hline \hline Start_s.java & 20 & $10^{*}$ & $10^{*}$ & $10^{*}$ & $10^{*}$ & $10^{*}$ & $10^{*}$ & $10^{*}$ \\
\hline Dead_s.java & 28 & 28 & 28 & 28 & 28 & 28 & 28 & 28 \\
\hline NestedMonitor_s.java & 13 & 11 & 11 & 11 & 11 & 11 & 11 & 11 \\
\hline PCSimple_s.java & 11 & 10 & 10 & 10 & 10 & 10 & 10 & 10 \\
\hline PipeInteger_s.java & 16 & $11^{*}$ & $11^{*}$ & $11^{*}$ & $11^{*}$ & $11^{*}$ & $11^{*}$ & $11^{*}$ \\
\hline
\end{tabular}

Tabela 6.2: Resultados para os programas sem Deadlock

\subsubsection{Programa Start.java}

Para o programa Start.java, tanto em sua versão com deadlock como sem deadlock os resultados obtidos encontram-se na Tabela 6.3.

\begin{tabular}{|l|c|c|c|c|c|c|c|c|}
\cline { 3 - 9 } \multicolumn{1}{c|}{} & \multicolumn{7}{|c|}{ pares exercitados } \\
\hline programa & pares DU & CE & EC & TE & TME & UE & D & NP \\
\hline \hline Start.java & 20 & 14 & 14 & 14 & 14 & 14 & 12 & 14 \\
\hline Start_s.java & 20 & $10^{*}$ & $10^{*}$ & $10^{*}$ & $10^{*}$ & $10^{*}$ & $10^{*}$ & $10^{*}$ \\
\hline
\end{tabular}

Tabela 6.3: Resultados para o programa Start

Os pares DU para cada objeto do programa Start.java encontram-se descritos a seguir:

- event1: $(48,50),(48,51),(48,19),(48,22),(48,24),(48,38),(38,19),(38,22),(38,24)$

- event2: $(49,50),(49,51),(49,36),(49,39),(49,41),(49,21),(21,36),(21,39),(21,41)$

- task1: $(50,52)$ 
- task2: $(51,53)$

Os pares exercitados pela ferramenta JPF encontram-se descritos a seguir:

- event1: $(48,50),(48,51),(48,19),(48,22),(48,38),(\mathbf{3 8 , 1 9}),(\mathbf{3 8 , 2 2})$

- event2: $(49,50),(49,51),(49,21),(21,36),(21,39)$

- task1: $(50,52)$

- task2: $(51,53)$

Em negrito encontram-se os pares que não foram exercitados na execução onde verifica-se a propriedade de deadlock. Como esta propriedade é violada, é feita a interrupção da execução do código e menos caminhos são percorridos. Como nenhuma das demais propriedades é violada, todas apresentam a mesma cobertura de código. A ferramenta prossegue em sua execução até o final, sem interrupções.

A Tabela 6.4 ilustra as estatísticas de estado geradas na execução do programa. Percebe-se que no primeiro caminho já foi violada a propriedade de deadlock, por isso não ocorre nenhum retorno. Para as demais propriedades são executados diversos caminhos sem que ocorra nenhuma violação.

\begin{tabular}{|c|c|c|c|c|c|}
\hline propriedade & $\begin{array}{c}\text { máxima } \\
\text { profundidade }\end{array}$ & $\begin{array}{c}\text { novos } \\
\text { estados }\end{array}$ & $\begin{array}{c}\text { estados } \\
\text { revisitados }\end{array}$ & $\begin{array}{c}\text { estados } \\
\text { finais }\end{array}$ & retornos \\
\hline \hline Deadlock & 9 & 10 & 0 & 0 & 0 \\
\hline demais & 24 & 356 & 467 & 0 & 822 \\
\hline
\end{tabular}

Tabela 6.4: Rastreamento de Estados para o programa Start

No caso do programa sem deadlock (Start_s.java) não foi possivel executar o código completo com a ferramenta JPF, devido a estouro de memória. Foi gerado um erro java.lang.OutOfMemoryError na execução do programa. Os resultados apresentados foram obtidos interropendo a execução do programa antes de seu término através de uma restrição de profundidade. Esta configuração da ferramenta permite que uma execução seja interrompida se a profundidade de busca ultrapassar um valor desejado. Foi utilizada uma profundidade máxima de valor 8 .

Os pares DU para cada objeto do programa Start_s.java encontram-se descritos a seguir: 
- event1: $(59,61),(59,62),(59,22),(59,27),(59,29),(59,46),(46,22),(46,27),(46,29)$

- event2: $(60,61),(60,62),(60,43),(60,48),(60,50),(60,25),(25,43),(25,48),(25,50)$

- task1: $(61,63)$

- task2: $(62,64)$

Os pares exercitados pela ferramenta JPF encontram-se descritos a seguir:

- event1: $(59,61),(59,62),(59,22),(59,27)$

- event2: $(60,61),(60,62),(60,43),(60,48)$

- task1: $(61,63)$

- task2: $(62,64)$

A Tabela 6.5 mostra as estatísticas de estado geradas na execução do programa sem deadlock, utilizando a restrição de profundidade. Nesta tabela, não pode ser observada nenhuma característica que indique porque não foi possivel completar a execução do programa, como por exemplo um número grande de estados.

\begin{tabular}{|c|c|c|c|c|c|}
\hline propriedade & $\begin{array}{c}\text { máxima } \\
\text { profundidade }\end{array}$ & $\begin{array}{c}\text { novos } \\
\text { estados }\end{array}$ & $\begin{array}{c}\text { estados } \\
\text { revisitados }\end{array}$ & $\begin{array}{c}\text { estados } \\
\text { finais }\end{array}$ & retornos \\
\hline \hline todas & 7 & 81 & 55 & 0 & 135 \\
\hline
\end{tabular}

Tabela 6.5: Rastreamento de Estados para o programa Start_s

Executando o programa com o auxílio de uma ferramenta de monitoração (NetBeans Profiler 6.0) foi possível constatar que o estouro de memória ocorre devido a uma grande quantidade de instâncias da classe gov.nasa.jpf.jum.Step criadas pela ferramenta. Estas instâncias são criadas para cada instrução executada no código do programa em um determinado caminho percorrido e descartadas conforme são executados retornos na execução dos caminhos. Rastreando as instruções executadas constatou-se que o programa entra em um laço infinito, executando repetidas vezes a mesma sequência de código até que ocorra o estouro de memória. Como este problema ocorre mesmo quando é feita a execução sem nenhuma das extensões criadas, aparenta ser um bug da ferramenta.

Como não faz parte do escopo deste estudo não foi feita uma investigação mais aprofundada. 


\subsubsection{Programa Dead.java}

Para o programa Dead.java, tanto em sua versão com deadlock como sem deadlock os resultados obtidos encontram-se na Tabela 6.6

\begin{tabular}{|l|c|c|c|c|c|c|c|c|}
\cline { 3 - 9 } \multicolumn{1}{c|}{} & \multicolumn{8}{|c|}{ pares exercitados } \\
\hline programa & pares DU & CE & EC & TE & TME & UE & D & NP \\
\hline \hline Dead.java & 28 & 28 & 28 & 28 & 28 & 28 & 18 & 28 \\
\hline Dead_s.java & 28 & 28 & 28 & 28 & 28 & 28 & 28 & 28 \\
\hline
\end{tabular}

Tabela 6.6: Resultados para o programa Dead

Os pares DU para cada objeto do programa Dead.java encontram-se descritos a seguir:

- lock1: $(7,19),(7,31)$

- lock2: $(8,20),(8,30)$

- $p 1:(9,11)$

- p2: $(10,12)$

- Dead: $(18,19),(18,20),(18,21),(\mathbf{1 8 , 2 9}),(\mathbf{1 8 , 3 0}),(\mathbf{1 8 , 3 1 )}, \mathbf{( 1 8 , 3 2 )},(21,29),(21,30),(21,31)$, $(21,32),(29,30),(29,31),(29,32),(\mathbf{2 9}, \mathbf{1 8}),(\mathbf{2 9 , 1 9}),(29,20),(29,21),(\mathbf{3 2}, \mathbf{1 8}),(\mathbf{3 2}, \mathbf{1 9}),(\mathbf{3 2}, \mathbf{2 0})$, $(32,21)$

Em negrito encontram-se os pares que não foram exercitados na execução onde verifica-se a propriedade de deadlock. Sem a verificação desta propriedade todos os pares DU são exercitados.

Para a versão sem deadlock todos os pares DU são exercitados.

A Tabela 6.7 mostra o rastreamento de estados gerado pela ferramenta JPF.

\begin{tabular}{|c|c|c|c|c|c|}
\hline propriedade & $\begin{array}{c}\text { máxima } \\
\text { profundidade }\end{array}$ & $\begin{array}{c}\text { novos } \\
\text { estados }\end{array}$ & $\begin{array}{c}\text { estados } \\
\text { revisitados }\end{array}$ & $\begin{array}{c}\text { estados } \\
\text { finais }\end{array}$ & retornos \\
\hline \hline Deadlock & 15 & 35 & 12 & 2 & 33 \\
\hline demais & 19 & 334 & 348 & 3 & 681 \\
\hline
\end{tabular}

Tabela 6.7: Rastreamento de Estados para o programa Dead 


\begin{tabular}{|c|c|c|c|c|c|}
\hline propriedade & $\begin{array}{c}\text { máxima } \\
\text { profundidade }\end{array}$ & $\begin{array}{c}\text { novos } \\
\text { estados }\end{array}$ & $\begin{array}{c}\text { estados } \\
\text { revisitados }\end{array}$ & $\begin{array}{c}\text { estados } \\
\text { finais }\end{array}$ & retornos \\
\hline \hline todas & 17 & 280 & 282 & 3 & 561 \\
\hline
\end{tabular}

Tabela 6.8: Rastreamento de Estados para o programa Dead_s

A Tabela 6.8 mostra as estatísticas de estado geradas na execução do programa sem deadlock.

Para ambos os programas a ferramenta simulou vários caminhos como pode ser visto pelo número de retornos realizados.

\subsubsection{Programa NestedMonitor.java}

Para o programa NestedMonitor.java, tanto em sua versão com deadlock como sem deadlock os resultados obtidos encontram-se na Tabela 6.9

\begin{tabular}{|l|c|c|c|c|c|c|c|c|}
\cline { 3 - 10 } \multicolumn{2}{c|}{} & \multicolumn{7}{|c|}{ pares exercitados } \\
\hline programa & pares DU & CE & EC & TE & TME & UE & D & NP \\
\hline \hline NestedMonitor.java & 13 & 11 & 11 & 11 & 11 & 11 & 8 & 11 \\
\hline NestedMonitor_s.java & 13 & 11 & 11 & 11 & 11 & 11 & 11 & 11 \\
\hline
\end{tabular}

Tabela 6.9: Resultados para o programa NestedMonitor

Os pares DU para cada objeto do programa NestedMonitor.java encontram-se descritos a seguir:

- $p:(3,4),(31,30),(30,31),(3,30),(3,31)$

- $w:(4,5),(4,6),(46,38),(38,46),(4,38),(4,46)$

- t1: $(5,8)$

- t2: $(6,9)$

Os pares exercitados pela ferramenta JPF encontram-se descritos a seguir:

- $p:(3,4),(3,30),(\mathbf{3 1}, \mathbf{3 0}),(\mathbf{3 0 , 3 1 )}$

- $w:(4,5),(4,6),(38,46),(4,38),(\mathbf{4 6 , 3 8 )}$

- t1: $(5,8)$ 
- t2: $(6,9)$

Em negrito encontram-se os pares que não foram exercitados na execução onde verifica-se a propriedade de deadlock. Os mesmos pares foram varridos na versão sem deadlock e na versão com deadlock, mas sem a verificação da propriedade.

A Tabela 6.10 ilustra as estatísticas de estado geradas na execução do programa. Percebe-se que no primeiro caminho já foi violada a propriedade de deadlock, por isso não ocorre nenhum retorno. Para as demais propriedades são executados diversos caminhos sem que ocorra nenhuma violação.

\begin{tabular}{|c|c|c|c|c|c|}
\hline propriedade & $\begin{array}{c}\text { máxima } \\
\text { profundidade }\end{array}$ & $\begin{array}{c}\text { novos } \\
\text { estados }\end{array}$ & $\begin{array}{c}\text { estados } \\
\text { revisitados }\end{array}$ & $\begin{array}{c}\text { estados } \\
\text { finais }\end{array}$ & retornos \\
\hline \hline Deadlock & 9 & 10 & 0 & 0 & 0 \\
\hline Demais & 13 & 94 & 92 & 1 & 185 \\
\hline
\end{tabular}

Tabela 6.10: Rastreamento de Estados para o programa NestedMonitor

A Tabela 6.11 mostra as estatísticas de estado geradas na execução do programa sem deadlock.

\begin{tabular}{|c|c|c|c|c|c|}
\hline propriedade & $\begin{array}{c}\text { máxima } \\
\text { profundidade }\end{array}$ & $\begin{array}{c}\text { novos } \\
\text { estados }\end{array}$ & $\begin{array}{c}\text { estados } \\
\text { revisitados }\end{array}$ & $\begin{array}{c}\text { estados } \\
\text { finais }\end{array}$ & retornos \\
\hline \hline todas & 15 & 119 & 127 & 1 & 245 \\
\hline
\end{tabular}

Tabela 6.11: Rastreamento de Estados para o programa NestedMonitor_s

\subsubsection{Programa PCSimple.java}

Para o programa PCSimple.java, tanto em sua versão com deadlock como sem deadlock os resultados obtidos encontram-se na Tabela 6.12

\begin{tabular}{|l|c|c|c|c|c|c|c|c|}
\cline { 3 - 10 } \multicolumn{2}{c|}{} & \multicolumn{8}{|c|}{ pares exercitados } \\
\hline programa & pares DU & CE & EC & TE & TME & UE & D & NP \\
\hline \hline PCSimple.java & 11 & 10 & 10 & 10 & 10 & 10 & 9 & 10 \\
\hline PCSimple_s.java & 11 & 10 & 10 & 10 & 10 & 10 & 10 & 10 \\
\hline
\end{tabular}

Tabela 6.12: Resultados para o programa PCSimple

Os pares DU para cada objeto do programa PCSimple.java encontram-se descritos a seguir:

- b: $(4,5),(4,6),(4,24),(4,41),(24,41),(41,24),(41,25),(25,41),(24,25)$ 
- $p:(5,7)$

- $c:(6,8)$

Os pares exercitados pela ferramenta JPF encontram-se descritos a seguir:

- b: $(4,5),(4,6),(4,24),(24,41),(41,24),(41,25),(25,41)(\mathbf{2 4 , 2 5})$

- $p:(5,7)$

- $c:(6,8)$

O par em negrito não foi exercitado quando utilizada a verificação de propriedade de deadlock. Os demais pares foram varridos tanto na versão do programa com quanto sem deadlock.

A Tabela 6.13 mostra o rastreamento de estados gerado pela ferramenta JPF.

\begin{tabular}{|c|c|c|c|c|c|}
\hline propriedade & $\begin{array}{c}\text { máxima } \\
\text { profundidade }\end{array}$ & $\begin{array}{c}\text { novos } \\
\text { estados }\end{array}$ & $\begin{array}{c}\text { estados } \\
\text { revisitados }\end{array}$ & $\begin{array}{c}\text { estados } \\
\text { finais }\end{array}$ & retornos \\
\hline \hline Deadlock & 26 & 30 & 1 & 1 & 4 \\
\hline Demais & 68 & 862 & 1012 & 1 & 1873 \\
\hline
\end{tabular}

Tabela 6.13: Rastreamento de Estados para o programa PCSimple

A Tabela 6.14 mostra as estatísticas de estado geradas na execução do programa sem deadlock.

\begin{tabular}{|c|c|c|c|c|c|}
\hline propriedade & $\begin{array}{c}\text { máxima } \\
\text { profundidade }\end{array}$ & $\begin{array}{c}\text { novos } \\
\text { estados }\end{array}$ & $\begin{array}{c}\text { estados } \\
\text { revisitados }\end{array}$ & $\begin{array}{c}\text { estados } \\
\text { finais }\end{array}$ & retornos \\
\hline \hline todas & 54 & 618 & 766 & 1 & 1383 \\
\hline
\end{tabular}

Tabela 6.14: Rastreamento de Estados para o programa PCSimple_s

\subsubsection{Programa PipeInteger.java}

Para o programa PipeInteger.java, tanto em sua versão com deadlock como sem deadlock os resultados obtidos encontram-se na Tabela 6.15

Os pares DU para cada objeto do programa PipeInteger.java encontram-se descritos a seguir:

- Heap.c1: $(7,55),(21,55),(22,55)$ 


\begin{tabular}{|l|c|c|c|c|c|c|c|c|}
\cline { 3 - 9 } \multicolumn{2}{c|}{} & \multicolumn{7}{c|}{ pares exercitados } \\
\hline programa & pares DU & CE & EC & TE & TME & UE & D & NP \\
\hline \hline PipeInteger.java & 16 & $11^{*}$ & $11^{*}$ & $11^{*}$ & $11^{*}$ & $11^{*}$ & 8 & $11^{*}$ \\
\hline PipeInteger_s.java & 16 & $11^{*}$ & $11^{*}$ & $11^{*}$ & $11^{*}$ & $11^{*}$ & $11^{*}$ & $11^{*}$ \\
\hline
\end{tabular}

Tabela 6.15: Resultados para o programa PipeInteger

- Heap.c2: $(8,68),(56,68),(58,68)$

- Heap.c3: $(11,81),(69,81),(71,81)$

- Heap.c4: $(14,94),(82,94),(84,94)$

- $s 1:(9,10)$

- $s 2:(12,13)$

- s3: $(15,16)$

- lis: $(17,18)$

Os pares exercitados pela ferramenta JPF encontram-se descritos a seguir:

- Heap.c1: $(22,55)$

- Heap.c2: $(58,68),(\mathbf{5 6 , 6 8 )}$

- Heap.c3: $(71,81),(\mathbf{6 9}, \mathbf{8 1})$

- Heap.c4: $(84,94),(\mathbf{8 2 , 9 4 )}$

- $s 1:(9,10)$

- s2: $(12,13)$

- s3: $(15,16)$

- lis: $(17,18)$ 
Os pares em negrito não foram exercitados quando ocorre a verificação da propriedade de deadlock.

Os pares exercitados pela ferramenta JPF na versão sem deadlock encontram-se descritos a seguir:

- Heap.c1: $(22,55),(21,55)$

- Heap.c2: $(58,68),(56,68)$

- Heap.c3: $(11,81),(69,81)$

- Heap.c4: $(14,94)$

- $s 1:(9,10)$

- s2: $(12,13)$

- $33:(15,16)$

- lis: $(17,18)$

Neste caso, diferente dos casos anteriores o número de pares percorridos foi o mesmo, mas os pares foram diferentes. Provavelmente, as alterações feitas no código para eliminar o deadlock fizeram com que caminhos diferentes fossem percorridos pela ferramenta.

Outra observação é que em nenhuma das execuções a ferramenta concluiu a verificação até o final. Quando ocorre a violação de propriedade a verificação é interrompida, como é esperado. Porém, nas execuções sem violação da propriedade a ferramenta abortou a execução devido a uma restrição de tamanho da memória. Assim como existe uma restrição de profundidade máxima de busca, o JPF também trabalha com uma restrição de valor mínimo de memória disponível. A configuração foi mantida em seu valor original de $1 \mathrm{Mb}$. Isto significa que a cada estado avançado a ferramenta calcula quanto de memória está disponível, e se o valor for menor do que a restrição, aborta a execução antes que ocorra um exceção de estouro de memória. Isto permite que o código encerre de maneira elegante e que sejam geradas as estatísticas de rastreamento. Este cálculo de memória disponível é feito após a coleta de lixo de memória.

Para conseguir a cobertura máxima obtida de 11 pares, foi necessário configurar a memória disponível para a JVM para um valor maior. Foi utilizado o valor de 1Gb. Sem esta configuração a restrição de memória é atingida antes, sendo obtida uma cobertura menor. 
A Tabela 6.16 mostra o rastreamento de estados gerado pela ferramenta JPF.

\begin{tabular}{|c|c|c|c|c|c|}
\hline propriedade & $\begin{array}{c}\text { máxima } \\
\text { profundidade }\end{array}$ & $\begin{array}{c}\text { novos } \\
\text { estados }\end{array}$ & $\begin{array}{c}\text { estados } \\
\text { revisitados }\end{array}$ & $\begin{array}{c}\text { estados } \\
\text { finais }\end{array}$ & retornos \\
\hline \hline Deadlock & 35 & 36 & 0 & 0 & 0 \\
\hline Demais & 48 & 2978 & 6331 & 0 & 9281 \\
\hline
\end{tabular}

Tabela 6.16: Rastreamento de Estados para o programa PipeInteger

A Tabela 6.17 mostra as estatísticas de estado geradas na execução do programa sem deadlock.

\begin{tabular}{|c|c|c|c|c|c|}
\hline propriedade & $\begin{array}{c}\text { máxima } \\
\text { profundidade }\end{array}$ & $\begin{array}{c}\text { novos } \\
\text { estados }\end{array}$ & $\begin{array}{c}\text { estados } \\
\text { revisitados }\end{array}$ & $\begin{array}{c}\text { estados } \\
\text { finais }\end{array}$ & retornos \\
\hline \hline todas & 52 & 2983 & 6334 & 1 & 9284 \\
\hline
\end{tabular}

Tabela 6.17: Rastreamento de Estados para o programa PipeInteger_s

Em relação aos programas anteriores temos um número bem maior de estados percorridos, o que ajuda a entender a violação da restrição de tamanho da ferramenta. Em relação ao código do programa Start_s.java aonde também ocorreu um problema de memória podemos dizer que a diferença principal está no tipo de problema. No programa anterior foi possivel que a ferramenta abortasse a execução de maneira elegante pois ela conseguiu perceber que a memória disponível era insuficiente. Esta verificação é feita pela ferramenta a cada estado avançado. No caso do programa Start_s.java o estouro de memória ocorreu durante o processamento de um estado gerando o lançamento de uma OutOfMemoryException e a finalização do programa.

\subsubsection{Conclusões Preliminares}

$\mathrm{Na}$ análise dos programas concorrentes pudemos confirmar algumas das características observadas na análise ds programas exemplo de propriedades feita no capítulo anterior. Estes programas são mais complexos e geram um número bem maior de estados em relação aos programas anteriores, então esta validação de características é importante, pois mostra que não são características apenas de programas muito pequenos.

Algumas características confirmadas foram:

- os melhores resultados são obtidos quando não ocorre a violação de nenhuma propriedade. 
- a cobertura obtida quando não se viola nenhuma propriedade é a mesma da execução da ferramenta sem a verificação de nenhuma propriedade.

Outras características observadas nos testes foram:

- a cobertura foi sempre a mesma para os programas sem deadlock.

- a cobertura dos programas sem deadlock corresponde a cobertura máxima obtida para os programas com deadlock. Apesar disso, as estatísticas de estado são diferentes.

As correções feitas para corrigir o deadlock dos programas [28] foram simples, não introduzindo nenhum novo par def-use no código. Porém os programas efetivamente são diferentes, por isso os resultados não são idênticos quando levamos em conta as estatísticas de estado para as verificações. Como este tipo de análise é mais detalhado do que simplesmente a cobertura de código, percebe-se a diferença no primeiro mas não no segundo. Estes são dados importantes pois deixam claro que não podemos simplesmente corrigir um erro detectado por uma verificação de propriedade e assumir que o comportamento será equivalente aos testes realizados anteriormente sem a verificação da propriedade corrigida. No nosso estudo, puramente do ponto de vista de cobertura de pares du poderiamos dizer que sim, mas seria necessário investigar programas maiores para tentar chegar a alguma conclusão mais forte a este respeito.

Nos programas concorrentes estudados também começamos a observar problemas de escalabilidade, sendo necessário utilizar algumas restrições de verificação da própria ferramenta para conseguir alguns resultados. Isto é uma característica comum em verificadores de modelo, por isso discutimos algumas técnicas para minimização dos estados gerados no capítulo 3.

Uma informação relevante mencionar é que durante a realização das verificações foi feita a calibração da ferramenta, visto que já tinhamos resultados para verificações dos mesmos programas realizadas anteriormente [28]. Observou-se que conforme foi feito o ajuste da ferramenta ocorreu uma diferença nos níveis de restrições necessários para obter os resultados. Por exemplo, para o programa PipeInteger_s.java chegou-se a obter 239.000 estados antes da ocorrência de falta de memória. Neste caso em particular, o listener de instruções executadas ainda não estava ajustado para levar em conta a ocorrência de retornos para o cálculo de pares, por isso o resultado de cobertura não é relevante, mas a correção da ferramenta afetou a memória utilizada na verificação. Isto é importante pois destaca que, em alguns casos, otimizações nos elementos de extensão podem diminuir a memória utilizada nas verificações. 
No desenvolvimento de qualquer extensão para a ferramenta deve-se tomar o cuidado de afetar ao mínimo possivel a escalabilidade dos programas testados. Para a ferramenta original, é mencionada uma limitação de 10.000 linhas de código [33]. 


\section{Capítulo 7}

\section{Conclusão}

Neste trabalho, apresentamos diversos critérios de teste de programas orientados a objetos, e algumas ferramentas de auxílio aos testes. Os critérios variam em custo (número de casos de teste necessários para atendê-los) e eficácia (alguns critérios não garantem a descoberta de alguns erros). De uma maneira geral, o critério de fluxo de objetos [6] vem apresentando bons resultados nos testes de programas orientados a objetos. O ideal é que o testador conheça vários critérios de teste, de forma a aplicar o melhor critério de acordo com as características do sistema que deve ser testado.

Apresentamos também as características básicas do tratamento de exceções em Java e um critério que adapta o fluxo de objetos para fluxo de exceções [31].

De forma a facilitar o trabalho do testador é importante um bom suporte de ferramentas. Neste trabalho executamos algumas atividades que têm o intuito de dar alguns passos na direção da criação de mecanismos que facilitem e tornem mais robustos os procedimentos de teste.

Com base nos itens apresentados neste trabalho foi utilizada a ferramenta Java PathFinder. Os principais fatores que levaram a esta escolha foram a facilidade de criação de novas propriedades e de extensão de funcionalidades, suporte a tratamento de exceções e à última versão do Java e a facilidade de integração com outros aplicativos.

Fizemos verificações e testes utilizando os critérios baseados em fluxo de objetos e fluxo de exceçoes, e utilizamos as propriedades baseadas em exceções definidas no capitulo 3.2.

Inicialmente, pretendiamos utilizar uma ferramenta para gerar os gráficos de fluxo de objetos e arquivos XML com os pares du ou triplas edu a serem varridos pelo JPF. Iriamos utilizar a ferramenta OCONGRA [25], desenvolvida no próprio IME-USP, que dispõe de funcionalidades para geração de 
gráficos de fluxo de objetos. Porém, a presente versão da ferramenta ainda não dispõe da capacidade de geração dos arquivos XML necessários como entrada para a verificação, por isso a geração foi feita manualmente. Isto limitou o tamanho dos programas para os quais pôde ser feito o teste.

As principais atividades desenvolvidas foram:

- Implementação de um listener de rastreamento de instruções executadas para o JPF capaz de gerar estatísticas de rastreamento de pares du, a partir de um arquivo XML de entrada;

- Definição de um formato de arquivo $\mathrm{XML}^{1}$ para entrada dos pares du a serem rastreados pela ferramenta JPF;

- Implementação de propriedades para a ferramenta JPF, baseadas em exceções;

- Implementação de um aplicativo gráfico para configuração da ferramenta, execução das verificações e exibição dos resultados.

- Realização de diversas verificações de propriedades para um conjunto de programas de teste utilizando tanto o critério de fluxo de objetos como de fluxo de exceções.

\section{$7.1 \quad$ Resultados Obtidos}

Os programas utilizados para os testes apresentam características distintas, com o primeiro grupo composto de programas bem simples voltados especificamente para demonstrar algumas práticas de tratamento de exceções e o segundo grupo de programas mais complexos, que utilizam código concorrente. Apesar de simples, existe uma variedade grande nas características dos programas, permitindo que diversos comportamentos fossem observados.

Como resultado da análise dos diversos programas apresentados podemos chegar a algumas conclusões que se aplicam de maneira geral e alguns cuidados que devem ser tomados. É importante ressaltar que as conclusões se aplicam à ferramenta utilizada.

\subsubsection{Características observadas}

De uma maneira geral podemos resumir algumas características observadas nos testes:

\footnotetext{
${ }^{1}$ Apesar do arquivo ter sido gerado manualmente, futuramente deve ser gerado por uma ferramenta
} 
1. os melhores resultados de cobertura são obtidos nas execuções aonde não ocorre nenhuma violação de propriedade. Isto ocorre pois a violação da propriedade aborta a execução do código, deixando alguns caminhos sem serem percorridos.

2. quando uma propriedade não é violada, sempre são executados os mesmos caminhos, independente de quantas e quais propriedades estejam configuradas para verificação. Ou seja, a cobertura é a mesma. Levando em consideração também o item anterior, para obter a cobertura máxima podemos executar os testes sem verificar nenhuma propriedade.

3. O elemento que efetivamente influencia a obtenção de uma cobertura maior ou menor é o gerador de escolhas.

4. Deve ser selecionado um gerador de escolhas de acordo com as características do programa testado. Para os exemplos de práticas relativas ao tratamento de exceções as melhores coberturas foram obtidas com o uso do gerador de escolhas de exceções. Nestes exemplos, como não há código concorrente, o gerador de Threads embutido da ferramenta foi irrelevante. Já nos programas de código concorrente observou-se o comportamento oposto.

5. A presença de condicionais no código afeta a cobertura obtida com os geradores de escolha utilizados. Como nenhum deles gera escolhas a partir das condicionais de forma a varrer todas as ramificações, a presença de condicionais faz com que o resultado dependa das entradas utilizadas.

6. Como os critérios utilizados não levam em consideração o lançamento implícito de exceções, as triplas identificadas não cobrem todo o comportamento excepcional do programa.

7. a cobertura foi sempre a mesma para os programas sem deadlock.

8. a cobertura dos programas sem deadlock corresponde a cobertura máxima obtida para os programas com deadlock. Apesar disso, as estatísticas de estado são diferentes.

Do exposto acima podemos concluir que se o objetivo é conseguir a maior cobertura de código possivel, os esforços devem ser concentrados em geradores de escolha e não em propriedades. Por outro lado, a verificação de propriedades ajuda a melhorar a qualidade do código, seja por meio da identificação de más práticas (propriedades de exceção desenvolvidas) ou mesmo de erros no código (deadlock). Por isso, como na verificação em que não há violação ocorre a melhor cobertura, 
correspondente a verificação sem verificação de propriedades, não há porque não realizar a verificação utilizando propriedades.

\subsubsection{Cuidados a serem tomados}

Alguns cuidados que devem ser tomados ao fazer-se a análise dos resultados obtidos com o uso do gerador de escolhas:

1. podem ser gerados caminhos que nunca são percorridos. Isto ocorreu para o programa ExceptionNeverThrownExample.java

2. podem ser gerados erros ou violações de propriedade que não ocorrem no sistema real, introduzidos pelo gerador. Isto ocorreu para o programa LostCause.java

Na implementação das extensões para a ferramenta deve-se tomar cuidado para minimizar o efeito na escalabilidade dos programas testados. Para o programa PipeInteger_s.java, foram gerados cerca de 239.000 estados sem o uso do listener de rastreamento de instruções, antes de ocorrer uma parada na verificação por falta de memória. Com o uso do listener o número de estados caiu para cerca de 3.000 antes da parada por falta de memória.

\subsection{Trabalhos Futuros}

Um trabalho futuro de interesse para a continuidade deste estudo, e que já está sendo feito, é a implementação da geração automática dos arquivos de entrada XML para verificação do JPF. Isto possibilitaria o teste de programas de maior porte, tornando viável a verificação de programas aplicativos desenvolvidos para uso em empresas, organizações, universidades, etc. Com esta implementação seria possivel realizar um estudo mais aprofundado sobre limites de escalabilidade da ferramenta, ou mesmo outros tipos de limitações que não puderam ser identificados para programas de pequeno porte.

Além disso, a geração dos arquivos poderia ser incrementada com a escolha dos critérios de teste a serem utilizados. $\mathrm{O}$ arquivo seria gerado de acordo com o critério selecionado. $\mathrm{O}$ rastreamento atual do listener de execução é feito baseado simplesmente no percentual de elementos varridos contra o percentual total possivel, por isso não seria afetado por uma implementação deste tipo. O controle dos elementos que devem ser varridos é mais fácil de implementar na ferramenta de geração dos grafos do que no verificador. 
Outras atividades de interesse relacionadas são:

- integração da ferramenta Ocongra com o aplicativo utilizado neste trabalho, de forma a oferecer um aplicativo único para um testador. Uma sugestão para criação deste aplicativo único seria escrever em cima de alguma plataforma de aplicativos como NetBeans platform ou Eclipse RCP. Com isso várias funcionalidades já implementadas nestas plataformas podem ser reutilizadas, como por exemplo a exibição e navegação da estrutura de classes em pacotes, a busca de utilização de determinados elementos, etc.

- implementação de outros tipos de geradores de escolha, de maneira a poder melhorar a cobertura para outros tipos de código. Por exemplo, poderiamos ter um gerador para ajudar a cobrir ramificações em estruturas condicionais IF.

- implementação de outras propriedades não relacionadas a exceções.

- estudo da eficiência da técnica aplicando a verificação em bibliotecas com bugs conhecidos 


\section{Apêndice A}

\section{Glossário de termos}

A seguir são apresentados alguns termos importantes relacionados às atividades de teste $[2,10,19]$.

- Teste de software

É a execução de código utilizando combinações de entradas e estado selecionados com o intuito de encontrar bugs. Envolve outras atividades que são o projeto do teste e a avaliação do teste.

- Escopo

É a coleção de componentes ou elementos de software que vão ser testados. Tradicionalmente é designado como unidade, integração ou sistema.

- Testes de unidade

Tipicamente englobam um executável relativamente pequeno. Em programação orientada a objeto, uma classe ou objeto é a menor unidade executável.

- Testes de integração

Tem como escopo um sistema ou sub-sistema completo. As unidades incluídas são interdependentes ou devem cooperar para atender um determinado requisito.

- Testes de sistema

Tem como escopo o aplicativo completo. Podem ser classificados de acordo com o tipo de conformidade que se espera: funcional (entradas/saídas), desempenho (tempo de resposta e uso de recursos), stress ou carga (resposta sob carga máxima ou sobrecarga). 
- Confiança

É a medida subjetiva da probabilidade de existirem bugs ocultos em um sistema de software. Os testes podem aumentar ou diminuir a confiança em um sistema.

- Caso de teste (test case)

Elemento que define o estado anterior ao teste do elemento a ser testado, bem como de seu ambiente, as entradas ou condições de teste e os resultados esperados. Os resultados esperados definem o que o sistema deve produzir a partir das entradas de teste. Isto inclui mensagens geradas pelo sistema, exceções, valores retornados e o estado resultante do sistema e de seu ambiente.

Um teste cujos resultados reais são iguais aos resultados esperados é classificado como "passou", caso contrário é um "não passou". Um teste com resultado "não passou" revela um bug e é considerado um teste com sucesso, mesmo que, na verdade os resultados indiquem um defeito no aplicativo.

- Conjunto de testes (test suite)

É um conjunto de casos de teste relacionados.

- Execução de teste (test run)

É a execução de um conjunto de testes (test suite).

- Plano de teste

É um documento preparado para uso humano que descreve o plano de trabalho, os procedimentos gerais, o projeto de testes, etc.

- Driver de teste

É uma classe ou programa utilitário que aplica casos de teste a um sistema.

- Stub

É uma implementação parcial, temporária de um componente. Pode servir como um substituto para um componente incompleto ou implementar código de suporte ao teste.

- Falha (failure) 
É a falta de capacidade de um sistema ou componente de fornecer a funcionalidade esperada. É percebido através de saídas incorretas, finalizações anormais ou o não cumprimento de metas estabelecidas para restrições de tempo e espaço.

- Defeito (fault)

É a ausência de código ou presença de código incorreto.

- Erro (error)

É uma ação humana que produz uma falha.

- Bug

É uma falha.

- Depuração (debugging)

É o trabalho necessário para diagnosticar e corrigir um bug.

- Estratégia de testes

É um algoritmo ou heurística criados para criar casos de teste a partir de uma representação, implementação ou modelo de teste. O projeto de testes utiliza uma estratégia de testes para criar os conjuntos de testes.

- Efetividade do teste

É a capacidade do teste em encontrar bugs.

- Eficiência do teste

É o custo relativo de encontrar um bug.

- Modelo de falhas (fault model)

Identifica os relacionamentos e componentes do sistema sob teste com maior chance de terem falhas.

- Teste caixa-preta

O projeto dos testes pode ser baseado nas responsabilidades ou comportamentos esperados do sistema, independente de como foi feita sua implementação. Nesta caso é comumente chamado de teste caixa-preta. 
- Teste caixa-branca

Quando o projeto do teste depende de uma análise do código implementado é comumente chamado de teste caixa-branca.

- Teste caixa-cinza

Projetos híbridos que misturam as abordagens orientadas a responsabilidade e a implementação são denominados testes caixa-cinza.

- Abordagem formal

Uma abordagem pode ser dita formal, quando suas capacidades em revelar falhas foram estabelecidas por uma análise matemática.

- Abordagem heurística

Abordagem baseada no julgamento ou experiência de especialistas para seleção dos casos de teste.

- Teste exaustivo

Um conjunto de teste exaustivo requer que sejam testados todos os valores e possíveis seqüências de entradas, e aplicados a todos os possíveis estados do sistema, o que é inviável mesmo para sistemas pequenos.

- Cobertura de teste

É o percentual de elementos exercitados por um dado conjunto de testes. Quão completo um conjunto de testes é, relativo a um método específico de projeto de caso de testes é medido pela cobertura. Vários modelos de cobertura foram propostos e estudados.

- Cobertura de instruções (statement coverage)

É o percentual de código fonte executado pelo menos uma vez por um conjunto de testes.

- Instrução de predicado

Instrução que resulta em uma transferência condicional de controle (if-then, laços).

- Ramificação (branching)

É a instrução posterior a uma instrução de predicado. 
- Cobertura de ramificações (branching coverage)

É o percentual de ramificações que foram executadas pelo menos uma vez.

- Validação

Confirmação de que o sistema atende os requisitos e necessidades solicitados pelo cliente.

- Verificação

Confirmação de que o sistema foi construído de acordo com a sua especificação. 


\section{Apêndice B}

\section{Código Fonte das Propriedades Criadas}

\section{B.1 Método declara lançar java.lang.Exception}

\section{B.1.1 ThrowsExceptionProperty.java}

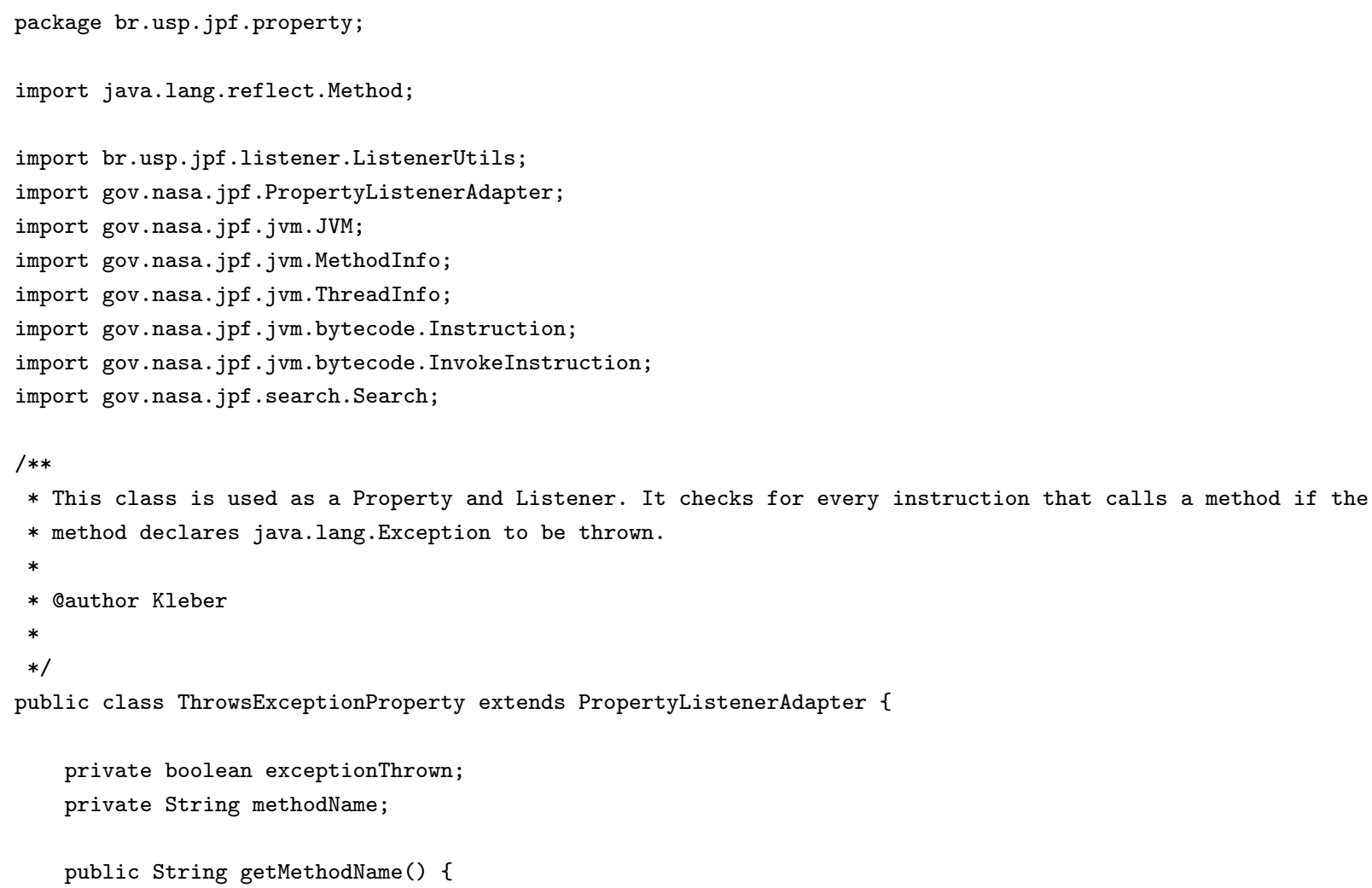




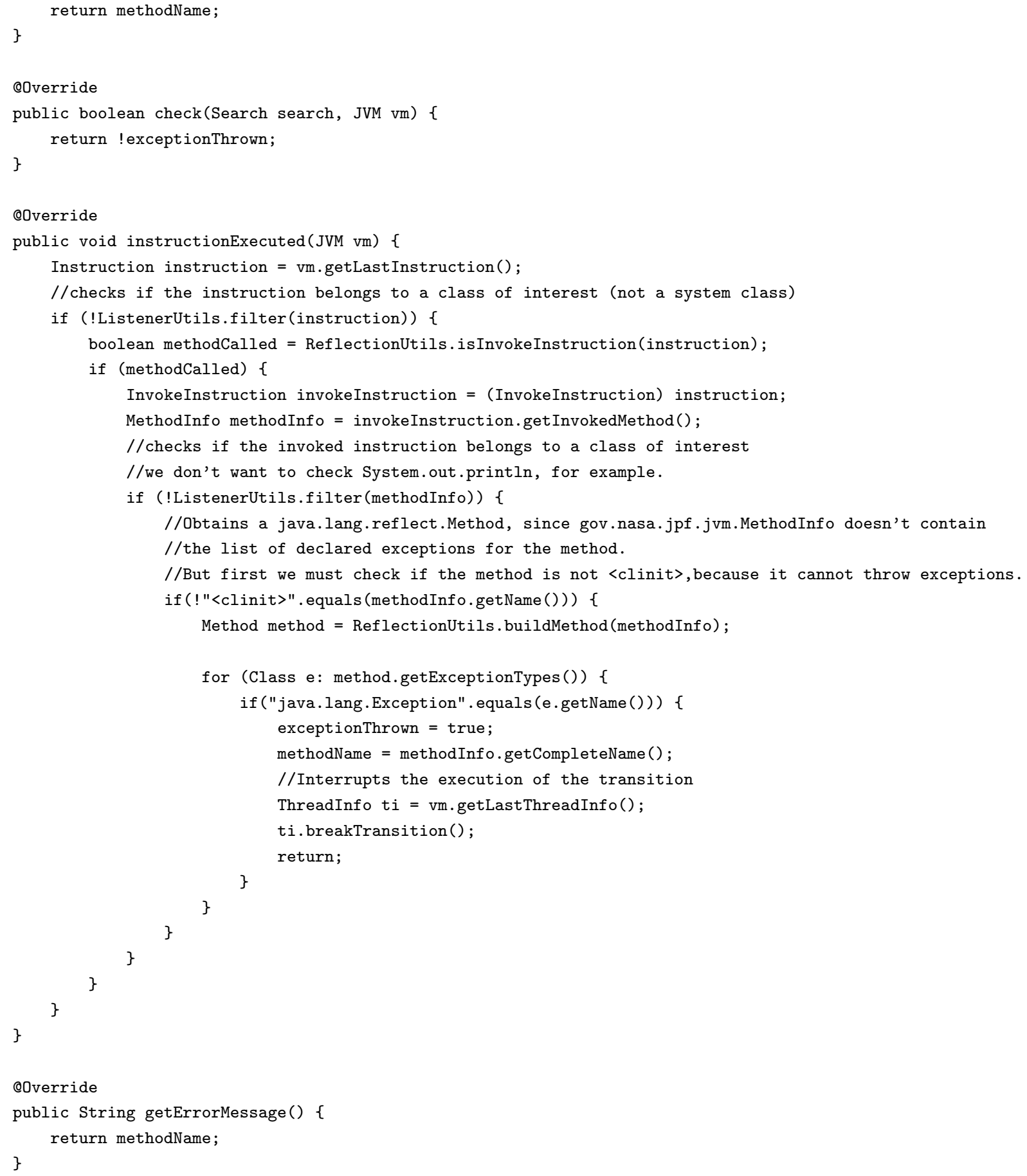




\section{B.2 Método declara lançar muitas exceções}

\section{B.2.1 ThrowsManyProperty.java}

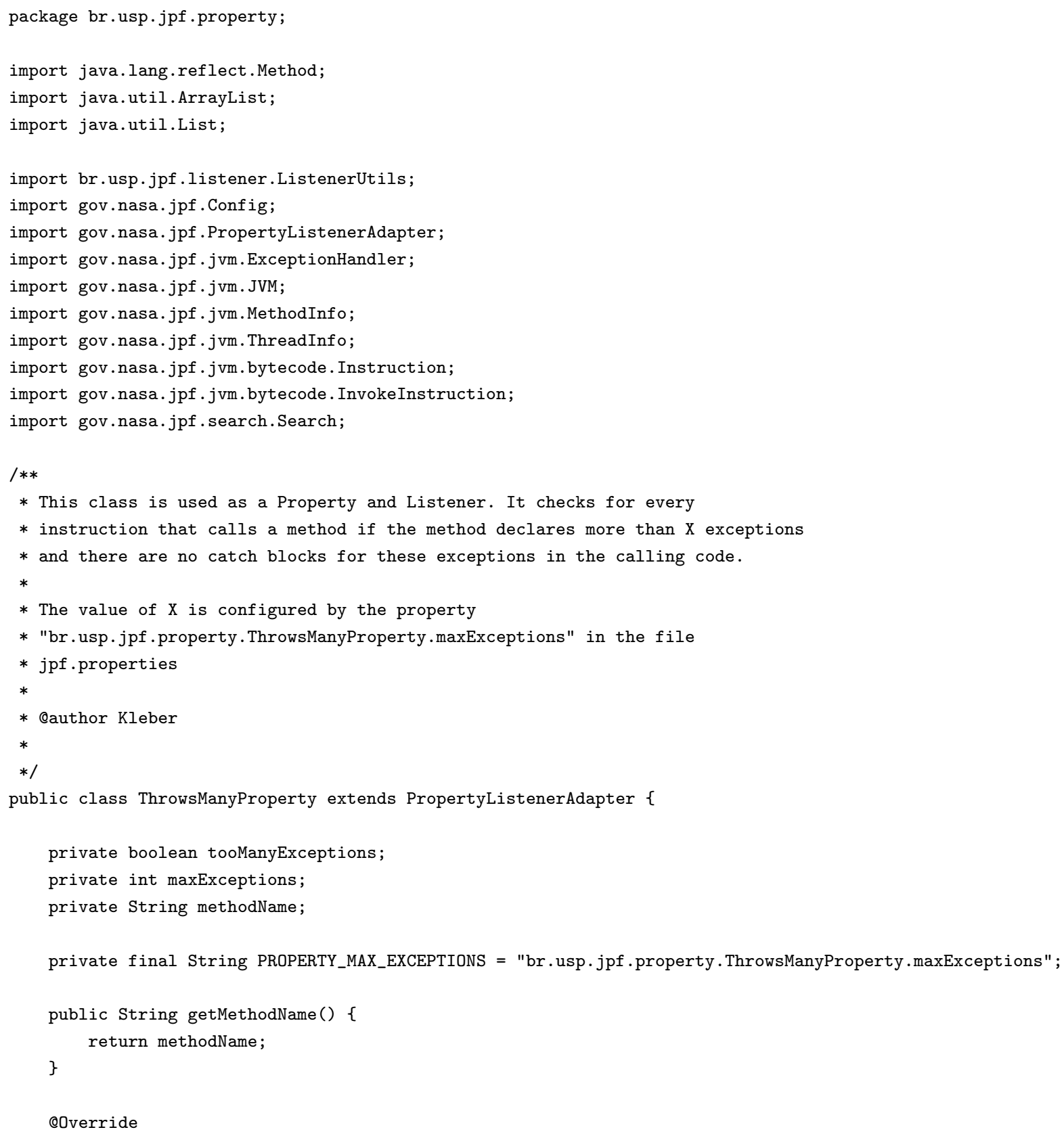




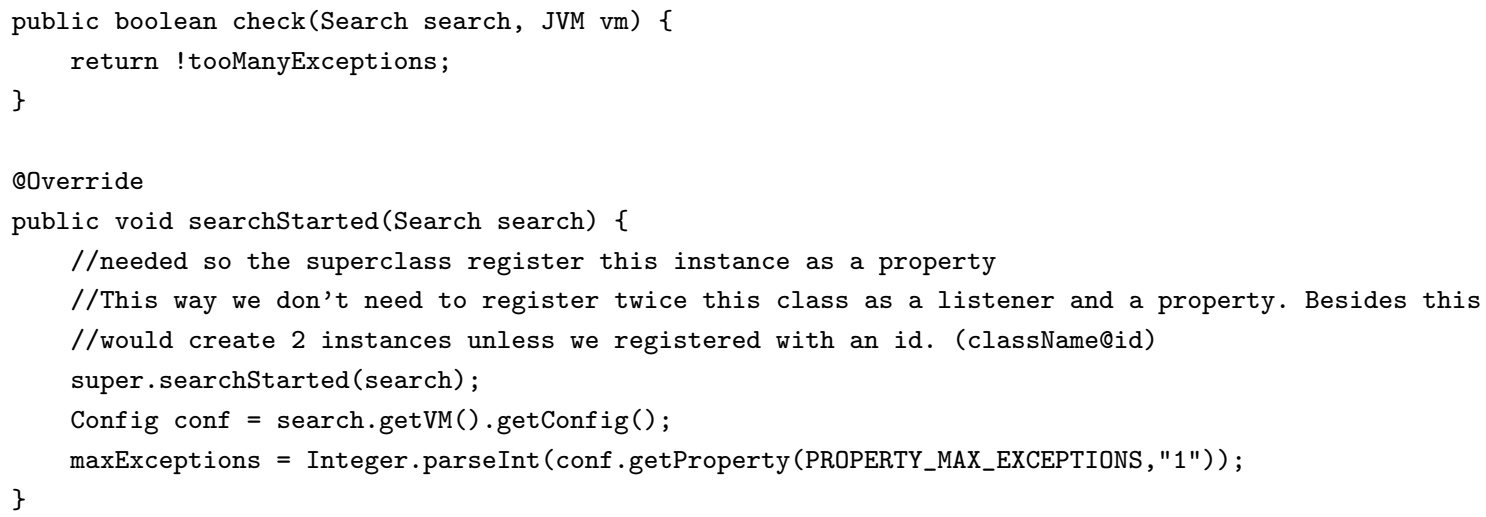




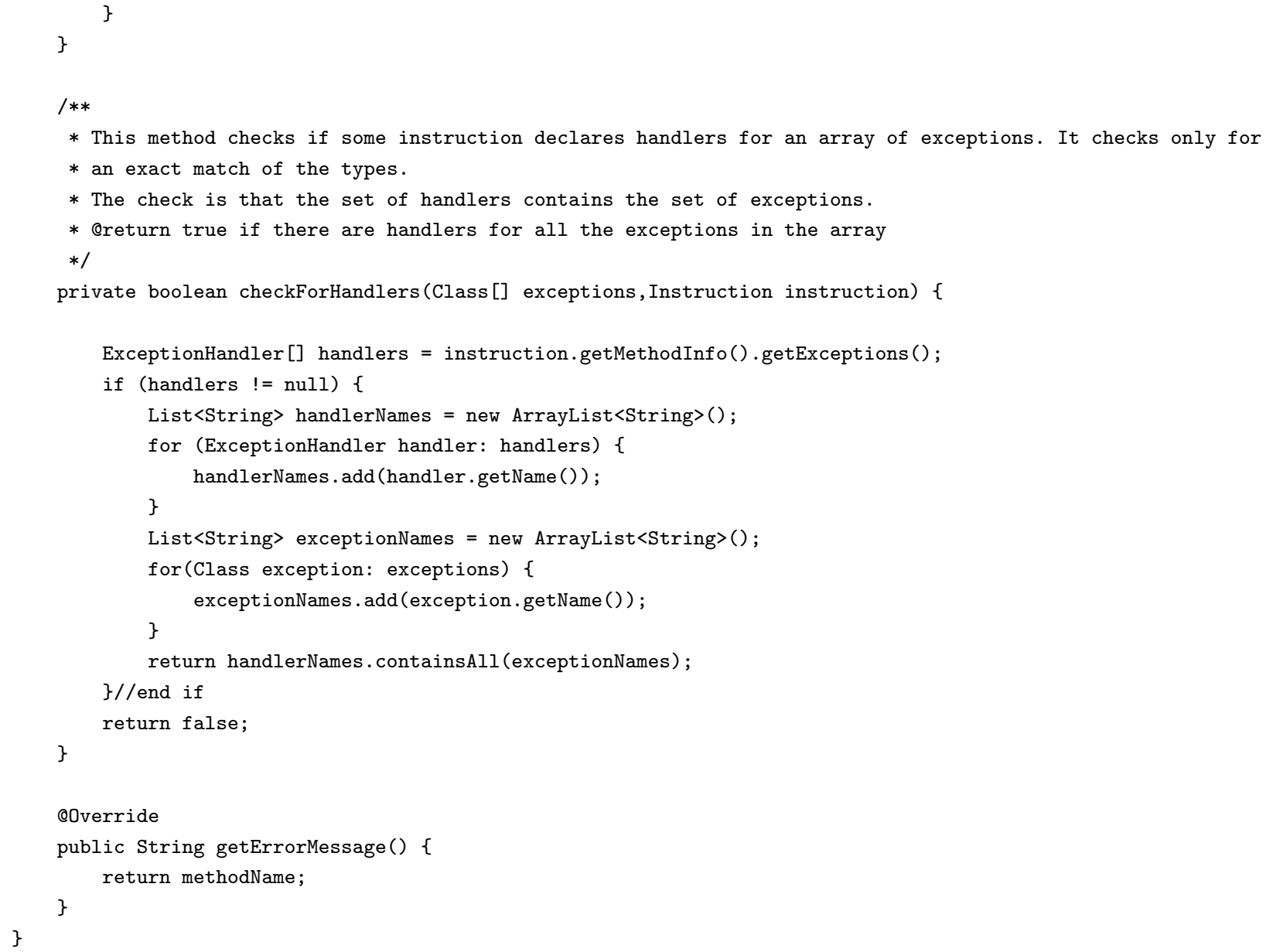

\section{B.3 Exceção declarada mas nunca lançada}

\section{B.3.1 ExceptionNeverThrownProperty.java}

package br.usp.jpf.property;

import br.usp.jpf.listener.ListenerUtils;

import gov.nasa.jpf.PropertyListenerAdapter;

import gov.nasa.jpf.jvm.JVM;

import gov.nasa.jpf.jvm.MethodInfo;

import gov.nasa.jpf.jvm.ThreadInfo;

import gov.nasa.jpf.jvm.bytecode.ATHROW;

import gov.nasa.jpf.jvm.bytecode.Instruction;

import gov.nasa.jpf.jvm.bytecode. InvokeInstruction; 


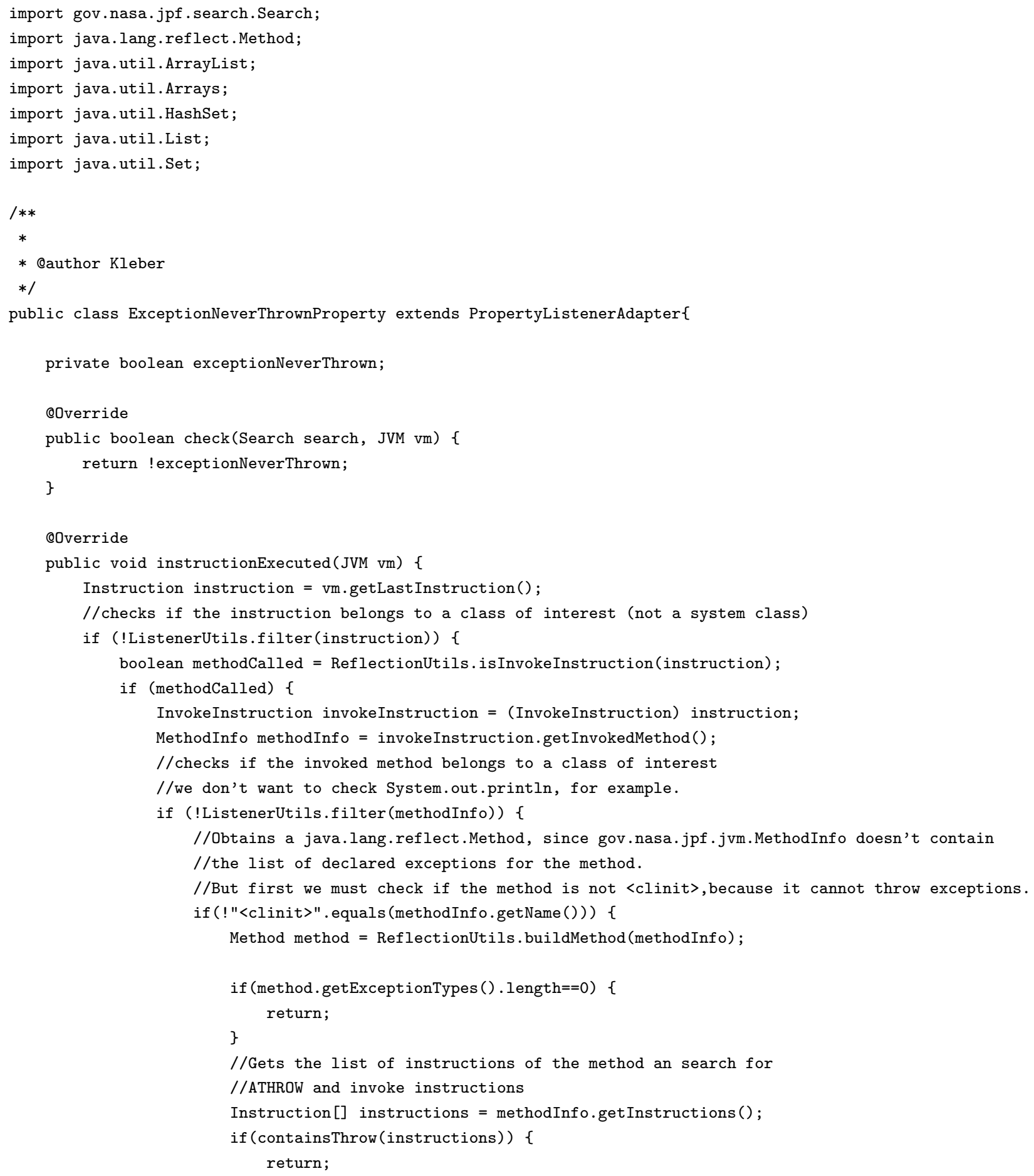




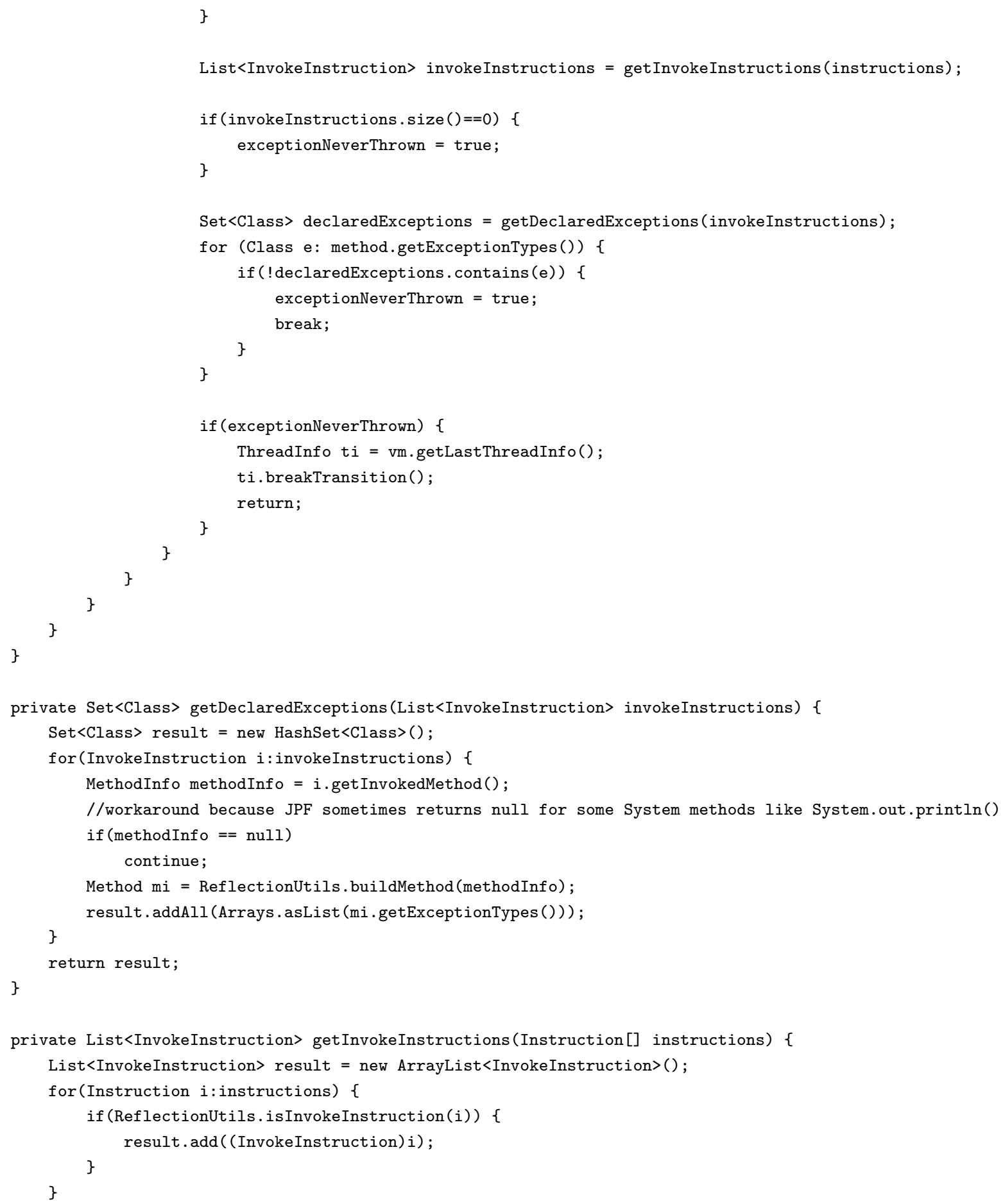




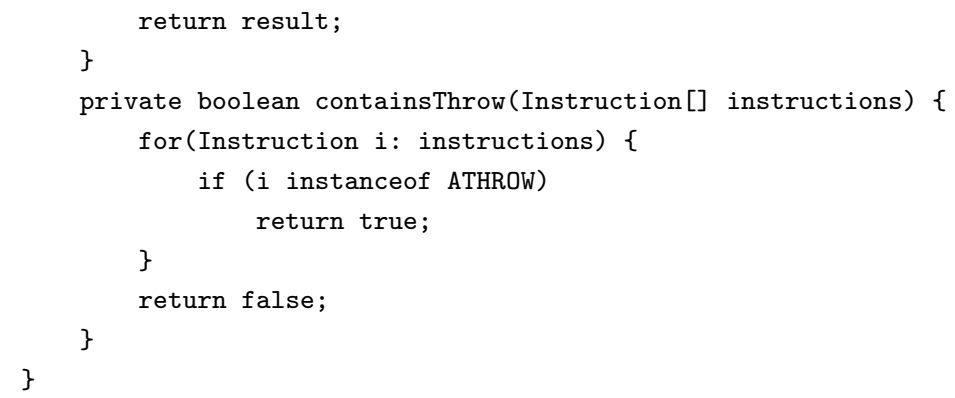

\section{B.4 Bloco de captura vazio}

\section{B.4.1 EmptyCatchProperty.java}

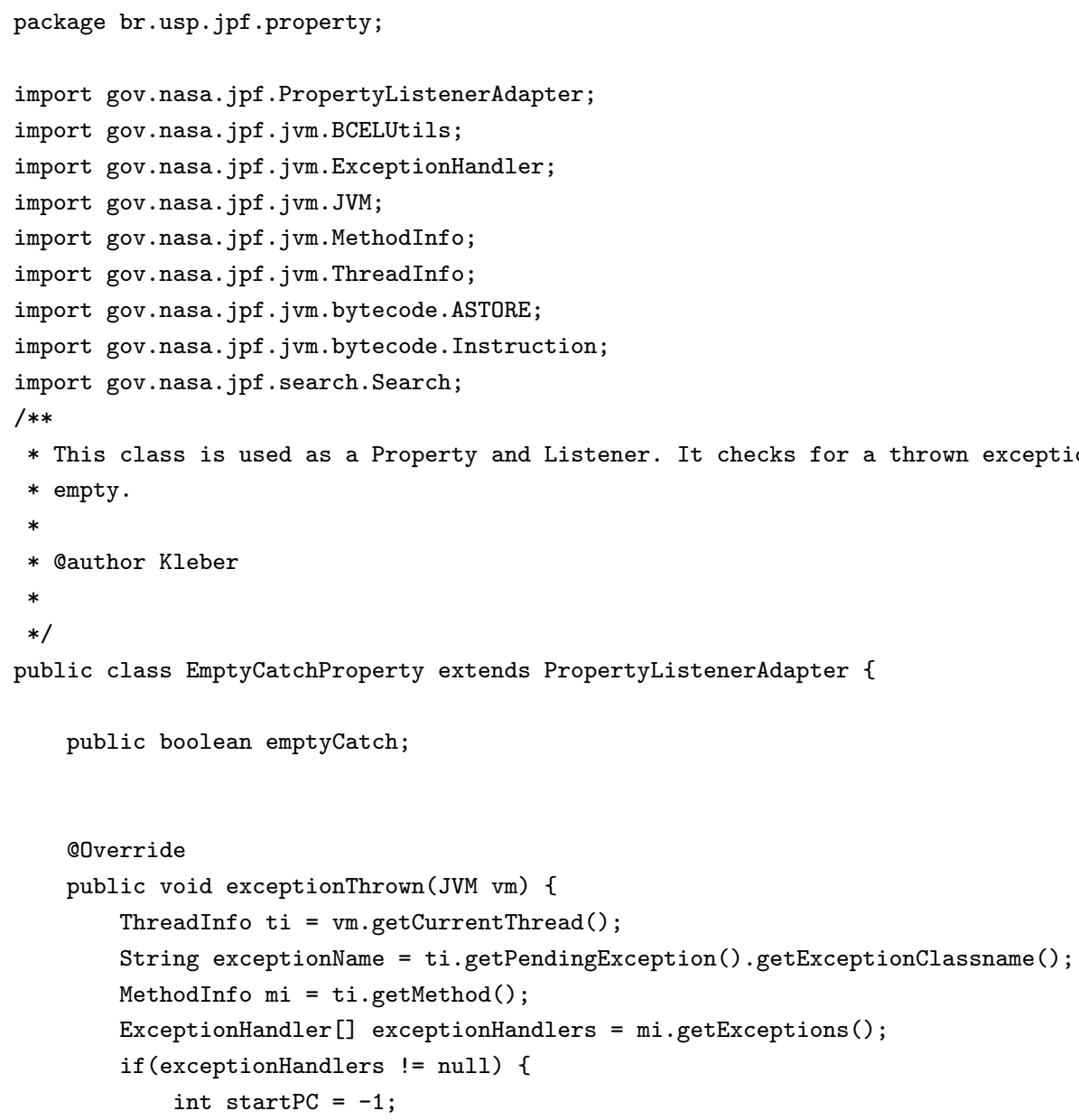




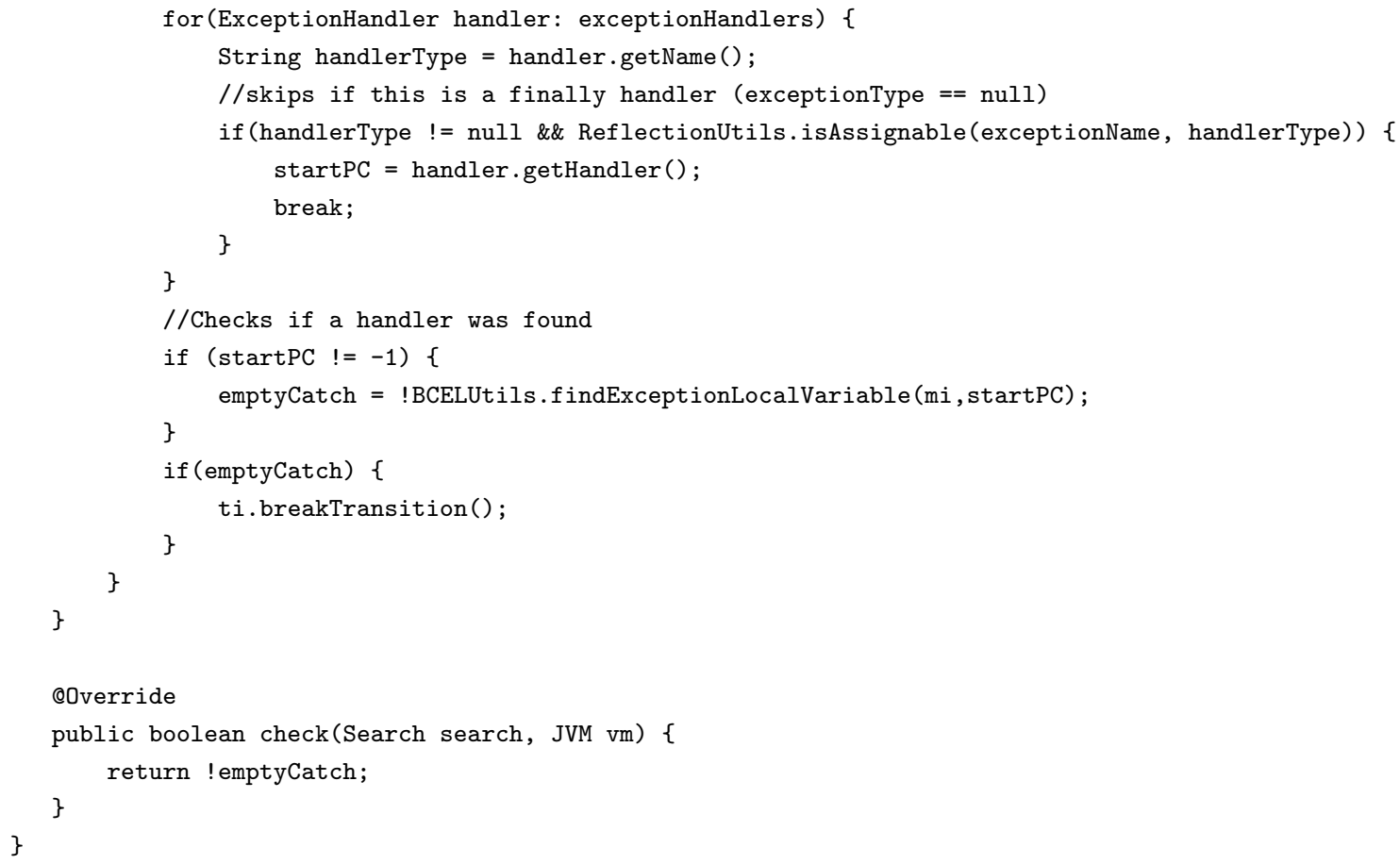

\section{B.5 Captura de java.lang.Exception}

\section{B.5.1 CatchExceptionProperty.java}

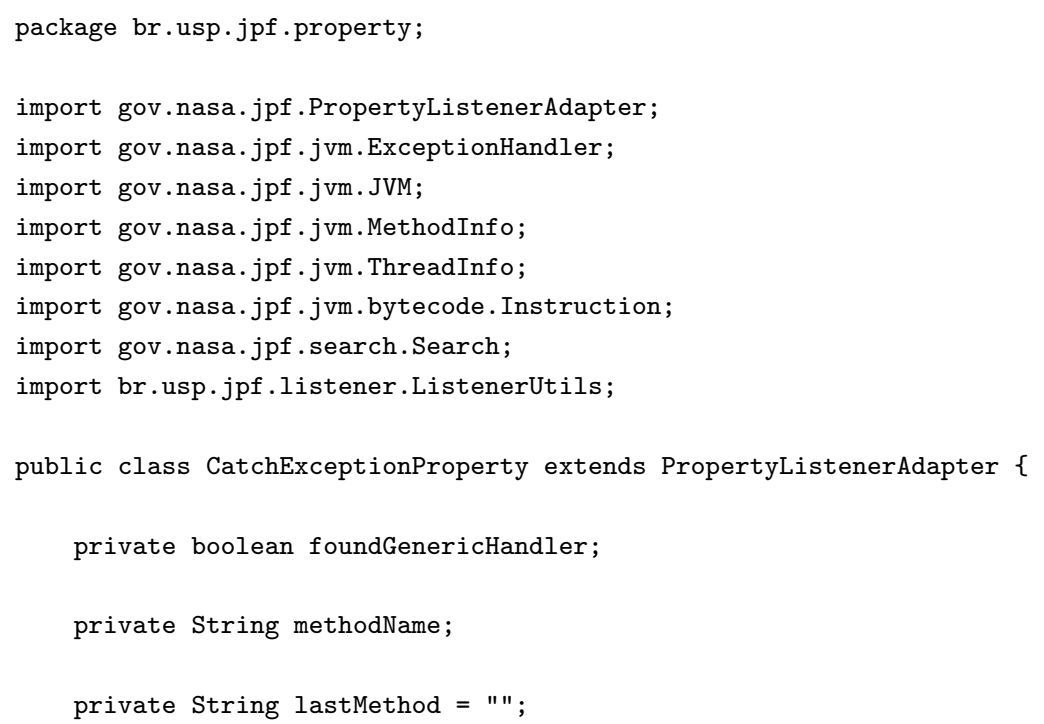




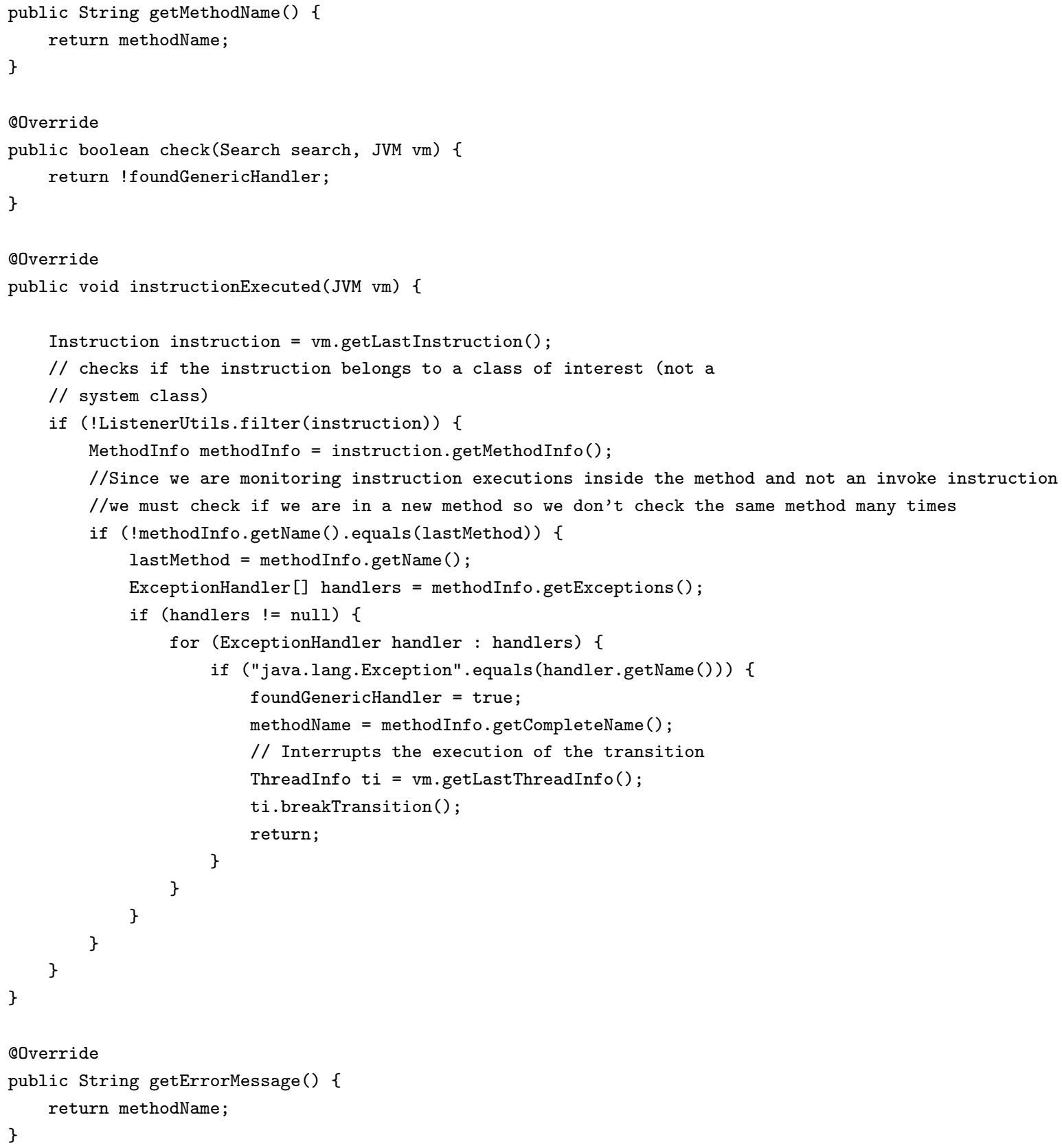




\section{Apêndice C}

\section{XML Schema dos arquivos de compartilhamento de da- dos}

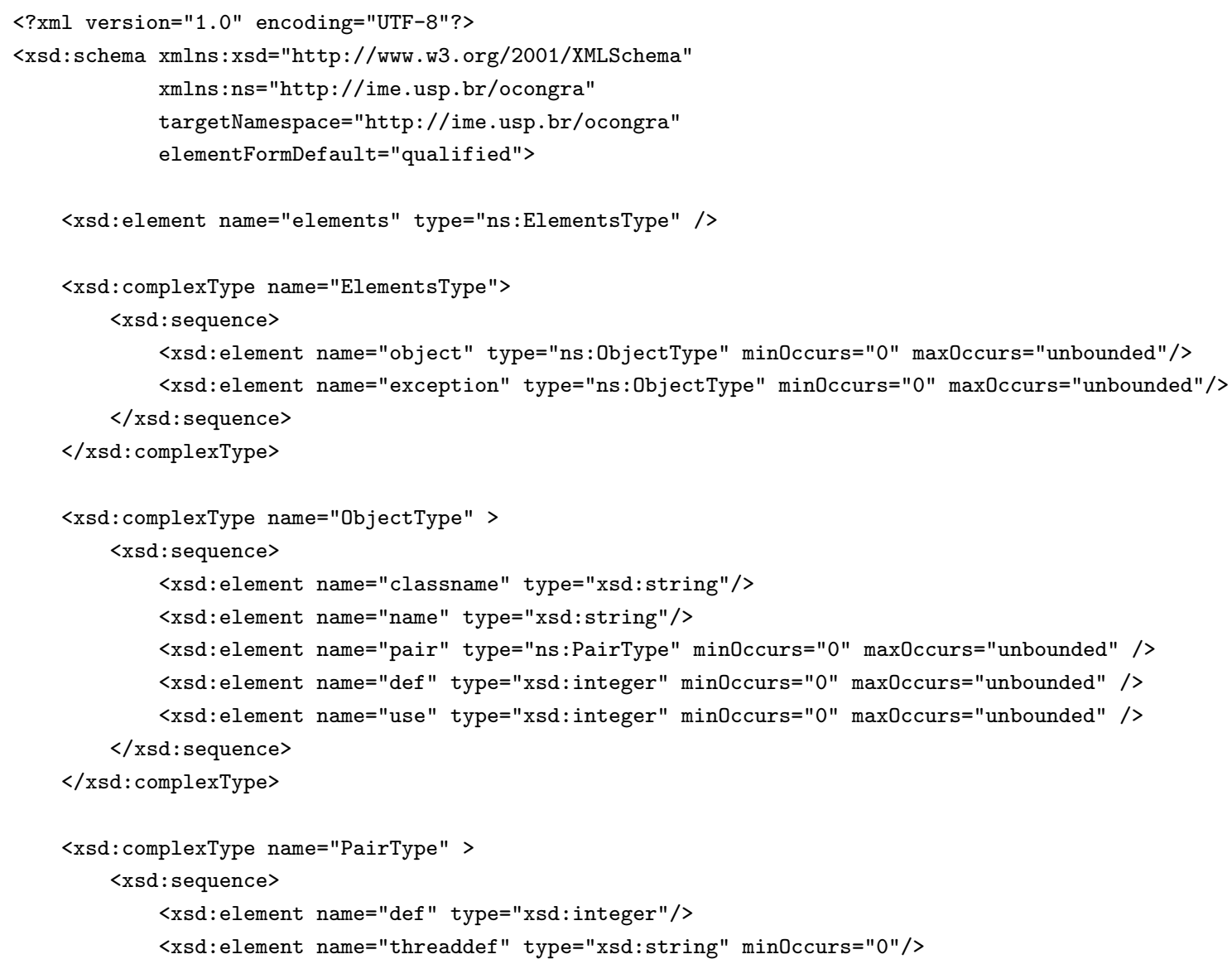


152 APENDICE C. XML SCHEMA DOS ARQUIVOS DE COMPARTILHAMENTO DE DADOS

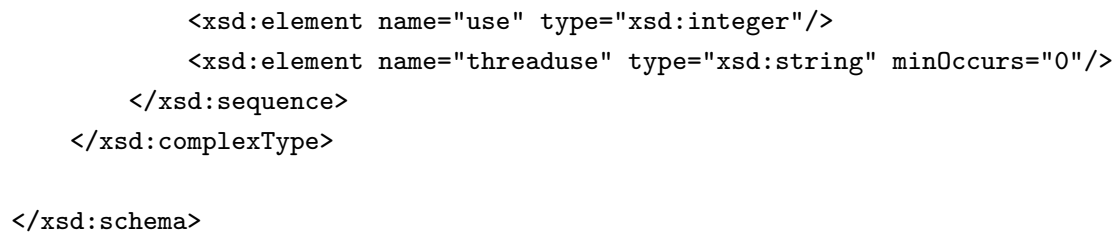




\section{Apêndice D}

\section{Código Fonte dos Programas de Código Concorrente}

\section{D.1 Código Fonte dos Programas Com Deadlock}

\section{D.1.1 Start.java}

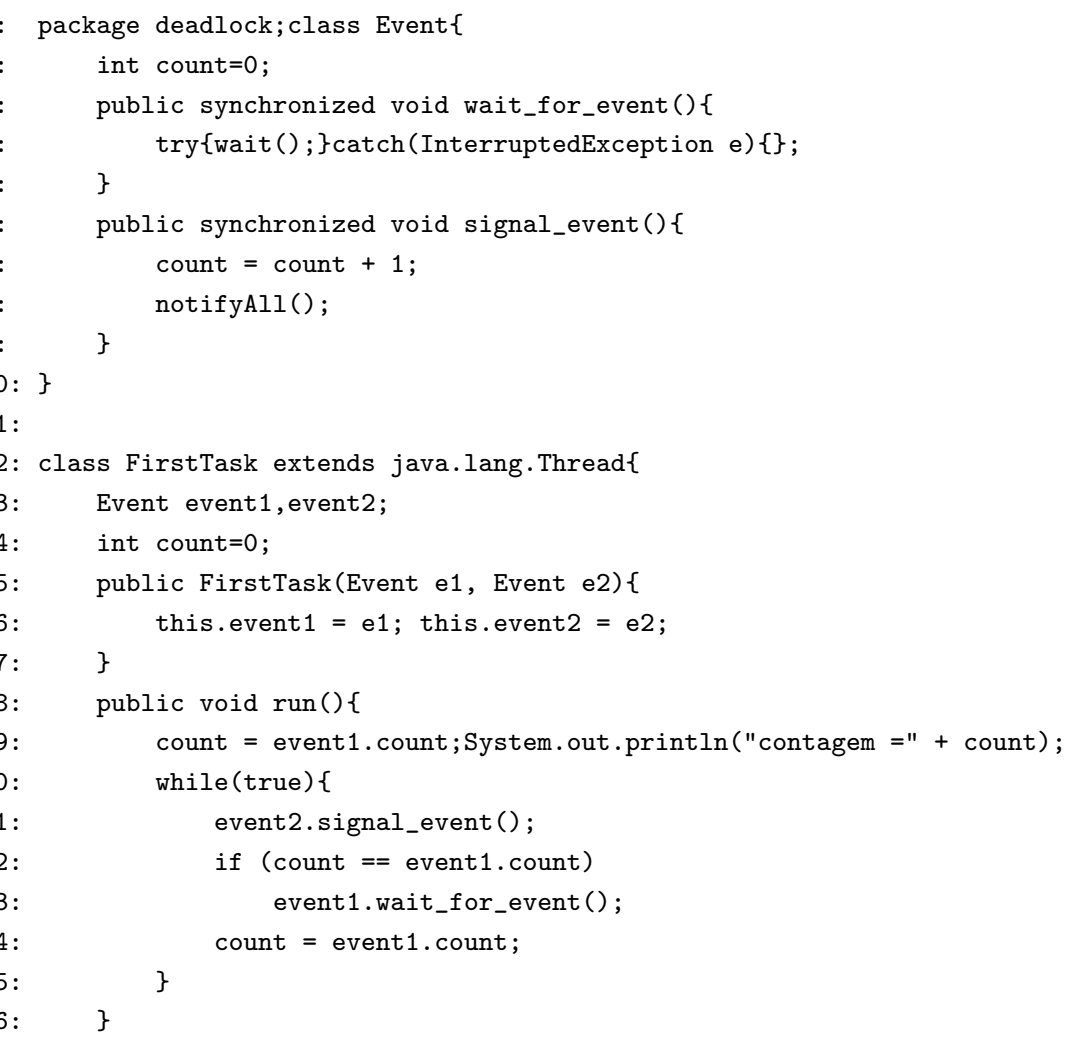


27: $\}$

28:

29: class SecondTask extends java.lang.Thread\{

30: $\quad$ Event event1, event2;

31: int count $=0$;

32: public SecondTask(Event e1, Event e2) \{

33: $\quad$ this.event1 $=\mathrm{e} 1$; this.event2 $=\mathrm{e} 2$;

34: \}

35: public void $\operatorname{run}()\{$

36: $\quad$ count $=$ event 2 . count;

37: while(true) \{

38: event1.signal_event ();

39: $\quad$ if (count $==$ event2. count)

40: event2.wait_for_event ()

41: $\quad$ count $=$ event2. count;

42: $\}$

43: $\}$

$44:\}$

45:

46: class Start \{

47: public static void main(String[] args) \{

48: $\quad$ Event event1 = new Event ();

49: $\quad$ Event event2 $=$ new Event () ;

50: $\quad$ FirstTask task1 = new FirstTask (event1, event2);

51: $\quad$ SecondTask task2 = new SecondTask (event2, event1);

52: task1.start ()

53: $\quad$ task2.start ();

54: \}

55: \}

\section{D.1.2 Dead.java}

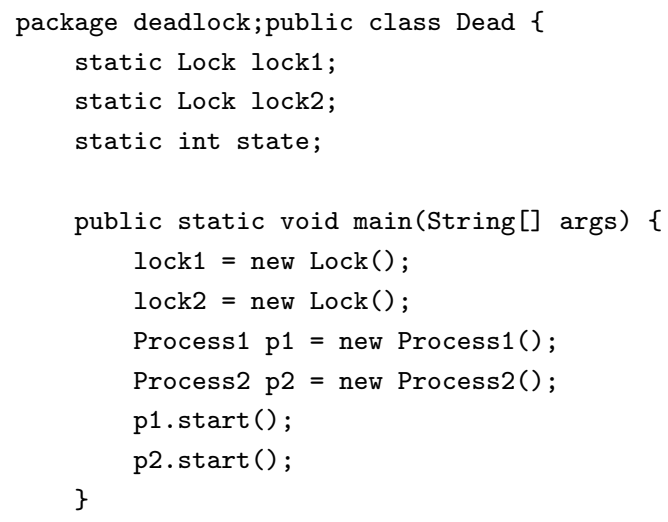

$14:\}$ 


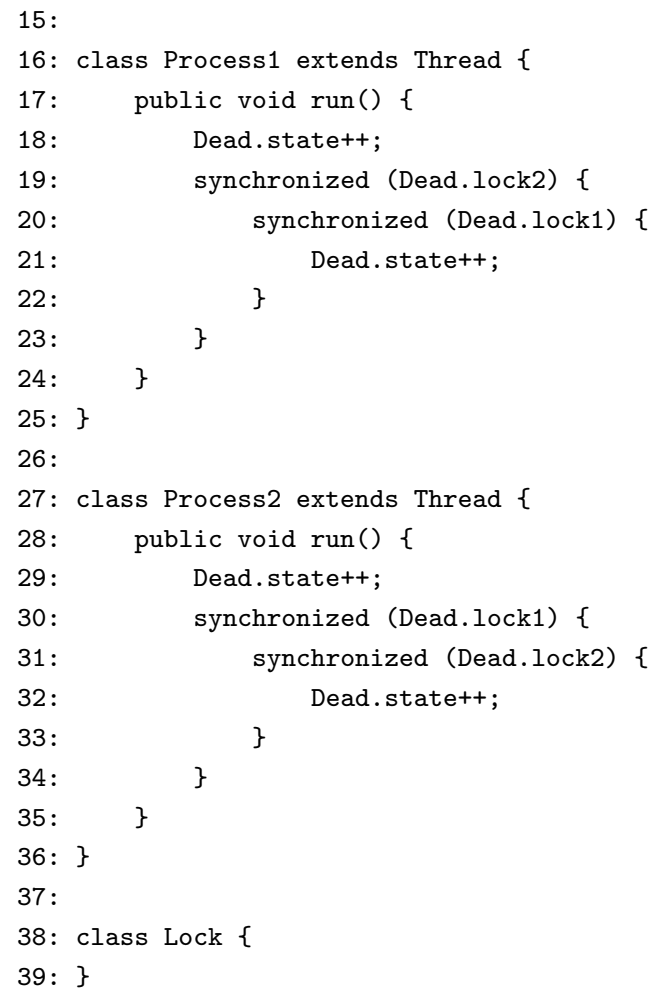

\section{D.1.3 NestedMonitor.java}

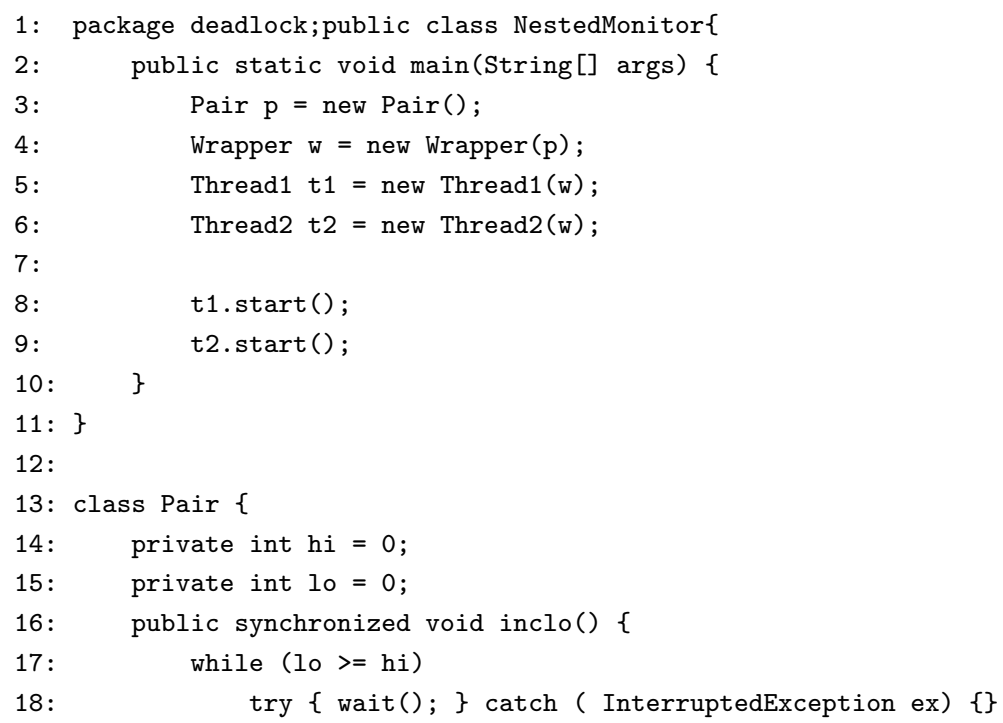




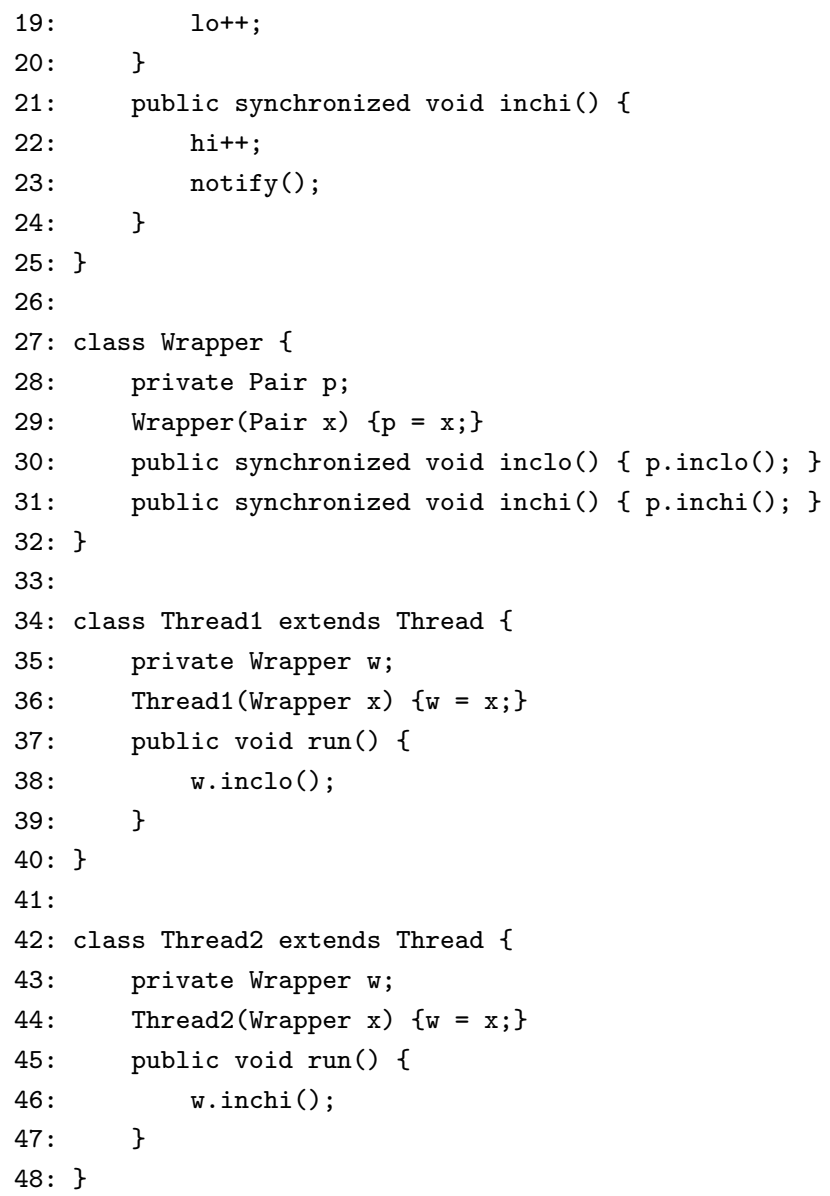

\section{D.1.4 PCSimple.java}

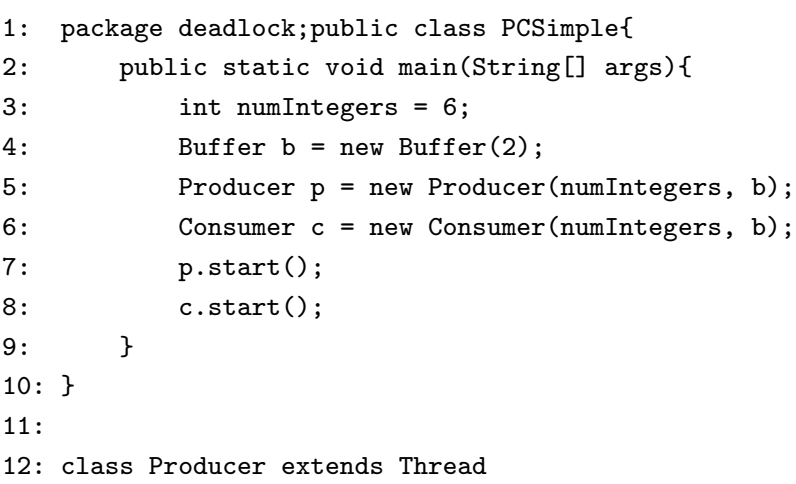




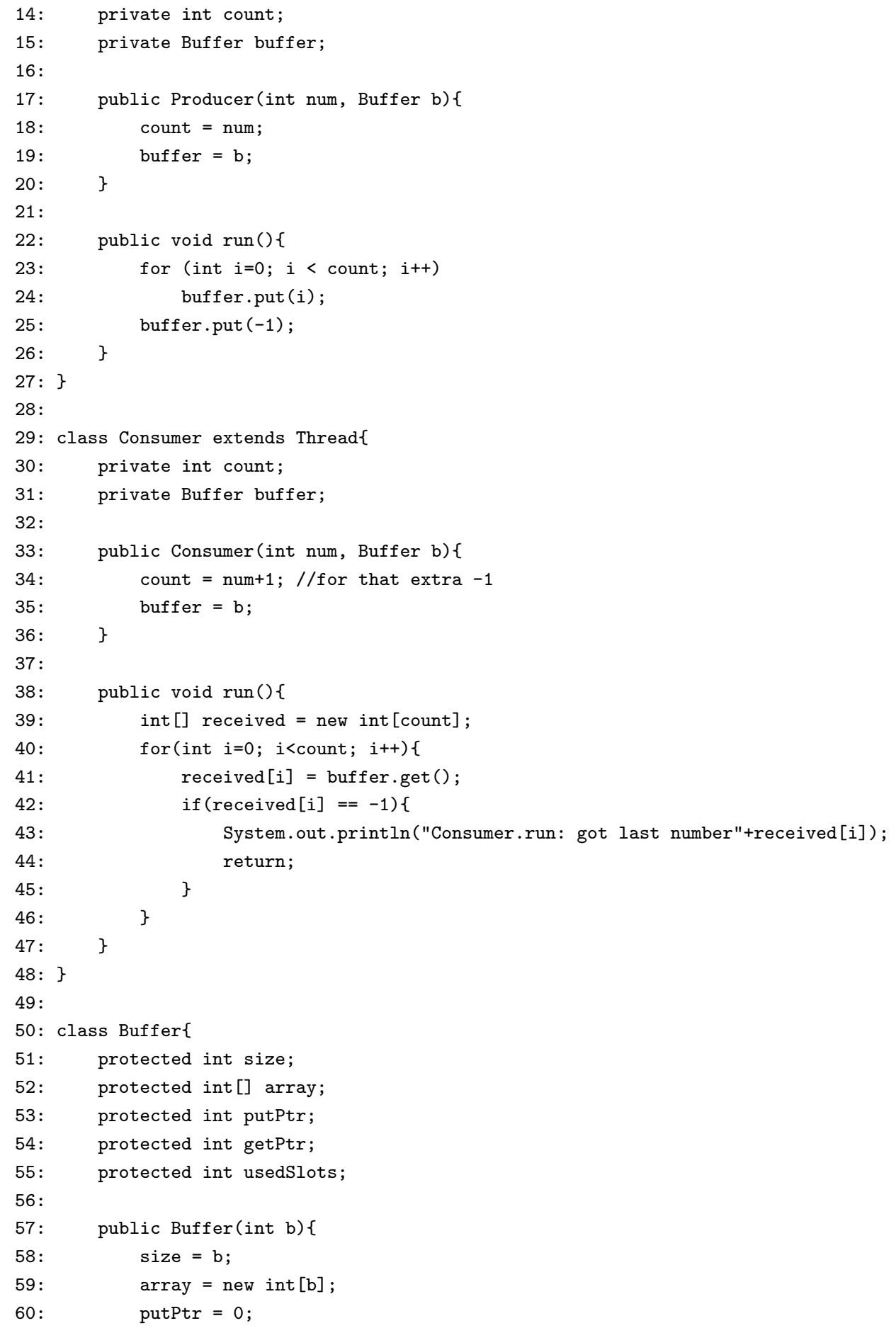




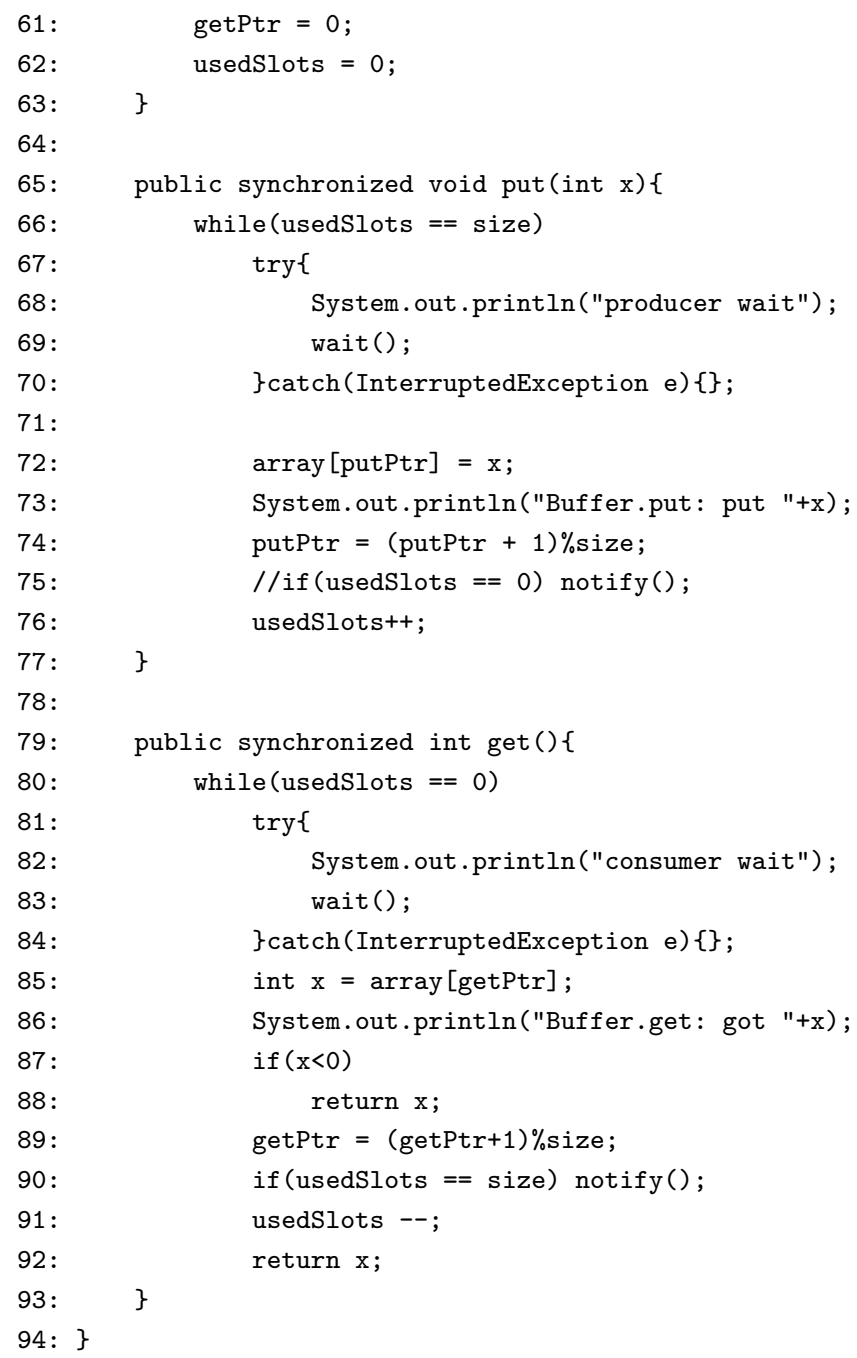

\section{D.1.5 PipeInteger.java}

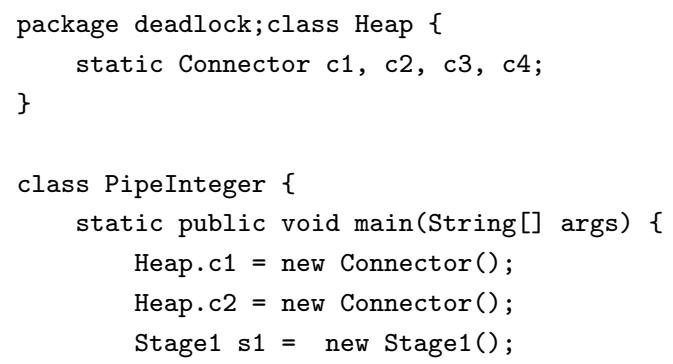




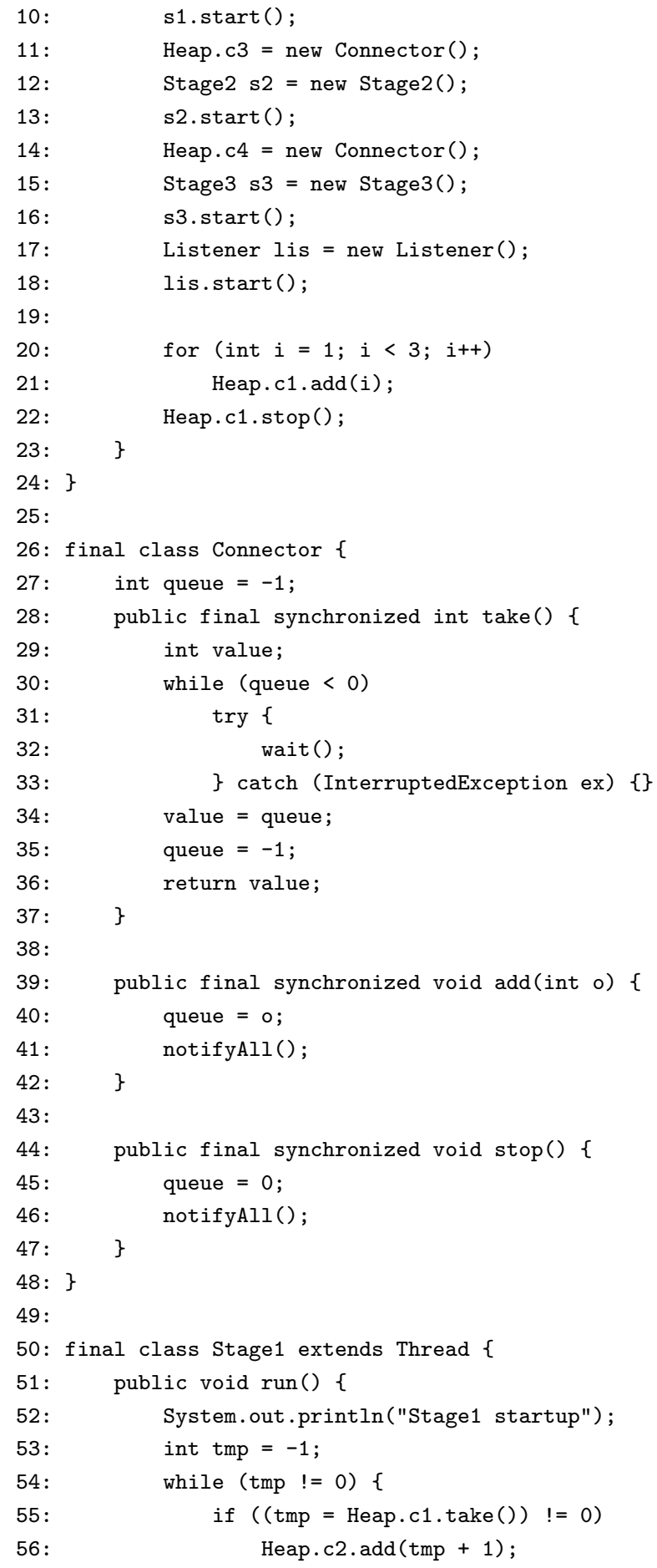




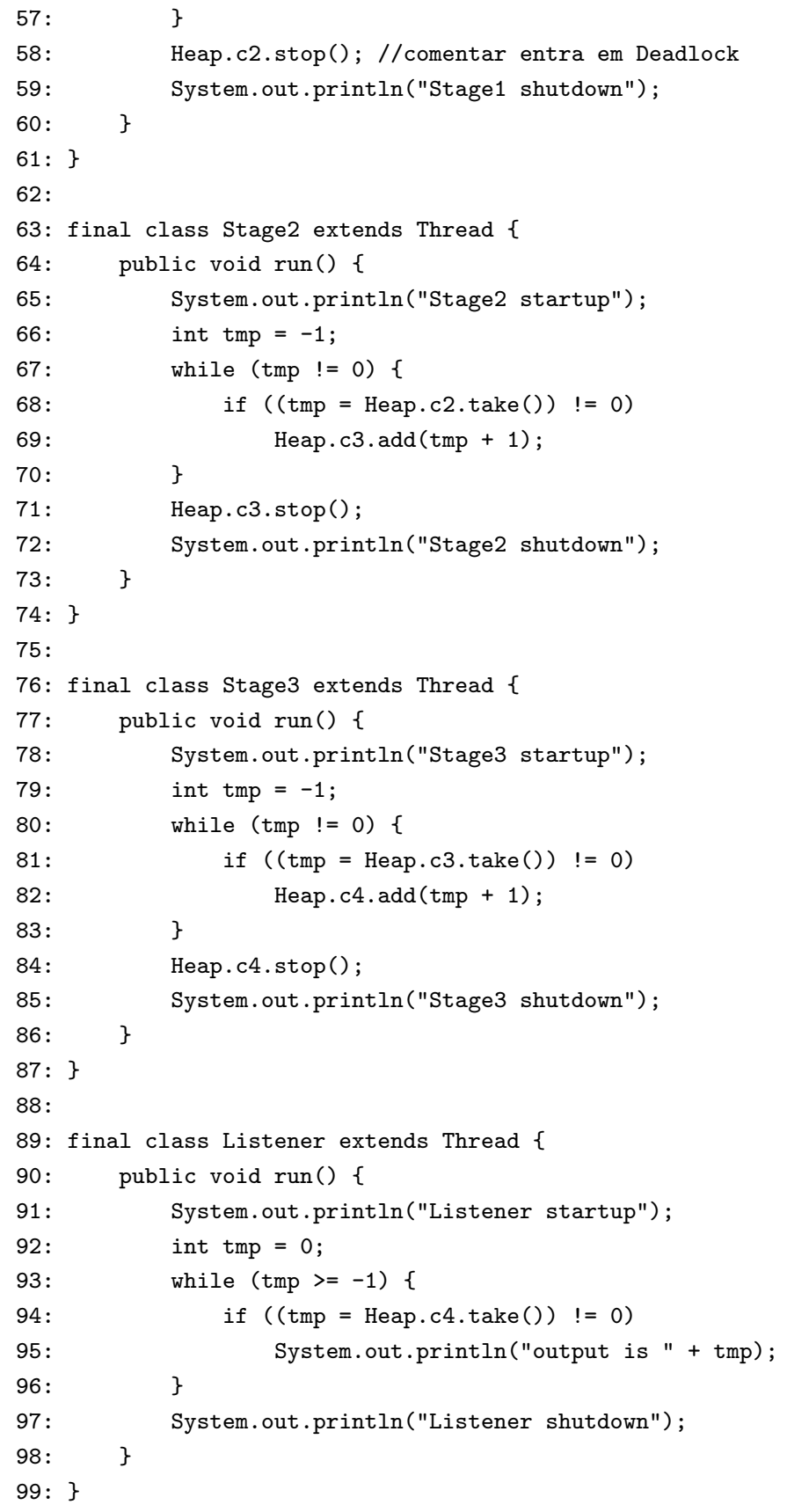




\section{D.2 Código Fonte dos Programas Sem Deadlock}

\section{D.2.1 Start_s.java}

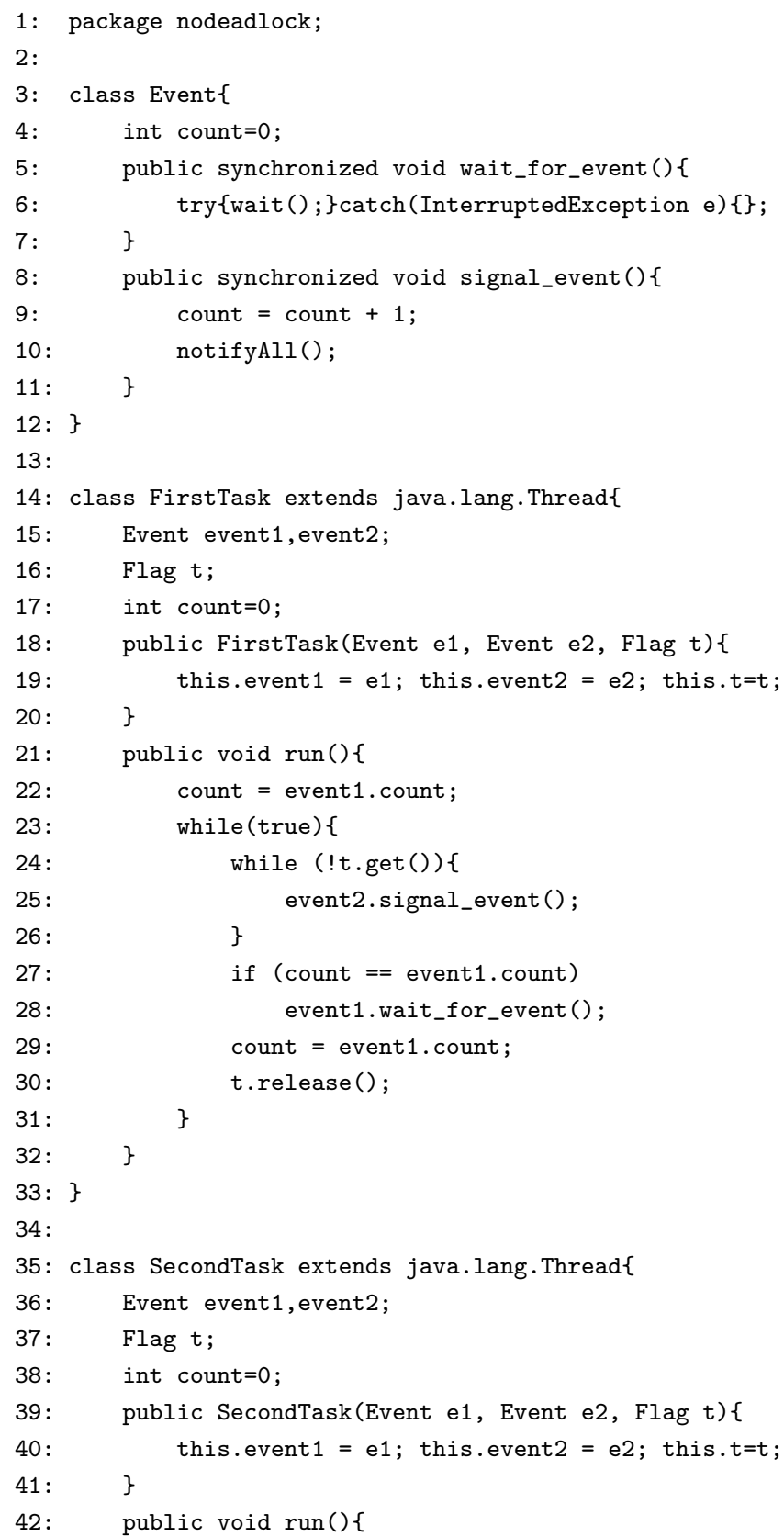




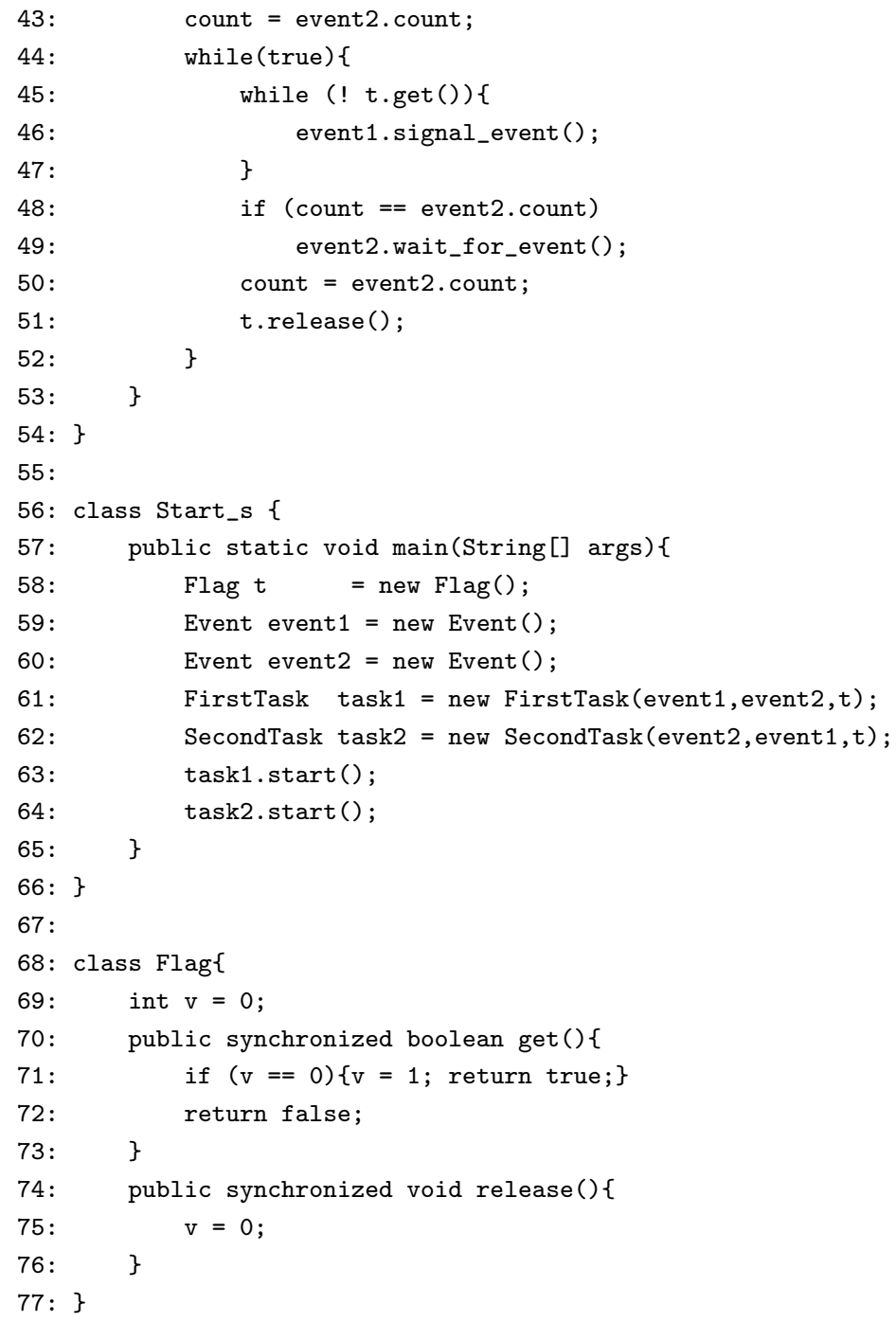

\section{D.2.2 Dead_s.java}

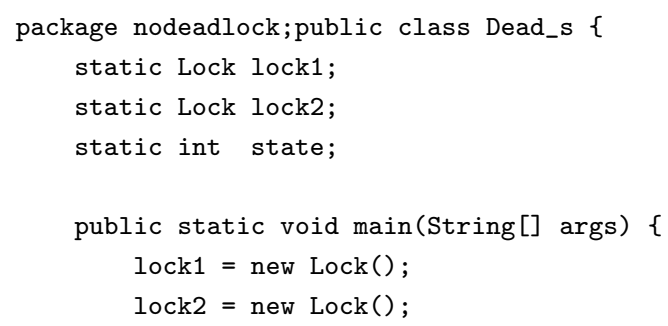




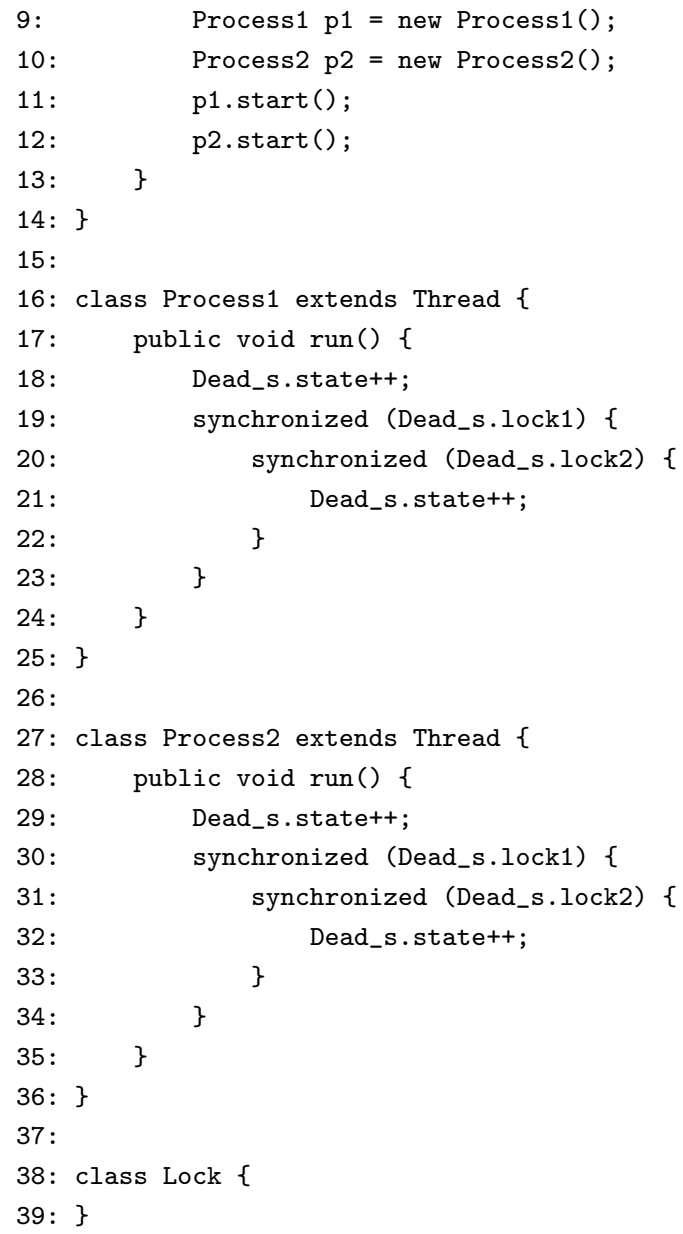

\section{D.2.3 NestedMonitor_s.java}

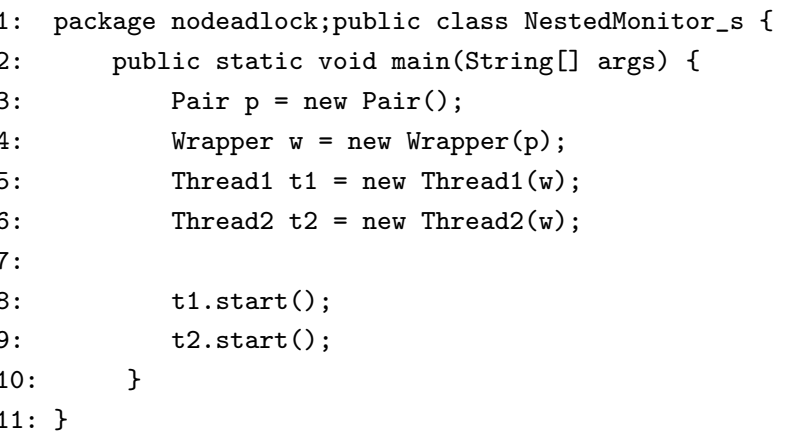




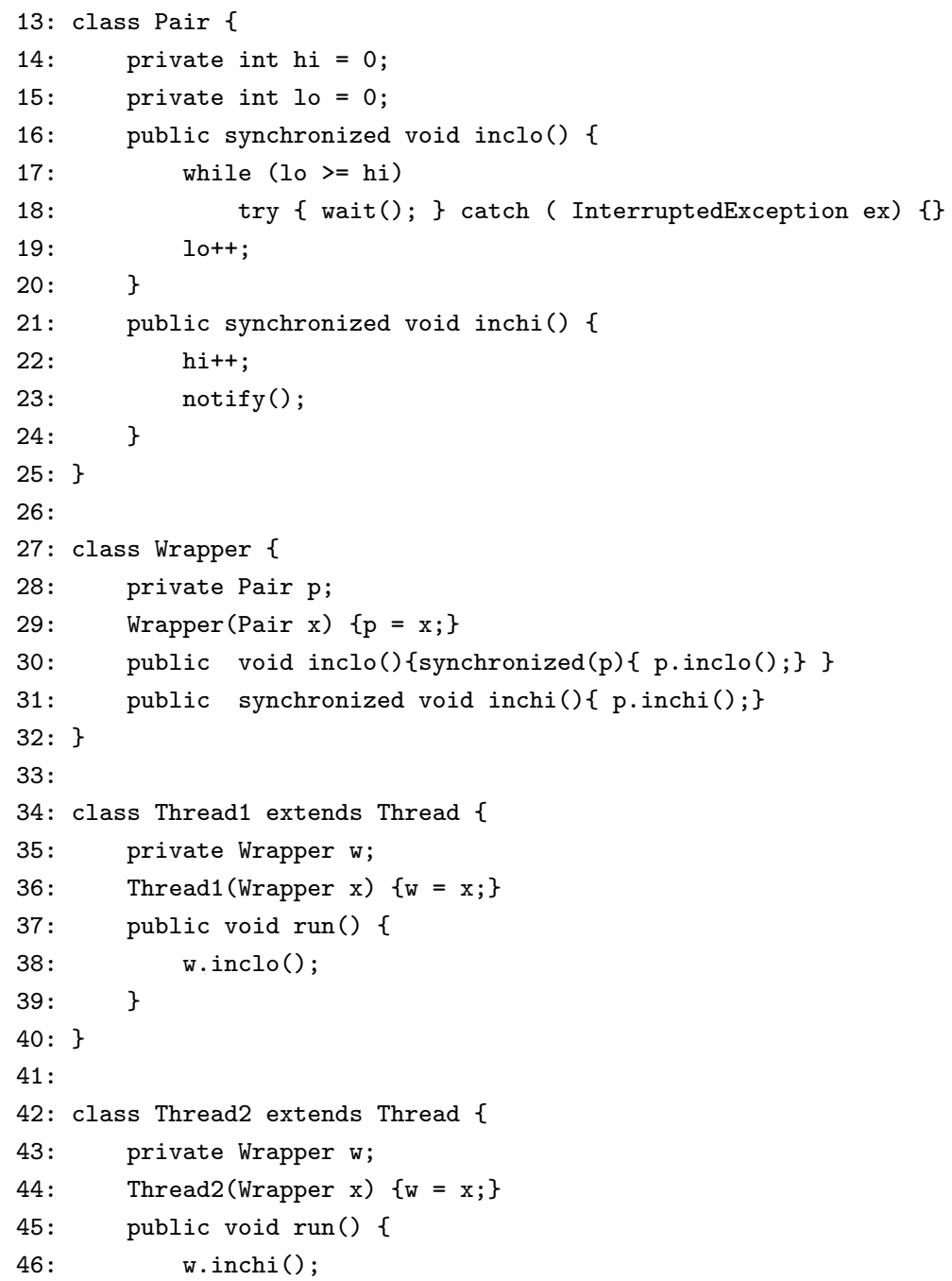

\section{D.2.4 PCSimple_s.java}

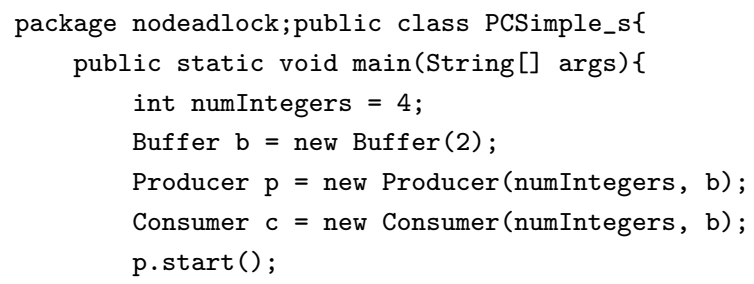




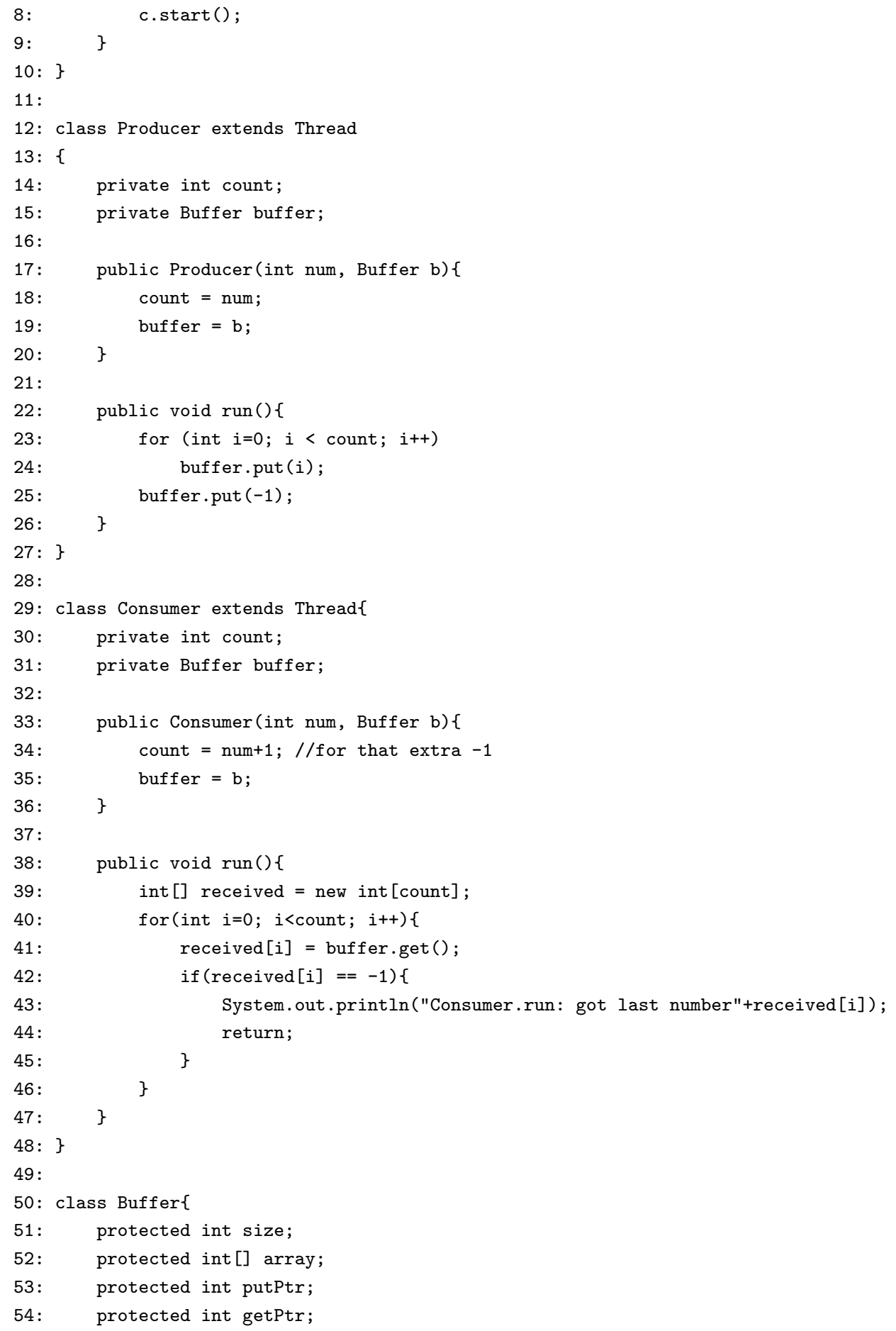


55:

56:

57:

58:

59:

60:

61:

62:

63:

64:

65:

66:

67:

68:

69:

70 :

71 :

72 :

73:

74:

75 :

76 :

77 :

78:

79:

80:

81:

82:

83:

84:

85:

86:

87 :

88:

89:

90:

91:

92:

93:

94: \}

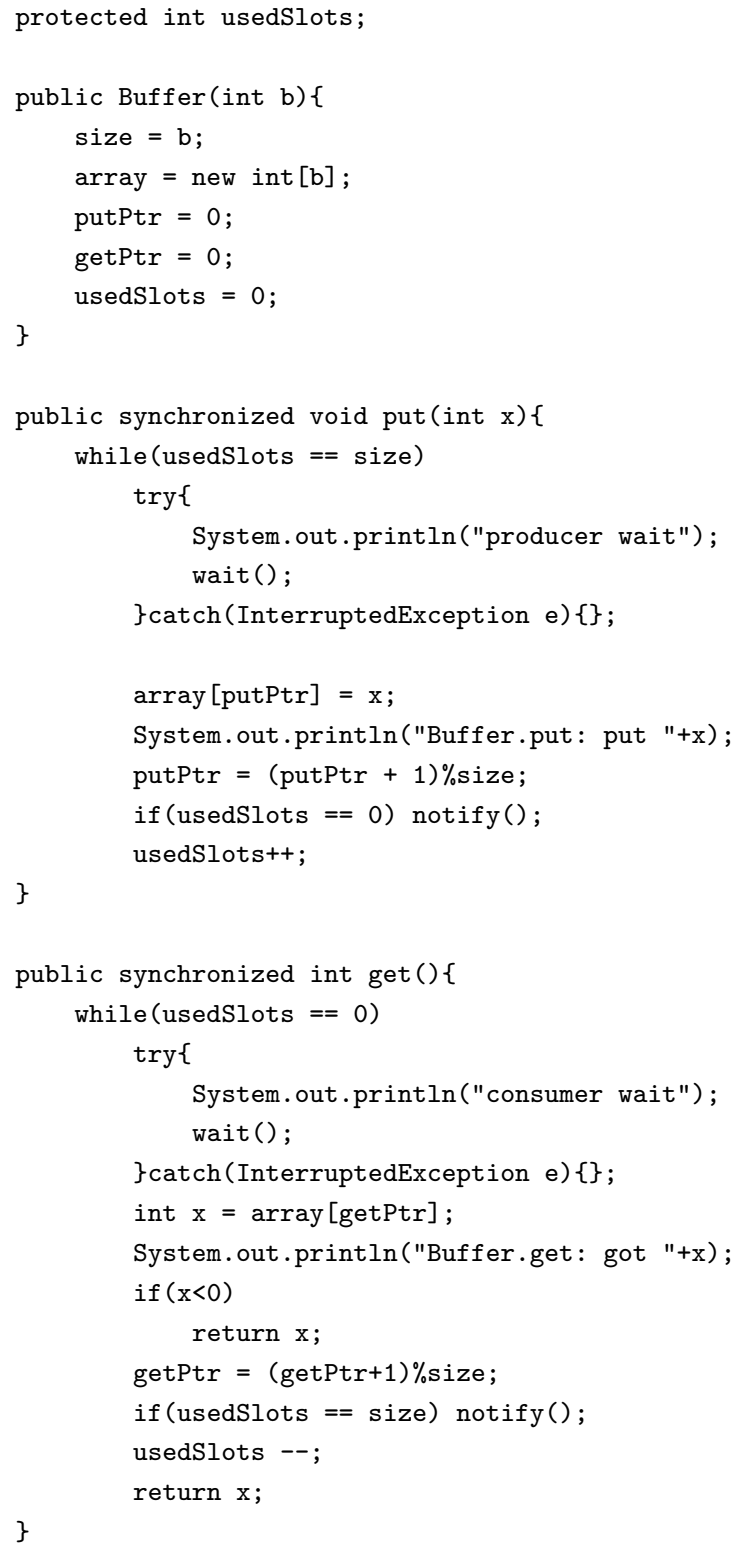

\section{D.2.5 PipeInteger_s.java}

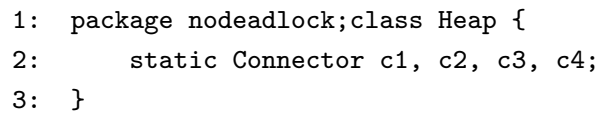




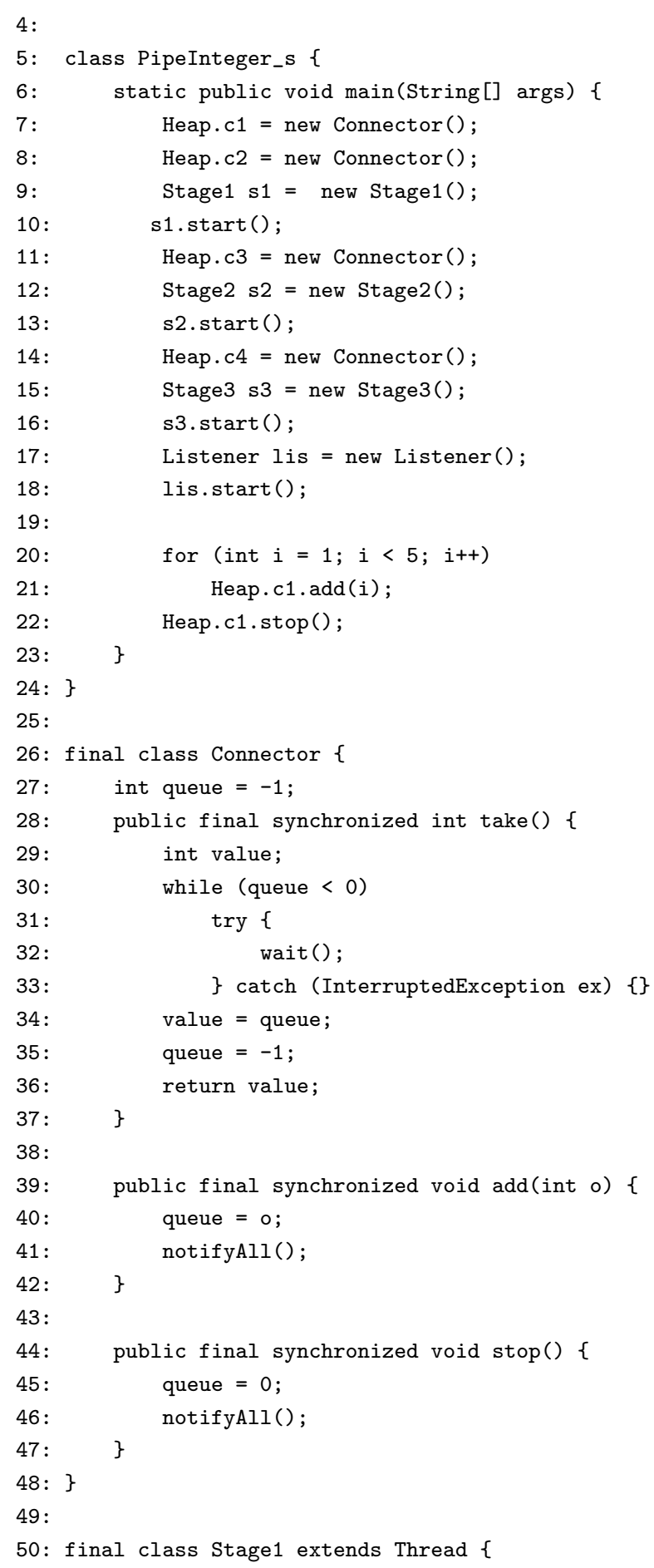




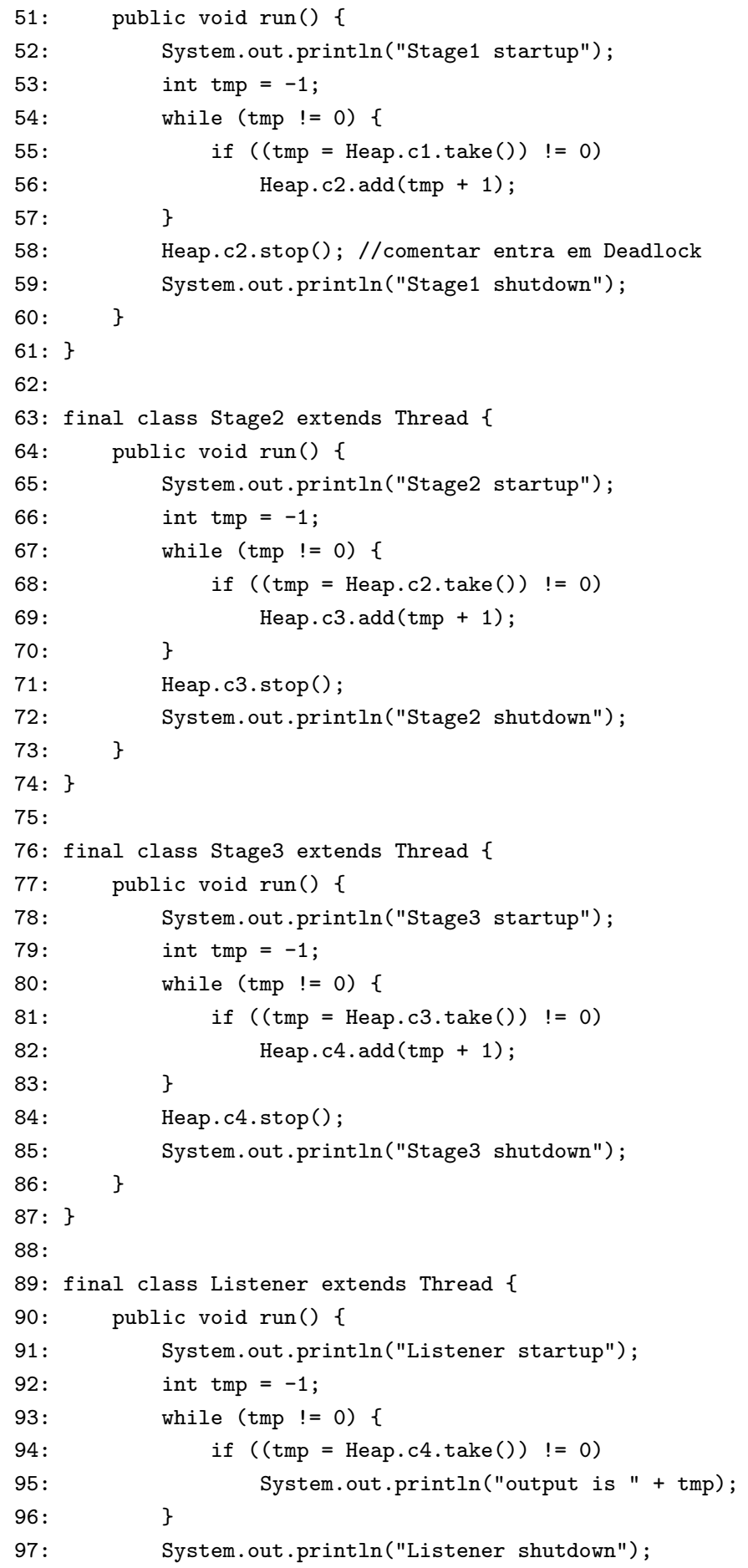


98: \}

99: \} 
170 APÊNDICE D. CÓDIGO FONTE DOS PROGRAMAS DE CÓDIGO CONCORRENTE 


\section{Referências Bibliográficas}

[1] Dirk Beyer, Adam J. Chlipala, Thomas A. Henzinger, Ranjit Jhala, and Rupak Majumdar, Generating tests from counterexamples, Proceedings of the 26th International Conference on Software Engineering (ICSE'04, Edinburgh), IEEE Computer Society Press, 2004, pp. 326-335.

[2] Robert Binder, Testing object-oriented systems: Models, patterns and tools, Addison-Wesley, 2000 .

[3] Joshua Bloch, Effective java: Programming language guide, Addison Wesley, 2001.

[4] Inquiry Board, Ariane 5 flight 501 failure, http://sunnyday.mit.edu/accidents/Ariane5accidentreport.html, Jul 1996.

[5] Ramkrishna Chatterjee and Barbara G. Ryder, Data-flow based testing of object-oriented libraries, Tech. Report DCS-TR-382, Rutgers University, March 1999.

[6] Mei-Hwa Chen and Howard M. Kao, Testing object-oriented programs - an integrated approach, Proceedings of the 10th International Symposium on Software Reliability Engineering, 1999.

[7] James C. Corbett, Matthew B. Dwyer, John Hatcliff, Shawn Laubach, Corina S. Pasareanu, Robby, and Hongjun Zheng, Bandera : Extracting finite-state models from java source code, Proceedings of the 22nd International Conference on Software Engineering, June 2000.

[8] Christoph Csallner and Yannis Smaragdakis, Check 'n' crash: Combining static checking and testing, Proceedings of the 27th International Conference on Software Engineering, June 2005.

[9] O. J. Dahl, E. Dijkstra, and C. A. R. Hoare, Structured programming, New York:Academic Press, 1972.

[10] Márcio Eduardo Delamaro, José Carlos Maldonado, and Mario Jino, Introdução ao teste de software, Elsevier, 2007.

[11] David Déharbe, Anamaria Martins Moreira, Leila Ribeiro, and Vanderlei Moraes Rodrigues, Introdução a métodos formais: Especificação, semântica e verificação de sistemas concorrentes, RITA 7 (2000), no. 1, 7-48. 
[12] Bruce Eckel, Thinking in java, 3rd ed., Prentice-Hall, 2002.

[13] Erich Gamma, Richard Helm, Ralph Johnson, and John Vlissides, Padrões de projeto: Soluções reutilizáveis de software orientado a objetos, Bookman, 2000.

[14] James Gosling, Bill Joy, Guy Steele, and Gilad Bracha, The java language specification, 3rd ed., Addison-Wesley, 2005.

[15] Mats P. E. Heimdahl and Devaraj George, On the effect of test-suite reduction on automatically generated model-based tests, Automated Software Engineering 14 (March 2007), no. 1, 37-57.

[16] Pei Hsia, Xiaolin Li, and David C. Kung, Class testing and code-based criteria, IBM Centre for Advanced Studies Conferences, 1996.

[17]__ Augmenting data flow criteria for class testing, Proceedings of the 1997 Conference of the Centre for Advanced Studies on Collaborative research, 1997.

[18] International Software Testing Qualifications Board, Certified tester foundation syllabus, 2005.

[19] International Software Testing Qualifications Board, Standard glossary of terms used in software testing, 2006.

[20] Shujuan Jiang, Yongping Zhang, Dashun Yan, and Yuanpeng Jiang, An approach to automatic testing exception handling, SIGPLAN Not. 40 (2005), no. 8, 34-39.

[21] Tim McCune, Exception-handling antipatterns, http://today.java.net/pub/a/today/2006/04/06/exceptionhandling-antipatterns.html, Jun 2006.

[22] C.C. Michael, G. McGraw, and M.A. Schatz, Generating software test data by evolution, Software Engineering, IEEE Transactions on 27 (Dec 2001), no. 12, 1085-1110.

[23] James Miller, Marek Reformat, and Howard Zhang, Automatic test data generation using genetic algorithm and program dependence graphs, Information and Software Technology 48 (2006), no. $7,586-605$.

[24] MPIAT, Mars program independent assessment team summary report, Mar 2000.

[25] Paulo Roberto Nunes and Ana C. V. de Melo, Ocongra - uma ferramenta para geração de grafos de controle de fluxo de objetos, Anais do 180. Simpósio Brasileiro de Engenharia de Software SBBD-SBES (Brasília-Distrito Federal, Brasil) (Jaelson F. B. de Castro, ed.), oct 2004.

[26] Roy P. Pargas, Mary Jean Harrold, and Robert Peck, Test-data generation using genetic algorithms, Software Testing, Verification \& Reliability 9 (1999), no. 4, 263-282.

[27] Roger S. Pressman, Software engineering: A practitioner's approach, 5th ed., McGraw-Hill, 2001. 
[28] Leandro Cesar Prudente, Um estudo sobre teste versus verificação formal de programas java, Master's thesis, IME-USP, Março 2004.

[29] Darrel Reimer and Harini Srinivasan, Analyzing exception usage in large java applications, Proceedings of the ECOOP 2003 Workshop on Exception Handling in Object-oriented Systems, 2003.

[30] S. Sinha and M. J. Harrold, Analysis of programs that contain exception-handling constructs, Proc. of Int'l Conf. On Softw. Maint, November 1998.

[31]__ Criteria for testing exception handling constructs in java programs, Proc. of Int'l Conf. On Softw. Maint, September 1999.

[32] _ Analysys and testing of programs with exception handling constructs, IEEE Transactions on Software Engineering 26 (2000), no. 9.

[33] Java PathFinder Team, Java pathfinder, http://javapathfinder.sourceforge.net/, Dec 2007.

[34] W. Visser, K. Havelund, G. Brat, S. Park, and F. Lerda, Model checking programs, Automated Software Engineering Journal 10 (2003), no. 2.

[35] Bruce W. Weide, William F. Ogden, and Stuart H. Zweben, Reusable software components, Advances in computers 33 (1991).

[36] Greta Yorsh, Thomas Ball, and Mooly Sagiv, Testing, abstraction, theorem proving: Better together!, International Symposium on Software Testing and Analysis, 2006. 